\author{
University of Kansas \\ Department of Chemistry \\ Lawrence, Kansas 66045 \\ COO-1140-219 \\ 1976 , August 17
}

\title{
HIGH TEMPERATURE THERMODYNAMICS AND VAPORIZATION \\ OF STOICHIOMETRIC TITANIUM MONOXIDE
}

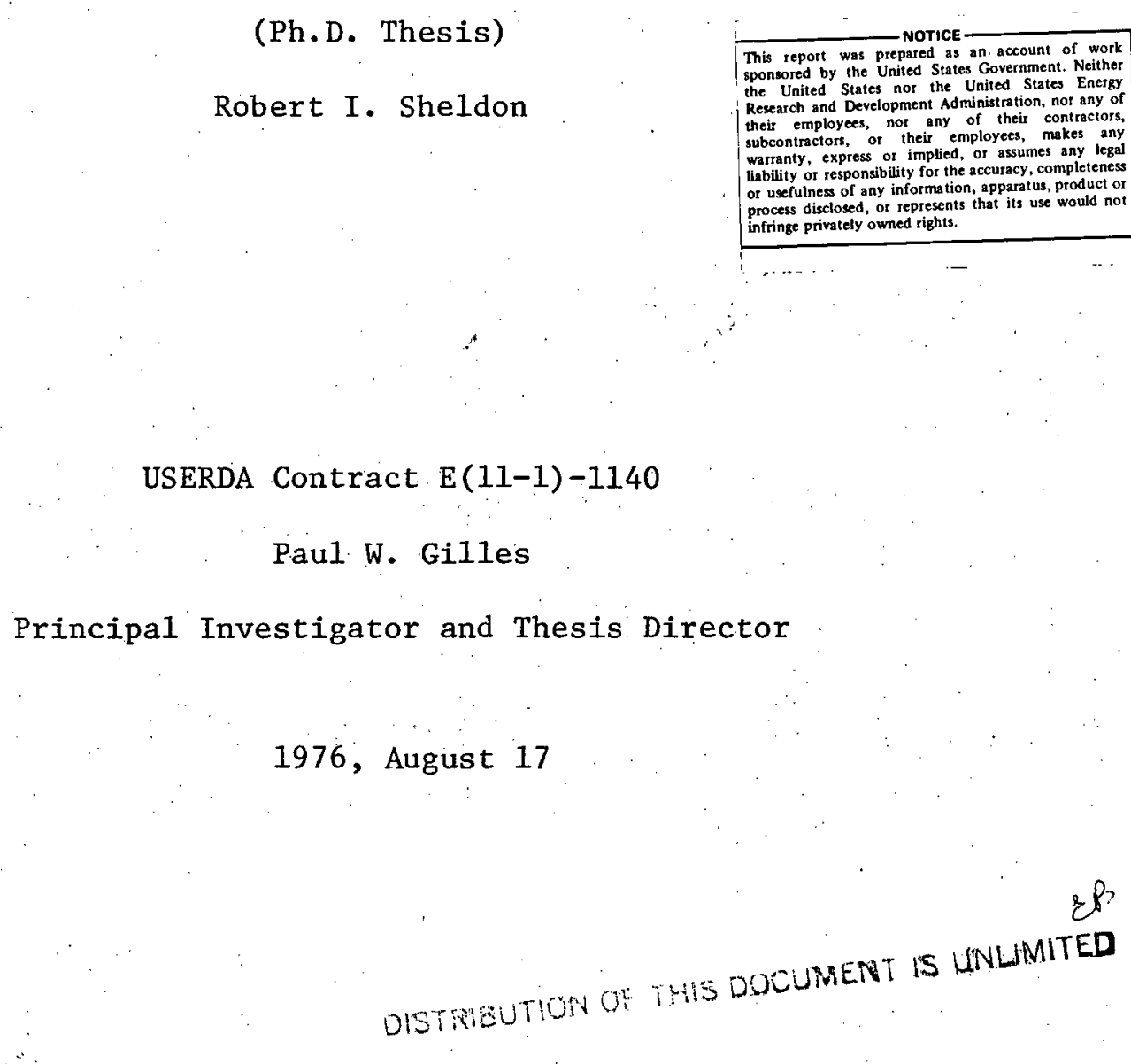




\section{DISCLAIMER}

This report was prepared as an account of work sponsored by an agency of the United States Government. Neither the United States Government nor any agency Thereof, nor any of their employees, makes any warranty, express or implied, or assumes any legal liability or responsibility for the accuracy, completeness, or usefulness of any information, apparatus, product, or process disclosed, or represents that its use would not infringe privately owned rights. Reference herein to any specific commercial product, process, or service by trade name, trademark, manufacturer, or otherwise does not necessarily constitute or imply its endorsement, recommendation, or favoring by the United States Government or any agency thereof. The views and opinions of authors expressed herein do not necessarily state or reflect those of the United States Government or any agency thereof. 


\section{DISCLAIMER}

Portions of this document may be illegible in electronic image products. Images are produced from the best available original document. 


\section{HIGH TEMPERATURE THERMODYNAMICS AND VAPORIZATION \\ OF STOICHIOMETRIC TITANIUM MONOXIDE}

\section{by}

Robert I. Sheldon

B.S., The University of Toledo, 1968

Submitted to the Department of Chemistry and the Faculty of the Graduate School of the University of Kansas in partial fulfillment of the requirements for the degree of Doctor of Philosophy

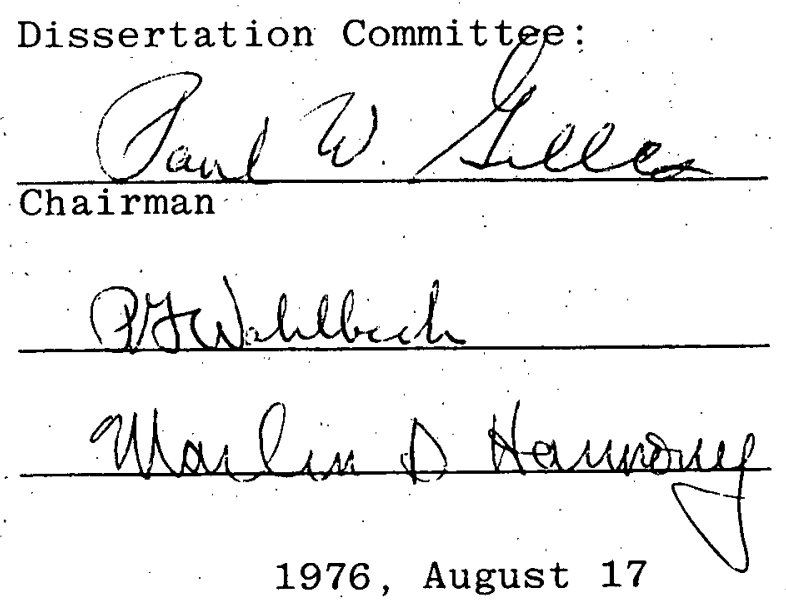




\author{
ABSTRACT \\ HIGH TEMPERATURE THERMODYNAMICS AND VAPORIZATION \\ OF STOICHIOMETRIC TITANIUM MONOXIDE \\ Robert I. Sheldon, Ph.D.
}

Three vaporization experiments were performed on samples of nearly stoichiometric titanium munoxide. Two experiments were constant temperature experiments (1806K) designed to measure the equilibrium vapor pressures of ilig) and $\mathrm{TiO}(\mathrm{g})$. In one experiment titanium monoxide was vaporized from a tungsten Knudsen effusion cell; the vapor was collected on a water cooled quartz cap surrounding the ret7; and the total amount of titanium deposited on the cap was analyzed colorimetrically. In the second constant temperature experiment (1806K) the vapor composition in equilibrium with nearly stoichiometric titanium monoxide was measureả mass spectrometrically. The mass spectrometer results were used to apportion the total titanium collected in the first experiment to $\mathrm{Ti}(\mathrm{g})$ and $\mathrm{TiO}(\mathrm{g})$. The measured vapor pressures are $\mathrm{P}_{\mathrm{TiO}}=(2.18 \pm 1.23) \times 10^{-8} \mathrm{~atm}$. and $\mathrm{P}_{\mathrm{Ti}}=(7.58 \pm 1.07) \times 10^{-8 \mathrm{~atm}}$. From the first pressure the standard free energy difference between $\mathrm{TiO}(\mathrm{g})$ and $\mathrm{TiO}(\mathrm{s})$ at $1806 \mathrm{~K}$ is calculated to be $\Delta \mathrm{H} 1806$ $=63.3 \pm 2.0 \mathrm{kcal}$. Combination of the second pressure with the vapor pressure of pure titanium at $1806 \mathrm{~K}$ yields an activity of titanium in a nearly stoichiometric solution of titanium 
monoxide of $0.130 \pm 0.041$. The partial molal free energy of solution of titanium in nearly stoichiometric titanium monoxide is calculated from the activity to be $\Delta \overline{\mathrm{F}}_{\mathrm{T} i}=-7.3 \pm 1.1$ kcal. From the results of this work and published thermodynamic data a partial molal free energy of solution of oxygen is calculated to be $\Delta \overline{\mathrm{F}}_{\mathrm{O}_{2}}=-164.0 \pm 6.1 \mathrm{kcal}$.

In the third experiment the temperature dependence of the ions $\mathrm{Ti}^{+}(48)$ and $\mathrm{TiO}^{+}(64)$ was measured mass spectrometrically. The data were treated both by the so-called second and third law methods. The second law results for the vaporization of solid titanium monoxide to yield gaseous titanium monoxide are $\Delta \mathrm{H}_{298}^{\circ}=138.2 \pm 3.0 \mathrm{kcal}$ and $\Delta \mathrm{S}_{298}^{\circ}=$ 45. $0 \pm 2.0$ e.u. The standard enthalpy change obtained from the third law treatment is $141.20 \pm 0.12 \mathrm{kcal}$. Partial molal heats and entropies of solution of titanium and oxygen are calculated from results obtained in this work and published thermodynamic data to be $\Delta \overline{\mathrm{H}}_{\mathrm{Ti}}=-7.3 \pm 3.4 \mathrm{kcal}, \Delta \overline{\mathrm{S}}_{\mathrm{Ti}}=0.021 \pm 1.8 \mathrm{e} . \mathrm{u}$. , $\Delta \overline{\mathrm{H}}_{\mathrm{O}_{2}}=-229.4 \pm 9.8 \mathrm{kcal}$, and $\Delta \overline{\mathrm{S}}_{\mathrm{O}_{2}}=-36.2 \pm 5.4 \mathrm{e} . \mathrm{u}$.

The results obtained in this work are compared with published thermodynamic properties of the titanium oxygen system. The results obtained in this work indicate the standard free energy of formation of titanium monoxide obtained from the earliest calorimetric measurements yielded a result not negative enough and also oxygen pressures obtained by emf measurements for stoichiometric titanium monoxide at $1806 \mathrm{~K}$ are high by a factor of 42.6 . The present results are 
in good agreement with the thermodynamic properties reported in recently issued pages of the JANAF Thermochemical Tables. 


\section{ACKNOWLEDGEMENTS}

The author wishes to express his gratitude to Professor Paul W. Gilles for his guidance and constant encouragement throughout the course of this work.

Thanks are expressed to Dr. K. K. Kelley and Professor Leo Brewer who furnished the titanium monoxide to this Iaboratory some two decades ago.

The financial support for this work provided by the United States Atomic Energy Commission under contract number $\mathrm{AT}(11-1)-1140$ is gratefully acknowledged. In addition financial support provided by teaching assistantships at the University of Kansas, an Emily Berger scholarship, and a Phillips Petroleum fellowship are gratefully appreciated.

I wish to thank my many friends and colleagues in the High Temperature Laboratory at the University of Kansas for their helpful suggestions and stimulating discussions.

I wish to dedicate this thesis to my wife, Patricia, for her support and patience throughout the course of this work.

R. I. S. 
TABLE OF CONTENTS

Page

ACKNOWLEDGEMENTS. . . . . . . . . . . . . . . . . . . . . . . . .

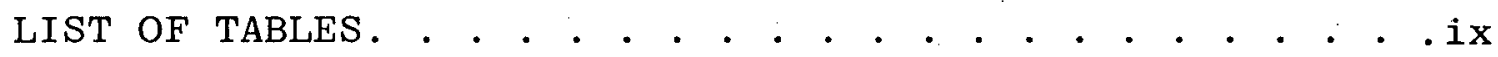

LIST OF FIGURES . . . . . . . . . . . . . . . . . . . . . . xi

Chapter

1 INTRODUCTION. . . . . . . . . . . . . . . . . 1

2 PREVIOUS WORK • . . . . . . . . . . . . . . 6

2.1 Phase Behavior . . . . . . . . . . . . 6

2.2 Thermodynamics of Vapor species, $\mathrm{TiO}$ and $\mathrm{TiO}_{2} \cdot 7$

2.3 Thermodynamics of Solid TiO. . . . . . . . 10

2.3.1 Partial Molal Free Energy of Oxygen. . . .10

2.3.2 Integral Thermodynamic Properties. . . . .12

3 EXPERIMENTAL. . . . . . . . . . . . . . . . . . . 18

3.1 Introduction ................. . . . . . . .

3.2 Samples and Materials. . . . . . . . . 19

3.3 Crucible. . . . . . . . . . . . . . . . 21

3.3.1 Orifice Dimensions and Clausing Factor . .21

3.3.2 Crucible Outgassing. . . . . . . . . . 26

3.4 Temperature Measurement and Correction . . . .26

3.5 X-Ray Analysis of Samples and Residues . . . .30

3.6 Knudsen Vapor Pressure Measurements. . . . . . 32

3.6.1 Vacuum System. . . . . . . . . . . . 32

3.6.2 Induction Generator. . . . . . . . . 34

3.6.3 Colorimetric Analysis. : . . . . . . . . . 35 
TABLE OF CONTENTS

Chapter

Page

(a) Preparation of $\mathrm{H}_{2} \mathrm{O}_{2}$... . . . . . . . . . . . . . . .

(b) Calibration Curve. . . . . . . . . . . . . . . .

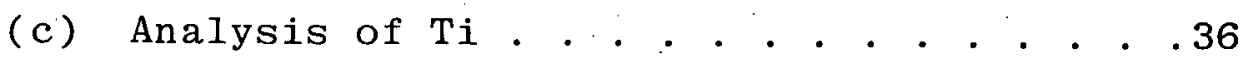

(d) Cleaning Procedure for Cap . . . . . . . 37

3.6.4 Specific Experiments . . . . . . . . . . 37

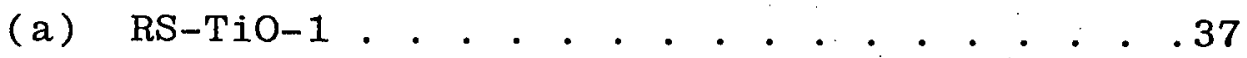

(b) RS-TiO-2 . . . . . . . . . . . . . . . . . . . . . . . . .

3.7 Mass Spectrometer Experiments. . . . . . . 40

3.7.1 Nuclide Mass Spectrometer. . . . . . . .40

(a) Molecular Source........... . . . . . 41

(b) Ion Source................ . . . . . . . .

(c) Analyzer and Detector. . . . . . . . . .45

3.7.2 Data Acquisition System. . . . . . . . . . 47

3.7.3 Procedures . . . . . . . . . . . . . . . . . . . . .

(a) Preliminaries. . . . . . . . . . . .49

(b) Mass Scans . . . . . . . . . . . . . . . 50

(c) Gain Check . . . . . . . . . . . . . . . . . .

(d) Focusing Conditions. . . . . . . . . . . 50

(e) Shutter Profiles and Intensity Measurements. . . . . . . . . . . . . . . . . 1

(f) Ionization Efficiency Curves . . . . . . . .52

3.7.4 Specific Experiments . . . . . . . . . . . . . 33

(a) RS-MS-TiO-X (Chart 1976-008, Disc Files
RS279-341). . . . . . . . . . . . . . . . . 33

(b) RS-MS-TiO-Y (Chart 1976-009, Disc Files RS342-363) . . . . . . . . . . . . . . . . 55 
TABLE OF CONTENTS

Chapter

Page

4 THEORY. . . . . . . . . . . . . . . . . . . . . . 57

4.1 Knudsen Effusion Equation. . . . . . . . . .57

4.2 Thermodynamics . . . . . . . . . . . . . . 57

4.2.1 Second Law Treatment . . . . . . . . . . 58

4.2.2 Third Law Treatment. . . . . . . . . . 59

4.2.3 Indirect Measurement of Oxygen Potentials................. . . . . . . . . .

4.2.4 Integral and Partial Molal Properties. . .60

4.3 Treatment of Nearly Constant Temperature

Experiments. . . . . . . . . . . . . . .64

5 RESULTS . . . . . . . . . . . . . . . . . . . . . . . . . .

5.1 Titanium Analysis. . . . . . . . . . . . 67

5.2 X-ray Diffraction of TiO-1 and Residues. . . .67

5.3 Knudsen Vapor Pressure Measurements. . . . . . 72

5.3 .1 RS-TiO-1 . . . . . . . . . . . . . . . . .72

5.3 .2 RS-TiO-2 . . . . . . . . . . . . . . . .73

(a) Analysis of Titanium . . . . . . . . .74

(b) Thermodynamic Results. . . . . . . . . 75

(1) Vapor Pressure, $\mathrm{P}_{\mathrm{E}}$. . . . . . . . . . . .

(2) Standard Free Energy . . . . . . . . 76

(c) Residue. . . . . . . . . . . . . . . . . . . .

5.4 Mass Spectrometer Results. . . . . . . . . . .77

5.4:1. RS-MS-TiO-X (Chart 1976-008, Disc Files $279-341)$. . . . . . . . . . . . . . . . . . .

(a) Intensity Data . . . . . . : . . . . . 78

(1) Intensity Ratio, $\mathrm{I}_{\mathrm{TiO}}^{+} / \mathrm{I}_{\mathrm{T}}^{+} \cdot . \cdot . \cdot . \cdot .78$ 
TABLE OF CONTENTS

Chapter

Page

(b) Shutter Profiles............. . . . . . . . .

(c) Thermodynamic Results. . . . . . . . . 87

(1) Vapor Pressures. . . . . . . . . . . . . . . . . .

(2) Standard Free Energy . . . . . . . . . . . .

(3) Oxygen Potential . . . : . . . . . . . . .

(4) Partial Molal Free Energies. . . . . . .96

(d) Ionization Efficiency Curves . . . . . . .99

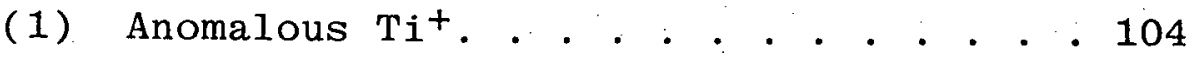

(e) Sample Composition . . . . . . . . . 104

(f) Residue. . . . . . . . . . . . . 105

5.4.2 RS-MS-TiO-Y (Chart 1976-009, Disc Files RS342-363) . . . . . . . . . . . 106

(a) Gaseous Species and Intensity Data . . 107

(1) Anomalous $\mathrm{T}^{+}$. . . . . . . . . 112

(b) Shutter Profiles . . . . . . . . . . 112

(c) Calibration of the Mass Spectrometer . . 114

(d) Thermodynamics . . . . . . . . . . 117

(1) Chemical Reactions . . . . . . . 117

(2) Second Law Results . . . . . . . 117

(3) Third Law Results. . . . . . . . . 120

(4) Oxygen Potential . . . . . . . . . 122

(5) Partial Molal Quantities . . . . . 123

(e) Sample Composition ........... . 128

(f) Residue................ . . 129

6 DISCUSSION . . . . . . . . . . . . . . . . 132 
TABLE OF CONTENTS

Chapter

Page

6.1 Titanium Analysis. . . . . . . . . . . . 132

6.2 X-ray Results on TiO-1 and Residues. . . . 134

6.3 Knudsen Vapor Pressure Measurements. . . . 136

6.3.1 Performance of Equipment . . . . . . 136

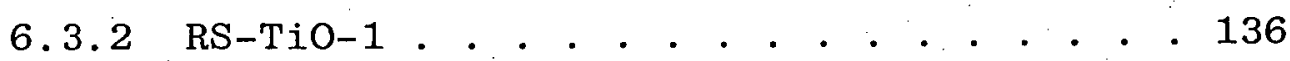

$6.3 .3 \mathrm{RS}-\mathrm{TiO}-2$. . . . . . . . . . . . 137

(a) Comparison with Wheatley . . . . . 138

(b) Total Titanium . . . . . . . 143

6.4 Mass Spectrometer Measurements . . . . . . 145

6.4 .1 Performance of Equipment . . . . . . . 145

6.4 .2 RS-MS-TiO-X. . . . . . . . . . . . . 148

(a) Intensity Ratio, $\mathrm{I}_{\mathrm{TiO}}^{+} / \mathrm{I}_{\mathrm{Ti}}^{+} \cdot \cdots \cdot . \cdot . \cdot .148$

(b) Thermodynamics . . . . . . . . . . 150

(1) Vapor Pressures. . . . . . . . . 150

(2) Standard Free Energy . . . . . . . . 156

(3) Activity of TiO. . . . . . . . . 158

(c) Ionization Efficiency Curves . . . . . . 159

(d) Summary and Conclusions. . . . . . . 161

6.4 .3 RS-MS-TiO-Y. . . . . . . . . . . . . 166

(a) Thermodynamics . . . . . . . . . . 166

(1) Standard States. . . . . . . . 166

(2) Second Law Results . . . . . . . . 168

(3) Third Law Results. . . . . . . 169

(4) Partial Molal Quantities . . . . . 170 
TABLE OF CONTENTS

Chapter

Page

6.5 Future Work. . . . . . . . . . . . 170

REFERENCES . . . . . . . . . . . . . . . . . . . . 173

APPENDIX I. . . . . . . . . . . . . . . . . . . . . . . . . . 178

APPENDIX II . . . . . . . . . . . . . . . . . . . . . 180

APPENDIX III. . . . . . . . . . . . . . . . . . . . . . . 189

viii 


\section{LIST OF TABLES}

Table

Page

3.1 Orifice Area Crucible \#4. . . . . . . . . . . . . 22

3.2 Orifice Length Crucible \#4. . . . . . . . . . . . 25

3.3 Temperature Correction Constant for the Window and Prism Used in Vacuum Line \#11, Experiments RS-TiO-1 and RS-TiO-2 . . . . . . . . . . . 28

3.4 Temperature Correction Constant for the Window and Prism Used in the Mass Spectrometer, Experiments RS-MS-TiO-X and RS-MS-TiO-Y. . . . . . . 29

3.5 Comparison of Pyrometers \#1 (H-scale) and \#4 $(\mathrm{H}$-scale $)$. . . . . . . . . . . . . . . 31

5.1 Debye-Scherrer Films. . . . . . . . . . . . . 70

5.2 Intensity Data Experiment RS-MS-TiO-X, Chart 1976-008, Disc Files RS279-341. . . . . . . . . 79

5.3 Intensity Ratio, $\mathrm{I}_{\mathrm{T} i \mathrm{O}}^{+} / \mathrm{I}_{\mathrm{T}}^{+}$, at $10.5 \mathrm{eV}$, Experiment RS-MS-TiO-X (Chart 1976-008). . . . . . . . . . 82

5.4 Intensity Ratio, I $\mathrm{T}_{\mathrm{T}}^{+} / \mathrm{I}_{\mathrm{T}}^{+}$, at $12.5 \mathrm{eV}$, Experiment RS-MS-TiO-X (Chart 1976-008). . . . . . . . . 82

5.5 Intensity Ratio, $\mathrm{I}_{\mathrm{TiO}}^{+} / \mathrm{I}_{\mathrm{T}}^{+}$, at $14.5 \mathrm{eV}$, Experiment RS-MS-TiO-X (Chart 1976-008). . . . . . . 83

5.6 Intensity Ratio, I $\mathrm{T}_{\mathrm{T}}^{+} / \mathrm{I}_{\mathrm{T}}^{+}$, at $22.5 \mathrm{eV}$, Experiment RS-MS-TiO-X (Chart 1976-008). . . . . . . . 83

5.7 Least Squares Results, I $\mathrm{T}_{\mathrm{T}}^{+} / \mathrm{I}_{\mathrm{T}}^{+}$Versus Time, Experiment RS-MS-TiO-X (Chart 1976-008) . . . 886

5. 8 Least Squares Fit to Linear Portion of I.E. Curves, Experiment RS-MS-TiO-X (Chart 1976-008) .102

5.9 Intensity Data $\mathrm{Ti}^{+}(48)$, Experiment RS-MS-TiO-Y (Chart 1976-009). . . . . . . . . . . . . . 108

5.10 Intensity Data $\mathrm{TiO}^{+}(64)$, Experiment RS-MS-TiO-Y (Chart 1976-009). . . . . . . . . . . . 109

5.11 Temperature Dependence of $\mathrm{Ti}^{+}(48)$ and $\mathrm{TiO}^{+}(64)$, Experiment RS-MS-TiO-Y (Chart 1976-009) . . . . .112 
Table

Page

5.12 Second Law Thermodynamics for Vaporization of $\mathrm{TiO}_{1.00}$, Experiment RS-MS-TiO-Y (Chart 1976009).

5.13 Third Law Thermodynamics for TiO( $\mathrm{TiO}_{1}$.00solid soln. $)=$ TiO (g, 1atm), Experiment RS-MSS-TiO-Y

(Chart 1976-009). . . . . . . . . . . . . . 121

5.14 JANAF Thermochemical Data (a) . . . . . . . . . 124

5.15 Partial Molal Quantities, Experiment RS-MS-

TiO-Y . . . . . . . . . . . . . . . . . . 125

5.16 Partial Molal Quantities, Experiment RS-MS-

TiO-Y . . . . . . . . . . . . . . . 126 


\section{LIST OF FIGURES}

Figure

Page

1 Free Energy Level Diagram. . . . . . . . . . . . . . 3

2.1 Partial Molal Free Energy of $\mathrm{O}_{2}$ at $1273^{\circ} \mathrm{K}$. . . 13

2.2 Comparison of $\Delta \mathrm{F}_{\mathrm{f}}^{\circ}[\mathrm{TiO}(\beta)] . \quad . \quad . \quad . \quad . \quad . \quad . \quad . \quad . \quad . \quad 15$

3.1 Optical Measurement of Orifice Length. . . . . . 23

3.2 Vacuum Line No. Eleven . . . . . . . . . . . . 33

3.3 Knudsen Cell Assembly. . . . . . . . . . . . . . . 42

3.4 Ion Source (with Potentials in Volts). . ... . 44

3.5 Data Acquisition and Equipment Control System
High Temperature Chemistry Laboratory. . . . . . 48

5.1 Ti Analysis Calibration Curve. . . . . . . . . 68

5.2 Plot of intensity ratio, $\mathrm{ITiO}^{+} / \mathrm{ITi}^{+}$, versus elapsed time at temperature. . . . . . . . . . 85

5.3 Shutter Profiles Ti(48)... . . . . . . . . . 88

5.4 Shutter Profiles TiO(64) . . . . . . . . . . . 89

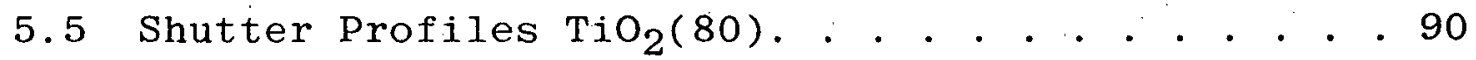

5.6 Ionization Efficiency Curves . . . . . . . . . . 100

5.7 Ionization Efficiency Curves . . . . . . . . . . 101

5.8 Plot of $\log _{\mathrm{e}}\left(\mathrm{I}^{+} \mathrm{T}\right)$ versus $\mathrm{I} / \mathrm{T} . \quad . \quad \cdot \quad \cdot \quad \cdot . \quad \cdot 110$

5.9 Plot of $\log _{\mathrm{e}}\left(\mathrm{I}^{+} \mathrm{T}\right)$ versus $\mathrm{I} / \mathrm{T}$ for $\mathrm{m} / \mathrm{e}=56 . . . .113$

5.10 Shutter Profiles Ti(48). . . . . . . . . . . . . 115

5.11 Shutter Profiles TiO(64) . . . . . . . . . . . 116

5.12 Temperature Profile--Experiment RS-MS-TiO-Y. . . .130

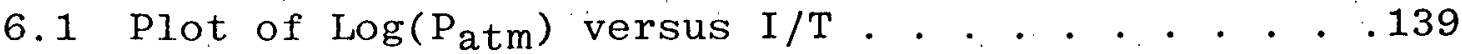

6.2 Plot of $\log _{10}\left(\mathrm{P}_{\mathrm{atm}}\right)$ versus composition, $\mathrm{X}_{\mathrm{O}} / \mathrm{X}_{\mathrm{T} i}$,

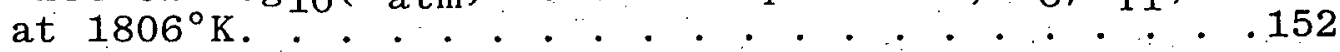


CHAPTER 1

INTRODUCTION

The titanium-oxygen system is a complicated system with an extensive experimental history. In recent years certain discrepancies became apparent in the thermodynamics of solid and gaseous TiO. The dissociation energy of TiO(g) was the subject of several experimental studies which may be divided into two groups according to the derived results. One set of measurements favored a value of the dissociation energy of about $158 \mathrm{kcal}$ while the second group reported a value approximately $10 \mathrm{kcal}$ higher. In an effort to resolve this discrepancy several laboratories performed additional experiments. At the present time these additional experiments support the lower of the two values.

Another discrepancy involved the standard free energy of formation of solid titanium monoxide obtained on the one hand from calorimetric measurements and on the other from integration of partial molal free energy data from various compositions to stoichiometric titanium monoxide. This discrepancy in the free energy of formation of solid titanium monoxide provided part of the motivation for the present. work.

One of the primary results measured in this work is the difference in standard free energy of gaseous and solid titanium monoxide at $1806^{\circ} \mathrm{K}$. The relationship of this quan- 
tity to the standard free energy of formation of gaseous and solid titanium monoxide is shown in Figure 1, page 3. Measurements of the standard free energy of formation of the gas and solid must be consistent with the free energy difference measured in this work. The value for the standard free energy of formation of the gas is derived from the measured dissociation energy and the molecular constants. The standard free energy of formation of the solid has been reported in the literature based both on calorimetry and integration of partial molal data. As noted above not all of these results are in agreement. If reported thermodynamic properties of the gas are assumed correct, then they may be combined with this work to yield a standard free energy of formation of solid titanium monoxide.

Three vaporization experiments were performed on a sample of nearly stoichiometric titanium monoxide. The sample was unique, being the only remaining stock from the U.S. Bureau of Mines on which heat of combustion, low temperature heat capacity, and high temperature enthalpy content measurements were made. The first two experiments were constant temperature experiments. In one experiment a small portion of titanium monoxide was vaporized from a tungsten crucible; the vapor was collected on a water cooled quartz cap; and the total amount of titanium deposited was analyzed colorimetrically. In the second experiment, which duplicated the heating regime of the first, the vapor composition in equili- 


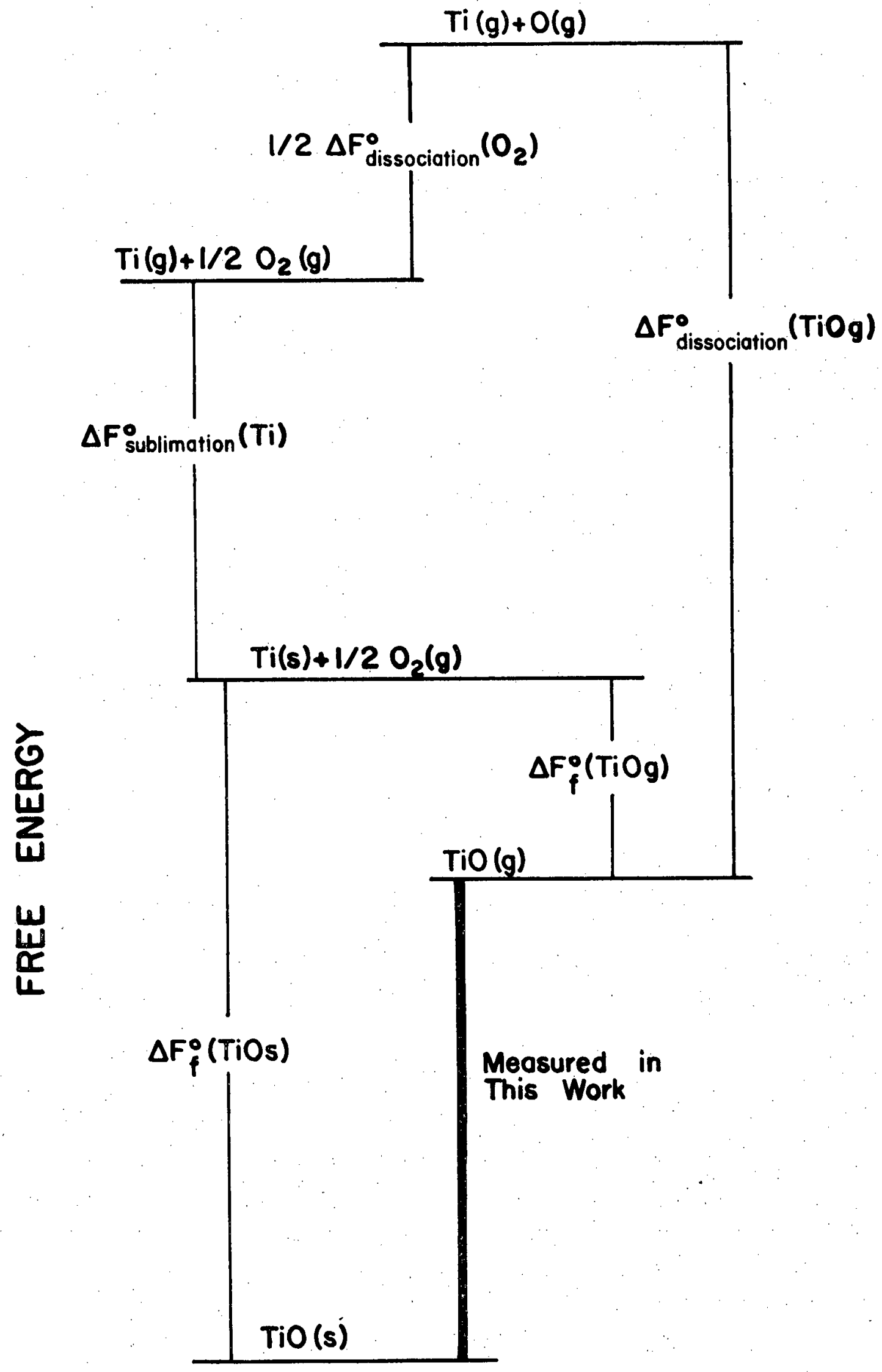

Fig. 1

FREE ENERGY LEVEL DIAGRAM 
brium with stoichiometric titanium monoxide was measured mass spectrometrically. From these two experiments the vapor pressures of $\mathrm{TiO}(\mathrm{g})$ and $\mathrm{Ti}(\mathrm{g})$ in equilibrium with stoichiometric titanium monoxide at $1806^{\circ} \mathrm{K}$ were calculated to be $\mathrm{P}_{\mathrm{TiO}}=\left(2.1 \mathbf{1}_{1} 1.23\right) \times 10^{-8}$ atm and $\mathrm{P}_{\mathrm{Ti}}=\left(7.58^{ \pm 1} .07\right) \times 10^{-8} \mathrm{~atm}$. The first result leads directly to the standard free energy difference between gaseous and solid titanium monoxide of $63.3 \pm 2.0 \mathrm{kcal}$ at $1806^{\circ} \mathrm{K}$. Combining this result with the free energy of formation of TiO(g) leads to a standard free energy of formation of $\mathrm{TiO}(\beta)$ at $1806^{\circ} \mathrm{K}$ of $-89.3 \pm 2.8 \mathrm{kcal}$. From the pressure of titanium given above a partial molal free energy of solution of titanium metal in stoichiometric titanium monoxide at $1806^{\circ} \mathrm{K}$ is calculated to be $-7.3 \pm 1.1 \mathrm{kcal}$.

In the third experiment the temperature dependences of $\mathrm{TiO}^{+}(64)$ and $\mathrm{Ti}^{+}(48)$ were measured mass spectrometrically. The mass spectrometer was calibrated from the pressures determined in the first two experiments. Second and third law heats for the vaporization of TiO(B) to give TiO(g) were determined to be $\Delta \mathrm{H}_{298}^{\circ}=138.2 \pm 3.0 \mathrm{kcal}$ and $\Delta \mathrm{H}_{298}^{\circ}=141.20 \pm 0.12$ kcal respectively. Partial molal enthalpies and entropies of solution of titanium and oxygen in stoichiometric titanium monoxide were also calculated.

The results reported in this work are shown to be consistent with the thermodynamic properties reported in recently issued pages of the JANAF Thermochemical Tables for TiO(g) and TiO(s). This agreement confirms that earliest 
calorimetric measurements on a portion of the same Tio sample used in this work yielded a standard free energy of formation of the solid which was not negative enough. Oxygen pressures in equilibrium with titanium monoxide at $1806^{\circ} \mathrm{K}$ previously reported in the literature and based on emf measurements are shown to be high by a factor of about 40 . 
CHAPTER 2

PREVIOUS WORK

The titanium-oxygen system is a complex system exhibiting many of the features associated with high temperature refractory materials. A complete description of the extensive literature of this system will not be attempted here; rather only previous work which has some bearing on the results of this thesis will be described.

\subsection{Phase Behavior}

A temperature-composition phase diagram for the titanium-oxygen system has been presented by Wahlbeck and Gilles (1). Several of the more notable features are: solid solution regions for the two metal phases, an extensive solid solution range for the high temperature monoxide phase, a low temperature monoxide phase showing a rather narrow range of homogeneity, and the occurrence of many. other phases including the Magnéli phases of the general formula $\mathrm{Ti}_{n} \mathrm{O}_{2 \mathrm{n}-1}$ with $\underline{\mathrm{n}}$ running from 5 to 10 .

The one congruently vaporizing composition in the titanium-oxygen system has been shown to lie in the very narrow solid solution range of $\mathrm{Ti}_{3} \mathrm{O}_{5}$ (2). This result has been confirmed by Hampson and Gilles in vaporization experiments performed in a mass spectrometer on samples initially more oxygen or more metal rich than the congruently vaporizing 
composition (3). The results of Hampson's experiments have been used to establish the compositions of the lower phase boundary, the congruently vaporizing solution, and the upper phase boundary of the $\mathrm{Ti}_{3} \mathrm{O}_{5}$ phase (4).

2.2 Thermodynamics of Vapor Species, $\mathrm{TiO}$ and $\mathrm{TiO}_{2}$

Two important titanium bearing molecules have been observed in the vapor phase in equilibrium with condensed phases of various compositions in the titanium-oxygen system. These molecules are $\mathrm{TiO}(\mathrm{g})$ and $\mathrm{TiO}_{2}(\mathrm{~g})$ (5). In addition atomic titanium becomes an increasingly important species for more metal rich samples. Gilles has discussed the use of mass spectrometer intensity ratios, $\mathrm{I}_{\mathrm{TiO}}^{+} / \mathrm{I}_{\mathrm{TiO}}^{+}$and $\mathrm{I}_{\mathrm{TiO}}^{+} / \mathrm{I}_{\mathrm{T} i}^{+}$, to obtain oxygen potentials (6). Gilles points out that actual values of the oxygen potential can be obtained only if the thermodynamic properties of the gas molecules are known; only relative values can be otherwise obtained.

The dissociation energy of $\mathrm{TiO}(\mathrm{g})$ has been a long standing and important problem in the titanium-oxygen system. Some of the earliest determinations of the dissociation energy by Knudsen effusion techniques and mass spectrometry were made on incongruently vaporizing samples of $\mathrm{TiO}_{1} \pm_{\mathrm{X}}(\mathrm{s})(5 ; 7,8)$.

Wahlbeck and Gilles reported a dissociation energy of $167.38 \pm 2.30 \mathrm{kcal}$ based on the vaporization reaction (2.1) (9) . 


$$
\mathrm{Ti}_{3} \mathrm{O}_{5}(\mathrm{~s})=3 \mathrm{TiO}(\mathrm{g})+20(\mathrm{~g})
$$

Drowart, et. al., measured the dissociation energy of TiO(g) from a mass spectrometric study of the isomolecular exchange reactions $(2.2)$ and $(2.3)(10)$.

$$
\begin{aligned}
& \mathrm{Ti}(\mathrm{g})+\mathrm{ScO}(\mathrm{g})=\mathrm{TiO}(\mathrm{g})+\mathrm{Sc}(\mathrm{g}) \\
& \mathrm{Ti}(\mathrm{g})+\mathrm{YO}(\mathrm{g})=\mathrm{TiO}(\mathrm{g})+\mathrm{Y}(\mathrm{g})
\end{aligned}
$$

From these reactions Drowart, et. al., calculated dissociation energies of $156.9 \pm 2.3 \mathrm{kcal}$ and $157.9 \pm 3.0 \mathrm{kcal}$ respectively. Using these data and other data $(5,8)$ they concluded that $\mathrm{D}_{\mathrm{o}}^{\circ}(\mathrm{TiO})$ was $157.8^{ \pm 1.0} \mathrm{kcal}$. Note that this value is some $10 \mathrm{kcal}$ lower than the result obtained by Wahlbeck and Gilles.

In an effort to clarify the discrepancies in the dissociation energy of $\mathrm{TiO}(\mathrm{g})$ obtained from various experiments (11), Hampson and Gilles performed extensive mass spectrometric studies (3). Their results indicated the vaporization of $\mathrm{Ti}_{3} \mathrm{O}_{5}(\mathrm{~s})$ proceeds mainly by reaction (2.4) rather than (2.1).

$$
\mathrm{Ti}_{3} \mathrm{O}_{5}(\mathrm{~s})=\mathrm{TiO}(\mathrm{g})+2 \mathrm{TiO}_{2}(\mathrm{~g})
$$

A study of the isomolecular exchange reaction (2.2) by Hampson and Gilles yielded a dissociation energy of TiO(g) of $156.9^{ \pm 2} .2 \mathrm{kcal}$. Hampson and Gilles also obtained a dissociation energy of TiO(g) of $159.2 \mathrm{kcal}$ based on reaction (2.5).

$$
\mathrm{TiO}(\mathrm{g})+\mathrm{Ge}(\mathrm{g})=\mathrm{Ti}(\mathrm{g})+\mathrm{GeO}(\mathrm{g})
$$

They considered this result less reliable than the one based on reaction $(2.2)$. 
Wu and Wahlbeck examined the vapor in equilibrium with a two phase mixture of $\mathrm{Ti}_{2} \mathrm{O}_{3}(\mathrm{~s})$ and $\mathrm{Ti}_{3} \mathrm{O}_{5}(\mathrm{~s})$ mass spectrometricaliy (12). The principal vaporization reaction was reported as

$$
2 \mathrm{Ti}_{2} \mathrm{O}_{3}(\mathrm{~s})=\mathrm{Ti}_{3} \mathrm{O}_{5}(\mathrm{~s})+\mathrm{TiO}(\mathrm{g})
$$

The vapor pressures of $\mathrm{TiO}(\mathrm{g})$ were determined as a function of temperature using the Knudsen effusion weight-loss method. The weight-loss was measured with a vacuum balance. A value of the dissociation energy of $\mathrm{TiO}(\mathrm{g})$ of $160.82 \pm 4.56 \mathrm{kcal}$ was determined through a third law analysis of the data.

The work described above and some additional work has been reviewed in recently issued pages of the JANAF Thermochemical Tables (13). Some additional work published. after the issuance of the JANAF supplements is described below.

Liu and Wahlbeck re-checked the vacuum balance work obtained for reaction (2.6) mass spectrometrically (14). They obtained a dissociation energy of TiO(g) of $158.2 \pm 3.7$ kcal. Gole and co-workers at M.I.T. deduced a lower bound of $156.2 \pm 4.5 \mathrm{kcal}$ for the dissociation energy of ground state titanium monoxide from a beam-gas chemiluminescent experiment (15).

Laser photoluminescence of $\mathrm{TiO}$ in Ne at $4^{\circ} \mathrm{K}$ has been used by Brom and Broida to establish the separation of the $\mathrm{a}^{1} \Delta$ electronic state and the $\mathrm{x}^{3} \Delta$ ground state (16). They report a separation of $3500 \mathrm{~cm}^{-1}$. Previously this separa- 
tion had been given as $581 \mathrm{~cm}^{-1}$ (17) and $1000 \mathrm{~cm}^{-1}$ (13).

The dissociation energy of $\mathrm{TiO}_{2}(\mathrm{~g})$. has been measured by several workers by a variety of techniques $(3,10,12)$. A comprehensive review is given by the JANAF Thermochemical Tables (13).

\subsection{Thermodynamics of Solid TiO}

Gilles has discussed certain discrepancies in the thermodynamics of the titanium-oxygen system (18). The first discrepancy involved the dissociation energy of TiO(g) as outlined in the previous paragraphs. The second discrepancy involves roughly a $10 \mathrm{kcal}$ disagreement in the standard free energy of formation of solid TiO obtained on the one hand from integration of partial molal free energy data from pure metal to stoichiometric TiO and on the other hand from combustion calorimetry and heat capacity measurements.

\subsubsection{Partial Molal Free Energy of Oxygen}

Kubaschewski and Dench presented a plot of the partial molal free energy of oxygen at $1273^{\circ} \mathrm{K}$ as a function of composition for the titanium-oxygen system (19). They obtained three experimental points by equilibration of titanium-oxygen alloys of various compositions with calcium, magnesium, and barium mixed with their respective oxides. The construction of their diagram was based in part on existing calorimetric data $(20,21,22)$. It is important to realize that a standard free energy of formation of solid TiO obtained by integration of Kubaschewski's partial molal free 
energy data does not give a result independent of the calorimetric data. Agreement between the integrated value and calorimetric results follows necessarily from the method of construction of Kubaschewski's diagram.

Kubaschewski has presented a reassessment of the partial molal free energy of oxygen for the titanium-oxygen system (23) based in part on the results of Komarek and Silver (24) for the metal rich side of the diagram. The results of Komarek and Silver indicate that oxygen is bound considerably more tightly in the condensed phases at $1273^{\circ} \mathrm{K}$ than previously indicated by Kubaschewski's original plot. The standard free energy formation of 1 mole of solid Tio at $1273^{\circ} \mathrm{K}$ obtained by integrating Kubaschewski's reassessed partial molal free energy data from pure metal to stoichiometric TiO yields a result roughly 10 kcal more negative than the result obtained by calorimetry $(20,21,22)$.

Oxygen potentials in the composition range $0.5 \leq 0 /$ $\mathrm{T} \mathbf{i} \leq 2.0$ and temperature range $1173^{\circ} \mathrm{K} \leq \mathrm{T} \leq 1873^{\circ} \mathrm{K}$ were obtained by Suzuki and Sambongi by emf measurements on oxygen concentration cells (25). Suzuki and Sambongi's oxygen potentials for coexisting two phase regions from $\mathrm{Ti}_{3} \mathrm{O}_{5}$ to $\mathrm{Ti}_{10} \mathrm{O}_{19}$ agree reasonably well with those obtained by Merritt and Hyde at $1304^{\circ} \mathrm{K}$ by gravimetric gas-solid equilibration techniques (26): Also Suzuki and Sambongi's oxygen potentials agree quite well with Cater and Sommers results for the two phase region $\mathrm{Ti}_{2} \mathrm{O}_{3}-\mathrm{Ti}_{3} \mathrm{O}_{5}$ (27). 
A plot of the partial molal free energy of solution of oxygen, $\Delta \overline{\mathrm{F}}_{\mathrm{O}_{2}}$, as a function of composition is shown in Figure 2.1, page 13. The plot is drawn for a temperature of $1273^{\circ} \mathrm{K}$. The results of Komarek and Silver were used in the composition range $\mathrm{O} \leq \mathrm{O} / \mathrm{T} \mathbf{i} \leq 0.499$; the results of Suzuki and Sambongi in the range of $0.499 \leq 0 / \mathrm{T} i \leq 1.5$, and the JANAF (13) results for the "compounds" in the range of $0 / \mathrm{Ti} \geq 1.5$. When necessary, experimental data were extrapolated to the phase boundaries given in the diagram of Wahlbeck and Gilles (1). The three experimental points determined by Kubaschewski and Dench (19) are indicated.

The dotted lines represent oxygen potentials calculated from the JANAF tables (13) for hypothetical two phase regions. For results to be consistent the areas under the dotted and solid lines should be equal. This is seen not to be the case for the hypothetical Ti-TiO equilibrium where the dotted line is more positive than any point on the solid curve.

2.3.2 Integral Thermodynamic Properties

Mah, Kelley, et. $\underline{\text { all. }}$, have measured the enthalpies of formation, low temperature heat capacities, and high temperature enthalpy contents of titanium-oxygen alloys (28). The heat of formation of $\mathrm{TiO}(\mathrm{s})$ has been measured by Humphrey at the U.S. Bureau of Mines using combustion calorimetry (20). Also at the U.S. Bureau of Mines, Naylor has measured the high temperature heat content and Shomate has measured the low temperature heat capacity of $\mathrm{TiO}(\mathrm{s})(21,22)$. In 


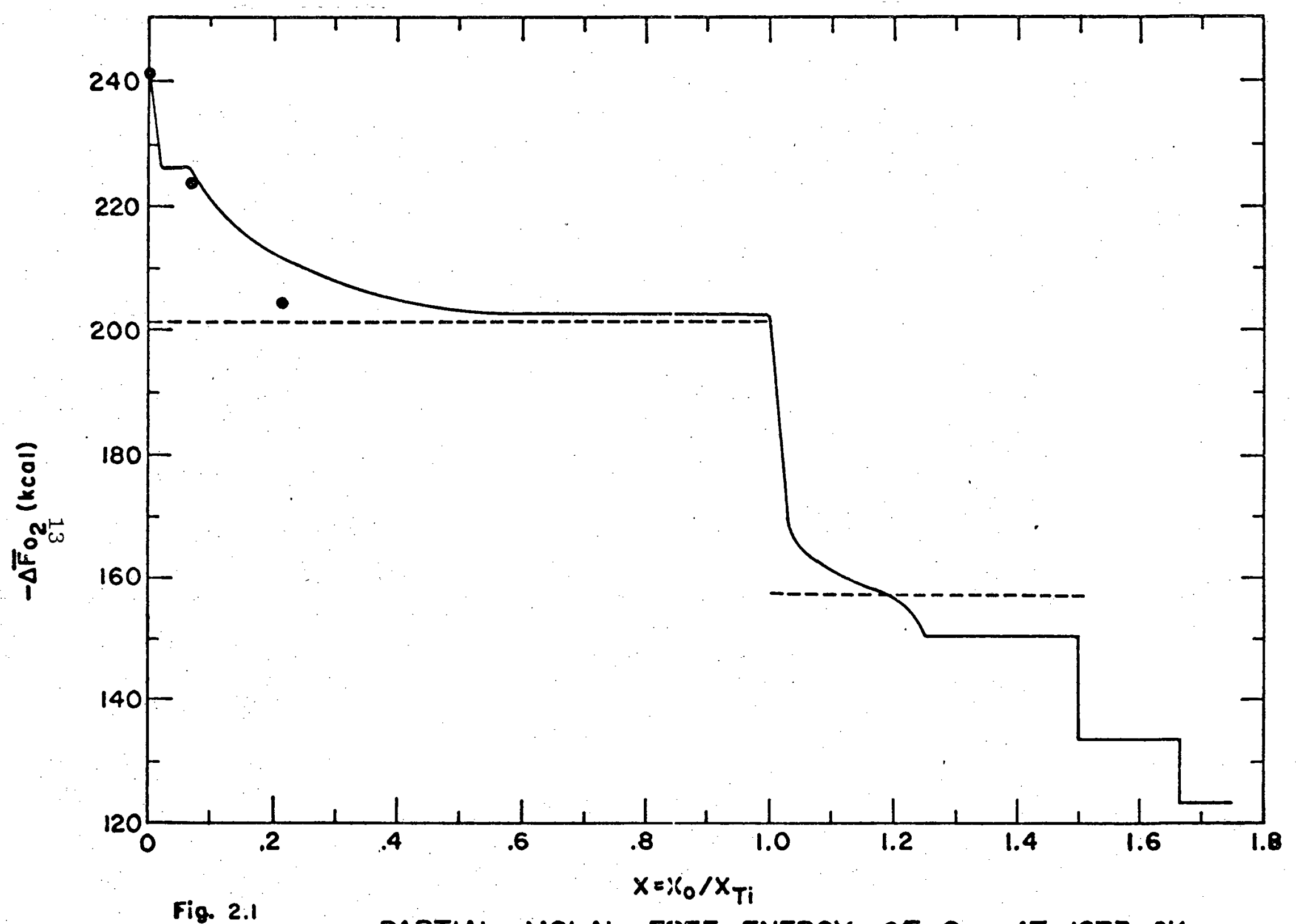

Fig. 2.1 PARTIAL MOLAL FREE ENERGY OF $\mathrm{O}_{2}$ AT $1273^{\circ} \mathrm{K}$ 
addition heats of formation of $\mathrm{TiO}(\mathrm{s})$ have been measured by Ariya, et. al., (29) and Charlu, Kleppa, and Reed (30). The results of Ariya, et. al., agree reasonably well with the results of Humphrey while the results of Charlu, Kleppa, and Reed yield a heat of formation significantly more negative than the value determined by Humphrey.

The JANAF Thermochemical Tables (13, 31) have presented a thorough review of the literature pertinent to the titanium-oxygen system. The results plotted in Figure 2.2, page 15, for the standard free energy of formation of TiO(s) are based on the discussion contained in recently issued pages of the JANAF tables for titanium monoxide (13). Figure 2.2 is a re-calculation of a plot originally done by Alan Syverud (32) and serves to compare results from many different experiments. A brief description of the construction of this plot follows.

The results plotted for the line labeled U.S.B.M. (U.S. Bureau of Mines) are essentially the results of Humphrey, Shomate, and Naylor. Humphrey's heat of formation has been adjusted to conform with the data of Mah and coworkers for rutile (28). The line denotated as "Kleppa" was calculated just as the U.S.B.M. line except that Kleppa's heat of formation for TiO(s) was used instead of Humphrey's. The remaining results contained in Figure 2.2 were obtained by integration of partial molal free energy data from various compositions to stoichiometric titanium monox- 


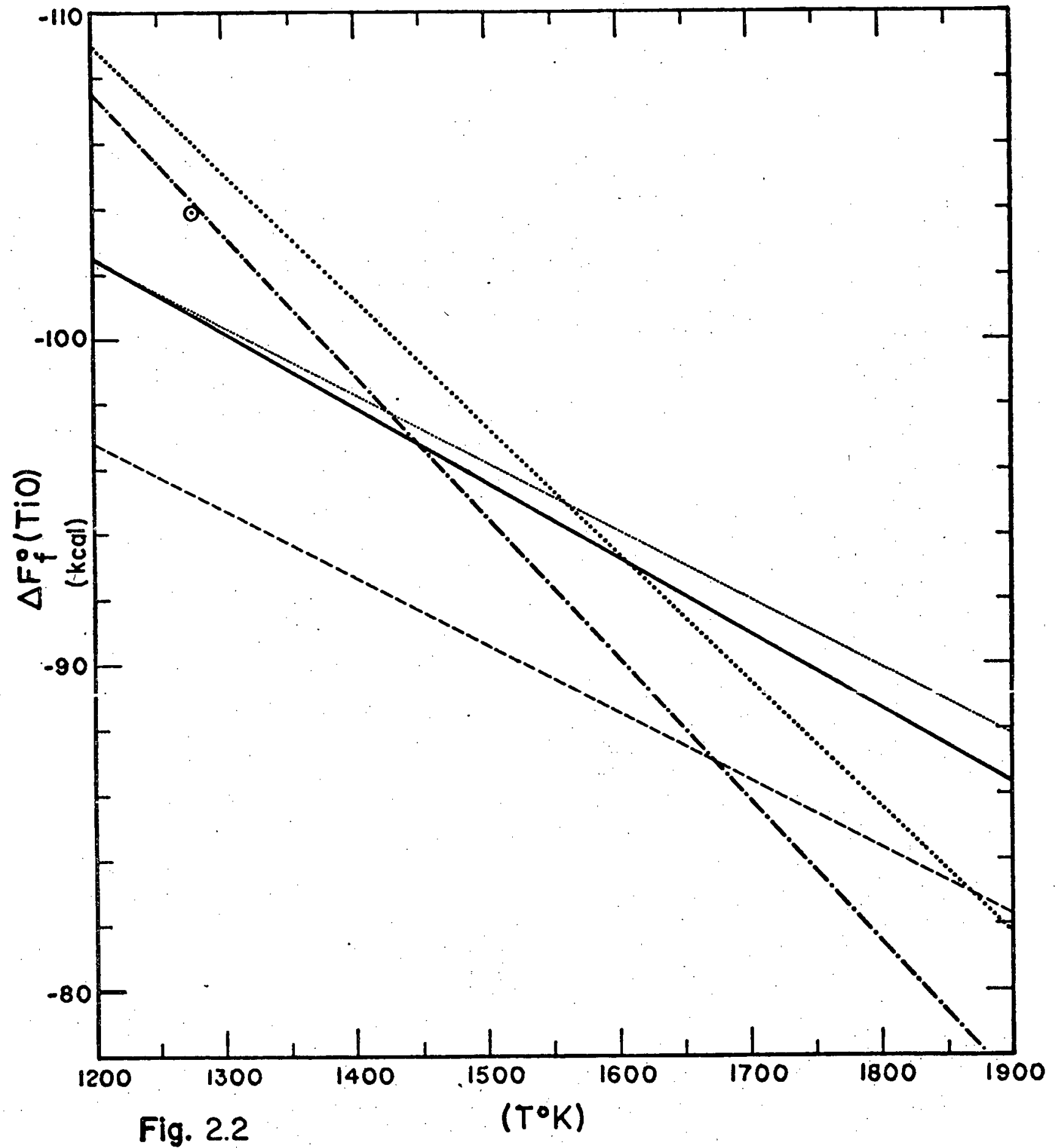

COMPARISON OF $\triangle \mathrm{F}_{f}^{\circ}[\mathrm{TiO}(\beta)]$. Calorimetry: U.S.B.M.-----, Kleppa - $\quad \Delta \overline{F O}_{2}$ Integration: $0.33 \leq 0 / T i \leq 1.0$ Positive Limit-_._, $0.33 \leq 0 / T_{i} \leq 1.0$ Negative Limit .........., $1.0 \leq 0 / T_{i} \leq 1.5$ $0.0 \leq 0 / T_{i} \leq 1.0 \cdot 0.15$ 
ide. The single point at $1273^{\circ} \mathrm{K}$ was obtained by integration of the partial molal free energy of oxygen plotted in Figure 2.1 from pure metal to Tio.

The solid line in Figure 2.2 was obtained by integration of the data of Suzuki and Sambongi from $\mathrm{Ti}_{2} \mathrm{O}_{3}$ to $\mathrm{TiO}$. The standard free energy formation of $\mathrm{Ti}_{2} \mathrm{O}_{3}(\mathrm{~s})$ which is needed for this calculation was obtained from the JANAF tables (13).

Negative and positive limits for the standard free energy of formation of solid titanium monoxide were obtained by integration of partial molal free energy data between $\mathrm{TiO}_{0.334}$ and TiO. The standard free energy of $\mathrm{TiO}_{0.334}(\mathrm{~s})$ was obtained from the combustion calorimetry, low temperature heat capacity measurements, and high temperature enthalpy contents of the U.S. Bureau of Mines (28). The residual entropy of the $\mathrm{TiO}_{0.334}$ solid solution at zero degrees was estimated from equation 10 given by Komarek and Silver (24).

The negative limit on $\Delta \mathrm{F}_{f}^{\circ}[\mathrm{TiO}(\mathrm{s})]$ was calculated assuming $\Delta \overline{\mathrm{F}}_{\mathrm{O}_{2}}$ in the range $0.334 \leq 0 / \mathrm{Ti} \leq 0.5$ is the same as the oxygen potential calculated for the hypothetical two phase equilibrium between $\mathrm{Ti}$ and $\mathrm{TiO}_{0.334}$. The partial molal free energy of oxygen in the range $0.5 \leq 0 / \mathrm{Ti} \leq 1.0$ was taken from the work of Suzuki and Sambongi (25).

The positive limit for the standard free energy of formation of solid Tio was calculated just as the negative 
limit except the partial molal free energy of oxygen in the range $0.334 \leq 0 / \mathrm{T} i \leq 0.5$ was taken to be the same as $\Delta \overline{\mathrm{F}}_{2}$ for the two phase field $\mathrm{Ti}_{2} \mathrm{O}-\mathrm{TiO}_{1-\mathrm{x}}$. 
CHAPTER 3

EXPERIMENTAL

\section{1 Introduction}

The experimental section of this thesis describes three different types of experiments. The first type consisted of a classical Knudsen effusion vapor pressure measurement on a titanium monoxide sample. The sample was heated in vacuum in a tungsten cell at constant temperature; the vapor was collected on a water cooled quartz cap surrounding the cell; and the total amount of titanium collected was analyzed colorimetrically. Because two titanium bearing species, $\mathrm{Ti}(\mathrm{g})$ and $\mathrm{TiO}(\mathrm{g})$, are important in the vapor, an analysis of the total titanium collected was not enough to establish both of these equilibrium vapor pressures. For this reason the second type of experiment was performed.

In the second type of experiment a titanium monoxide sample was vaporized in a mass spectrometer to measure the vapor composition. Specifically, the mass spectrometric results were used to apportion to $\mathrm{Ti}(\mathrm{g})$ and $\mathrm{TiO}(\mathrm{g})$ the total titanium collected in the first experiment. The experimental conditions in the mass spectrometer were chosen to match the conditions in the collection experiment with regard to sample, sample weight, sample container, temperature, and per- 
cent sample vaporized.

The third type experiment was a mass spectrometric measurement of the temperature dependence of $\mathrm{Ti}^{+}$and $\mathrm{TiO}^{+}$ over a titanium monoxide sample.

\subsection{Samples and Materials}

Titanium, laboratory designation Ti-5, was used to prepare a calibration curve for the colorimetric analysis of titanium. The metal was filed from a bar of iodide titanium which was obtained from the Foote Mineral Company, 18 West Chelten Avenue, Philadelphia, Pennsylvania. A magnet was used to remove any iron introduced in the filing procedure. A spectrographic analysis by the Foote Company showed the total metallic impurities to be less than $0.02 \%$, the major impurity being $0.01 \% \mathrm{Zr}$. The metal filings were degreased in toluene, rinsed with acetone and dried. A combustion analysis of the metal filings by Hampson showed their composition to be $99.8 \% \mathrm{Ti}$ (3).

The titanium monoxide sample, laboratory designation TiO-1, used throughout the course of this work was obtained from the United States Bureau of Mines and is part of the same material on which low-temperature heat capacity measurements (21), high-temperature heat capacity measurements (22), and heat of formation measurements (20) were made. Another. portion of this sample was used by Wheatley in a study of the dissociation energy of $\mathrm{TiO}(\mathrm{g})$ (7). The high temperature laboratory at the University of Kansas has the only remaining 
stock of this titanium monoxide sample because the Bureau of Mines samples were discarded when it was moved from Berkeley, California, to Albany, Oregon (33).

The titanium monoxide sample was prepared by reaction of equimolal quantities of titanium dioxide and titanium metal at $1350^{\circ} \mathrm{C}$ in vacuo. Analysis showed $99.2 \%$ titanium monoxide, $0.1 \%$ titanium carbide and $0.7 \%$ silicon (21). According to Kelley the silicon should have been reported as $0.7 \%$ SiO (34) as Humphrey reported in a re-analysis of the same material (20).

In addition to the above analysis Wheatley reported a combustion analysis of the monoxide made in air at $1000^{\circ} \mathrm{C}$ of $\mathrm{TiO}_{0.997 \pm 0.004}(7)$. He also reported $\mathrm{TiO}_{0.999 \pm 0.004}$ as the value corrected for Humphrey's reported SiO and TiC impurities on the assumption that these were converted to $\mathrm{SiO}_{2}$ and $\mathrm{TiO}_{2}$ respectively. Wheatley also reported an oxygen analysis of the sample in which the monoxide and $\mathrm{BrF}_{3}$ ' reacted and the amount of oxygen evolved analyzed. An analysis of the titanium monoxide using this method yielded a composition of $\mathrm{TiO}_{0.993 \pm 0.005}$. Wheatley reported a value of $\mathrm{TiO}_{0.989 \pm 0.005}$ as a lower oxygen composition limit based on corrections made for impurities. No additional determination of the sample composition was made in this work.

Because recent uncertainties have been raised about whether this titanium monoxide sample consists of the lowtemperature alpha phase, the high-temperature beta phase, or 
a multi-phase mixture $(13,30)$ an $\mathrm{X}$-ray analysis was performed on the original material. The detailed procedures of the X-ray work are described in a later section.

\subsection{Crucible}

The same tungsten cell, laboratory designation \#4, and lid were used throughout this work. This cell was used previously by Wahlbeck in his vaporization study of $\mathrm{Ti}_{3} \mathrm{O}_{5}(\mathrm{~s})$ (9). The cell and lid were fabricated with tungsten carbide tools from swaged tungsten rod. The outer diameter of the crucible was $1.6 \mathrm{~cm}$ with an inner cavity of $0.9 \mathrm{~cm}$ in diameter and $0.5 \mathrm{~cm}$ deep. The height of the cell with lid was $1.7 \mathrm{~cm}$. A hole, $1.6 \mathrm{~mm}$ in diameter and $5 \mathrm{~mm}$ deep, in the bottom of the crucible body served as a black body hole for temperature measurement. Three removable, pointed tungsten legs splayed from equally spaced holes near the outer edge of the bottom of the crucible. These legs were replaced by support rods in the mass spectrometer experiments.

\subsubsection{Orifice Dimensions and Clausing Factor}

The orifice area was measured with a Lietz "DialuxPol" polarizing microscope (serial number 611348) and special eyepiece attachment which allowed both a magnified image of the orifice and a piece of graph paper placed next to the microscope to be viewed simultaneously. The image of the orifice was traced onto the paper three times with the lid in three different orientations with respect to rotation about the axis of the orifice. The image of a $1 \mathrm{~mm}$ scale 
was traced onto each orifice measurement to obtain the magnification factor. The number of squares contained within each tracing was counted and the corresponding areas calculated. The results are summarized in Table 3.1, below. The first column gives the total squares counted. The second column is the projected area obtained from the graph paper grid ( 1 square $=0.01 \mathrm{~cm}^{2}$ ) and the number of squares given in the first column. The third column gives the linear magnification factor obtained from the trace of the $1 \mathrm{~mm}$ scale as viewed through the microscope. The last column gives the calculated orifice area obtained from the value in the second column divided by the square of the value in the third column .

Table 3.1

Orifice Area Crucible \#4

\begin{tabular}{cccc}
\hline Total Squares & $\begin{array}{c}\text { Projected Area } \\
\left(\mathrm{cm}^{2}\right)\end{array}$ & $\begin{array}{l}\text { Linear Magni- } \\
\text { fication } \\
\text { Factor }\end{array}$ & $\begin{array}{l}\text { Orifice } \\
\text { Area } \\
\left(\mathrm{cm}^{2}\right)\end{array}$ \\
\hline 8236.5 & 82.365 & 61.76 & 0.02159 \\
8233.5 & 82.335 & 61.68 & 0.02164 \\
8255.5 & 82.555 & 61.68 & 0.02170 \\
\hline
\end{tabular}

Average Area $=0.02164 \pm 0.00003 \mathrm{~cm}^{2}$

The orifice used in this study was cylindrical in shape and its length was determined optically as iliustrated in Figure 3.1, page 23. The 1id was centered on the stage of 


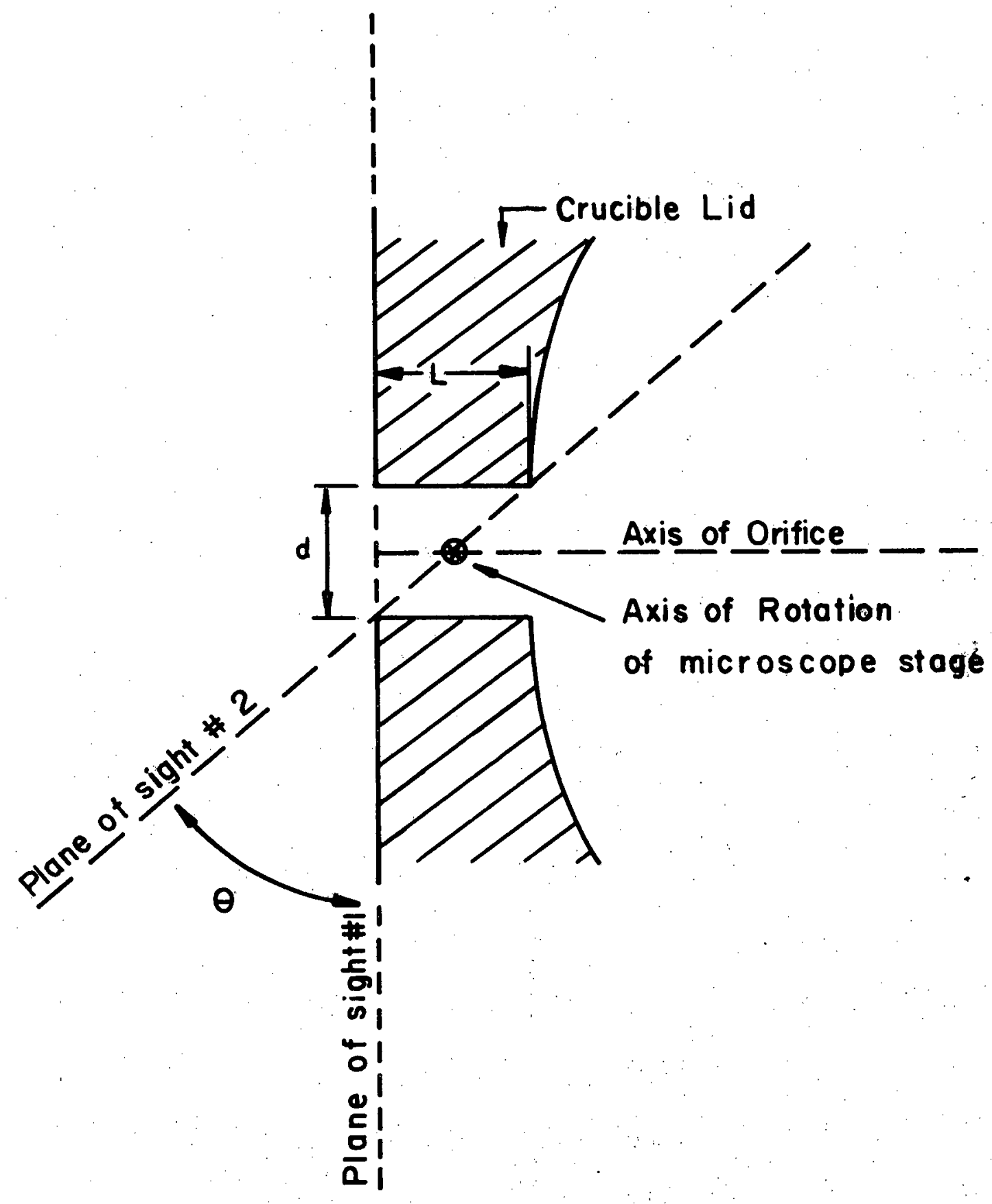

FIG. 3.1 
the Lietz microscope with the axis of rotation as shown in the figure. The lid was sighted with a telescope and turned about the axis of rotation until the plane of the lid was parallel to the plane of sight \#1 on the figure. Next the lid was rotated to plane of sight \#2 on the figure and the angle theta determined by a scale on the rotating stage of the microscope. The orifice length, was measured for four different orientations of the lid about the axis of the orifice. Four determinations of theta were made for each orientation of the lid. The results are summarized in Table 3.2, page 25. Columns one and two give the position of the microscope stage for plane of sight \#1 and \#2 respectively as shown in Figure 3.1. The third column gives the angle theta obtained from the absolute difference of the values contained in columns one and two. The fourth column gives the tangent of theta and the last column the calculated orifice length obtained from the equation

$$
L=\operatorname{dtan}(\theta)
$$

In equation (3.1) $\mathrm{d}$, the diameter of the orifice, was calculated to be $0.1660 \pm 0.0001 \mathrm{~cm}$ from the orifice area given in Table 3.1 .

The Clausing factor for the orifice, which gives the probability a molecule will escape the cell upon entering the orifice, was calculated from the tabulation of DeMarcus (35). For a cylindrical orifice, the Clausing factor is a function of the ratio of the length to radius of the orifice. 
Table 3.2

Orifice Length Crucible \#4

\begin{tabular}{|c|c|c|c|c|}
\hline (degrees) $^{\Theta_{1}}(\mathrm{a})$ & $\begin{array}{c}{ }^{{ }_{2}} \\
\text { (degrees) }\end{array}$ & $\begin{array}{c}\theta=\left|\theta_{1}-\theta_{2}\right| \\
(\text { degrees })\end{array}$ & $\tan \theta$ & $\begin{array}{c}\mathrm{L} \\
(\mathrm{cm})\end{array}$ \\
\hline \multirow[t]{4}{*}{279.1} & 267.4 & 11.7 & 0.2071 & 0.03438 \\
\hline & 268.3 & 10.8 & 0.1908 & 0.03167 \\
\hline & 268.2 & 10.9 & 0.1926 & 0.03197 \\
\hline & 268.3 & 10.8 & 0.1908 & 0.03167 \\
\hline \multirow[t]{4}{*}{267.3} & 265.3 & 11.0 & 0.1944 & 0.03227 \\
\hline & 265.6 & 10.7 & 0.1890 & 0.03137 \\
\hline & 265.5 & 10.8 & 0.1908 & 0.03167 \\
\hline & 265.9 & 10.4 & 0.1835 & 0.03046 \\
\hline \multirow[t]{4}{*}{278.3} & 267.0 & 11.3 & 0.1998 & 0.03317 \\
\hline & 266.8 & 11.5 & 0.2035 & 0.03378 \\
\hline & 267.9 & 10.4 & 0.1835 & 0.03046 \\
\hline & 267.5 & 10.8 & 0.1908 & 0.03167 \\
\hline \multirow[t]{4}{*}{280.6} & 269.0 & 11.6 & 0.2053 & 0.03408 \\
\hline & 268.8 & 11.8 & 0.2089 & 0.03468 \\
\hline & 268.8 & 11.8 & 0.2089 & 0.03468 \\
\hline & 269.1 & 11.5 & 0.2035 & 0.03378 \\
\hline
\end{tabular}

(a) $\Theta_{1}$ was measured only once for each orientation of the 1 id.

Average Length $=0.03261 \pm 0.00036$ 
For the present case this ratio was calculated to be 0.3929 and the corresponding clausing factor, $W$, interpolated from DeMarcus' tabulation found to be $0.8367 \pm 0.0015$. Dushman gives 0.8366 for the same quantity (36).

\subsubsection{Crucible Outgassing}

Prior to each experiment the tungsten crucible was outgassed in vacuum at about $2200^{\circ} \mathrm{K}$ for a minimum of four hours. The pressure was never higher than $5 \times 10^{-5}$ torr during the outgassing and typically was an order of magnitude less than this maximum value.

\subsection{Temperature Measurement and Correction}

Temperature measurements reported in this work were made in the $H$ Range scale on a Leeds and Northrup disappearing filament optical pyrometer, laboratory designation \#4 (serial number 1524978).

Temperatures were corrected for the attenuation of radiation by a window and prism arrangement which was in the optical path during temperature measurements. The correction was made by viewing a tungsten strip lamp at several temperatures both with and without the window and prism in the optical path. Power was delivered to the lamp from the secondary of a Westinghouse Signaling Transformer (catalog number 3F17). Power to the transformer primary was adjustable by means of a Powerstat Autotransformer, type 3PN116B. At least ten minutes was allowed for the temperature of the lamp to come to thermal equilibrium at each new power set- 
ting. Six readings were taken with the window and prism in place between the lamp and pyrometer and six readings without the window and prism. Care was taken to observe the same section of the lamp filament when a measurement was made. At each power setting an average temperature was calculated both with and without the window and prism. A value of $\underline{C}$, the window and prism constant, was calculated at each temperature from the equation

$$
1 / \mathrm{T}_{\text {with }}=1 / \mathrm{T}_{\text {without }}+\mathrm{C}
$$

where $\mathrm{T}_{\text {with }}$ and $\mathrm{T}_{\mathrm{without}}$ are the observed temperatures in degrees Kelvin with and without the window and prism respectively. An average value of $\underline{C}$ was then calculated.

Two sets of window and prism corrections were made, one set for use with vacuum line \#11, experiments RS-TiO-1 and RS-TiO-2, and the other set for mass spectrometer experiments RS-MS-TiO-X and RS-MS-TiO-Y. The results are summarized in Tables 3.3 and 3.4 respectively, pages 28 and 29. Column one gives the average of six observed temperatures with pyrometer \#4 with the window and prism. Column two gives the average of six observed temperatures without the window and prism. The third and fourth columns give the reciprocal temperature with and without the window and prism respectively. The last column gives the value of the window and prism correction constant as calculated from equation $(3.2)$.

Pyrometer \#4 was compared against a pyrometer, lab- 
Table 3.3

Temperature Correction Constant for the Window and Prism Used in Vacuum Line \#11, Experiments

$$
\text { RS-TiO-1 and RS-TiO-2 }
$$

\begin{tabular}{clccc}
\hline $\begin{array}{l}\text { Twith } \\
\left({ }^{\circ} \mathrm{K}\right)\end{array}$ & $\begin{array}{l}\mathrm{T}_{\mathrm{Without}} \\
\left({ }^{\circ} \mathrm{K}\right)\end{array}$ & $\begin{array}{l}1 / \mathrm{T}_{\mathrm{With}} \\
\left(10^{-4}{ }^{\circ} \mathrm{K}^{-1}\right)\end{array}$ & $\begin{array}{c}1 / \mathrm{T}_{\mathrm{Without}} \\
\left(10^{-4}{ }^{\circ} \mathrm{K}^{-1}\right)\end{array}$ & $\begin{array}{c}\mathrm{C} \\
\left(10^{-5}{ }^{\circ} \mathrm{K}^{-1}\right)\end{array}$ \\
\hline 1680.3 & 1720.8 & 5.9513 & 5.8113 & 1.4007 \\
1942.2 & 1984.0 & 5.1488 & 5.0403 & 1.0848 \\
1817.6 & 1852.8 & 5.5018 & 5.3972 & 1.0452 \\
1590.8 & 1617.3 & 6.2861 & 6.1831 & 1.0300 \\
1842.6 & 1882.0 & 5.4271 & 5.3135 & 1.1362 \\
\hline
\end{tabular}

Average Constant $=1.139 \pm 0.068$

Temperatures are listed in the order measured.

Each temperature reported is the average of six observations with the pyrometer. 
Table 3.4

Temperature Correction Constant for the Window and Prism

Used in the Mass Spectrometer, Experiments

RS-MS-TiO-X and RS-MS-TiO-Y

\begin{tabular}{cllll}
\hline $\begin{array}{c}\mathrm{T}_{\text {with }} \\
\left({ }^{\circ} \mathrm{K}\right)\end{array}$ & $\begin{array}{l}\mathrm{T}_{\text {without }} \\
\left({ }^{\circ} \mathrm{K}\right)\end{array}$ & $\begin{array}{l}1 / \mathrm{T}_{\mathrm{with}} \\
\left(10^{-4}{ }^{\circ} \mathrm{K}^{-1}\right)\end{array}$ & $\begin{array}{l}1 / \mathrm{T}_{\mathrm{without}} \\
\left(10^{-4}{ }^{\circ} \mathrm{K}^{-1}\right)\end{array}$ & $\begin{array}{c}\mathrm{C} \\
\left(10^{-5}{ }^{\circ} \mathrm{K}-1\right)\end{array}$ \\
\hline 1681.6 & 1710.0 & 5.9467 & 5.8480 & 0.98764 \\
1810.8 & 1850.6 & 5.5224 & 5.4037 & 1.1877 \\
1759.5 & 1796.5 & 5.6834 & 5.5664 & 1.1705 \\
1711.2 & 1746.3 & 5.8439 & 5.7264 & 1.1746 \\
1772.8 & 1812.0 & 5.6408 & 5.5188 & 1.2203 \\
\hline
\end{tabular}

Average Constant $=1.148 \pm 0.041$

Temperatures are listed in the order measured.

Each temperature reported is the average of six observations with the pyrometer. 
oratory designation \#1 (serial number 723042), which was calibrated at the National Bureau of Standards in January, 1969 , test number 197304. The comparison of the two pyrometers was made by alternately reading the temperature of a tungsten crucible inductively heated in vacuum. The crucible, laboratory designation \#114, had a hole drilled into its base which served as a black body radiator. The results of the comparison are given in Table 3.5 , page 31 . The first two columns give the average of four readings on the "H scale" for pyrometers \#1 and \#4 respectively. Column three gives corrected temperatures to the 1948 International Practical Temperature Scale obtained by linear interpolation of the Bureau of Standards calibration of pyrometer \#1. Column four gives temperatures in column three corrected to the 1968 International Practical Temperature Scale using the data of Rossini (37). Corrections for temperatures reported in this work not appearing in Table 3.5 were obtained by linear interpolation.

\subsection{X-Ray Analysis of Samples and Residues}

The TiO sample and residues were examined by powder $X$-ray diffraction techniques in an effort to identify the phases present. The X-ray specimens were ground in agate, when necessary, and loaded into $0.2 \mathrm{~mm}$ diameter glass capillaries. The X-ray camera was a Norelco Debye-Scherrer powder camera, laboratory designation $\# 1$, with a $114.59 \mathrm{~mm}$ diameter. The X-ray diffraction patterns were always obtained 
Table 3.5

Comparison of Pyrometers \#1 (H-scale)

and \#4 (H-scale)

\begin{tabular}{cccc}
\hline $\begin{array}{c}\text { Pyrometer } \# 1 \\
\left({ }^{\circ} \mathrm{C}\right)\end{array}$ & $\begin{array}{c}\text { Pyrometer } \\
\left({ }^{\circ} \mathrm{C}\right)\end{array}$ & $\begin{array}{c}1948 \text { IPTS } \\
\left({ }^{\circ} \mathrm{C}\right)\end{array}$ & $\begin{array}{c}1968 \text { IPTS } \\
\left({ }^{\circ} \mathrm{C}\right)\end{array}$ \\
\hline 1365.8 & 1370.5 & 1367.1 & 1368.6 \\
1410.0 & 1409.3 & 1412.2 & 1413.8 \\
1456.5 & 1458.8 & 1459.6 & 1461.3 \\
1491.8 & 1491.5 & 1495.6 & 1497.3 \\
1526.8 & 1528.5 & 1530.8 & 1532.6 \\
1555.8 & 1560.0 & 1559.8 & 1561.6 \\
1608.5 & 1610.5 & 1612.4 & 1614.3 \\
\hline
\end{tabular}

Temperatures are listed in the order of measurement.

Each temperature reported is the average of four observations with the pyrometer. 
on 1 aboratory generator "C", port \#1. A copper target and nickel filter were used. Exposures were normally for eight hours but a few longer exposures were attempted.

\subsection{Knudsen Vapor Pressure Measurements}

The vacuum system, induction heater, and analysis scheme for titanium used in the Knudsen vapor pressure measurements are described. In addition two specific Knudsen effusion-collection experiments, RS-TiO-1 and RS-TiO-2, are discussed.

\subsubsection{Vacuum System}

The high vacuum side of the vacuum system, laboratory designation line \#11, used for the Knudsen vapor pressure measurements is shown in Figure 3.2, page 33. The system was pumped by a Welch Duo-Seal mechanical fore pump (serial number 41551-0) and a single stage, divergent nozzle mercury diffusion pump. The pumps were trapped with liquid nitrogen. Pressures in the range of $10^{-4}$ to $10^{-7}$ torr were measured with a Consolidated Vacuum Corporation ionization gauge tube, type VG-1A, connected to a Consolidated Vacuum Corporation ionization gauge control circuit, type DPA-38. Higher pressures could be measured with a McLeod gauge or mercury manometer.

The tungsten crucible was supported by three tungsten legs which rested on a fused silica table. The crucible was surrounded by a water cooled fused silica cap, laboratory designation $17 \mathrm{~b}$, which served to collect the effu- 


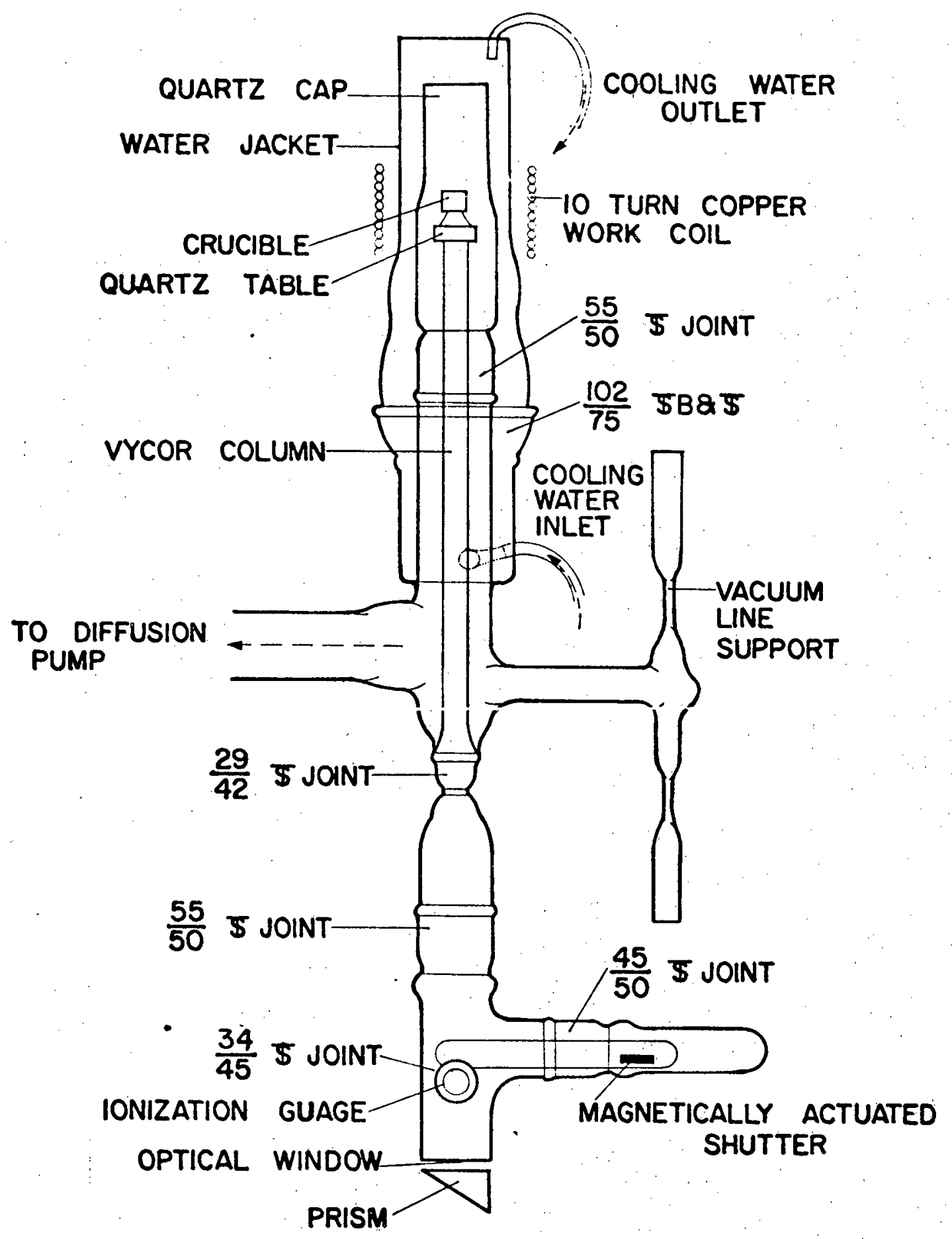

FIG. 3.2

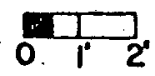

\section{VACUUM LINE NO. ELEVEN}


sate.

The optical window in the base of the system was covered with a magnetically operated shutter except when temperature measurements were being made. A prism placed under the window allowed the pyrometer telescope to be used in a convenient horizontal position:

\subsubsection{Induction Generator}

The tungsten crucible was heated inductively by a ten turn, water cooled, 0.25 inch diameter copper work coil. The outer diameter of the coil was 3.5 inches. Power to the coil was supplied by a $20 \mathrm{kw}$ General Electric Electronic Induction Heater, type HM-20-L1. The operating frequency of the induction generator was about $500 \mathrm{kc}$.

The output power of the induction generator was controlled by a feedback circuit. The output of a small pickup coil located inside the generator enclosure was converted to a d.c. voltage by a Leeds and Northrup a:c. to d.c. converter, part number 171002. The d.c: output of the converter was connected to a Leeds and Northrup D.C. Null Detector, catalog number 9834-2. The input, to the null detector was compared against a reference emf and an output proportional to the difference of the two emf's was input to a Leeds and Northrup P.A.T. Control Unit, part number 354161-S. The control unit adjusted the power output of the induction generator until the difference in the two emf's was zero. In this way constant power output was obtained from the induc- 
tion generator. In actual practice the sensitivity of the control unit was adjusted so the temperature of the crucible was maintained constant within about $10^{\circ} \mathrm{K}$ at $1800^{\circ} \mathrm{K}$. A higher sensitivity setting caused the unit to constantly "hunt" for the null setting.

\subsubsection{Colorimetric Analysis}

Titanium collected in the Knudsen vapor pressure measurements was analyzed colorimetrically based on the yellow color developed with $\mathrm{H}_{2} \mathrm{O}_{2}$. The same procedure has been used in the past by several workers $(7,9,38)$. The method used in this study outlined below is basically the same as described by Sandell (39).

Unless stated otherwise reagent grade chemicals were used throughout the analysis.

\section{(a) Preparation of $\mathrm{H}_{2} \mathrm{O}_{2}$}

The $3 \% \mathrm{H}_{2} \mathrm{O}_{2}$ was always prepared fresh just prior to use by adding $14 \mathrm{~g}$ of $\mathrm{Na}_{2} \mathrm{O}_{2}$ to $50 \mathrm{ml}$ of $18 \mathrm{~N} \mathrm{H}_{2} \mathrm{SO}_{4}$ and diluting to $200 \mathrm{ml}$. The solution was cooled in an ice bath while slowly adding the $\mathrm{Na}_{2} \mathrm{O}_{2}$ to prevent too vigorous a reaction.

(b) Calibration Curve

A calibration curve was prepared by dissolving $1.37077 \mathrm{~g}$ of $\mathrm{Ti}$ filings, laboratory designation $\mathrm{Ti}-5$, in 55 $\mathrm{ml}$ of $18 \mathrm{~N} \mathrm{H}_{2} \mathrm{SO}_{4}$. The resulting violet solution was accurately diluted to $500 \mathrm{ml}$ with distilled water. At this stage the solution was approximately $2 \mathrm{~N} \mathrm{H}_{2} \mathrm{SO}_{4}$. A volume of $10 \mathrm{ml}$ of 
this solution was accurately pipetted into a $1000 \mathrm{ml}$ volumetric flask and diluted to the mark with $2 \mathrm{~N} \mathrm{H}_{2} \mathrm{SO}_{4}$. The resulting solution contained $27.4154 \mu \mathrm{g} / \mathrm{ml}$ of titanium. From this solution 1 to $15 \mathrm{ml}$ aliquots were pipetted into $25 \mathrm{ml}$ volumetric flasks; $3 \mathrm{ml}$ of freshly prepared $3 \% \mathrm{H}_{2} \mathrm{O}_{2}$ was added to each flask; and each flask was filled to the mark with $2 \mathrm{~N} \mathrm{H}_{2} \mathrm{SO}_{4}$. A blank solution was also prepared by diluting $30 \mathrm{ml}$ of the $3 \% \mathrm{H}_{2} \mathrm{O}_{2}$ to $250 \mathrm{ml}$ with $2 \mathrm{~N} \mathrm{H}_{2} \mathrm{SO}_{4}$. The absorbances of the 15 standard solutions were measured against the blank solution at $412 \mathrm{~nm}$ using a model 2400 Beckman DU Spectrophotometer (serial number 113815) and matched set of pyrex Beckman cells. The results were plotted as absorbance versus micrograms per miliiliter of Ti. A straight line was drawn through the points using a linear least squares computer program, laboratory designation LS2H.

\section{(c) Analysis of $\mathrm{Ti}$}

The titanium collected in the effusion experiments was analyzed by adding $1.5 \mathrm{ml}$ of $36 \mathrm{~N} \mathrm{H}_{2} \mathrm{SO}_{4}$ to the cap and heating over a bunsen burner with swirling to remove all deposited sublimate. Heating was continued until the acid was fuming then the heating was terminated and the swirling continued until the solution had cooled. The contents of the cap were added to a $25 \mathrm{ml}$ volumetric flask. The cap was rinsed several times with a small quantity of distilled water and the washings added to the volumetric flask. The flask was cooled in ice water to prevent spattering of the 
contents when the washings came in contact with the concentrated acid. A pipetted $3 \mathrm{ml}$ of $3 \% \mathrm{H}_{2} \mathrm{O}_{2}$ was added to the flask and the contents allowed to come to room temperature before diluting to the mark. The absorbance of the resulting solution was measured against the blank solution as described in the previous paragraph. The amount of titanium collected was then obtained from the calibration curve.

(d) Cleaning Procedure for Cap

Prior to each run the quartz cap on which the sublimate was collected was cleaned with a small quantity of HF. The HF was poured out and the cap rinsed several times with distilled water. A few milliliters of $36 \mathrm{~N} \mathrm{H}_{2} \mathrm{SO}_{4}$ was added to the cap and heated to fuming. The acid was swirled and poured out. The cap was rinsed several more times with distilled water and dried at $140^{\circ} \mathrm{C}$ in an oven.

3.6.4. Specific Experiments

Two Knudsen effusion experiments, RS-TiO-1 and RSTiO-2, are described. The first experiment was a blank run with an empty crucible. The second experiment consisted of a vaporization of titanium monoxide at constant temperature followed by analysis of the collected sublimate for $\mathrm{Ti}$.

(a) $\mathrm{RS}-\mathrm{TiO}-1$

A blank run was made with an empty crucible, laboratory designation \#4. This blank run served as a check on the outgassing procedure for the crucible, as a check for possible interference in the analysis from impurities in the 
quartz cap on which the sublimates were collected, and as a check on the performance of the equipment. The crucible was placed in the vacuum line, laboratory designation \#11, and the line evacuated to a pressure of $5 \times 10^{-6}$ torr. Power was slowly supplied to the 10 turn work coil in such a manner that the pressure was always less than $1.0 \times 10^{-5}$ torr. The total time at temperature was determined by a Time-It timer manufactured by the Precision Scientific Company, Chicago, Illinois. The timer was accurate to $0.01 \mathrm{~min}$. Heating and cooling times were considered negligible compared to the total time at temperature of $720 \mathrm{~min}$. The average temperature of the run was $1858^{\circ} \mathrm{K}$ and was maintained constant to within a few degrees.

During RS-TiO-1 it was observed by alternately sighting the pyrometer on the surface of the cell lid and cell body that the lid was $20^{\circ} \mathrm{K}$ hotter than the body. These observations were made by sighting horizontally between turns of the work coil. In an effort to obtain a more uniform temperature distribution the coil was lowered so that three turns extended above the crucible and five turns below. After this adjustment the temperature of the lid was observed to be $5^{\circ} \mathrm{K}$ hotter than the body of the cell. This position of the coil was used for the remainder of the work with vacuum line \#11.

The quartz cap was subjected to the titanium analysis described in section 3.6.3. 


\section{(b) $\mathrm{RS}-\mathrm{TiO}-2$}

The purpose of this experiment was to measure the total amount of titanium vaporized from a nearly stoichiometric sample of titanium monoxide. Preliminary calculations based on published thermodynamic data were done to estimate the pressures of important gaseous species; the total amount of titanium expected for a given temperature, orifice and time at temperature; the fraction of titanium arising from each important titanium bearing gaseous species; and the expected change in composition of the solid due to incongruent vaporization of the monoxide. From these calculations convenient experimental parameters including the temperature, mass of sample, orifice dimensions, and time of vaporization were chosen. The calculations indicated a $10 \mathrm{mg}$ sample of TiO vaporized in crucible \#4 (described in section 3.3 ) at $1800^{\circ} \mathrm{K}$ for 12 hours would give a convenient amount of titanium to analyze colorimetrically and result in a negligible change in sample composition.

A sample of $10.24 \mathrm{mg}$ of titanium monoxide, laboratory designation TiO-1, was weighed into tungsten crucible \#4 using a one pan Mettler Gram-atic Balance (serial number 60337). In addition, the total mass of the cell, 1id, and sample was determined prior to placing the crucible in vacuum line \#11: The vacuum system was pumped down and power supplied to the work coil. The temperature was raised slowly with the highest pressure registered by the ioniza- 
tion gauge being $2.6 \times 10^{-6}$ torr and the average pressure during the run being about $6 \times 10^{-7}$ torr. When the temperature reached $1802^{\circ} \mathrm{K}$ the Time-It timer, described in section 3.6.4, was started to measure the vaporization time. Times. for heating and cooling of the cell were neglected. The temperature was read every 15 minutes with each temperature reading consisting of the average of four observations with the pyrometer. After a total of 12 hours at an average temperature of $1806^{\circ} \mathrm{K}$ heating was terminated, the crucible allowed to cool, and the vacuum broken. The crucible was weighed out of the vacuum system and the amount of titanium collected analyzed as described in section 3.6.3. The residue was examined by X-ray diffraction techniques.

\subsection{Mass Spectrometer Experiments}

3.7.1 Nuc1ide Mass Spectrometer

The mass spectrometer was a Nuclide Analysis Associates, model $\mathrm{HT}-2$, first-order direction focusing instrument with a 12 inch radius flight tube and $60^{\circ}$ magnetic sector. The instrument was equipped with a high-temperature molecular source in which the Knudsen cell was inclined at an angle of $60^{\circ}$ with respect to the horizontal. The crucible region, ion source, and analyzer were each evacuated with its own three stage mercury diffusion pump. The pumps were constructed by the H.S. Martin \& Company, Evanston, IIIinois. The three diffusion pumps were backed with a single Welch Duo-Seal mechanical pump (serial number 37769-5). The gen- 
eral design of the instrument has been previously discussed by Inghram and Hayden (40) and Chupka and Inghram (41). A few of the major features are described below.

(a) Molecular Source

The Knudsen source assembly is shown in drawing 3.3, page 42. The tungsten crucible was supported by three 0.060 inch diameter tungsten rods. The cell was surrounded by four tungsten ribbon filaments, 0.001 inch thick and 0.030 inch wide. The filaments were spot welded to tantalum foil sleeves placed on six 0.060 inch diameter tungsten support rods located around the cell. The crucible and filament assembly were surrounded by four concentric tantalum cans which served as radiation shields. Holes were punched in the top of the cans to allow the molecular beam to pass. Four circular tantalum radiation shields rested on three 0.060 inch diameter tungsten rods below the crucible. A small hole in the center of these was provided to allow a line of sight to the bottom of the crucible for temperature measurements. Mechanical support for the shield cans, filament support rods, and crucible was provided by three parallel, circular, Inconel plates. The shield cans were attached to the top plate; filament support rods were attached to the middle plate but were electrically insulated from the plate by ceramic holders; and the crucible was attached to the bottom plate. The top two plates were in electrical contact but were insulated from the bottom plate by quartz 
MOVABLE SHUTTER

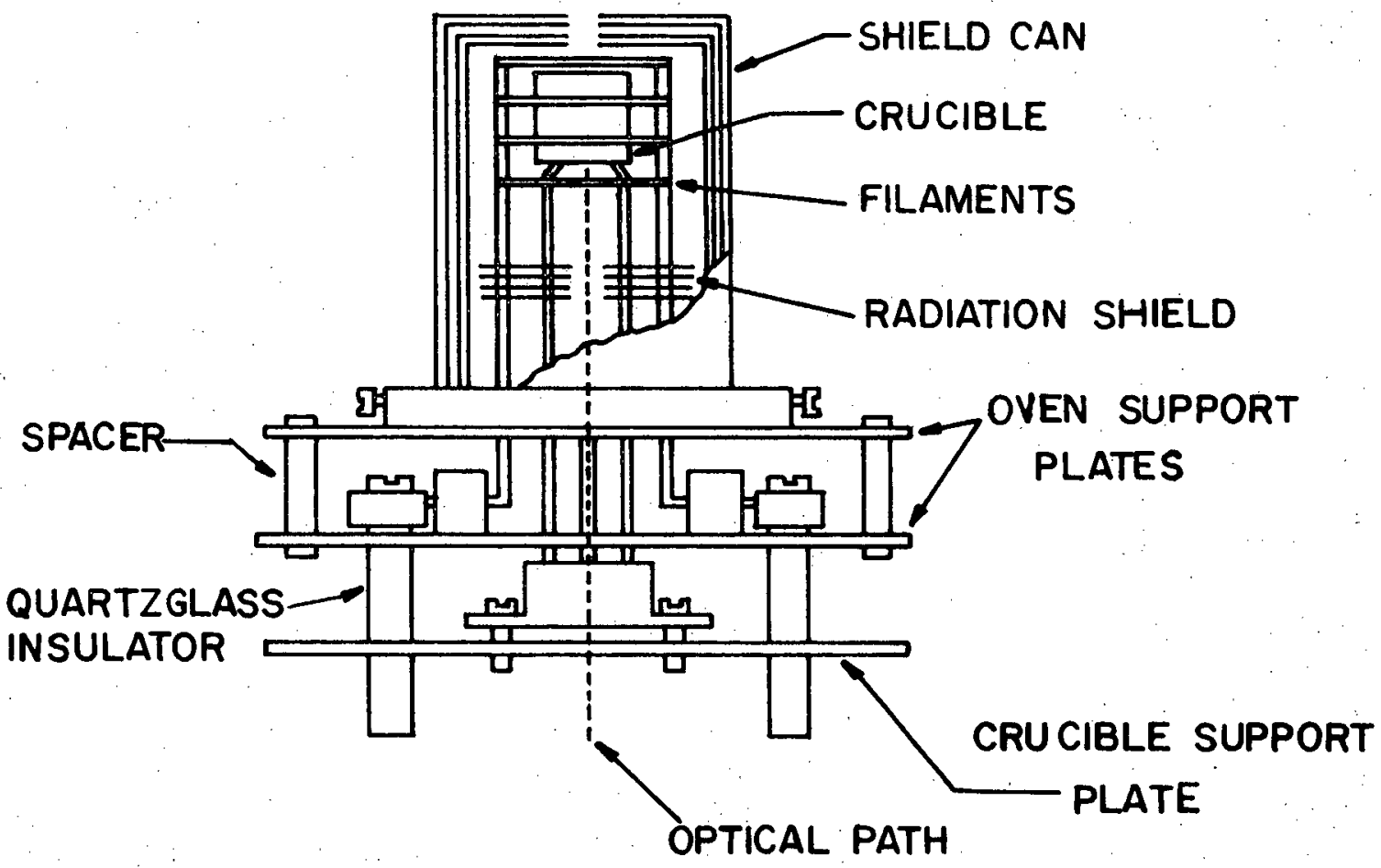

KNUDSEN CELL ASSEMBLY

AS MOUNTED ON $X-Y$ TABLE

FIG. 3.3 
spacers. The filaments and shield cans. were kept at ground potential. A variable positive potential could be placed on the crucible to allow heating by electron bombardment.

The Knudsen cell assembly was separated from the ion source by a plate containing a movable slide containing a 0.025 inch slit which served as a shutter. The shutter slide could be moved from outside the vacuum housing either manually or by a belt driven by a stepper motor, type ss501001, made by the Superior Electric Company, Bristol, Connecticut. The entire Knudsen assembly was mounted on a socalled $\mathrm{X}-\mathrm{Y}$ table so that it could be positioned in a plane parallel to the shutter plate by means of two linear motion feedthroughs oriented at $90^{\circ}$ to each other. This arrangement allowed optimum alignment of the Knudsen cell for maximum signal.

\section{(b) Ion Source}

After leaving the crucible and passing through the shutter slit the molecular beam entered the ion source. The ion source served to produce ions from neutral atoms or molecules and to focus and accelerate the ions into the analyzer. A schematic representation of the ion source illustrating the various focusing and deflection plates and their typical operating potentials is shown in Figure 3.4, page 44. The designations of the plates given on the left side of the drawing correspond to controls on the electronic circuitry which allowed adjustment of the various potentials. 
$J_{9}$

$J_{7}, v_{8}$

$J_{6}$

$J_{4}, J_{5}$

$J_{3}$

$\mathrm{J}_{2}$

$J_{1}$

$R_{1}, R_{2}$

$\mathrm{C}_{4}$

$\mathrm{C}_{2}, \mathrm{C}_{3}$

$c_{1}$

$V=0$ FINAL COLLIMATING SLIT

$0<V<210$

BEAM CENTERING PLATES

$V=0$ PRIMARY COLLIMATING PLATE $\mathrm{HV}-4000<\mathrm{V}<\mathrm{J}_{3}$ FOCUSING PLATES $J_{2}-200<V<J_{2}$

$\mathrm{HV}-200<\mathrm{V}<\mathrm{HV}$ DISCRIMINATING PLATE -DEFOCUSING PLATE HV ( $=4750$ NORMALLY $)$ $\sqrt{\circ}$ SHIELD PLATE $\mathrm{HV}<\mathrm{V}<\mathrm{HV}+50$ $H V<V<H V+90$ - COLLIMATING PLATE(TRAP) HV HV or HV+300 HV ELECTRODES HVCOLLIMATING PLATE

$V=0$ SHUTTER

FIG. 3.4 ION SOURCE(WITH POTENTIALS IN VOLTS) 
These potentials were adjusted at the start of each experiment to give maximum signals. The total potential difference through which ions were accelerated could be monitored by means of a 1000:1 voltage divider and a 2401C HewlettPackard Integrating Digital Volt Meter. Approximate potentials on the various ion source plates could be calculated by means of a microammeter on the mass spectrometer console. Ions were produced by electron impact. The ionizing electron beam traveled at right angles to the molecular beam and is indicated by the black dot directly below the shield plate in Figure 3.4. Both the current and energy of the electron beam were adjustable.

(c) Analyzer and Detector

After leaving the ionization region all ions of the same charge entered the analyzer with the same energy but different momenta depending on their mass. The ion source and analyzer were separated by an adjustable slit. The sensitivity and resolution of the instrument depend in part on the adjustment of this slit. The analyzer consisted of a $60^{\circ}, 12$ inch radius magnetic sector. Ions were separated according to their momenta, for a given accelerating voltage and magnetic field only ions within a narrow mass to charge ratio would have the proper trajectory to pass through the detector slit. A Hall effect probe, Bell Model YA-60-108 (serial number 56502), inserted between the magnet pole pieces and a Bell 640 Incremental Gaussmeter 
were used to measure the magnetic field. The output from the gaussmeter could be displayed on the 2401C Hewlett-Packard digital voltmeter.

The detector consisted of a 16 stage $\mathrm{Be}-\mathrm{Cu}$ electron multiplier. In addition a Faraday cup could be positioned from outside the vacuum system to intercept the ion beam directly in front of the electron multiplier. The signal from the multiplier or the Faraday cup was passed through a $10^{10} \mathrm{ohm}$ or $10^{12} \mathrm{ohm}$ resistor respectively to ground. The voltage developed across these resistors was monitored by a Cary 31 Vibrating Reed Electrometer (serial number 31-918). The output from the Cary electrometer was recorded with a Brown strip chart recorder, model number Y153x28-VDH-II-III$30-\mathrm{N} 4 \mathrm{P} 12(\mathrm{~A} 8)$.

In addition to the analog signal provided by the vibrating reed electrometer, digital signals could be obtained by counting pulses from the electron multiplier. Ideally there should be a one to one correspondence between ions hitting the first dynode of the multiplier and amplified current pulses output from the multiplier. The pulse-counting chain consisted of a 109A Ortec Preamplifier, a 451 Ortec Spectroscopy Amplifier, a 5201L Hewlett-Packard ScalerTimer, and a 2100 Hewlett-Packard Computer which was part of the data acquisition system described below. Typical pulse counting parameters used in this work are listed in Appendix I. 


\subsubsection{Data Acquisition System}

The data acquisition system shown in block form in Figure 3.5 , page 48 , was used in an on-line fashion in the mass spectrometric experiments for acquisition of data, reduction and display of data, and control of equipment. At the heart of the system was a 2100 Hewlett-Packard Computer with $16 \mathrm{k}$ words of memory and an additional $8 \mathrm{k}$ words of memory provided by a 2800 Daconics Expandable Memory. Peripheral equipment included two 2870A Hewlett-Packard Disc Drives, a 2020 Hewlett-Packard Magnetic Tape Drive, a time base generator, a 2401C Hewlett-Packard Integrating Digital Voltmeter, a 2911 Hewlett-Packard Guarded Cross Bar Scanner, a 6130B Hewlett-Packard Digital Voltage Source, a 140B HewlettPackard Oscilloscope used in the X-Y mode for display of data, a custom built party line, a 306 Centronics printer, a Hazeltine CRT, a teletype and several other I/O devices. The party line is a device that allows several devices to use the same computer I/O slot; it was designed and constructed by David L. Nordlund and his assistants at the University of Kansas Computation Center; it has been described by Marple (42). Devices on the party line included a stepper motor control, Chrono-log time of day clock, X-Y recorder pen control, and HP5400 Hewlett-Packard Multi-Channel Analyzer.

The laboratory data acquisition system was linked to the Chemical Physics Tri-Level Computer Network (CPTCN) at the University of Kansas. A detailed description of the 
DATA ACQUISITION AND EQUIPMENT CONTROL SYSTEM HIGH TEMPERATURE CHEMISTRY LABORATORY

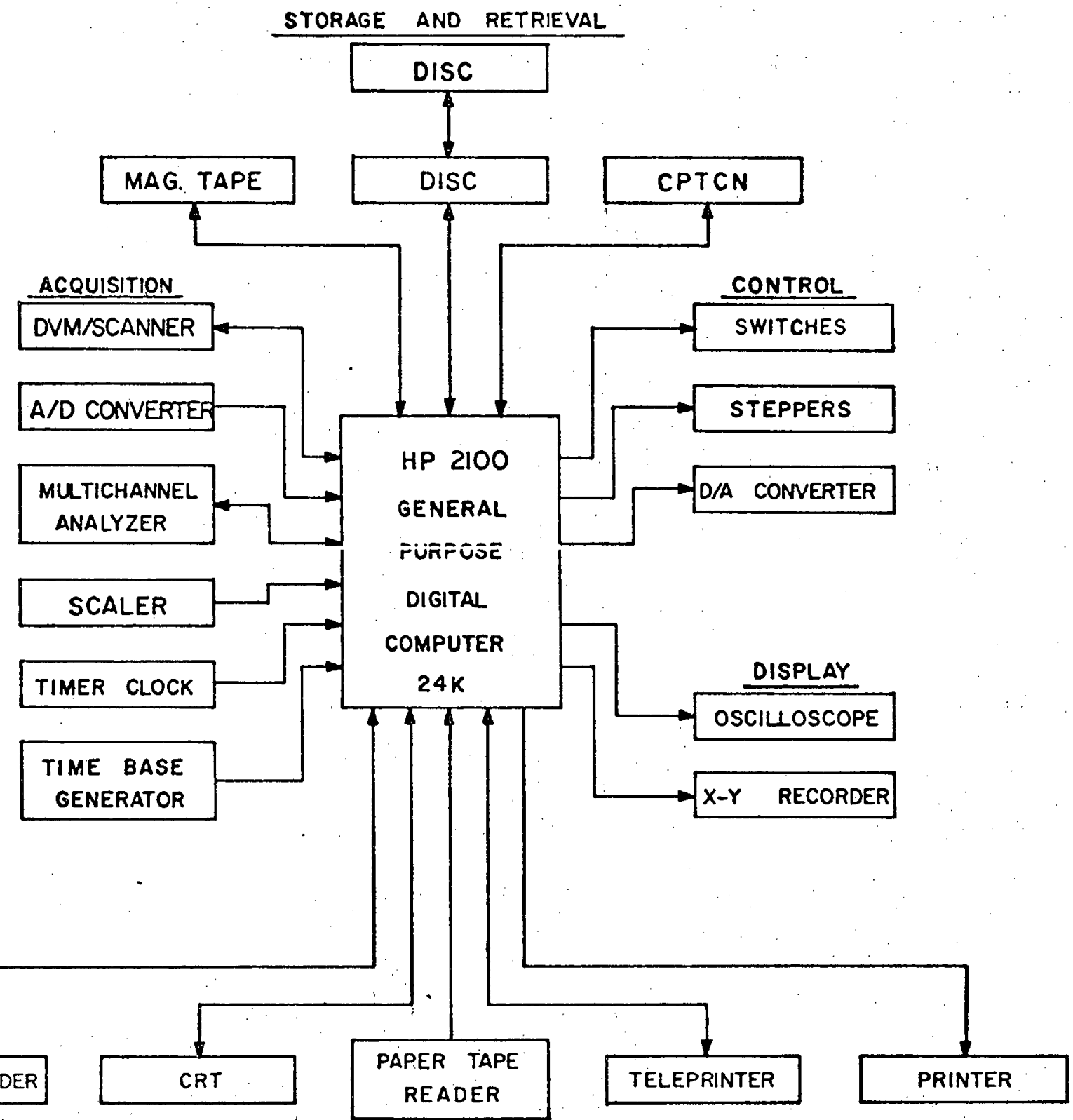
OPERATOR INTERACTION

FIG. 3.5 
network is given by Marple (42).

A brief description of the main computer programs used in the course of the mass spectrometric work is given in Appendix II. A more detailed description of these programs may be found in the complete documentation of the programs (43).

\subsubsection{Procedures}

Certain general procedures common to mass spectrometric experiments are discussed below.

(a) Preliminaries

Samples were weighed into the outgassed tungsten crucible with a Mettler Gram-atic Balance (serial number 60337). The crucible was positioned on the Knudsen assembly and the filaments spot welded to the filament support rods with a Weldmatic, model 1034 , spot welder manufactured by the Ultek Corporation, Monrovia, California. The crucible was aligned with the mass spectrometer axis by means of an alignment jig, the shield cans mounted in position, and the alignment rechecked. The Knudsen assembly was torqued to about $16 \mathrm{ft}-\mathrm{lb}$ on to the mating flange of the mass spectrometer and the system evacuated. Vacuum seal was made by compression of a 0.025 inch gold " 0 "! ring. The entire system was baked out at about $100^{\circ} \mathrm{C}$ for 12 to 24 hours by means of heating tapes. Following bakeout, pressures of $10^{-7}$ torr were easily obtained. Electronics were allowed to warm up for one hour and the spectrometer was ready for use. 


\section{(b) Mass Scans}

The mass spectrum could be scanned by either sweeping the magnetic field or the accelerating voltage. The former method was the usual one while the latter was used for slow scans over a few masses. At the beginning of each experiment a background scan was performed ranging from about mass 10 to 210. Peaks were identified by counting peaks from easily identifiable background ions. These included peaks at $\mathrm{m} / \mathrm{e}$ of $18\left(\mathrm{H}_{2} \mathrm{O}^{+}\right), 28\left(\mathrm{CO}^{+}, \mathrm{N}_{2}^{+}\right), 44\left(\mathrm{CO}_{2}^{+}\right), 55-57$ (hydrocarbons), 99$102\left(\mathrm{Hg}^{++}\right)$, and $198-204\left(\mathrm{Hg}^{+}\right)$.

\section{(c) Gain Check}

A gain check was performed at the beginning of each experiment to ascertain the performance of the electron multiplier. The gain of the multiplier is defined by the absolute value of the ratio of the current out of the multiplier to the ion current striking the first dynode of the multiplier. The gain measurement was made by comparing the signals obtained with the multiplier and Faraday cup while focused on $\mathrm{H}_{2} \mathrm{O}^{+}(18)$.

\section{(d) Focusing Conditions}

Focusing conditions in the mass spectrometer were optimized at the beginning of each experiment by adjustment of various potentials on plates in the ion source as discussed in section 3.7.1. The potentials were adjusted to give the maximum signal for $\mathrm{TiO}^{+}(64)$. These settings were checked occasionally during the course of an experiment to 
insure that they had not drifted from their optimum values.

(e) Shutter Profiles and Intensity Measurements Shutter profiles and intensity measurements were taken simultaneously with the data acquisition system and laboratory computer programs SPOBM and ARECM. A shutter profile was obtained by driving the shutter slit across the molecular beam. At each shutter position the ion intensity was measured by pulse-counting with the scaler. The data could optionally be listed on the printer and displayed on the scope as counts/second versus shutter position. Data were also stored on disc file with an appropriate identification. Multiple passes on the same species with signal averaging were possible: This procedure led to greatly improved shutter profiles for weak signals. Typically. 100 to 200 points were taken per pass; the total shutter movement was 0.100 inch; and the scaler gate time was 1 second.

Ion intensity data were obtained from shutter profile data using program ARECM. ARECM calculated the totai area under a shutter profile by summing the counts at each shutter position. The contribution to the total area from the background was obtained by determining the background intensity from the wings of the shutter profile. The background area was calculated on the assumption that a shutter profile of a background species is rectangular in shape, i.e., the signal from a background species was assumed to be independent of shutter position. The difference in total 
area and background was taken as a measure of the ion intensity. In addition to the pulse-counting data described above analog data were always obtained with the vibrating reed electrometer and strip chart recorder.

\section{(f) Ionization Efficiency Curves}

An ionization efficiency curve is a plot of the intensity for a given $\mathrm{m} / \mathrm{e}$ value as a function of the energy of the ionizing electron beam. Ionization efficiency curves may be used to obtain appearance potentials for ions and often yield information about fragmentation of molecular species. Ionization efficiency curves were obtained with program. I50KM and the data acquisition system. The electron energy was incremented with a Miniangle stepper Motor, model $23 \mathrm{H}-502 \mathrm{C}$, and the ion intensity was obtained from the pulsecounting equipment. An ionization efficiency curve run on $\mathrm{Hg}^{+}(202)$ was used to calibrate the energy of the electron beam from the known ionization potential of mercury. Data could optionally be listed on the printer and displayed on the scope as counts/second at each electron energy. Data were stored on disc file with appropriate identification. Multiple passes on the same species with signal averaging were possible. Electron energies ranged from 2.5 to $72.5 \mathrm{eV}$, with a resolution of $0.5 \mathrm{eV}$. Additional measurements of the initial part of the curves were obtained with a resolution of $0.2 \mathrm{eV}$ but smaller range of electron energy. Scaler gate times were 1 second. 


\subsubsection{Specific Experiments}

(a) RS-MS-TiO-X (Chart 1976-008, Disc Files RS279-341)

The purposes of this experiment were to ascertain the vapor composition over nearly stoichiometric titanium monoxide at $1806^{\circ} \mathrm{K}$, to obtain appearance potentials for the important vapor species $\mathrm{Ti}(\mathrm{g})$ and $\mathrm{TiO}(\mathrm{g})$, to determine the importance of fragmentation of $\mathrm{TiO}(\mathrm{g})$ to $\mathrm{yield} \mathrm{Ti}^{+}$, and to observe the change in relative oxygen potential with changing sample composition resulting from incongruent vaporization at fixed temperature. The relative oxygen potential was given by the intensity ratio $\mathrm{I}^{+} \mathrm{TiO} / \mathrm{I}^{+} \mathrm{Ti} \cdot$ The sample, mass of sample, temperature, crucible, orifice, and time of vaporization of RS-MS-TiO-X were chosen to match RS-TiO-2 as closely as possible.

The titanium monoxide sample, laboratory designation TiO-1, and tungsten crucible, laboratory designation \#4, have been described in sections 3.2 and 3.3. A quantity $10.41 \mathrm{mg}$ of the titanium monoxide was weighed into the cell. General procedures of operation of the mass spectrometer have been described in section 3.7.3. As described in that section the electron multiplier gain on $\mathrm{H}_{2} \mathrm{O}^{+}(18)$ was measured to be $3.51 \times 10^{5}$. The temperature was slowly increased to $1805^{\circ} \mathrm{K}$. The pressure in the crucible region was always less than $1.0 \times 10^{-5}$ torr during the initial heating of the sample and at least an order of magnitude lower than this after the sample had outgassed. At $1805^{\circ} \mathrm{K}$ a shutter check 
revealed the presence of $\mathrm{TiO}^{+}(64)$ and the Knudsen cell was positioned by the two linear motion feedthroughs to give the maximum signal. The average temperature of the experiment was $1806^{\circ} \mathrm{K}$ and was maintained constant within about $3^{\circ} \mathrm{K}$. Shutter profiles were run on ions $\mathrm{Ti}^{+}(48)$ and $\mathrm{TiO}^{+}(64)$ at $10.5 \mathrm{eV}, 12.5 \mathrm{eV}, 14.5 \mathrm{eV}$, and $22.5 \mathrm{eV}$. Shutter profiles were also run on $\mathrm{TiO}_{2}^{+}(80)$ at $70 \mathrm{ev}$ periodically throughout the experiment. All data were taken at an emission current of 0.3mA. Occasionally a check was made for anamolous $\mathrm{Ti}^{+}$by lowering the electron energy to near zero while focused on $\mathrm{Ti}^{+}(48)$. After 12 hours at temperature ionization efficiency curves were obtained for $\mathrm{Ti}^{+}(48), \mathrm{TiO}^{+}(64)$, and $\mathrm{Hg}^{+}(202)$. After 14 hours at temperature the crucible was removed from the mass spectrometer. The crucible body and residue were weighed. The residue was lightly scraped from the cell with a tungsten rod and the crucible was re-weighed. The crucible lid was also weighed. The residue was examined by X-ray diffraction techniques.

During the course of the vaporization the electron bombardment relay tripped off at 77 and 635 minutes elapsed at temperature. Just prior to the second shutdown of the bombardment heating the sample may have been hotter than $1806^{\circ} \mathrm{K}$ for a few seconds. The problem was caused by poor control of the bombardment voltage. In both cases the heating was brought back on without incident. The times for heating and cooling were negligible compared with the total 
elapsed time at temperature of 843 minutes.

(b) RS-MS-TiO-Y (Chart 1976-009, Disc Files RS342-363)

The purpose of this mass spectrometer experiment was to measure the temperature dependence of $\mathrm{Ti}^{+}(48)$ and $\mathrm{TiO}^{+}(64)$ over a nearly stoichiometric titanium monoxide sample.

An amount of $99.08 \mathrm{mg}$ of titanium monoxide, laboratory designation TiO-1, was weighed into tungsten crucible, laboratory designation \#4. This quantity was about ten times that for experiment RS-MS-TiO-X. The crucible body plus sample and crucible lid were also weighed. The general procedures described in section 3.7 .3 were followed. The electron multiplier gain for $\mathrm{H}_{2} \mathrm{O}^{+}(18)$ was measured to be $3.05 \mathrm{x}$ $10^{5}$.

Intensity data were taken using computer programs SPOBM and ARECM and the data acquisition system as described in section $3.7 .3 \mathrm{TiO}^{+}(64)$ and $\mathrm{Ti}^{+}(48)$ intensity data were taken at $14.5 \mathrm{eV}$ and $13.6 \mathrm{eV}$ respectively. These values correspond to taking intensities at the same distance above the appearance potential for respective ions. An emission current of $0.3 \mathrm{~mA}$ was used throughout the experiment. Temperatures ranged from $1694^{\circ} \mathrm{K}$ to $1919^{\circ} \mathrm{K}$. Ten points were obtained for $\mathrm{TiO}^{+}(64)$ and ten for $\mathrm{Ti}^{+}(48)$.

Following the experiment the crucible body plus residue were weighed and the lid weighed. The residue was examined by X-ray diffraction techniques.

During the above experiment problems with the elec- 
tron bombardment heating were encountered. During the initial heating the bombardment began to "run away" and in this excursion the sample was at an undetermined temperature for 35.5 seconds. 


\section{CHAPTER 4}

\section{THEORY}

This chapter presents a summary of theoretical principles pertinent to this work. Because detailed discussions of these topics may be found in textbooks and the literature, only a brief outline is given here.

\subsection{Knudsen Effusion Equation}

For pressures in the range of $10^{-3}$ to $10^{-9}$ atmospheres, the pressure of the ith species, $\mathrm{P}_{\underline{i}}$, in a Knudsen cell may be related to the rate of mass loss of the ith species, $d m_{i} / d t$, by the Knudsen effusion equation (4.1).

$\mathrm{P}_{i}=\left(\mathrm{T}^{\frac{1}{2}} \mathrm{dm} i\right) /\left(44.33 \mathrm{aWM}_{i}^{\frac{1}{2}} \mathrm{dt}\right)$

In equation (4.1) $\underline{\text { a }}$ is the orifice area of the Knudsen cell in square centimeters, W the Clausing factor, $\underline{T}$ the absolute temperature in degrees Kelvin, and $M_{i}$ the molecular weight of the ith species. The pressure is given in atmospheres and the rate of mass loss in grams per second. The Clausing factor, $\underline{W}$, occurs because not every molecule which enters the orifice necessarily escapes from the cell. Clausing factors have been calculated and tabulated for various orifice geometrics $(35,44)$.

\subsection{Thermodynamics}

The so-called second law and third law treatments of equilibrium measurements are presented; the use of mass 
spectrometer ion intensity ratios as oxygen potential indicators is noted; and some useful relationships between integral and partial molal properties are given.

\subsubsection{Second Law Treatment}

If the equilibrium constant of a chemical reaction is measured as a function of temperature, information about the standard enthalpy and entropy change of the reaction may be deduced from equations (4.2), (4.3), and (4.4).

$$
\begin{aligned}
\Delta \mathrm{F}_{\mathrm{T}}^{\circ} & =\Delta \mathrm{H}_{\mathrm{T}}^{\circ}-\mathrm{T} \Delta \mathrm{S}_{\mathrm{T}}^{\circ} \\
\Delta \mathrm{F}_{\mathrm{T}}^{\circ} & =-\mathrm{RT} \operatorname{lnK} .
\end{aligned}
$$

and

$$
\operatorname{lnK}=-\Delta \mathrm{H}_{\mathrm{T}}^{\circ} / \mathrm{RT}+\Delta \mathrm{S}_{\mathrm{T}}^{\circ} / \mathrm{R}
$$

If $\Delta \mathrm{H}_{\mathrm{T}}^{\circ}$ and $\Delta \mathrm{S}_{\mathrm{T}}^{\circ}$ are independent of temperature, i.e., if $\Delta \mathrm{C}_{\mathrm{p}}^{\circ}$ for the reaction is zero, then a plot of $1 \mathrm{nK}$ versus $1 / \mathrm{T}$ yields a straight line from which the standard enthalpy and entropy change may be deduced from the slope and intercept respectively. Even if $\Delta \mathrm{C}_{\mathrm{p}}^{\circ}$ is not zero such a plot often yields a straight line within the precision of the measurements and over temperature ranges typically accessible. For such a case the standard enthalpy and entropy are normally reported at the mean temperature of the measurements.

Enthalpy and entropy changes measured by the second law method may be reduced to reference temperatures if enthalpy and entropy increments are available for reactants and products. Reference temperatures are chosen as either $0^{\circ} \mathrm{K}$ or $298.15^{\circ} \mathrm{K}$. 


\subsubsection{Third Law Treatment}

When free energy functions are available for products and reactants the third law method may be applied to calculate a standard enthalpy change of reaction at $0^{\circ} \mathrm{K}$ or $298.15^{\circ} \mathrm{K}$ from each measurement of the equilibrium constant. The method of calculation is illustrated in equation (4.5) for a reference temperature of $298.15^{\circ} \mathrm{K}$.

$$
\Delta \mathrm{H}_{2}^{2} 98=-\mathrm{RT} \ln \mathrm{K}+\mathrm{T}(\Delta \mathrm{fef})
$$

where

$$
\begin{aligned}
& \Delta \text { fef }=\Sigma-\left(\mathrm{F}_{\mathrm{T}}^{\circ}-\mathrm{H}_{298}^{\circ}\right) / \mathrm{T}-\Sigma-\left(\mathrm{F}_{\mathrm{T}}^{\circ}-\mathrm{H}_{298}^{\circ}\right) / \mathrm{T} \\
& \text { products reactants }
\end{aligned}
$$

A knowledge of molecular structure and spectroscopic data are needed to compute free energy functions of gaseous species. Free energy functions for solids may be computed from heat capacity data. When structures, spectroscopic data and heat capacities are lacking, estimates of the unknown quantities may be attempted.

When possible both a second and third law analysis should be performed and the results from both methods compared. Often the third law treatment will reveal trends in the equilibrium constants that indicate non-equilibrium or measurement errors.

\subsubsection{Indirect Measurement of Oxygen Potentials}

For the temperatures and sample composition studied in this work the vapor pressures of atomic and diatomic oxygen are extremely small. Direct observation of shutterable 
oxygen with the mass spectrometer is impossible. As discussed by Gilles (6) oxygen potentials may be determined indirectly in studies of condensed metal oxide systems. Gilles points out that at constant temperature just as $\mathrm{H}_{2} \mathrm{O} / \mathrm{H}_{2}$ and $\mathrm{CO}_{2} / \mathrm{CO}$ pressure ratios in equilibrium with an oxide sample are measures of the oxygen pressure, so also are the pressure ratios $\mathrm{MO}_{2} / \mathrm{MO}$ and $\mathrm{MO} / \mathrm{M}$ where $\mathrm{M}$ represents a metal atom. Such ratios are proportional to mass spectrometer intensity ratios, $\mathrm{I}_{\mathrm{MO}_{2}}^{+} / \mathrm{I}_{\mathrm{MO}}^{+}$and $\mathrm{I}_{\mathrm{MO}}^{+} / \mathrm{I}_{\mathrm{M}}^{+}$. The situation for the titanium-oxygen system applicable to the present work is illustrated in equations (4.7) and (4.8)

$$
\begin{aligned}
& \mathrm{TiO}(\mathrm{g})=\mathrm{Ti}(\mathrm{g})+\mathrm{O}(\mathrm{g}) \\
& \mathrm{P}_{\mathrm{O}}=\mathrm{K}\left(\mathrm{P}_{\mathrm{TiO}} / \mathrm{P}_{\mathrm{Ti}}\right) \propto \mathrm{I}_{\mathrm{T}}^{+}{ }_{\mathrm{O}} / \mathrm{I}_{\mathrm{T}}^{+}
\end{aligned}
$$

If absolute pressures of oxygen are to be obtained the thermodynamic properties of the reactants and products in equation (4.7) must be known so that the equilibrium constant, $\underline{K}$, may be calculated. However, relative oxygen potentials can always be obtained from the mass spectrometric intensity ratios barring any problems arising, from fragmentation or anomalous ions.

\subsubsection{Integral and Partial Molal Properties}

Because the standard free energy of formation of solid titanium monoxide has been determined both from calorimetric measurements and by integration of partial molal free energy data, it is of interest to consider briefly some of the relationships between integral and partial molal proper- 
ties. More detailed discussions of this nature may be found in one of the several available metallurgical thermochemistry textbooks $(45,46,47)$. Although the results illustrated below are for free energy most of the equations also apply to the other thermodynamic properties such as enthalpy, entropy, etc. Also in the following discussion constant temperature and pressure conditions will be assumed to prevail. Before deriving relationships between partial molal and integral quantities it is first desirable to give precise definitions of them. The integral free energy of formation, $\Delta \mathrm{F}$, of a binary solution from components $\underline{A}$ and $\underline{B}$ is given in equation (4.9).

$$
\mathrm{X}_{\mathrm{A}} \mathrm{A}+\mathrm{X}_{\mathrm{B}^{\mathrm{B}}}=\mathrm{X}_{\mathrm{A}} \mathrm{A} \cdot \mathrm{X}_{\mathrm{B}^{\mathrm{B}}} \quad \Delta \mathrm{F}
$$

In the above equation $X_{A}$ and $X_{B}$ are the mole fractions of the respective components $\underline{A}$ and $\underline{B}$. Often such reactions are written with the pure reactants in their specified standard states.

The partial molal free energy of solution of component $\underline{A}^{\prime}, \Delta \bar{F}_{A}$, is the free energy change associated with the addition of 1 mole of pure $\underline{A}$, normally in some standard state, to a large amount of solution.

$$
\begin{aligned}
& \text { A(std. state) }+A_{m} B_{n}=A_{m+1} B_{n} \Delta \bar{F}_{A} \\
& \Delta \bar{F}_{A}=\bar{F}_{A}-F_{A}^{\circ}=\operatorname{RT} \ln a_{A}=\operatorname{RTIn}\left(f_{A} / f_{A}^{\circ}\right)
\end{aligned}
$$

The amount of solution should be large enough that the addition of 1 mole of $\underline{A}$ does not appreciably alter its composition, i.e., the ratio $\mathrm{m} /(\mathrm{m}+1)$ should be nearly unity. In 
equation (4.11) $\overline{\mathrm{F}}_{\mathrm{A}}$ and $\underline{\mathrm{F}}_{\mathrm{A}}^{\circ}$ are the partial molal free energy and molal free energy of component $\underline{A}$. The quantity $a_{A}$ is the activity of component $\underline{A}$ in the solution where the activity is given by the ratio of fugacity of $\underline{A}$ in the solution to the fugacity of $\underline{A}$ in its standard state. Of course a similar set of equations could be written for component $\underline{B}$. Reaction ( 4.10 ) is often written in the more compact but less descriptive form (4.12)

$$
A(\text { std. state })=A(\text { solution })
$$

Alternatively to the above definition, the partial molal free energy of solution of component $\underline{A}$ may be defined as the free energy change per mole of $\underline{A}$ associated with the addition of an infinitesimal amount of $\underline{A}$ to a finite amount of solution.

A relation between the partial molal free energies of solution of components $\underline{A}$ and $\underline{B}$ and the integral free energy of formation of 1 total mole of solution may be obtained by writing the free energy change for reaction (4.9) as the difference in free energies of the products and reactants.

$$
\begin{aligned}
\Delta \mathrm{F} & =\mathrm{F}_{\text {soln. }}-\mathrm{X}_{\mathrm{A}} \mathrm{F}_{\mathrm{A}}^{\circ}-\mathrm{X}_{\mathrm{B}} \mathrm{F}_{\mathrm{B}}^{\circ} \\
& =\mathrm{X}_{\mathrm{A}} \overline{\mathrm{F}}_{\mathrm{A}}+\mathrm{X}_{\mathrm{B}} \overline{\mathrm{F}}_{\mathrm{B}}-\mathrm{X}_{\mathrm{A}} \mathrm{F}_{\mathrm{A}}^{\circ}-\mathrm{X}_{\mathrm{B}} \mathrm{F}_{\mathrm{B}}^{\circ}
\end{aligned}
$$

Using definition (4.11) and the corresponding quantity for component $\underline{B}$ in equation (4.13) yields equation (4.14).

$$
\Delta \mathrm{F}=\mathrm{X}_{\mathrm{A}} \Delta \overline{\mathrm{F}}_{\mathrm{A}}+\mathrm{X}_{\mathrm{B}} \Delta \overline{\mathrm{F}}_{\mathrm{B}}=\mathrm{RT}\left(\mathrm{X}_{\mathrm{A}} \ln \mathrm{a}_{\mathrm{A}}+\mathrm{X}_{\mathrm{B}} \ln _{\mathrm{B}}\right)
$$

For an ideal solution the activities are replaced by their respective mole fractions and the usual equation for the free 
energy of formation of an ideal solution results.

If the partial molal free energies of both components (or equivalently the activities of both components) are known for some composition then the integral free energy of formation of 1 total mole of solution can be calculated from equation (4:14). Often only one activity is experimentally accessible. If the activity of one component is known as a function of composition the integral free energy of formation can still be obtained using the Gibbs-Duhem equation. The method is illustrated below.

Differentiation of equation (4.14) with respect to $\mathrm{X}_{\mathrm{B}}$ yields equation (4.15).

$$
\mathrm{d} \Delta \mathrm{F} / \mathrm{dX} \mathrm{X}_{\mathrm{B}}=-\Delta \overline{\mathrm{F}}_{\mathrm{A}}+\Delta \overline{\mathrm{F}}_{\mathrm{B}}+\mathrm{X}_{\mathrm{A}} \mathrm{d} \Delta \overline{\mathrm{F}}_{\mathrm{A}} / \mathrm{dX} \mathrm{X}_{\mathrm{B}}+\mathrm{X}_{\mathrm{B}} \mathrm{d} \Delta \overline{\mathrm{F}}_{\mathrm{B}} / \mathrm{dX} \mathrm{X}_{\mathrm{B}} \text { (4.15) }
$$

Noting the last two terms are zero by the Gibbs-Duhem relationship, equation $(4.15)$ is multiplied by $\mathrm{x}_{\mathrm{A}}$ and added to (4.14) to yield equation (4.16).

$$
\mathrm{d} \Delta \mathrm{F}+\Delta \mathrm{FdX}_{\mathrm{B}} /\left(1-\mathrm{X}_{\mathrm{B}}\right)=\Delta \overline{\mathrm{F}}_{\mathrm{B}} \mathrm{dX_{ \textrm {B } }} /\left(1-\mathrm{X}_{\mathrm{B}}\right)
$$

An integrating factor for this first order, linear differential equation is $1 /\left(1-\mathrm{X}_{\mathrm{B}}\right)$. Integration of equation (4.16) from pure component $\underline{A}$ to some composition $\mathrm{X}_{\mathrm{B}}^{\prime}$ yields the desired result.

$$
\Delta \mathrm{F}=\left(1-\mathrm{X}_{\mathrm{B}}\right) \int_{\mathrm{o}}^{\mathrm{x}_{\mathrm{B}}^{\prime}} \Delta \overline{\mathrm{F}}_{\mathrm{B}} /\left(1-\mathrm{X}_{\mathrm{B}}\right)^{2} \mathrm{dX}_{\mathrm{B}}
$$

Letting $x$ be equal to the mole fraction ratio $\mathrm{X}_{\mathrm{B}} / \mathrm{X}_{\mathrm{A}}$ renders equation (4.17) into the simpler form given in equation (4.18)

$$
\Delta F=[1 /(1+x)] \int_{0}^{x^{1}} \Delta \bar{F}_{B} d x
$$


This equation may be used to calculate the integral free energy of formation from the partial molal free energy of solution of one component known as a function of composition. A similar result may be derived in terms of $\Delta \overline{\mathrm{F}}_{A}$.

of course the integration of equation (4.16) need not start at a pure component. Integrating between two compositions yields a relationship between the integral free energies of formation of solutions of the two compositions. If one of these energies is known from additional sources, say calorimetry, then the other may be calculated.

The above equations are invaluable in checking the consistency of integral and partial molal data from widely different experimental sources for the titanium-oxygen system. Although the above method has stressed calculation of integral values from partial molal data the reverse process is obviously possible too. However, the numerical or graphical integration involved in the former process is generally easier than the numerical or graphical differentiation involved in the latter.

\subsection{Treatment of Nearly Constant Temperature Experiments.}

For a constant temperature experiment the Knudsen effusion equation (4.1) is easily integrated to yield equation (4.19).

$$
\mathrm{P}_{i}=\left(\mathrm{m}_{\mathrm{i}} \mathrm{T}^{\frac{1}{2}}\right) /\left(44.33 \mathrm{aWM} \mathrm{i}_{i}^{\frac{1}{2}} \mathrm{t}\right)
$$

For a single vapor species, collector or weight-ioss measurements may be used to determine the vapor pressure. Often 
the temperature may not be constant within the precision of the temperature measurements. What then are the appropriate temperature and pressure to report for such a "nearly" constant temperature experiment? This question presupposes that there are a single temperature, $\mathrm{T}_{0}$, and pressure, $\mathrm{P}_{0}$, appropriate for such an experiment. One reasonable requirement of $\underline{T}_{0}$ and ${\underline{P_{0}}}_{0}$ is that they be consistent with the measured mass-loss, i.e.,

$$
\mathrm{P}_{\mathrm{o}}=\left(\mathrm{m}_{\mathrm{i}} \mathrm{T}_{0}^{\frac{1}{2}}\right) /\left(44.33 \mathrm{aWM}_{\mathrm{i}}^{\frac{1}{2}} \mathrm{t}\right)
$$

The measured weight-loss must of course also be given in terms of the actual pressures and temperatures.

$$
\mathrm{m}_{\mathrm{i}}=44.33 \mathrm{aWM} \mathrm{i}_{\mathrm{i}}^{\frac{1}{2}} \int_{0}^{\mathrm{t}} \mathrm{P}_{\mathrm{i}} / \mathrm{T}^{\frac{1}{2}} \mathrm{dt} \mathrm{t}^{\prime}
$$

The pressure $P_{i}$ may be eliminated from equation (4.21) by means of the van't Hoff equation (4.22).

$$
\ln \left(\mathrm{P}_{\mathrm{i}} / \mathrm{P}_{\circ}\right)=-\Delta \mathrm{H}_{\mathrm{T}_{0}}^{\circ}\left(1 / \mathrm{T}-1 / \mathrm{T}_{0}\right) / \mathrm{R}
$$

Equation (4.22) assumes the enthalpy of vaporization is constant. This assumption is reasonable for small variations in the temperature. Combining equations (4.21) and (4.22) yields equation (4.23).

$$
\mathrm{m}_{\mathrm{i}}=44.33 \mathrm{aWM} \mathrm{M}_{\mathrm{i}}^{\frac{1}{2}} \mathrm{P}_{0} \int_{0}^{\mathrm{t}} \mathrm{T}^{-\frac{1}{2}} \exp \left(-\Delta \mathrm{H}_{\mathrm{T}_{0}}^{0}\left(1 / \mathrm{T}-1 / \mathrm{T}_{\circ}\right) / \mathrm{R}\right) \mathrm{d} \mathrm{t}^{\prime}
$$

Elimination of $\mathrm{m}_{\mathbf{i}}$ from equations (4.20 and (4.23) yields equation $(4.24)$.

$$
1=\mathrm{T}_{0}^{\frac{1}{2}} / \mathrm{t} \int_{\mathrm{o}}^{\mathrm{t}_{\mathrm{T}}-\frac{1}{2}} \exp \left(-\Delta \mathrm{H}_{\mathrm{T}}^{\circ}\left(1 / \mathrm{T}-1 / \mathrm{T}_{\mathrm{o}}\right) / \mathrm{R}\right) \mathrm{d} \mathrm{t}^{\prime}
$$

Note for the case of constant temperature, $\mathrm{T}_{\mathrm{o}}=\mathrm{T}$, equation (4.24) gives the proper result. 
In equation (4.24) the temperature $\underline{T}$ represents the actual temperature measured as a function of time. It is instructive to consider a simple case to which equation (4.24) can be applied. Consider a hypothetical experiment in which a temperature $\mathrm{T}_{1}=1810^{\circ} \mathrm{K}$ is measured in the first half and $\mathrm{T}_{2}=1790^{\circ} \mathrm{K}$ measured in the second half. Take the heat of vaporization to be $133.7 \mathrm{kcal}$ (the value given by the JANAF tables for the heat of sublimation of TiO(s) to $\mathrm{TiO}(\mathrm{g})$ at $\left.1800^{\circ} \mathrm{K}\right)$. Substitution of these values into equation (4.24) and numerical solution for $T_{0}$ yields a value of about $1801^{\circ} \mathrm{K}$. This result indicates that at least for this case the average temperature is negligibly different from $\mathrm{T}$. 


\section{CHAPTER 5}

\section{RESULTS}

\subsection{Titanium Analysis}

The calibration curve used for colorimetric determination of the titanium collected in the Knudsen effusion experiments is shown in Figure 5.1, page 68. The measured absorbance of 15 standard solutions is plotted against the concentration of titanium in micrograms of $\mathrm{Ti}$ per milliliter. The absorbance was measured at a wavelength of $412 \mathrm{~nm}$ and a slit width of $0.064 \mathrm{~mm}$.

A linear least squares computer program, laboratory designation LS2H, was used to fit the points of the calibration curve to a straight line. All points were weighted equally in the least squares calculation. The least squares results are given in equation (5.1).

$$
A=(1.5688 \pm 0.0092) \times 10^{-2} \mathrm{C}+(8.0 \pm 9.2) \times 10^{-4}(5.1)
$$

In the previous equation, $\underline{A}$ is the absorbance and $\underline{C}$ is the concentration of titanium in micrograms per miliiliter. Errors are standard deviations.

\subsection{X-ray Diffraction of TiO-1 and Residues}

$\mathrm{X}$-ray powder diffraction patterns were used to identify high temperature ( $\beta$ ) titanium monoxide which has a NaCl structure (48) and low temperature ( $\alpha$ ) titanium monoxide which has a closely related monoclinic structure (49). As 


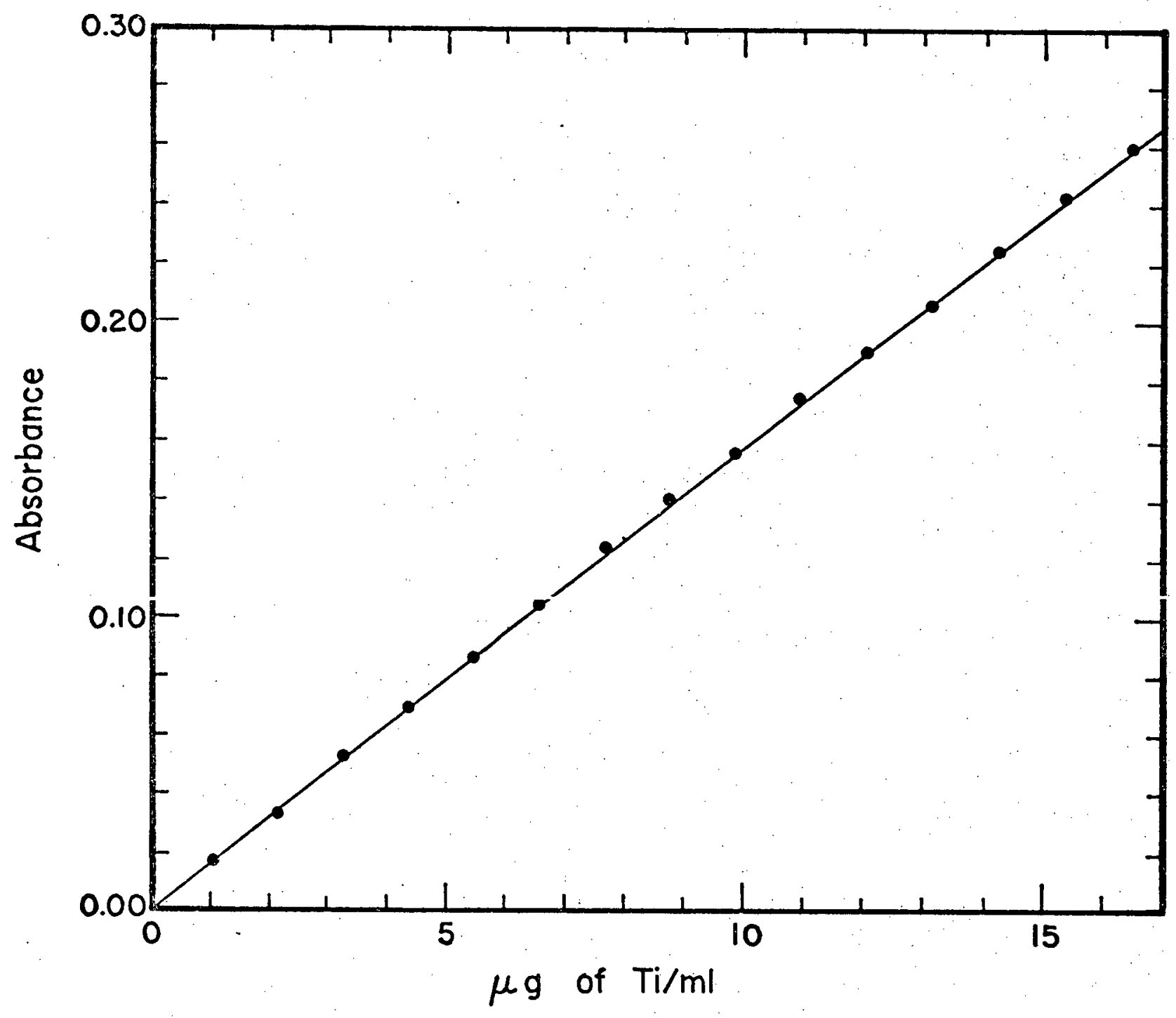

Fig. 5.1

Ti ANALYSIS CALIBRATION CURVE 
is not uncommon for titanium monoxide, the films are of only poor to fair quality.

The X-ray patterns taken of the original sample indicate both high and low temperature titanium monoxide to be present. This result is especially significant because questions had been raised in the literature about the nature of the U.S. Bureau of Mines samples, a portion of which was used in the present work $(13,30)$. In an effort to obtain more quantitative information about the proportions of the phases in the Bureau of Mines samples, Gilles, et. all., performed additional work using an X-ray diffractometer and data acquisition system to do ensemble averaging over various reflections (50). Their results indicate the original Bureau of Mines samples contain about one-third high temperature TiO ( $30 \pm 5 \% \mathrm{H} . \mathrm{T}^{\mathrm{N}}$ ) and two-thirds low temperature TiO. The diffraction photographs of residues from vaporization experiments RS-TiO-2 and RS-MS-TiO-X indicate mostly high temperature TiO but some low temperature material is also present. The residue from experiment RS-MS-TiO-Y appeared to have about the same proportions of the high and low temperature phases as the original sample.

A summary of the films taken in the present work is given in Table 5.1, page 70. The first column gives the film number. The second column identifies the sample. The third column indicates the film quality and the last column contains remarks. 
Table 5.1

Debye-Scherrer Films

\begin{tabular}{|c|c|c|c|}
\hline Film No. & Sample & $\begin{array}{l}\text { Film } \\
\text { Quality }\end{array}$ & Comments \\
\hline $\mathrm{C} 5688$ & TiO- 1 & Fair & Both high and low temperature TiO. \\
\hline C5689 & TiO-1 & Fair & Longer exposure than C5688, both phases. \\
\hline C5692 & Residue, RS-TiO-2 & Poor & $\begin{array}{l}\text { High temperature form mostly, some low tem- } \\
\text { perature. }\end{array}$ \\
\hline C5693 & Residue, RS-TiO-2 & Poor & $\begin{array}{l}\text { Repeat of C5692, same capillary but differ- } \\
\text { ent place. }\end{array}$ \\
\hline C5694 & Residue, RS-TiO-2 & Fair & $\begin{array}{l}\text { New portion of same residue, mostly cubic } \\
\text { phase. }\end{array}$ \\
\hline C5695 & Residue, RS-TiO-2 & Fair & $\begin{array}{l}\text { Repeat of C } 5694 \text {, same capillary but differ- } \\
\text { ent place. }\end{array}$ \\
\hline C5700 & Residue, RS-TiO-2 & Poor & Long exposure with foil, lines very weak. \\
\hline C5696. & Residue, RS-TiO-X & Fair & $\begin{array}{l}\text { Mostly high temperature form, some low tem- } \\
\text { perature. }\end{array}$ \\
\hline C5701 & Residue, RS-TiO-X & Poor & Long exposure, same capillary as C5696. \\
\hline C5690 & Residue, RS-TiO-Y & Fair & $\begin{array}{l}\text { About same proportions of phases as original } \\
\text { sample, contains some tungsten. }\end{array}$ \\
\hline
\end{tabular}


Table 5.1 (Continued)

Debye-Scherrer Films

\begin{tabular}{llll}
\hline Film No. Sample & $\begin{array}{l}\text { Film } \\
\text { Quality }\end{array}$ & Comments \\
\hline C5691 & Residue, RS-TiO-Y Fair & $\begin{array}{l}\text { Same capillary as C5690, but different } \\
\text { place }\end{array}$ \\
C5697 & Residue, RS-TiO-Y Fair & Portion of sample which may have melted. \\
C5698 & Residue, RS-TiO-Y Fair & \\
\hline C5702 & Residue, RS-TiO-Y Fair & Long exposure. \\
\hline
\end{tabular}




\subsection{Knudsen Vapor Pressure Measurements}

The results of two Knudsen effusion-collection experiments are described. The first experiment, RS-TiO-1, consisted of a blank run with an empty crucible. The second experiment, RS-TiO-2, consisted of vaporization of a nearly stoichiometric titanium monoxide sample in vacuum at constant temperature, collection of vapor on a water cooled quartz cap surrounding the crucible, and analysis of the sublimate for titanium. An equilibrium pressure of $\mathrm{TiO}(\mathrm{g})$ is calculated on the basis the TiO molecule is the only vapor species.

\subsubsection{RS-TiO-1}

RS-TiO-1 was a blank run in vacuum line \#11 with empty crucible \#4. The experiment served as a check on the outgassing procedure for the cell; to insure no impurities from the cap on which the effusate was collected would interfere with the colorimetric analysis of titanium; and to check the operation of the equipment. The average temperature of the crucible during the experiment was $1858^{\circ} \mathrm{K}$ and the temperature was maintained constant within about $10^{\circ} \mathrm{K}$. The total time at temperature was 12 hours.

After heating, the quartz cap surrounding the crucible was subjected to the analysis described in section 3.6.3. Briefly, this consisted of dissolving any sublimate from the cap with $\mathrm{H}_{2} \mathrm{SO}_{4}$. The $\mathrm{H}_{2} \mathrm{SO}_{4}$, washings from the cap, and $3 \mathrm{ml}$ of $3 \% \mathrm{H}_{2} \mathrm{O}_{2}$ were diluted to a total volume of $25 \mathrm{ml}$ and the 
absorbance of this solution was read on the Beckman DU Spectrophotometer. The measured absorbance of the solution was $0.0037 \pm 0.0002$. This result corresponds to a titanium concentration of $0.18 \pm 0.06 \mu \mathrm{g} / \mathrm{ml}$ or an apparent $4.5 \pm 1.5 \mu \mathrm{g}$ of $\mathrm{ti-}$ tanium in the $25 \mathrm{ml}$ solution. The absorbance was also measured with blank solution $\left(30 \mathrm{ml}\right.$ of $3 \% \mathrm{H}_{2} \mathrm{O}_{2}+220 \mathrm{ml}$ of $2 \mathrm{~N}$ $\mathrm{H}_{2} \mathrm{SO}_{4}$ ) in both spectrophotometric cells. The absorbance was found to be $0.0027 \pm 0.0003$ which corresponds to a titanium concentration of $0.12 \pm 0.06 \mu \mathrm{g} / \mathrm{ml}$ or $3.0 \pm 1.5 \mu \mathrm{g}$ of titanium in $25 \mathrm{ml}$ of solution.

The apparent amount of titanium of $4.5 \mathrm{\mu g}$ measured in RS-TiO-1 is less than $1 \%$ of the titanium collected in the actual vaporization of titanium monoxide, experiment RS-TiO-2. This result indicates the outgassing procedure for the crucible was satisfactory and no impurity from the quartz cap interfered with the analysis.

\subsection{RS-TiO-2}

Experiment RS-TiO-2 consisted of a Knudsen vaporization in vacuum of a nearly stoichiometric sample of titanium monoxide, laboratory designation TiO-1, from a tungsten crucible, laboratory designation \#4. The vapor was collected on a water cooled quartz cap completely surrounding the crucible. The titanium collected was analyzed colorimetrically. The sample, crucible, equipment, and analysis have all been described in earlier sections.

The vaporization lasted for 12 hours. The pressure 
in the vacuum line was never higher than $2.6 \times 10^{-6}$ torr and was typically about $6.0 \times 10^{-7}$ torr after the initial heating period. Approximately every 15 minutes temperatures were read during the 12 hour experiment with each temperature being the average of four observations with the pyrometer. It became obvious during RS-TiO-2 that the variation in temperature readings was outside the range of statistical error estimated to be about $\pm_{1}^{\circ} \mathrm{K}$ and hence represents a real variation. It was shown in section 4.3 the average temperature is appropriate for such a case provided the variation is less than about $\pm 10^{\circ} \mathrm{K}$. The variation in temperature readings taken during RS-TiO-2 was less than $\pm 10^{\circ} \mathrm{K}$ with the difference between the high and low reading being about $14^{\circ} \mathrm{K}$. The average temperature of the experiment was $1806 \pm 1^{\circ} \mathrm{K}$.

(a) Analysis of Titanium

The sublimate collected on the quartz cap during the vaporization portion of RS-TiO-2 appeared as a dark bluegray deposit. The sublimate was dissolved from the cap with $\mathrm{H}_{2} \mathrm{SO}_{4}$. The $\mathrm{H}_{2} \mathrm{SO}_{4}$, washings from the cap, and $3 \mathrm{ml}$ of $3 \%$ $\mathrm{H}_{2} \mathrm{O}_{2}$ were diluted to $25 \mathrm{ml}$ and the absorbance of the resulting solution measured with the Beckman DU Spectrophotometer. The details of the analysis have been described in section 3.6.3. The measured absorbance of the solution was $0.3362^{ \pm}$ 0.0002 . The concentration of titanium is calculated to be $21.38 \pm 0.08 \mu \mathrm{g} / \mathrm{ml}$ from the measured absorbance and equation (5.1). This concentration corresponds to $534.5 \pm 2.0 \mu \mathrm{g}$ of 
titanium collected on the quartz cap. Because an absorbance of $0.3362^{ \pm 0.0002 ~ w a s ~ s l i g h t l y ~ o u t s i d e ~ t h e ~ r a n g e ~ o f ~ t h e ~ c a l i b r a-~}$ tion curve, $5 \mathrm{ml}$ of the original $25 \mathrm{ml}$ solution from the cap was diluted to $25 \mathrm{ml}$ with $2 \mathrm{~N} \mathrm{H}_{2} \mathrm{SO}_{4}$. The absorbance of this solution was measured to be $0.0677 \pm 0.0002$. This value corresponds to a titanium concentration of $4.264 \pm 0.038 \mu \mathrm{g} / \mathrm{ml}$ or a total amount of titanium of $533.0 \pm 4.8 \mu \mathrm{g}$. This result demonstrates the validity of the extrapolation of the calibration curve.

A rough check on the analysis may be obtained from the crucible weight loss. The weight of the crucible, lid and sample into vacuum line $\# 11$ was $56.20584 \pm 0.00005 \mathrm{~g}$ and the weight out of line \#11 after vaporization was $56.20535 \pm 0.00005 \mathrm{~g}$ yielding a weight loss of $490 \pm 70 \mu \mathrm{g}$. This number, which has a large uncertainty, is not directly comparable with the $534.5 \pm 2.0 \mu \mathrm{g}$ of titanium found in the colorimetric analysis until the vapor composition has been determined because not all the titanium analyzed resulted from $\mathrm{Ti}(\mathrm{g})$.

(b) Thermodynamic Results

(1) Vapor Pressure, $\mathrm{P}_{\mathrm{E}}$

Although TiO(g) cannot be the only important vapor species since $\mathrm{TiO}(\mathrm{s})$ is known to vaporize incongruently (2, 3), it will be of use in future discussion and comparison with other work to treat the vapor as $\mathrm{TiO}(\mathrm{g})$. Under this assumption the vaporization of titanium monoxide may be represented by equation $(5.2)$.

$$
\operatorname{TiO}(\beta)=\operatorname{TiO}(\mathrm{g})
$$


The pressure calculated on the assumption the vapor is TiO(g) is denoted as $\underline{P}_{E}$. This pressure is calculated from equation (4.19) and the measured temperature of $1806 \pm 1^{\circ} \mathrm{K}$, orifice area of $0.02164 \pm 0.00003 \mathrm{~cm}^{2}$, Clausing factor of $0.8367 \pm 0.0015$, time of vaporization of $43200 \pm 200$ seconds, mass of titanium monoxide of $(7.130 \pm 0.027) \times 10^{-4} \mathrm{~g}$ obtained from the mass of titanium. The result is $\mathrm{P}_{\mathrm{E}}=(1.093 \pm 0.007) \times 10^{-7} \mathrm{~atm}$.

\section{(2) Standard Free Energy}

Continuing with the invalid assumption the vapor over titanium monoxide is entirely $\mathrm{TiO}(\mathrm{g})$, a standard free energy change at $1806^{\circ} \mathrm{K}$ for reaction (5.2) is calculated to be

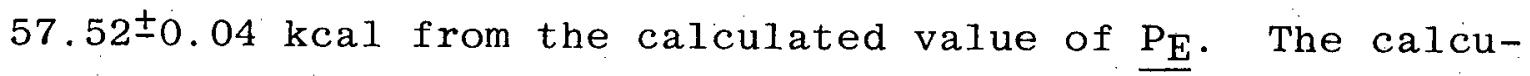
lation assumes the gas behaves ideally and the activity of the solid is taken as unity. It will be shown in section 5.4.1 that $\mathrm{Ti}(\mathrm{g})$ and $\mathrm{TiO}(\mathrm{g})$ are both important vapor species. Thus the value of $\mathrm{P}_{E}$ obtained above represents an upper limit to the true vapor pressure of TiO(g) over titanium monoxide and the result $57.52 \pm 0.04$ kcal represents a lower limit for the standard free energy change of reaction. (5.2) at $1806^{\circ} \mathrm{K}$.

\section{(c) Residue}

The residue from experiment $\mathrm{RS}-\mathrm{TiO}-2$ had the typical golden-brown color of titanium monoxide. It appeared not to have melted but did show evidence of sintering. There was no visible sign of material condensed on the cell walls, lid, or orifice. 


\subsection{Mass Spectrometer Results}

The results of two mass spectrometer experiments, RS-MS-TiO-X and RS-MS-TiO-Y, are presented. Both experiments involved the vaporization of titanium monoxide. RSMS-TiO-X was a constant temperature experiment to duplicate the heating regime of RS-TiO-2 while RS-MS-TiO-Y consisted of the measurement of the temperature dependencies of important vapor species.

5.4.1 RS-MS-TiO-X (Chart 1976-008, Disc Files RS279$341)$

The titanium monoxide sample, laboratory designation TiO-1, and tungsten crucible; laboratory designation \#4, have been described previously in sections 3.2 and 3.3 . Experiment RS-MS-TiO-X consisted of a constant temperature vaporization in the mass spectrometer. The sample, sample mass, crucible, orifice, temperature, and mass of sample vaporized were chosen to match experiment RS-TiO-2. The primary purpose of RS-MS-TiO-X was to measure the vapor composition in equilibrium with stoichiometric titanium monoxide in order that the titanium found in RS-TiO-2 could be apportioned to the important titanium bearing vapor species. Secondary results of $\mathrm{RS}-\mathrm{MS}-\mathrm{TiO}-\mathrm{X}$ include appearance potentials for $\mathrm{Ti}(\mathrm{g})$ and $\mathrm{TiO}(\mathrm{g})$, the relative change in oxygen potential with changing composition due to the incongruent nature of the vaporization, and the importance of fragmentation of $\mathrm{TiO}(\mathrm{g})$ to give $\mathrm{Ti}^{+}$. 


\section{(a) Intensity Data}

A summary of intensity data taken during RS-MS-TiO-X is listed in Table 5.2, page 79. The first column contains the disc storage file of the data. The second column ists the ion and the third column gives the electron energy at which the measurement was made. The fourth column contains the temperature in degrees Kelvin. The fifth column lists the elapsed time at temperature. Intensities are given in the last column. Intensities were obtained with computer programs ARECM and SPOBM as discussed in section 3.7.3.

(1) Intensity Ratio, $\mathrm{I}_{\mathrm{TiO}}^{+} / \mathrm{I}_{\mathrm{T} \mathrm{i}}^{+}$

As discussed in section 4.2 .3 the intensity ratio, $\mathrm{I}_{\mathrm{TiO}}^{+} / \dot{\mathrm{I}}_{\mathrm{Ti}}^{+}$, is proportional to the pressure of atomic oxygen at fixed temperature if equilibrium exists between the gaseous species: $\mathrm{TiO}(\mathrm{g})$, $\mathrm{Ti}(\mathrm{g})$, and $\mathrm{O}(\mathrm{g})$. Also this ratio is important for apportioning the titanium collected in experiment RS-TiO-2 to titanium arising from $\mathrm{Ti}(\mathrm{g})$ and $\mathrm{TiO}(\mathrm{g})$. Intensity ratios at $10.5 \mathrm{eV}, 12.5 \mathrm{eV}, 14.5 \mathrm{eV}$, and $22.5 \mathrm{eV}$ were calculated from the results in Table 5.2. These results are listed in Tables 5.3 through 5.6, pages 82 through 83 . The first column gives the disc data files used in the ratio calculation. The second column gives the intensity ratio $\mathrm{I}_{\mathrm{TiO}}^{+} / \mathrm{I}_{\mathrm{Ti}}^{+}$. The third column gives the time difference in minutes between the measurement of the intensity of $\mathrm{TiO}^{+}(64)$ and $\mathrm{Ti}^{+}(48)$. The last column contains the average elapsed time at temperature of the ratio measurement. Ideally ratios 
Table 5.2

Intensity Data Experiment RS-MS-TiO-X

Chart 1976-008 Disc Files RS279-341

\begin{tabular}{|c|c|c|c|c|c|c|}
\hline \multirow{2}{*}{$\begin{array}{l}\text { Disc } \\
\text { File } \\
\text { RS279 }\end{array}$} & \multirow{2}{*}{$\begin{array}{l}\begin{array}{l}\text { Ion } \\
(\mathrm{m} / \mathrm{e})\end{array} \\
\mathrm{TiO}(64)\end{array}$} & \multirow{2}{*}{$\begin{array}{l}\text { Electron } \\
\text { Energy }(\mathrm{eV})\end{array}$} & \multirow{2}{*}{$\frac{\begin{array}{c}\text { Temp } \\
\left({ }^{\circ} \mathrm{K}\right)\end{array}}{1805}$} & $\begin{array}{l}\text { Elapsed } \\
\text { Time (Min) }\end{array}$ & \multicolumn{2}{|c|}{$\begin{array}{l}\text { Intensity } \\
\text { (Counts) }\end{array}$} \\
\hline & & & & 40 & $135184 \pm$ & 1441 \\
\hline $\mathrm{RS} 280$ & $\mathrm{TiO}(64)$ & 14.5 & 1805 & 52 & $42589 \pm$ & 330 \\
\hline $\mathrm{RS} 281(\mathrm{~b})$ & $\mathrm{Ti}(48)$ & 14.5 & 1808 & 70 & $151923 \pm$ & 395 \\
\hline $\mathrm{RS} 282$ & $\mathrm{Ti}(48)$ & 14.5 & 1804 & 88 & $143342 \pm$ & 384 \\
\hline $\mathrm{RS} 283$ & $\mathrm{TiO}(64)$ & 14.5 & 1807 & 107 & $29468 \pm$ & 269 \\
\hline $\mathrm{RS} 284(\mathrm{c})$ & $\operatorname{TiO}(64)$ & 12.5 & 1803 & 117 & $17312 \pm$ & 161 \\
\hline $\mathrm{RS} 285$ & $\operatorname{TiO}(64)$ & 22.5 & 1805 & 128 & $95204 \pm$ & 568 \\
\hline $\mathrm{RS} 286$ & $\operatorname{TiO}(64)$ & 12.5 & 1805 & 138 & $30798 \pm$ & 200 \\
\hline $\mathrm{RS} 287$ & $\operatorname{Ti}(48)$ & 12.5 & 1804 & 155 & $107997 \pm$ & 334 \\
\hline $\mathrm{RS} 288$ & $\mathrm{Ti}(48)$ & 14.5 & 1805 & 164 & $145694 \pm$ & 394 \\
\hline $\mathrm{RS} 289$ & $\mathrm{Ti}(48)$ & 22.5 & 1805 & 173 & $243225 \pm$ & 528 \\
\hline $\mathrm{RS} 290$ & $\mathrm{Ti}(48)$ & 10.5 & 1805 & 182 & $66274 \pm$ & 262 \\
\hline $\mathrm{RS} 291$ & $\mathrm{TiO}(64)$ & 10.5 & 1805 & 199 & $16309 \pm$ & 138 \\
\hline RS292 & $\mathrm{TiO}(64)$ & 12.5 & 1803 & 210 & $28828 \pm$ & 186 \\
\hline $\mathrm{RS} 293$ & $\operatorname{TiO}(64)$ & 14.5 & 1805 & 219 & $42140 \pm$ & 243 \\
\hline $\mathrm{RS} 294$ & $\operatorname{TiO}(64)$ & 22.5 & 1805 & 227 & $84320 \pm$ & 470 \\
\hline $\mathrm{RS} 295$ & $\mathrm{TiO}_{2}(80)$ & 72.5 & 1807 & 244 & $-682 \pm$ & 656 \\
\hline $\mathrm{RS} 296$ & $\mathrm{TiO}(64)$ & 22.5 & 1809 & $260^{\circ}$ & $90232 \pm$ & 440 \\
\hline $\mathrm{RS} 297$ & $\operatorname{TiO}(64)$ & 14.5 & 1807 & 268 & $44768 \pm$ & 249 \\
\hline $\mathrm{RS} 298$ & $\operatorname{TiO}(64)$ & 12.5 & 1807 & 276 & $30308 \pm$ & 189 \\
\hline
\end{tabular}


Table 5.2 (Continued)

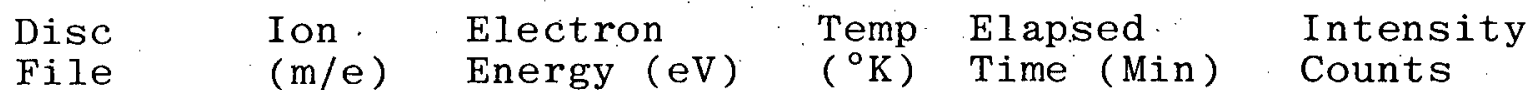

\begin{tabular}{|c|c|c|c|c|c|c|}
\hline RS299 & $\operatorname{TiO}(64)$ & 10.5 & 1805 & 284 & $17606 \pm$ & 142 \\
\hline RS300 & $\mathrm{Ti}(48)$ & 10.5 & 1805 & 305 & $60679 \pm$ & 251 \\
\hline RS301 & $\operatorname{Ti}(48)$ & 12.5 & 1805 & 312 & $96328 \pm$ & 315 \\
\hline RS302 & $\operatorname{Ti}(48)$ & 14.5 & 1807 & 321 & $127957 \pm$ & 361 \\
\hline RS303 & $\operatorname{Ti}(48)$ & 22.5 & 1807 & 328 & $220600 \pm$ & 488 \\
\hline RS304 & $\operatorname{TiO}(64)$ & 72.5 & 1805 & 345 & $136930 \pm$ & 570 \\
\hline RS305 & $\operatorname{TiO}(64)$ & 22.5 & 1805 & 366 & $86899 \pm$ & 376 \\
\hline RS306 & $\operatorname{TiO}(64)$ & 14.5 & 1805 & 377 & $44515 \pm$ & 229 \\
\hline RS 307 & $\operatorname{TiO}(64)$ & 12.5 & 1805 & 385 & $31668 \pm$ & 188 \\
\hline RS308 & $\operatorname{TiO}(64)$ & 10.5 & 1807 & 393 & $18356 \pm$ & 140 \\
\hline RS309 & $\mathrm{Ti}(48)$ & 10.5 & 1805 & 410 & $64510 \pm$ & 256 \\
\hline RS310 & $\mathrm{Ti}(48)$ & 12.5 & 1807 & 420 & $97150 \pm$ & 316 \\
\hline RS311 & $\mathrm{Ti}(48)$ & 14.5 & 1808 & 430 & $128546 \pm$ & 362 \\
\hline RS312 & $\mathrm{Ti}(48)$ & 22.5 & 1805 & 438 & $215055 \pm$ & 477 \\
\hline RS313 & $\mathrm{Ti}(48)$ & 72.5 & 1807 & 446 & $233099 \pm$ & 530 \\
\hline RS314 & $\mathrm{TiO}_{2}(80)$ & 72.5 & 1807 & 475 & $273 \pm$ & 432 \\
\hline RS315 & $\operatorname{TiO}(64)$ & 22.5 & 1807 & 493 & $87439 \pm$ & 371 \\
\hline RS316 & $\operatorname{TiO}(64)$ & 14.5 & 1805 & 502 & $45436 \pm$ & 234 \\
\hline $\mathrm{RS} 317$ & $\operatorname{TiO}(64)$ & 12.5 & 1804 & 512 & $30889 \pm$ & 187 \\
\hline RS318 & $\mathrm{TiO}(64)$ & 10.5 & 1805 & 521 & $18084 \pm$ & 159 \\
\hline RS 319 & $\mathrm{Ti}(48)$ & 22.5 & 1805 & 539 & $211171 \pm$ & 476 \\
\hline RS 320 & $\mathrm{Ti}(48)$ & 14.5 & 1804 & 557 & $125187 \pm$ & 357 \\
\hline RS321 & $\mathrm{Ti}(48)$ & 12.5 & 1807 & 567 & $92754 \pm$ & 307 \\
\hline
\end{tabular}


Table 5.2 (Continued)

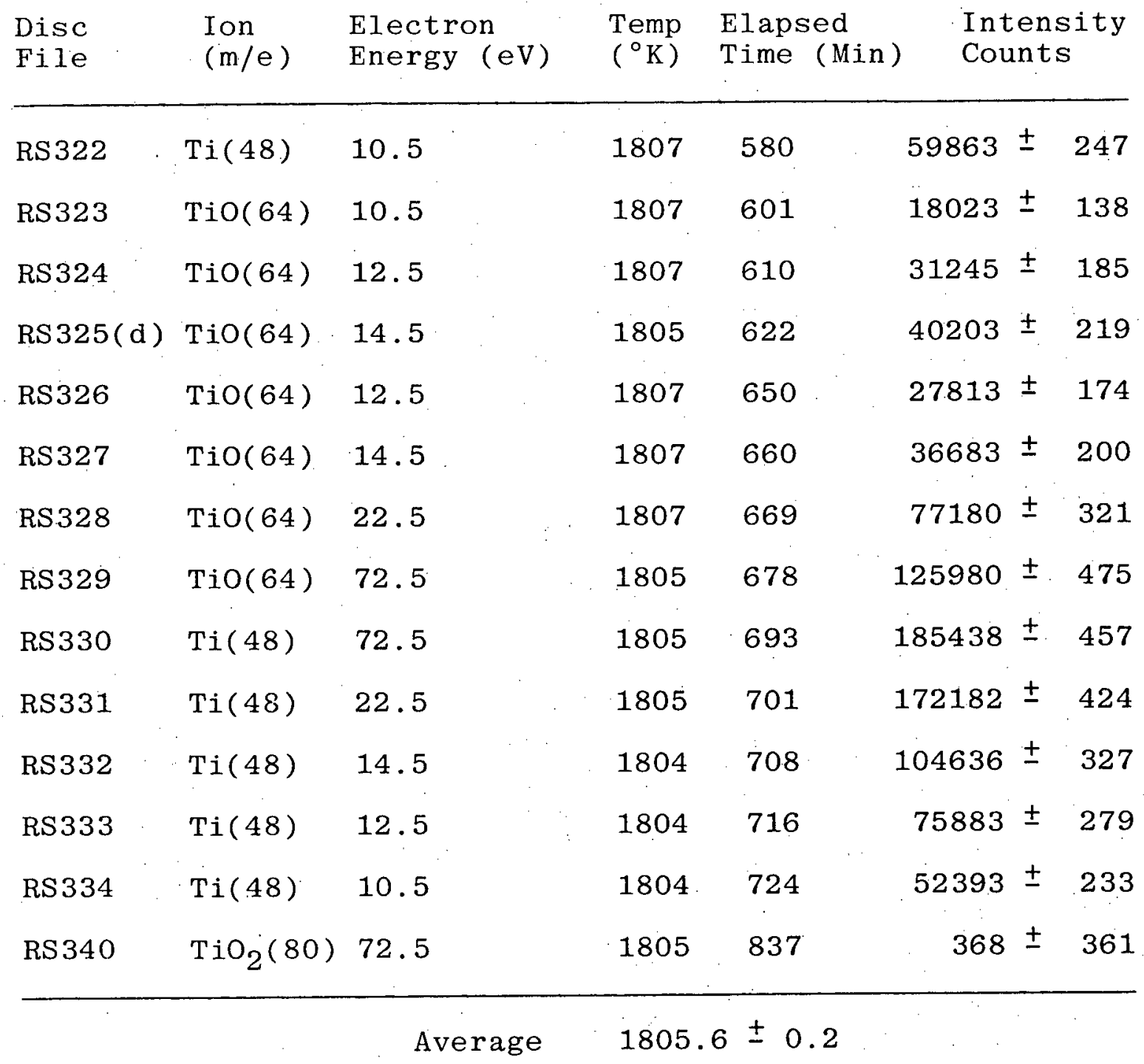

(a) Calibrated by A.P. of $\mathrm{Hg}^{+}=10.44 \mathrm{eV}$

(b) Electron bombardment went off just after completion of RS281

(c) Measurement made in RS284 repeated in RS286, bad focus in RS284.

(d) Electron bombardment went off, sample may have been hotter than $1806^{\circ} \mathrm{K}$ for a few seconds. 
Table 5.3

Intensity Ratio, $\mathrm{I}_{\mathrm{TiO}}^{+} / \mathrm{I}_{\mathrm{Ti}}^{+}$at $10.5 \mathrm{eV}$

Experiment RS-MS-TiO-X (Chart 1976-008)

\begin{tabular}{lccc}
\hline $\begin{array}{l}\text { Disc } \\
\text { Files }\end{array}$ & $\mathrm{I}_{\mathrm{TiO}}^{+} / \mathrm{I}_{\mathrm{Ti}}^{+}$ & $\begin{array}{l}\Delta \mathrm{t} \\
\text { (min.) }\end{array}$ & $\begin{array}{c}\text { Average } \\
\text { Elapsed } \\
\text { Time (min.) }\end{array}$ \\
\hline RS290, 291 & 0.246 & 17 & 190 \\
$\mathrm{RS} 299,300$ & 0.290 & -21 & 294 \\
$\mathrm{RS} 308,309$ & 0.285 & -17 & 402 \\
$\mathrm{RS} 322,323$ & 0.301 & 21 & 590 \\
\hline
\end{tabular}

Table 5.4

Intensity Ratio, $\mathrm{I}_{\mathrm{TiO}}^{+} / \mathrm{I}_{\mathrm{Ti}}^{+}$at $12.5 \mathrm{eV}$

Experiment RS-MS-TiO-X (Chart 1976-008)

\begin{tabular}{lccc}
\hline $\begin{array}{c}\text { Disc } \\
\text { Files }\end{array}$ & $\mathrm{I}_{\mathrm{TiO}}^{+} / \mathrm{I}_{\mathrm{Ti}}^{+}$ & $\begin{array}{l}\Delta \mathrm{t} \\
\text { (min.) }\end{array}$ & $\begin{array}{c}\text { Average } \\
\text { Elapsed } \\
\text { Time (min.) }\end{array}$ \\
\hline RS286, 287 & 0.285 & -17 & 146 \\
RS298, 301 & 0.315 & -36 & 294 \\
RS307, 310 & 0.326 & -35 & 402 \\
RS321, 324 & 0.337 & 43 & 588 \\
RS326, 333 & 0.367 & -66 & 683 \\
\hline
\end{tabular}


Table 5.5

Intensity Ratio, $\mathrm{I}_{\mathrm{TiO}}^{+} / \mathrm{I}_{\mathrm{Ti}}^{+}$at $14.5 \mathrm{eV}$

Experiment RS-MS-TiO-X (Chart 1976-008)

\begin{tabular}{lccc}
\hline $\begin{array}{c}\text { Disc } \\
\text { Files }\end{array}$ & $\mathrm{I}_{\mathrm{TiO}}^{+} / \mathrm{I}_{\mathrm{Ti}}^{+}$ & $\begin{array}{l}\Delta \mathrm{t} \\
\text { (min.) }\end{array}$ & $\begin{array}{c}\text { Average } \\
\begin{array}{c}\text { Elapsed } \\
\text { Time (min.) }\end{array}\end{array}$ \\
\hline RS280, 281 & 0.280 & -18 & 61 \\
$\mathrm{RS} 282,283$ & 0.206 & 19 & 98 \\
$\mathrm{RS} 288,293$ & 0.289 & 55 & 192 \\
$\mathrm{RS} 297,302$ & 0.350 & -53 & 294 \\
$\mathrm{RS} 306,311$ & 0.346 & -53 & 403 \\
$\mathrm{RS} 316,320$ & 0.363 & -55 & 530 \\
$\mathrm{RS} 327,332$ & 0.351 & -48 & 684 \\
\hline
\end{tabular}

Table 5.6

Intensity Ratio, $\mathrm{I}_{\mathrm{TiO}}^{+} / \mathrm{I}_{\mathrm{Ti}}^{+}$at $22.5 \mathrm{eV}$

Experiment RS-MS-TiO-X (Chart 1976-008)

\begin{tabular}{llll}
\hline $\begin{array}{l}\text { Disc } \\
\text { Files }\end{array}$ & $\mathrm{I}_{\mathrm{TiO}}^{+} / \mathrm{I}_{\mathrm{T} i}^{+}$ & $\begin{array}{l}\Delta t \\
\text { (min.) }\end{array}$ & $\begin{array}{c}\text { Average } \\
\text { Elapsed } \\
\text { Time (min.) }\end{array}$ \\
\hline RS285, 289, 294 & 0.369 & $-45,+54$ & 176 \\
$\mathrm{RS} 296,303$ & 0.409 & -68 & 294 \\
$\mathrm{RS} 305,312$ & 0.404 & -72 & 402 \\
$\mathrm{RS} 315,319$ & 0.414 & -46 & 516 \\
$\mathrm{RS} 328,331$ & 0.448 & -32 & 685 \\
\hline
\end{tabular}


should be calculated from intensity measurements of $\mathrm{TiO}^{+}(64)$ and $\mathrm{Ti}^{+}(48)$ made simultaneously because the sample was vaporizing incongruently. This ideal situation was not realized experimentally but ratios were calculated from intensity measurements made as nearly simultaneous as experimental procedure would allow.

The intensity ratios contained in Tables 5.3 through 5.6 are plotted in Figure 5.2, page 85, as a function of elapsed time at temperature. A straight line was drawn through each set of data at each electron energy using a linear least squares computer program, LS2H. A straight line was also calculated for all points irrespective of their electron energy using LS2H. All points were weighted equally in the least squares calculation. A summary of the least squares results is contained in Table 5.7 , page 86 . The first column gives the electron energy for which the least squares line is calculated. The second and third columns contain the least squares slope and intercept respectively. Errors quoted for the slope and intercept are standard deviations.

The results plotted in Figure 5.2 show the incongruent nature of the vaporization of titanium monoxide. The one congruently vaporizing composition in the titaniumoxygen system has been shown to lie within the $\mathrm{Ti}_{3} \mathrm{O}_{5}$ phase ( 2 and 3 ). As titanium monoxide vaporizes its composition will become more oxygen rich. It is expected and 


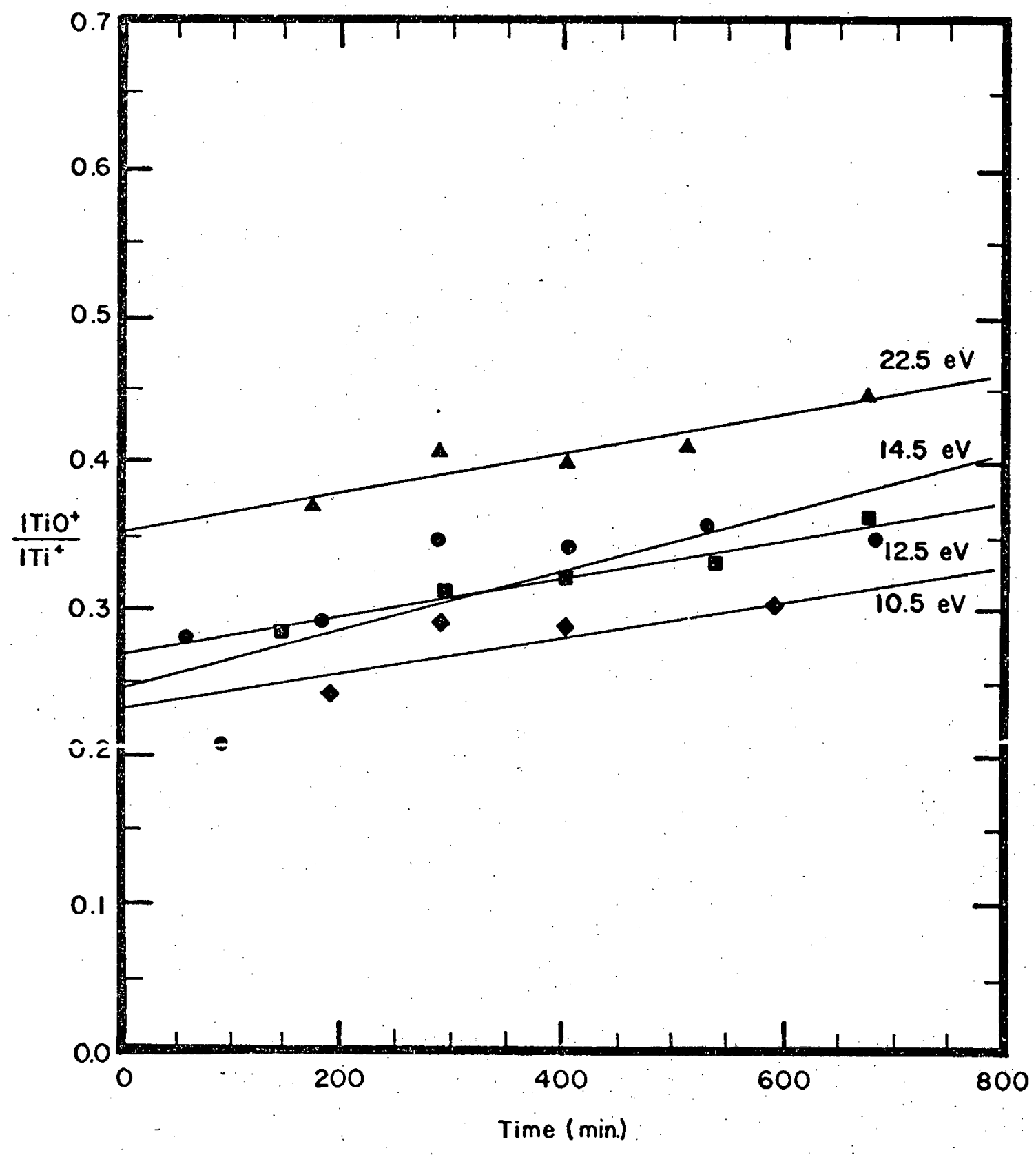

FIG. 5.2

Plot of intensity ratio, $\mathrm{ITiO}^{+} / \mathrm{ITi}^{+}$, versus elapsed time at temperature. Results from Experiment RS-MS-TiO-X. 
Table 5.7

Least Squares Results, $\mathrm{I}_{\mathrm{TiO}}^{+} / \mathrm{I}_{\mathrm{T} i}^{+}$Versus Time

Experiment RS-MS-TiO-X (Chart 1976-008)

$\mathrm{I}_{\mathrm{TiO}}^{+} / \mathrm{I}_{\mathrm{Ti}}^{+}=\mathrm{bt}+\mathrm{c}$

(a)

\begin{tabular}{ccc}
\hline $\begin{array}{l}\text { Electron } \\
\text { Energy (eV) }\end{array}$ & $\begin{array}{c}\text { Slope, b } \\
(10-3 \min -1)\end{array}$ & Intercept, c \\
\hline 10.5 & $0.116 \pm 0.056$ & $0.238 \pm 0.022$ \\
12.5 & $0.134 \pm 0.020$ & $0.269 \pm 0.009$ \\
14.5 & $0.194 \pm 0.069$ & $0.249 \pm 0.027$ \\
22.5 & $0.133 \pm 0.030$ & $0.354 \pm 0.013$ \\
A11 energies & $0.178 \pm 0.056$ & $0.265 \pm 0.024$ \\
\hline
\end{tabular}

(a) $t=$ elapsed time in minutes 
observed, in Figure 5.2 that the oxygen potential which is proportional to the ratio $\mathrm{I}_{\mathrm{TiO}}^{+} / \mathrm{I}_{\mathrm{Ti}}^{+}$increases as vaporization progresses.

(b) Shutter Profiles

Typical shutter profiles taken near the beginning, middle, and end of experiment RS-MS-TiO-X for $\mathrm{Ti}^{+}(48)$, $\mathrm{TiO}^{+}(64)$, and $\mathrm{TiO}_{2}^{+}(80)$ are shown in Figures 5.3 through 5.5 respectively, pages 88 through 90 . Shutter profiles of $\mathrm{Ti}^{+}(48)$ and $\mathrm{TiO}^{+}(64)$ taken in $\mathrm{RS}-\mathrm{MS}-\mathrm{TiO}-\mathrm{X}$ were symmetric with respect to reflection about a vertical line through their maxima. This indicates ions were formed from molecular species arising from the interior of the Knudsen cell. Shutter profiles over mass eighty revealed no shutterable $\mathrm{TiO}_{2}^{+}(80)$

(c) Thermodynamic Results

(1) Vapor Pressures

The results of experiments RS-TiO-2 and RS-MS-TiO-X may be combined to calculate the pressures of $\mathrm{TiO}(\mathrm{g})$ and $\mathrm{Ti}(\mathrm{g})$ in equilibrium with nearly stoichiometric titanium monoxide at $1806^{\circ} \mathrm{K}$. The pressures may be calculated from the total titanium measured in the Knudsen effusion-collection experiment, RS-TiO-2, and the intensity ratio, $\mathrm{I}_{\mathrm{TiO}}^{+} / \mathrm{I}_{\mathrm{T} i}^{+}$, from experiment RS-MS-TiO-X. The results of experiment RS-MS-TiO-X indicate that both TiO(g) and $\mathrm{Ti}(\mathrm{g})$ contributed to the titanium collected in RS-TiO-2 but $\mathrm{TiO}_{2}(\mathrm{~g})$ made no contribution within the sensitivity of the measurements. 


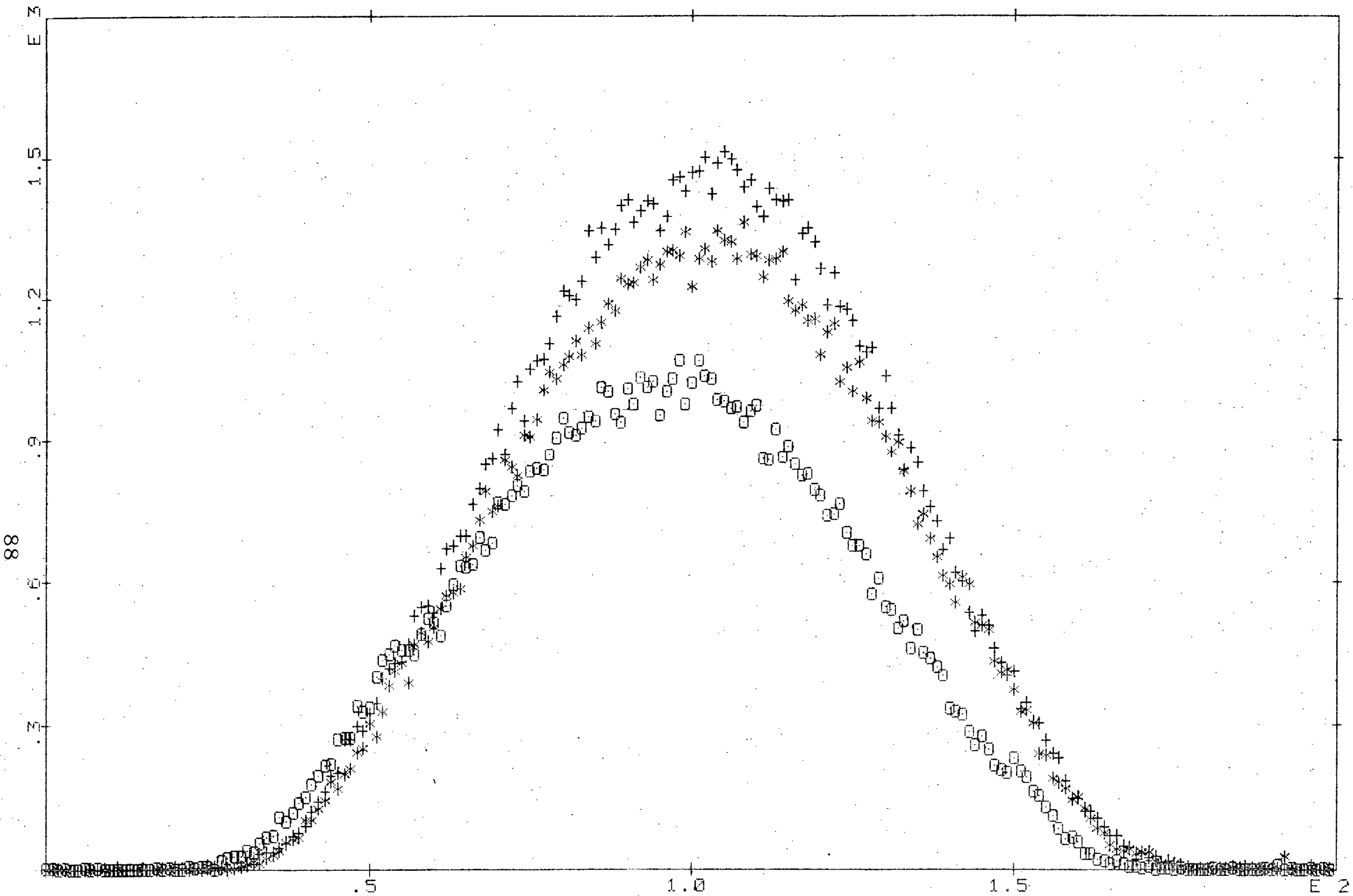

FIE. 5.3

SHUTTEF FROFILES TI 48 )

DISE FILES-REE +

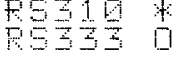




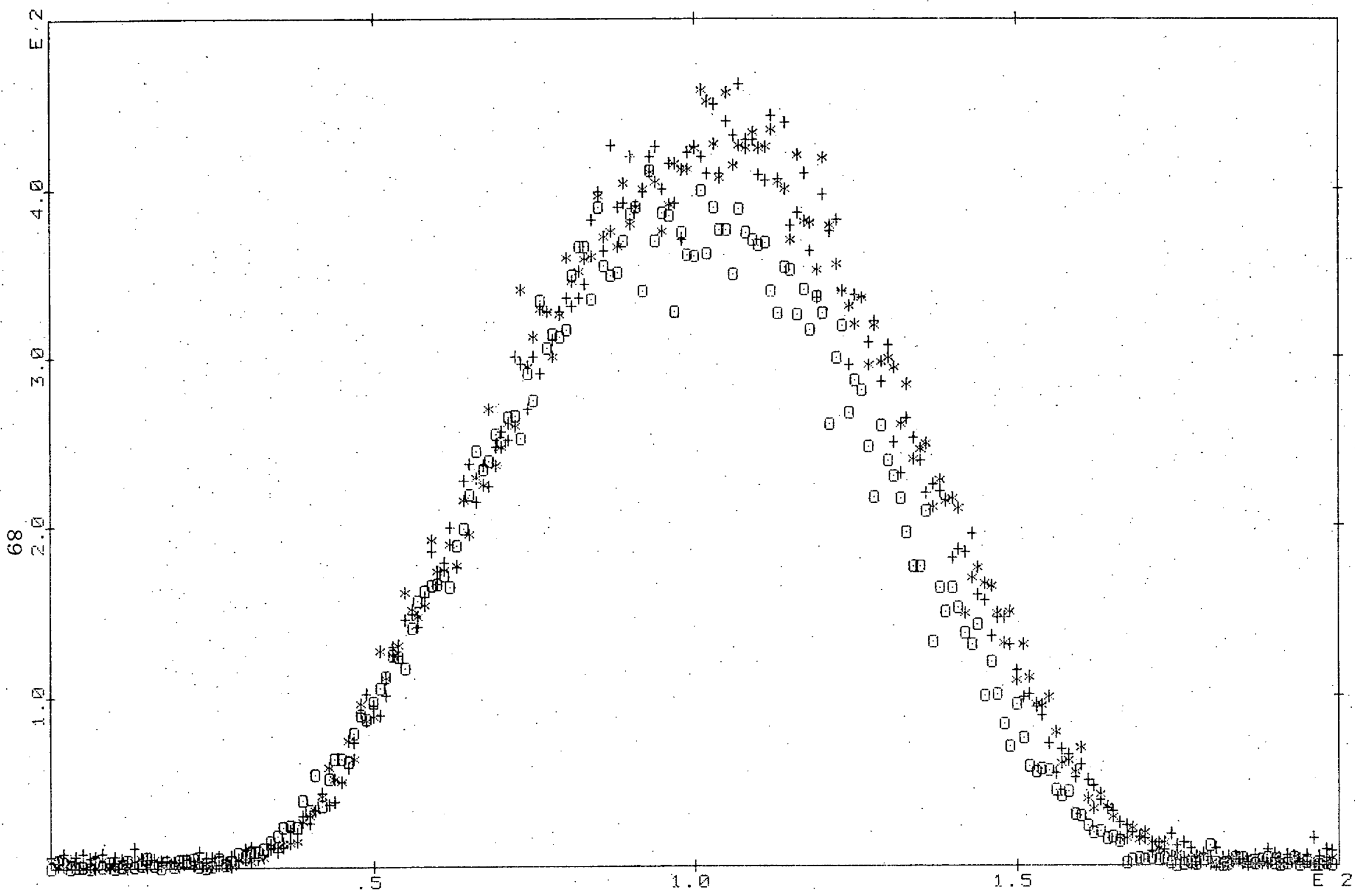

FIE. 5.4

SHUTTER FROFILES TIOC64)

ESE FIEES-FS2G

FES 


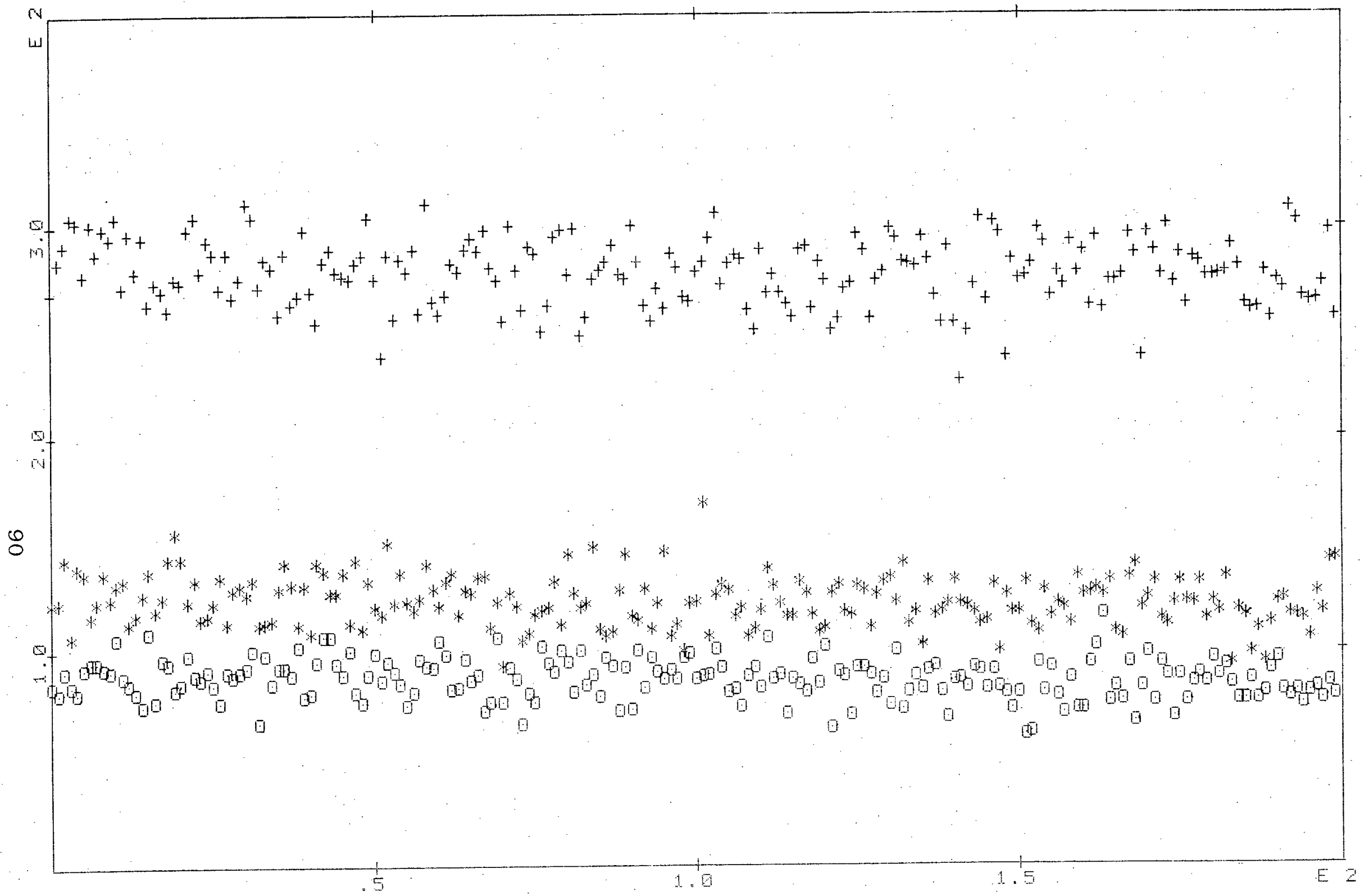

FIC. 5.5

SHUTTER PREFILES, TIOZ(90)

DET FILES- $-9995+$

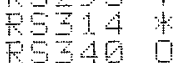


The total titanium collected in RS-TiO-2 may be written as the sum of the titanium from $\mathrm{TiO}(\mathrm{g})$ and $\mathrm{Ti}(\mathrm{g})$ as indicated in equation (5.3).

$$
\mathrm{m}=\mathrm{m}_{\mathrm{Ti}}+\left(\mathrm{M}_{\mathrm{Ti}} / \mathrm{M}_{\mathrm{TiO}}\right) \mathrm{m}_{\mathrm{TiO}}
$$

In equation (5.3) $\mathrm{m}$ is the total mass in grams of titanium collected in RS-TiO-2, $\mathrm{m}_{\mathrm{Ti}}$ and $\underline{\mathrm{m}_{\mathrm{TiO}}}$ are the masses in grams of titanium and titanium monoxide vaporized in RS-TiO-2, and $\underline{M_{T i}}$ and $M_{\mathrm{TiO}}$ are the molecular weights of titanium and titanium monoxide.

The pressures of $\mathrm{Ti}(\mathrm{g})$ and $\mathrm{TiO}(\mathrm{g})$ may be related to the masses $\mathrm{m}_{\mathrm{T} i}$ and $\mathrm{m}_{\mathrm{TiO}}$ by the Knudsen equation (4.19).

$$
\begin{aligned}
& \mathrm{P}_{\mathrm{Ti}}=\left(\mathrm{m}_{\mathrm{Ti}} / 44.33 \mathrm{aWt}\right) \sqrt{\mathrm{T} / \mathrm{M}_{\mathrm{Ti}}} \\
& \mathrm{P}_{\mathrm{TiO}}=\left(\mathrm{m}_{\mathrm{TiO}} / 44.33 \mathrm{aWt}\right) \sqrt{\mathrm{T} / \mathrm{M}_{\mathrm{TiO}}}
\end{aligned}
$$

The quantities ${\underline{\mathrm{P}_{\mathrm{Ti}}}}_{\text {and }} \mathrm{P}_{\mathrm{TiO}}$ are the pressures in atmospheres of titanium and titanium monoxide, $\underline{a}$ is the cell orifice area in square centimeters, $\underline{W}$ the Clausing factor, $t$ the time of vaporization in seconds, and $\underline{T}$ the absolute temperature.

The pressure ratio, $\mathrm{P}_{\mathrm{TiO}} / \mathrm{P}_{\mathrm{Ti}}$, is related to the mass spectrometric intensity ratio, $\mathrm{I}_{\mathrm{TiO}}^{+} / \mathrm{I}_{\mathrm{T} i}^{+}$, by equation (5.6).

$$
\mathrm{P}_{\mathrm{TiO}} / \mathrm{P}_{\mathrm{Ti}}=\left(\sigma_{\mathrm{Ti}} / \sigma_{\mathrm{TiO}}\right)\left(\mathrm{I}_{\mathrm{TiO}}^{+} / \mathrm{I}_{\mathrm{Ti}}^{+}\right)
$$

The quantities $\sigma_{\mathrm{T} i}$ and $\sigma_{\mathrm{TiO}}$ are the ionization cross sections for $\mathrm{Ti}(\mathrm{g})$ and $\mathrm{TiO}(\mathrm{g})$ respectively. Equation (5.6) assumes cancellation of the mass spectrometer constant, electron multiplier gain, and isotopic fraction of $\mathrm{TiO}(\mathrm{g})$ and $\mathrm{Ti}(\mathrm{g})$.

Equations (5.3) through (5.6) represent four equations in four unknowns: $\mathrm{m}_{\mathrm{Ti}}, \mathrm{m}_{\mathrm{TiO}}, \mathrm{P}_{\mathrm{Ti}}$, and $\underline{\mathrm{P}_{\mathrm{TiO}}}$. The re91 
maining quantities. were either measured or estimated from published data. Mann gives 8.67 and 1.27 as the maximum ionization cross sections of titanium and oxygen respectively (51). An ionization cross section for titanium monoxide of 9.94 is calculated assuming the cross section of the molecule equal to the sum of the cross sections of the constituent atoms. Cross sections of 8.67 and $9.94^{\circ}$ are used in equation (5.6) for oTi and ${ }^{\mathrm{TT} i \mathrm{O}}$ even though electron energies used in RS-MS-TiO-X did not correspond to energies at which maximum ionization cross sections were calculated by Mann. The intensity ratio, $\mathrm{I}_{\mathrm{TiO}}^{+} / \mathrm{I}_{\mathrm{T}}^{+}$, in equation (5.6) is taken as $0.329 \pm 0.011$ from the least squares results, Table 5.7 , for all points irrespective of electron energy and at a time of 360 minutes, i.e., midway through the vaporization. If fragmentation of $\mathrm{TiO}(\mathrm{g})$ to give $\mathrm{Ti}^{+}$were an important process in RS-MS-TiO-X it would be more appropriate to calculate the intensity ratio, $\mathrm{I}_{\mathrm{TiO}}^{+} / \mathrm{I}_{\mathrm{Ti}}^{+}$, at the lowest possible electron energy where fragmentation would be less important rather than using all points irrespective of electron energy. If fragmentation were important the intensity ratio should decrease with increasing electron energy. From Figure 5.2 this is not seen to be the case.

The orifice area, Clausing factor, time of vaporization, and temperature in equations (5.4) and (5.5) are taken as $0.02164 \pm 0.00003 \mathrm{~cm}^{2}, 0.8367 \pm 0.0015,43200 \pm 200$ seconds, and $1806 \pm 1{ }^{\circ} \mathrm{K}$ respectively. The mass of titanium collected 
in RS-TiO-2 was measured to be $\left(5.345^{ \pm} 0.020\right) \times 10^{-4} \mathrm{~g}$.

Solution of equations (5.3) through (5.6) for the unknown masses yields $\mathrm{m}_{\mathrm{Ti}}=(4.28 \pm 0.60) \times 10^{-4} \mathrm{~g}$ and $\mathrm{m}_{\mathrm{TiO}}=$ $(1.42 \pm 0.80) \times 10^{-4} \mathrm{~g}$. Substitution of $\mathrm{m}_{\mathrm{Ti}}$ and $\mathrm{m}_{\mathrm{TiO}}$ into equations (5.4) and (5.5) yields $\mathrm{P}_{\mathrm{Ti}}=(7.58 \pm 1.07) \mathrm{x} \cdot 10^{-8} \mathrm{~atm}$ and $\mathrm{P}_{\mathrm{TiO}}=\left(2.18^{ \pm 1.23}\right) \times 10^{-8} \mathrm{~atm}$. The uncertainties given in the masses and pressures are calculated on the arbitrary assumption the ionization cross sections are uncertain by $50 \%$. The uncertainties of the other parameters in equations (5.3) through (5.6) are negligible compared with the assumed uncertainties in the cross sections. More significant figures are given for the pressures than justified by their quoted uncertainties even though the uncertainties themselves are quite uncertain.

(2) Standard Free Energy

The standard free energy change for reaction (5.2) may be calculated from the calculated pressure of $\mathrm{TiO}(\mathrm{g})$ if it is assumed the vapor behaves ideally and the activity of the solid is unity. The assumption of ideal behavior of the gas is certainly valid at the low pressure involved. The assumption of unit activity for the solid depends on the choice of standard state for solid titanium monoxide and whether this state is experimentally realized in RS-TiO-2 and RS-MS-TiO-X. Conventionally the standard state for solid titanium monoxide would be taken as the stable form under a total external pressure of $1 \mathrm{~atm}$. The solid was not 
in its conventional standard state in RS-TiO-2 and RS-MS-TiO$X$ since it was not subjected to a total external pressure of 1 atm. However, the effect of pressure on the free energy of condensed phases is negligible for pressures not too different than 1 atm (52). Another deviation from standard conditions occurs if the composition of the solid deviates from the stoichiometric composition." Because titanium monoxide vaporizes incongruently only a small fraction of the sample may be vaporized if negligible change in composition is to occur. In experiments RS-TiO-2 and RS-MS-TiO-X less than 6\% of the sample was vaporized. The effect of the incongruent vaporization on the sample composition and on the activity of titanium monoxide will be discussed later; for the present the activity is taken as unity.

The standard free energy change'for a reaction (5.2) at $1806^{\circ} \mathrm{K}$ is calculated from equation (5.7) with $\mathrm{P}_{\mathrm{TiO}}=$ $(2.18 \pm 1.23) \times 10^{-8}$ atm.

$$
\Delta \mathrm{F}_{1806}^{\circ}=-\mathrm{RT} \ln =-\mathrm{RT} \ln \mathrm{P}_{\mathrm{TiO}}
$$

The result is $\Delta \mathrm{F}_{1806}^{0}=63.3 \pm 2.0 \mathrm{kcal}$. The uncertainty in the free energy is based on the estimated uncertainty in the pressure which arises principally from the uncertainty in the cross sections. This result which is independent of auxiliary thermodynamic data is considered one of the primary results of experiments RS-TiO-2 and RS-MS-TiO-X. The use which is made of this result depends on other available thermodynamic data. 
The above result may be combined with the standard free energy of formation of $-26.016 \pm 2.0 \mathrm{kcal}$ for $\mathrm{TiO}(\mathrm{g})$ at $1806^{\circ} \mathrm{K}$ (13) to yield a standard free energy of formation of $\mathrm{TiO}(\beta)$ at $1806^{\circ} \mathrm{K}$. The result is $\Delta \mathrm{F}_{1806}^{\circ}=-89.3 \pm 2.8 \mathrm{kcal}$. The reverse calculation using the published standard free energy of formation of solid titanium monoxide and the standard free energy change for reaction (5.2) measured in this work to calculate the standard free energy of formation of TiO(g) was not done owing to uncertainties in the thermodynamics of the solid discussed in Chapter 2 of this thesis. The standard free energy change at $1806^{\circ} \mathrm{K}$ for reaction (5.2) based on the very crude assumption the vapor over titanium monoxide was solely $\mathrm{TiO}(\mathrm{g})$ was calculated in section 5.3 .2 to be $57.52 \pm 0.04 \mathrm{kcal}$. The same result using experiment RS-MS-TiO-X to apportion the vapor to $\mathrm{Ti}(\mathrm{g})$ and TiO(g) was calculated above to be only 5.8 kcal higher.

The standard free energy change for reaction (5.2) of $63.3 \pm 2.0 \mathrm{kcal}$ calculated above was based on the intensity ratio, $\mathrm{I}_{\mathrm{T} i \mathrm{O}}^{+} / \mathrm{I}_{\mathrm{T} i}^{+}$, calculated using all points in Figure 5.2 irrespective of the electron energy of the measurement. The standard free energy change for reaction (5.2) at $1806^{\circ} \mathrm{K}$ calculated from the least squares results in Table 5.7 for the intensity ratio at $10.5 \mathrm{eV}$ and $22.5 \mathrm{eV}$ is $63.8 \mathrm{kcal}$ and $62.8 \mathrm{kcal}$ respectively. The calculations are based on an elapsed time at temperature of 360 minutes. The difference in these results is much less than the estimated uncertainty 
of $2.0 \mathrm{kcal}$ in the standard free energy of reaction (5.2).

(3) Oxygen Potential

Oxygen pressures over stoichiometric titanium monoxide at $1806^{\circ} \mathrm{K}$ may be calculated from gaseous equilibria (5:8) and (5.9) using the pressures of $\mathrm{TiO}(\mathrm{g})$ and $\mathrm{Ti}(\mathrm{g})$ given above and the following published data: $\Delta \mathrm{F}_{1806, f}^{\circ}[\mathrm{O}(\mathrm{g})]=32.175 \pm$ $0.03 \mathrm{kcal}(31), \Delta \mathrm{F}_{1806, \mathrm{f}}^{\circ}\left[\mathrm{O}_{2}(\mathrm{~g})\right]=0 \mathrm{kcal}, \Delta \mathrm{F}_{1806, \mathrm{f}}^{\circ}[\mathrm{Ti}(\mathrm{g})]=$ $51.520 \pm 1.0 \mathrm{kcal}(31)$, and $\Delta \mathrm{F}_{1806, f}[\mathrm{TiO}(\mathrm{g})]=-26.016^{ \pm 2} .0 \mathrm{kcal}$ (13). The free energy of formation of TiO(g) depends in part on the measured dissociation energy, $\mathrm{D}_{\circ}^{\circ}(\mathrm{TiO})=158.5^{ \pm}$ $2.0 \mathrm{kcal}(13)$.

$$
\begin{aligned}
& \mathrm{TiO}(\mathrm{g})=\mathrm{Ti}(\mathrm{g})+\mathrm{O}(\mathrm{g}) \\
& \mathrm{O}_{2}(\mathrm{~g})=20(\mathrm{~g})
\end{aligned}
$$

The calculated oxygen pressures over stoichiometric titanium monoxide at $1806^{\circ} \mathrm{K}$ are $\mathrm{P}_{\mathrm{O}}=1.52 \times 10^{-14}$ atm and $\mathrm{P}_{\mathrm{O}_{2}}=1.41 \mathrm{x}$ $10^{-20} \mathrm{~atm}$. These pressures are estimated to be uncertain by a factor of 2.3 and 5.5 respectively. The uncertainties are based on the uncertainties in the pressures of $\mathrm{TiO}(\mathrm{g})$ and $\mathrm{Ti}(\mathrm{g})$ and the uncertainties in the published thermodynamic data.

\section{(4) Partial Molal Free Energies}

At high temperatures titanium monoxide may exhibit large deviations from stoichiometry (1) and hence is properly treated as a solid solution and by the thermodynamics associated with solutions. The thermodynamic properties of solid titanium monoxide will be a function of the composition 
of the phase as well as the temperature and pressure. With these thoughts in mind, partial molal free energies for titanium and oxygen in a titanium monoxide solid solution are defined and calculated.

The difference in free energy of 1 mole of titanium in titanium monoxide solid solution and 1 mole of pure titanium metal is denoted by $\Delta \overline{\mathrm{F}}_{\mathrm{T} i}$ and represented by reaction $(5.10)$.

$$
\mathrm{Ti}(\mathrm{s})=\mathrm{Ti}\left(\mathrm{TiO}_{1} \pm \mathrm{x} \text { solid } \text { soln. }\right)
$$

The quantity $\Delta \overline{\mathrm{F}}_{\mathrm{Ti}}$ may be calculated from equation (5.11).

$$
\Delta \overline{\mathrm{F}}_{\mathrm{T} \mathrm{i}}=\overline{\mathrm{F}}_{\mathrm{T} \mathrm{i}}-\mathrm{F}_{\mathrm{T} i}^{\circ}=\operatorname{RT} \ln \left(\mathrm{a}_{\mathrm{T} i}\right)
$$

The quantities $\overline{\mathrm{F}}_{\mathrm{Ti}}$ and a $_{\mathrm{Ti}}$ are the partial molal free energy and activity of titanium in a titanium monoxide solid solution. The quantity $F_{\mathrm{T} i}^{\circ}$ is the molal free energy of titanium metal. In equations (5.10) and (5.11) the standard state of titanium is taken as the stable form of the pure metal at the temperature T. As is often the case the effect of pressure on the free energy of condensed phases is ignored. The activity of titanium in the solid solution is related to the vapor pressure of titanium, $\mathrm{P}_{\mathrm{Ti}}$, over the solid solution in equation (5.12).

$$
\mathrm{a}_{\mathrm{T} i}=\mathrm{P}_{\mathrm{T} \mathrm{i}} / \mathrm{P}_{\mathrm{T} i}^{\circ}
$$

In the above equation $\mathrm{P}_{\mathrm{T} i}^{\circ}$ is the vapor pressure of pure metal titanium. Equation (5.12) assumes $\mathrm{Ti}(\mathrm{g})$ behaves as an ideal gas. For nearly stoichiometric titanium monoxide at $1806^{\circ} \mathrm{K} \mathrm{P}_{\mathrm{T} i}$ was measured to be $(7.58 \pm 1.07) \times 10^{-8} \mathrm{~atm}$. The 
vapor pressure of $\mathrm{Ti}(\beta)$ at $1806^{\circ} \mathrm{K}$ is taken to be $(5.82 \pm 1.62)$ $x 0^{-7} \mathrm{~atm}(31)$. From these pressures the activity of titanium is calculated to be $0.130 \pm 0.041$ in a stoichiometric titanium monoxide solid solution at $1806^{\circ} \mathrm{K}$. The partial molal free energy of solution of titanium is calculated from equation (5.11). The result is $\Delta \overline{\mathrm{F}}_{\mathrm{Ti}}=-7.3 \pm 1.1 \mathrm{kcal}$ for stoichiometric titanium monoxide at $1806^{\circ} \mathrm{K}$.

A similar calculation may be performed for the partial molal free energy of oxygen. The quantity $\Delta \overline{\mathrm{F}}_{\mathrm{O}_{2}}$ is defined by equations (5.13) and (5.14).

$$
\begin{aligned}
& \mathrm{O}_{2}(\mathrm{~g}, 1 \mathrm{~atm})=\mathrm{O}_{2}\left(\mathrm{TiO}_{1} \pm_{\mathrm{x}} \text { solid soln. }\right) \\
& \Delta \overline{\mathrm{F}}_{\mathrm{O}_{2}}=\overline{\mathrm{F}}_{\mathrm{O}_{2}}-\mathrm{F}_{2}=\mathrm{RT} \ln \left(\mathrm{a}_{\mathrm{O}_{2}}\right)=\mathrm{RT} \ln \mathrm{O}_{2}
\end{aligned}
$$

The standard state for oxygen gas is taken as $\mathrm{O}_{2}(\mathrm{~g})$ at unit fugacity. For nearly stoichiometric titanium monoxide at . $1806^{\circ} \mathrm{K}$ the equilibrium pressure of oxygen was calculated to be $1.41 \times 10^{-20}$ atm. The partial molal free energy of solution of oxygen in stoichiometric titanium monoxide at $1806^{\circ} \mathrm{K}$ is calculated from equation (5.14). The result is $\Delta \overline{\mathrm{F}}_{\mathrm{O}_{2}}=$ $-164.0 \pm 6.1 \mathrm{kcal}$.

The partial molal free energies of titanium and oxygen are related to the integral free energy of formation of 1 mole of solid solution, $\underline{\Delta F}$, in equations (5.15) and (5.16).

$$
\begin{gathered}
2 / 3 \mathrm{Ti}(\mathrm{s})+1 / 3 \mathrm{O}_{2}(\mathrm{~g}, 1 \mathrm{~atm})=2 / 3 \mathrm{Ti}\left(\mathrm{O}_{2}\right)_{\frac{1}{2}} \\
\Delta \mathrm{F}=\mathrm{X}_{\mathrm{Ti}} \Delta \overline{\mathrm{F}}_{\mathrm{Ti}}+\mathrm{X}_{\mathrm{O}_{2}} \Delta \overline{\mathrm{F}}_{\mathrm{O}_{2}}=2 / 3(-7.3 \pm 1.1)+ \\
1 / 3(-164.0 \pm 6.1)=-59.5 \pm 2.2 \mathrm{kcal}
\end{gathered}
$$

The standard free energy of formation of 1 mole of solid ti- 
tanium monoxide is obtained by multiplying the free energy of formation of 1 mole of solution, $-59.5 \pm 2.2 \mathrm{kcal}$, by $3 / 2$. The necessary result is $\Delta F_{1806, f}^{\circ}=-89.3 \pm 3.3 \mathrm{kcal}$ as obtained previously.

\section{(d) Ionization Efficiency Curves}

Ionization efficiency curves for $\mathrm{Ti}^{+}(48)$ and $\mathrm{TiO}^{+}(64)$ are shown in Figure 5.6, page 100: Ionization efficiency curves for $\mathrm{Ti}^{+}(48), \mathrm{TiO}^{+}(64)$, and $\mathrm{Hg}^{+}(202)$ are shown in $\mathrm{Fig}-$ ure 5.7 , page 101, over a smaller range of electron energy but with the abscissa expanded relative to the scale in Figure 5.6. The abscissa in Figures 5.6 and 5.7 do not represent the true electron energy but rather the energy as read from a 10 turn "pot" on the mass spectrometer console.

Appearance potentials were obtained for $\mathrm{Ti}^{+}(48)$ and $\mathrm{TiO}^{+}(64)$ from the ionization efficiency curves using the linear extrapolation technique. A line was drawn through the linear portion of the curves shown in Figure 5.7 using a linear least squares computer program, laboratory designation LS2H. The range of the linear portion was chosen as $5.9-11.7 \mathrm{eV}, 7.5-13.3 \mathrm{eV}$, and $9.1-14.9 \mathrm{eV}$ for $\mathrm{Ti}^{+}(48), \mathrm{TiO}^{+}(64)$, and $\mathrm{Hg}^{+}$(202) respectively on Figure 5.7. Thirty equally weighted points were used to calculate each least squares line. The least squares results are summarized in Table 5.8 , page 102. The first column lists the disc data storage file. The second column gives the ion. The least squares slope and intercept are given in the third and fourth column respec- 


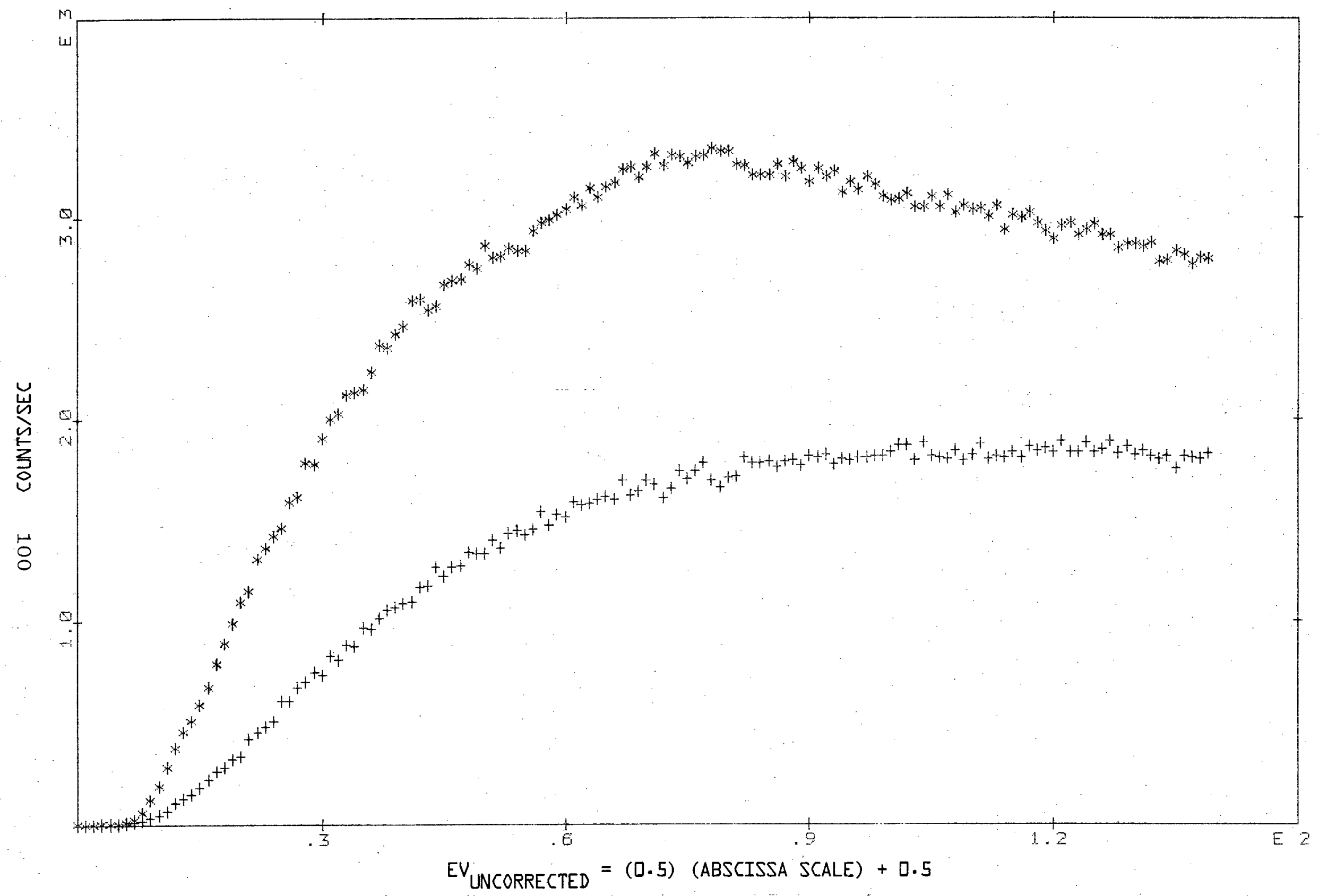

FIE. 5.6

IDIZATIOH EFFECENCY CUFVES

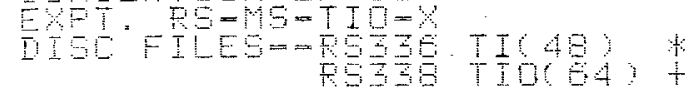




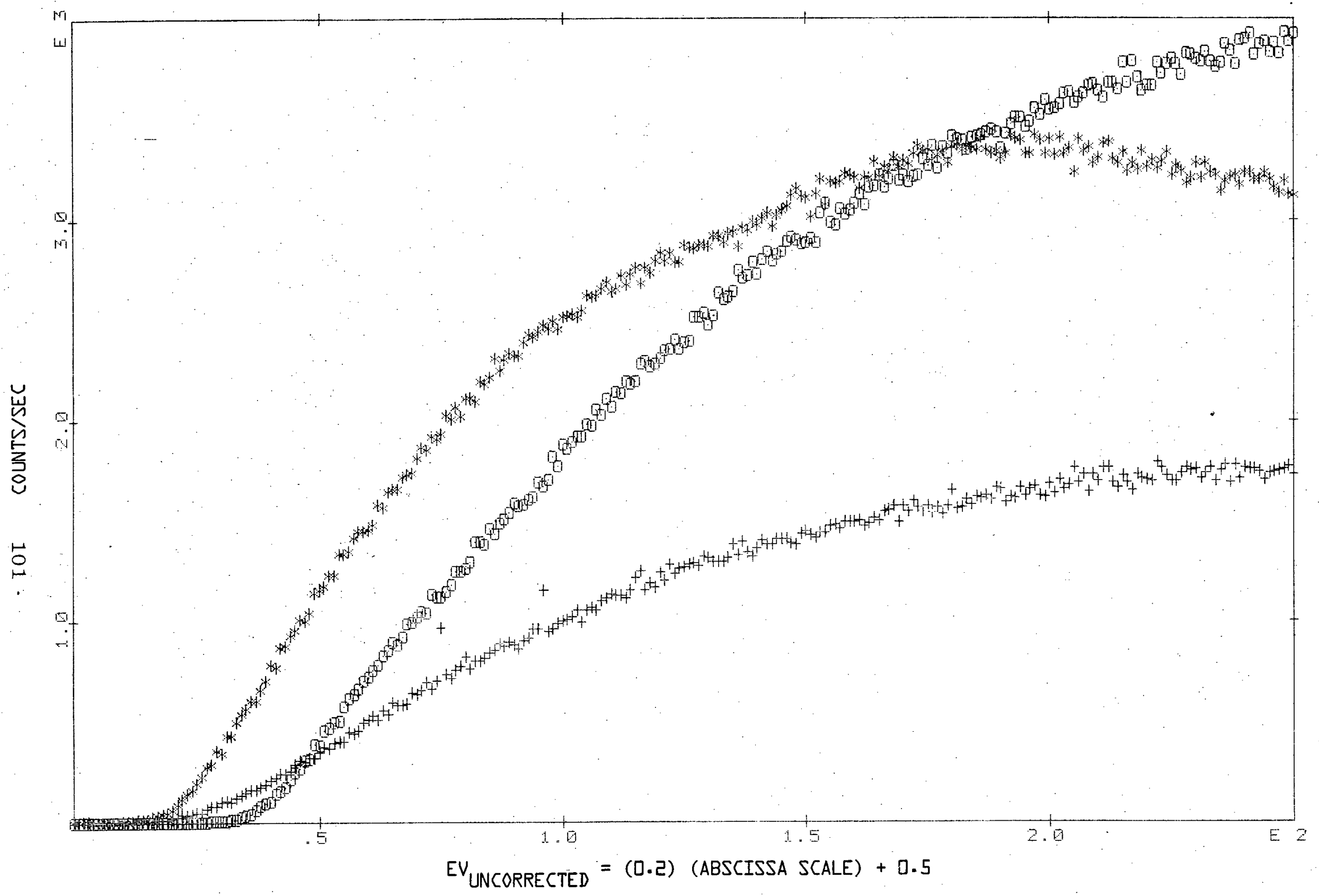

\section{FIE. $\mathbf{5 . 7}$}

IDNIZATION EFFEIENCY CUFUE

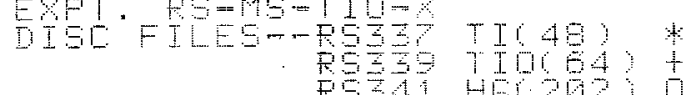


Table 5.8

Least Squares Fit to Linear Portion of I.E. Curves Experiment RS-MS-TiO-X (Chart. 1976-008)

$\mathrm{I}^{+}=\mathrm{b}(\mathrm{eV})+\mathrm{c}$

(a)

\begin{tabular}{llcc}
\hline $\begin{array}{c}\text { Disc } \\
\text { File }\end{array}$ & Ion(m/e) & $\begin{array}{c}\text { Slope, b } \\
(\mathrm{cps} / \mathrm{eV})\end{array}$ & $\begin{array}{c}\text { Intercept, c } \\
(\mathrm{cps})\end{array}$ \\
\hline RS337 & $\mathrm{Ti}^{+}(48)$ & $193.0 \pm 2.3$ & $-885 \pm 21$ \\
$\mathrm{RS339}$ & $\mathrm{TiO}^{+}(64)$ & $71.5 \pm 1.2$ & $-402 \pm 13$ \\
$\mathrm{RS341}$ & $\mathrm{Hg}^{+}(202)$ & $156.0 \pm 1.9$ & $-1236 \pm 23$ \\
\hline
\end{tabular}

(a) $\mathrm{I}^{+}$counts per second Electron energies un-calibrated 
tively.

The electron energy scale was calibrated using the ionization potential of $\mathrm{Hg}^{+}(202)$. From Table 5.8 the least squares line for $\mathrm{Hg}^{+}(202)$ is calculated to intercept the abscissa of Figure 5.7 at $7.92 \mathrm{eV}$. The ionization potential of $\mathrm{Hg}(\mathrm{g})$ obtained from spectroscopy is $10.44 \mathrm{eV}$ (53). These results indicate the electron energy read from the 10 turn "pot" on the mass spectrometer console is low by about $2.5 \mathrm{eV}$. Corrected electron energies may be obtained from equation $(5.17)$.

$$
(\mathrm{eV}) \text { corrected }=(\mathrm{eV})+2.5
$$

In equation (5.17) (eV)corrected is the corrected electron energy based on the ionization potential of mercury. The quantity (eV) is the electron energy as read from the "pot" dial, i.e., the uncorrected electron energy.

The appearance potentials of $\mathrm{Ti}^{+}(48)$ and $\mathrm{TiO}^{+}(64)$ are calculated from the extrapolation of the linear portion of their ionization efficiency curves as given by the least squares lines in Table 5.8 to zero ion counts. The appearance potentials obtained by extrapolation to zero ion counts are corrected by equation (5.17). The calculated appearance potentials are $7.1 \mathrm{eV}$ and $8.1 \mathrm{eV}$ for $\mathrm{Ti}^{+}(48)$ and $\mathrm{TiO}^{+}(64)$ respectively.

The ionization efficiency curves in Figures 5.6 and 5.7 show no break which might indicate the fragmentation of $\mathrm{TiO}(\mathrm{g})$ to form $\mathrm{Ti}^{+}$is important. The appearance potential 
of $\mathrm{Ti}^{+}(48)$ indicates that at least some of the titanium ion observed in the mass spectrometer arises from Ti(g). Final1y, the results of Figure 5.2 show a higher ratio, I at higher electron energies, a result inconsistent with fragmentation of $\mathrm{TiO}(\mathrm{g})$ to form $\mathrm{Ti}^{+}$.

(1) Anomalous $\mathrm{Ti}^{+}$

An anomalous ion is defined as an ion formed by a process other than electron impact. Because anomalous $\mathrm{Ti}^{+}$ had been a problem in previous mass spectrometric work on the titanium oxygen system ( 3 ), special care was taken in this work to check for anomalous $\mathrm{Ti}^{+}$. Periodically during RS-MS-TiO-X a check was made for anomalous $\mathrm{Ti}^{+}$by lowering the electron energy while focused on $\mathrm{m} / \mathrm{e}=48$. In every case the signal feli to the level of the background intensity indicating no anomalous $\mathrm{Ti}^{+}$.

\section{(e) Sample Composition}

The thermodynamic properties for titanium monoxide reported in this work have been for "nearly stoichiometric" material. Because titanium monoxide vaporizes incongruently it is impossible in practice to study a fixed composition in a vaporization experiment. For this reason it is of interest to estimate the change in sample composition in experiments RS-TiO-2 and RS-MS-TiO-X. Essentially the same change in composition is expected in both experiments since the sample, sample mass, crucible, orifice, temperature, and vaporization time were approximately the same in both. The initial sam- 
ple composition is taken as $\mathrm{TiO}_{0.997} \pm_{0.004}$ from Wheatley's combustion analysis ( 7 ). The initial masses of titanium monoxide used in RS-TiO-2 and RS-MS-TiO-X were $10.24 \mathrm{mg}$ and $10.41 \mathrm{mg}$ respectively. The smaller of the two masses will be used in the calculation since this will yield the larger calculated change in composition. The amounts of titanium and titanium monoxide vaporized were calculated previously from the results of RS-TiO-2 and RS-MS-TiO-X as (4.28士0.60) $\mathrm{x} 10^{-4} \mathrm{~g}$ and $(1.42 \pm 0.80) \times 10^{-4} \mathrm{~g}$ respectively. From the initial mass and composition of the sample and the calculated mass loss of titanium and oxygen as Ti(g) and $\mathrm{TiO}(\mathrm{g})$, the final sample composition is calculated as $\mathrm{TiO}_{1} .06 \pm 0.02 \cdot \mathrm{Be}-$ cause some material had condensed on the lid of the crucible in RS-MS-TiO-X (see next paragraph) the calculation of the final composition is less certain for RS-MS-TiO-X than RSTiO-2.

\section{(f) Residue}

The residue from experiment RS-MS-TiO-X appeared not to have melted but did show evidence of sintering. It had the typical golden-brown color characteristic of titanium monoxide. The orifice was clear of condensed material but a small amount of material had condensed on the cell lid. The condensed material had the same color as the bulk of the residue. The material had condensed in a "pie" shaped section on the inside of the lid extending from near the orifice fanning out to the outer edge of the lid. The material 
covered about $10 \%$ of the lid surface. It proved impossible to scrape enough material from the lid for an X-ray photograph. The amount of material condensed on the lid was estimated to be $0.27 \pm 0.07 \mathrm{mg}$ based on a measured mass of 9.97745 $\pm 0.00005 \mathrm{~g}$ for the lid following RS-MS-TiO-X and 9.97718士 $0.00005 \mathrm{~g}$ after outgassing the cell and lid. The condensed material had completely disappeared following the outgassing procedure.

The reason for the condensed material was a cold spot on the lid caused by a filament which had sagged slightly below the top surface of the crucible.

5.4.2 RS-MS-TiO-Y (Chart 1976-009, Disc Files RS342363)

The titanium monoxide sample, laboratory designation TiO-1, and tungsten crucible, laboratory designation \#4, have been previously, described in sections 3.2 and 3.3 . Experiment RS-MS-TiO-Y consisted of measurements of the temperature dependence of intensity of $\mathrm{Ti}^{+}(48)$ and $\mathrm{TiO}^{+}(64)$ over nearly stoichiometric titanium monoxide. The mass of sample in RS-MS-TiO-Y was $99.08 \mathrm{mg}$, approximately ten times the amount used in RS-TiO-2 and RS-MS-TiO-X. "The larger sample was used to minimize the effect of the incongruent vaporization on the sample composition. The temperature range of RS-MS-TiO-Y was $1694^{\circ} \mathrm{K}$ to $1919^{\circ} \mathrm{K}$. The pressures of $\mathrm{Ti}(\mathrm{g})$ and $\mathrm{TiO}(\mathrm{g})$ calculated from RS-TiO-2 and RS-MS-TiO-X at $1806^{\circ} \mathrm{K}$ are used to calibrate the mass spectrometer in RS-MS-TiO-Y. 
The data from RS-MS-TiO-Y are treated both by the so-called second and third law methods. Both integral and partial molal quantities are obtained. The temperature dependence of the oxygen potential is calculated from the measured temperature dependence of the pressures of $\mathrm{Ti}(\mathrm{g})$ and $\mathrm{TiO}(\mathrm{g})$ and published thermodynamic data.

(a) Gaseous Species and Intensity Data

Ion intensities in RS-MS-TiO-Y were obtained using laboratory computer program ARECM to integrate areas under shutter profiles obtained with laboratory computer program SPOBM. The temperature dependence of two ions, $\mathrm{Ti}^{+}(48)$ and $\mathrm{TiO}^{+}(64)$, was measured. The results of these measurements are summarized in Tables 5.9 and 5.10, pages 108 and 109 . The first column contains the disc data storage file. The second column gives the number of signal averaged passes made with program SPOBM. The third and fourth columns give the absolute temperature and the reciprocal of the absolute temperature respectively. The fifth column gives the net counts obtained with program ARECM. The last column contains the logarithm of the product of the net counts divided by the number of passes and the absolute temperature.

The data from Tables 5.9 and 5.10 are plotted in Figure 5.8, page 110. The ordinate is the logarithm of the product of the net counts divided by the number of passes and the absolute temperature. The points are numbered in the order of measurement. A straight line was drawn through 
Table 5.9

Intensity Data $\mathrm{Ti}^{+}(48)$

Experiment RS-MS-TiO-Y (Chart 1976-009)

\begin{tabular}{|c|c|c|c|c|c|}
\hline $\begin{array}{l}\text { Disc } \\
\text { File }\end{array}$ & $\begin{array}{l}\text { No. of } \\
\text { Passes, } \\
\quad \text { N }\end{array}$ & $\left.{ }^{\mathrm{T}} \mathrm{K}\right)$ & $\left(10^{-4 / T} \frac{\mathrm{T}}{\mathrm{K}-1}\right)$ & $\begin{array}{c}\text { Net } \\
\text { Counts, C }\end{array}$ & $\ln (\mathrm{CT} / \mathrm{N})$ \\
\hline RS344 & 2 & 1744 & 5.734 & $43795 \pm 213$ & 17.458 \\
\hline $\mathrm{RS} 345$ & 2 & 1793 & 5.578 & $136989 \pm 374$ & 18.626 \\
\hline RS 349 & 2 & 1766 & 5.663 & $71473 \pm 272$ & 17.960 \\
\hline RS350 & 2 & 1724 & 5.801 & $28002 \pm 172$ & 16.999 \\
\hline RS354 & 2 & 1696 & 5.897 & $17894 \pm 140$ & 16.535 \\
\hline RS 355 & 1 & 1805 & 5.539 & $60330 \pm 248$ & 18.506 \\
\hline RS358 & 1 . & 1869 & 5.349 & $207689 \pm 458$ & 19.777 \\
\hline RS359 & 1 & 1919 & 5.211 & $416558 \pm 649$ & 20.499 \\
\hline $\mathrm{RS} 362$ & 1 & 1843 & 5.425 & $124950 \pm 357$ & 19.255 \\
\hline RS363 & 2 & 1843 & 5.425 & $258888 \pm 512$ & 19.290 \\
\hline
\end{tabular}


Table 5.10

Intensity Data $\mathrm{TiO}^{+}(64)$

Experiment RS-MS-TiO-Y (Chart 1976-009)

\begin{tabular}{|c|c|c|c|c|c|}
\hline $\begin{array}{l}\text { Disc } \\
\text { File }\end{array}$ & $\begin{array}{l}\text { No. of } \\
\text { Passes, } \\
\quad \mathrm{N}\end{array}$ & $\left({ }^{\mathrm{T}} \mathrm{K}\right)$ & $\left(10^{-4} \frac{1}{\circ} \mathrm{K}^{-1}\right)$ & $\begin{array}{c}\text { Net } \\
\text { Counts, } C\end{array}$ & $\ln (\mathrm{CT} / \mathrm{N})$ \\
\hline RS343 & 4 & 1744 & $5.734^{\circ}$ & $26968 \pm 323$ & 16.280 \\
\hline $\mathrm{RS} 346$ & 2 & 1795 & 5.571 & $49650 \pm 270$ & 17.612 \\
\hline RS347 & 2 & 1765 & 5.666 & $23145 \pm 211$ & 16.832 \\
\hline RS351 & 4 & 1724 & 5.801 & $16193 \pm 219$ & 15.758 \\
\hline RS352 & 3 & 1694 & 5.902 & $7870 \pm 168$ & 15.307 \\
\hline RS353 & 4 & 1694 & 5.902 & $10143 \pm 182$ & 15.273 \\
\hline RS356 & 2 & 1805 & 5.539 & $44203 \pm 243$ & 17.502 \\
\hline RS357 & 1 & 1869 & 5.349 & $85658 \pm 305$ & 18.892 \\
\hline RS360 & 1 & 1919 & 5.211 & $194835 \pm 453$ & 19.739 \\
\hline RS361 & 1 & 1843 & 5.425 & $51434 \pm 241$ & 18.367 \\
\hline
\end{tabular}




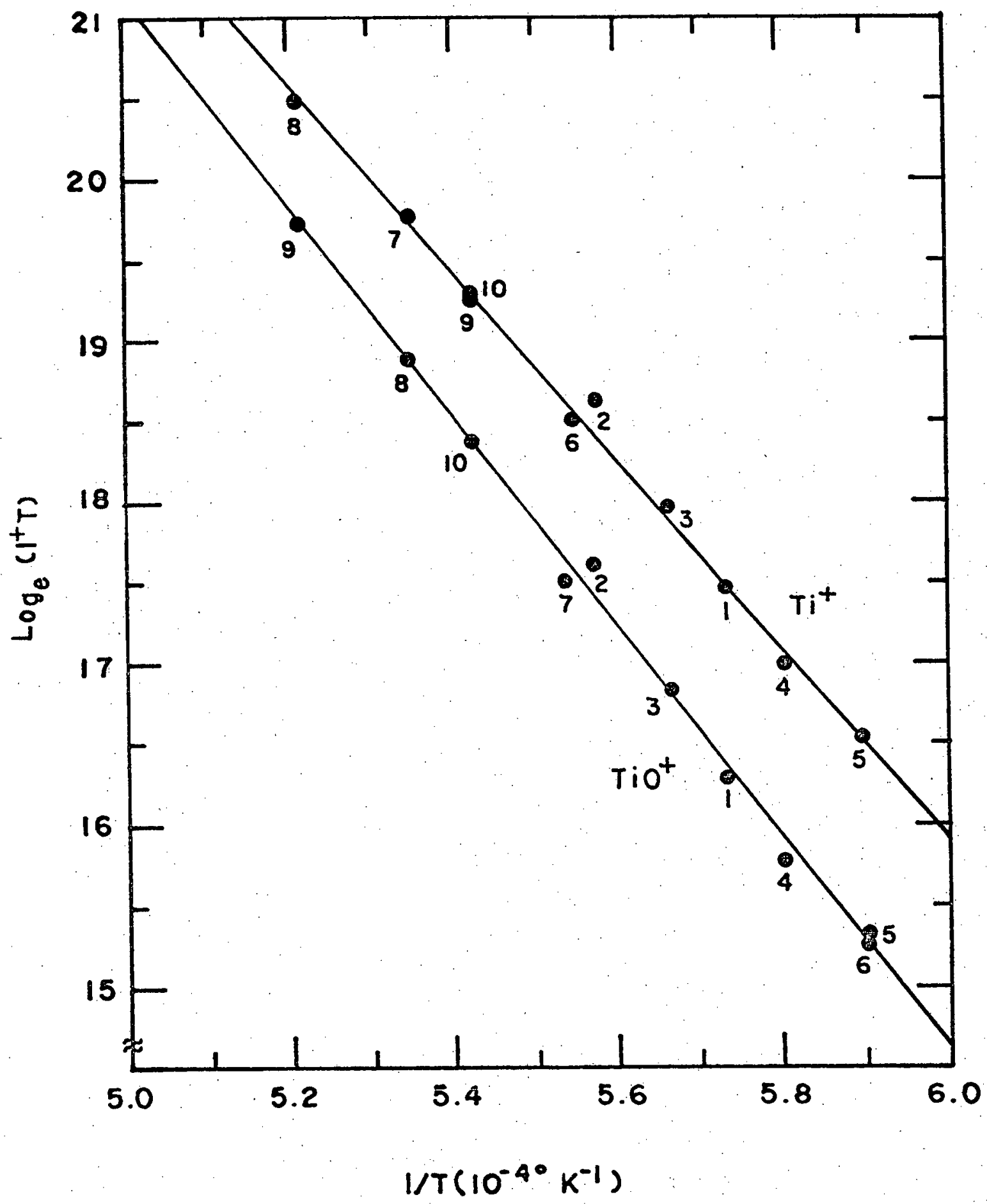

FIG. 5.8

Plot of $\log _{\theta}\left(l^{+} T\right)$ versus $I / T$. Results from Experiment RS-MS-TiO-Y. 
the data using Iinear least squares computer program LS2H. The least squares results are summarized in Table 5.11, page 112. The first column indentifies the ion. The second and third columns contain the least squares slope and intercept respectively. The quoted errors are standard deviations. The last column gives the temperature range in degrees Kelvin over which the measurements were made.

Intensity measurements on $\mathrm{Ti}^{+}(48)$ and $\mathrm{TiO}^{+}(64)$ were made at an electron energy of $13.6 \mathrm{eV}$ and $14.5 \mathrm{eV}$ respectively and an emission current of $0.3 \mathrm{~mA}$. The electron energies were chosen such that measurements would be made at approximately the same distance above the appearance potentials of the respective ions.

Although no attempt was made to search for shutterable species other than $\mathrm{Ti}^{+}(48)$ and $\mathrm{TiO}^{+}(64)$ i.t became apparent during the course of RS-MS-TiO-Y that a temperature dependent ion existed on the low mass side of $\mathrm{m} / \mathrm{e}=56$. The species was clearly resolved from the hydrocarbon background at $\mathrm{m} / \mathrm{e}=56$. Because titanium monoxide vaporizes incongruently and it was desired to measure the temperature dependence of $\mathrm{Ti}^{+}(48)$ and $\mathrm{TiO}^{+}(64)$ at as nearly a constant composition as possible, time was not taken to run a shutter profile on $\mathrm{m} / \mathrm{e}=56$. The temperature dependent ion at $\mathrm{m} / \mathrm{e}=56$ was most likely $\mathrm{Fe}^{+}$originating as an impurity in the sample. The relative abundance of $\mathrm{Fe}(56)$ is $91.66 \%$ with the next most abundant isotope being $F e(54)$ at $5.82 \%$. A check on the low 
Table 5.11

$$
\begin{aligned}
& \text { Temperature Dependence of } \mathrm{Ti}^{+}(48) \text { and } \mathrm{TiO}^{+}(64) \\
& \text { Experiment RS-MS-TiO-Y (Chart 1976-009) } \\
& \ln \left(\mathrm{I}^{+} \mathrm{T}\right)=\mathrm{b} / \mathrm{T}+\mathrm{c}
\end{aligned}
$$

\begin{tabular}{lccc}
\hline Ion $(\mathrm{m} / \mathrm{e})$ & $\begin{array}{c}\text { Slope }, \mathrm{b} \\
\left({ }^{\circ} \mathrm{K}\right)\end{array}$ & Intercept, c & $\begin{array}{l}\text { Temperature } \\
\text { Range }\left({ }^{\circ} \mathrm{K}\right)\end{array}$ \\
\hline $\mathrm{Ti}^{+}(48)$ & $-58511 \pm 1591$ & $51.04 \pm 0.89$ & $1696-1919$ \\
$\mathrm{TiO}^{+}(64)$ & $-65508 \pm 1491$ & $53.91 \pm 0.84$ & $1694-1919$ \\
\hline
\end{tabular}

mass side of $\mathrm{m} / \mathrm{e}=54$ indicated the possibility of a shoulder at the higher temperatures.

A plot of the logarithm of the product of the intensity and the absolute temperature versus the reciprocal of the absolute temperature for the temperature dependent ion at $\mathrm{m} / \mathrm{e}^{\prime}=56$ is given in Figure 5.9, page 113. Intensities were estimated from the strip chart. Points are numbered in the order of measurement. The plot indicates the iron was: rapidly distilling out of the sample.

(1) Anomalous $\mathrm{Ti}^{+}$

One check for anomalous $\mathrm{Ti}^{+}$was made during RS-MSTiO-Y at a temperature of $1792^{\circ} \mathrm{K}$. No anomalous titanium ion was found.

(b) Shutter Profiles

Typical shutter profiles for $\mathrm{Ti}^{+}(48)$ and $\mathrm{TiO}^{+}(64)$ taken during the initial, intermediate, and final parts of 


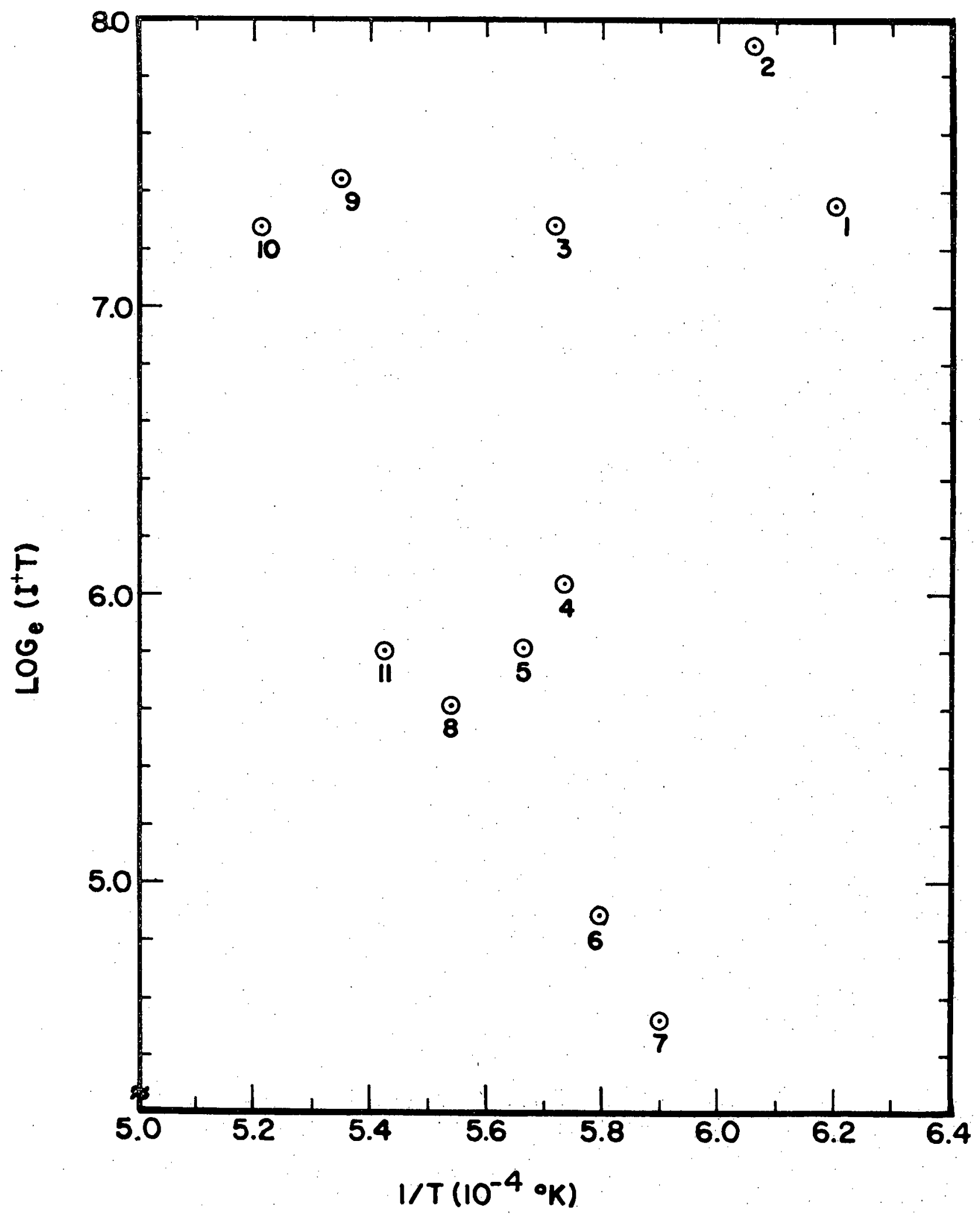

FIG. 5.9

Plot of $\mathrm{LOG}_{e}\left(I^{+} T\right)$ versus $I / T$ for $m / e=56$. Results from Experiment RS-MS-TiO-Y. 
RS-MS-TiO-Y are plotted in Figures 5.10 and 5.11 , pages 115 and 116. All shutter profiles were generally symmetric indicating shutterable ions were formed from neutral species originating from within the Knudsen cell.

(c) Calibration of the Mass Spectrometer

Pressures may be calculated from measured intensities in experiment RS-MS-TiO-Y once the constants $\mathrm{C}_{\mathrm{Ti}}$ and $\mathrm{C}_{\mathrm{TiO}}$ in equations $(5.18)$ and $(5.19)$ have been found.

$$
\begin{aligned}
& \mathrm{P}_{\mathrm{Ti}}=\mathrm{C}_{\mathrm{T} i}\left(\mathrm{I}_{\mathrm{T} i}^{+} \mathrm{T}\right) \\
& \mathrm{P}_{\mathrm{TiO}}=\mathrm{C}_{\mathrm{TiO}}\left(\mathrm{I}_{\mathrm{TiO}}^{\mathrm{T}}\right)
\end{aligned}
$$

The vapor pressures of $\mathrm{Ti}(\mathrm{g})$ and $\mathrm{TiO}(\mathrm{g})$ at $1806^{\circ} \mathrm{K}$ in equilibrium with nearly stoichiometric titanium monoxide were calculated from experiments RS-TiO-2 and RS-MS-TiO-X to be $(7.58 \pm 1.07) \times 10^{-8} \mathrm{~atm}$ and $\left(2.18^{ \pm 1.23}\right) \times 10^{-8}$ atm respectively. From the least squares results in Table $5.11 \mathrm{I}_{\mathrm{Ti}}^{+} \mathrm{T}$ and $\mathrm{I}_{\mathrm{TiO}}^{+}$ are calculated to be $(1.248 \pm 0.041) \times 10^{8} \mathrm{cts} \mathrm{deg}$ and $\left(4.57^{ \pm}\right.$ $0.16) \times 10^{7}$ cts deg respectively at $1806^{\circ} \mathrm{K}$. Substitution of these results into equations (5.18) and (5.19) yield $\mathrm{C}_{\mathrm{Ti}}=$ $(6.07 \pm 0.88) \times 10^{-16} \mathrm{~atm} /(\mathrm{cts} \mathrm{deg})$ and $\mathrm{C}_{\mathrm{TiO}}=(4.77 \pm 2.70) \mathrm{x}$ $10^{-16} \mathrm{~atm} /(\mathrm{cts} \mathrm{deg})$. Equations (5.20) and (5.21) for the pressures of $\mathrm{Ti}(\mathrm{g})$ and $\mathrm{TiO}(\mathrm{g})$ are obtained from the least squares results in Table 5.11, equations (5.18) and (5.19), and the constants $\underline{\mathrm{C}}_{\mathrm{Ti}}$ and $\mathrm{C}_{\mathrm{TiO}}$ given above.

$$
\begin{aligned}
& \ln \left(\mathrm{P}_{\mathrm{Ti}}\right)=\frac{-58511 \pm 1591}{\mathrm{~T}}+16.00 \pm 0.90 \\
& \ln \left(\mathrm{P}_{\mathrm{TiO}}\right)=\frac{-65508 \pm 1491}{\mathrm{~T}}+18.63 \pm 1.01
\end{aligned}
$$




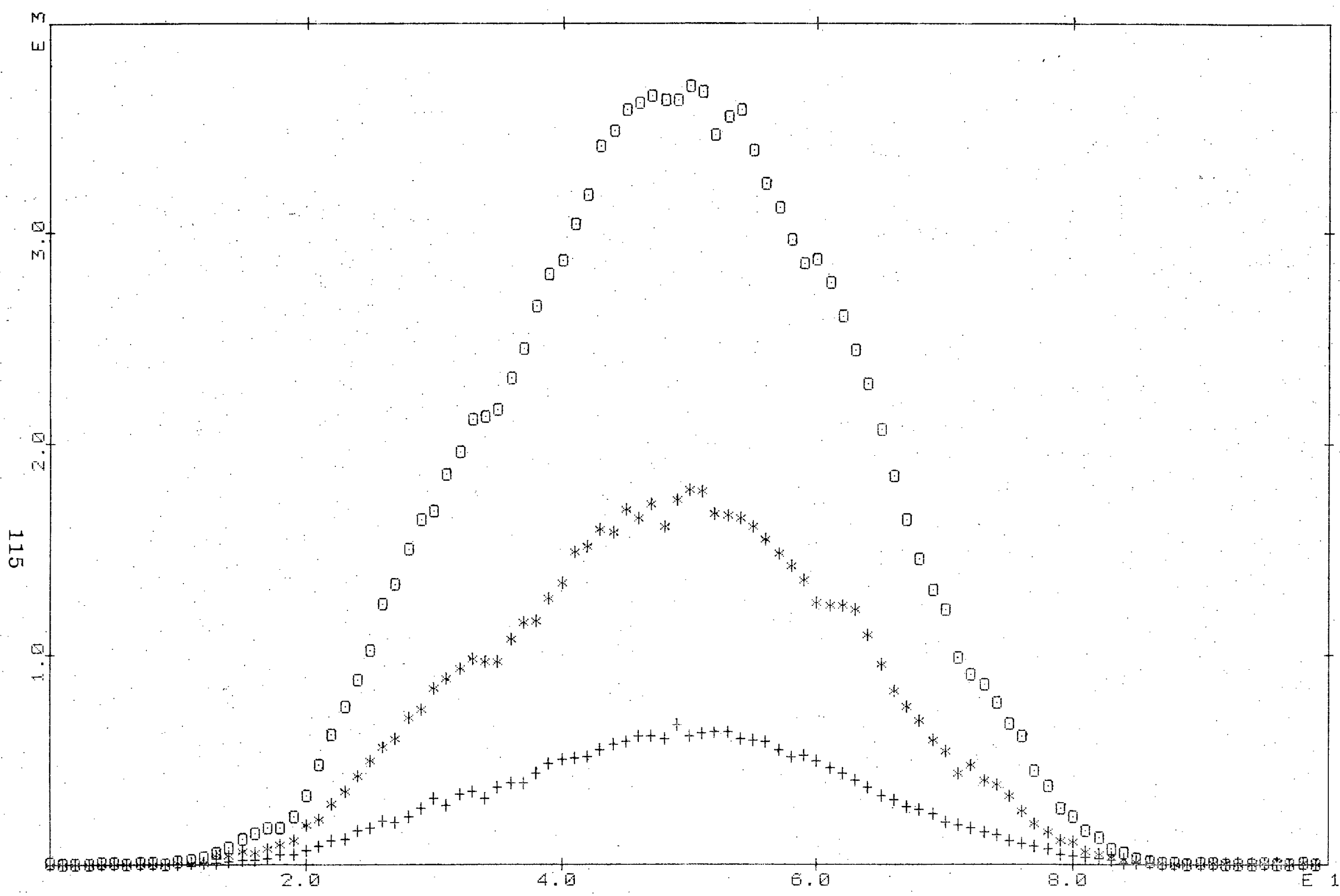

FIE. 5.10

BUYTTEF FEOFTESTISA

DISI:FILESE-TES-Y 


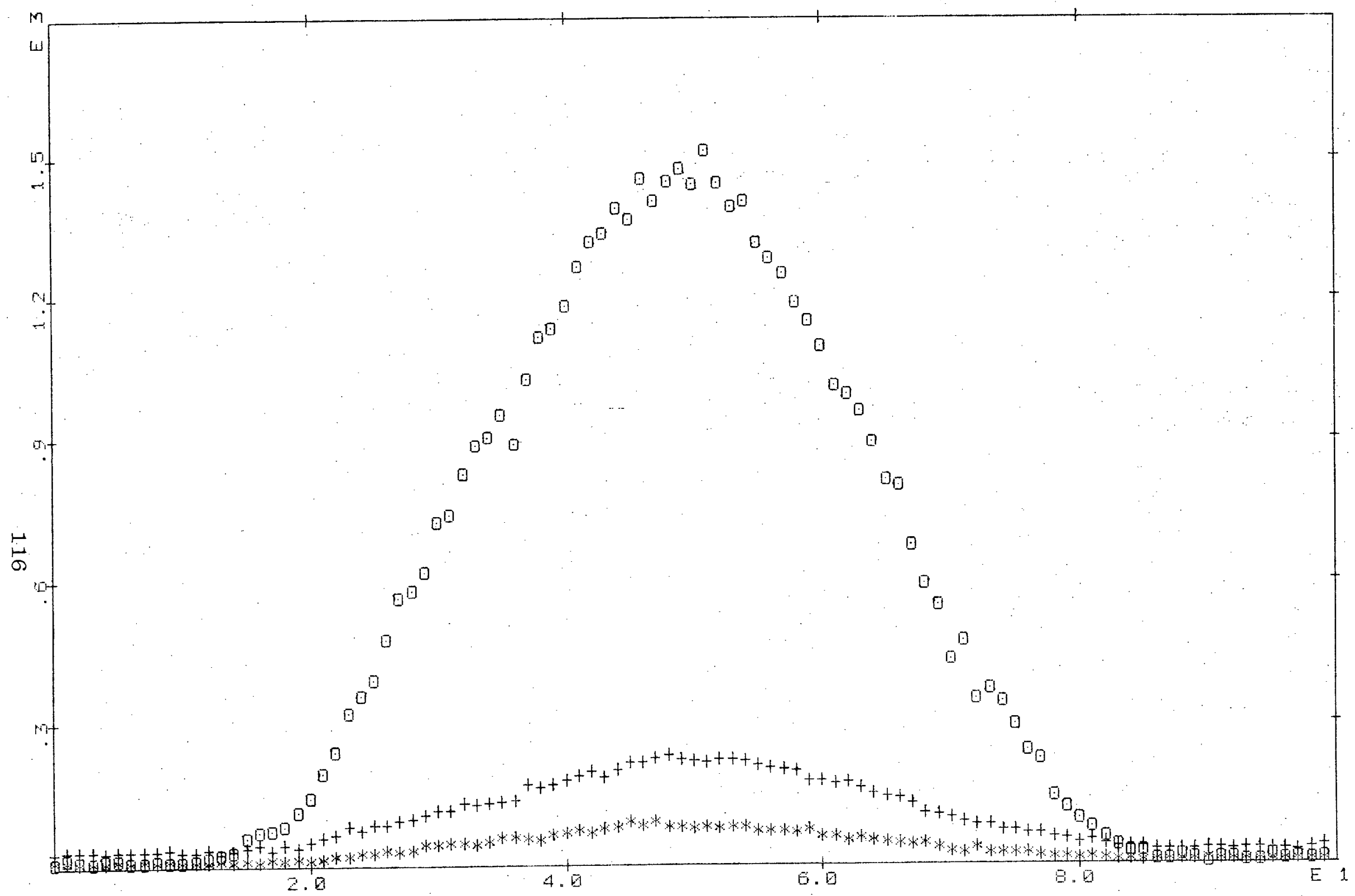

FIE. $\mathbf{5 . 1 1}$

SHYTTEF FFEFILES TIOCBA3

GEL"FIES- $=4=4$

Reses

$\infty$

$\sigma$ 


\section{(d) Thermodynamics}

(1) Chemical Reactions

The important chemical reactions appropriate for describing the vaporization of stoichiometric titanium monoxide are given in reactions (5.22) and (5.23).

$$
\begin{aligned}
& \mathrm{TiO}\left(\mathrm{TiO}_{1} .00_{\text {solid soln. }}\right)=\mathrm{TiO}(\mathrm{g}) \\
& \mathrm{Ti}\left(\mathrm{TiO}_{1} .00_{\text {solid }} \text { soln. }\right)=\mathrm{Ti}(\mathrm{g})
\end{aligned}
$$

Although reactions (5.2) and (5.22) are meant to describe the same chemical process, reactions (5.22) and (5.23) are written here to emphasize the solid solution characteristics exhibited by titanium monoxide. The incongruent nature of vaporization of titanium monoxide is also evident from reactions (5.22) and (5.23). The solid becomes more oxygen $\mathrm{rich}$ as vaporization proceeds.

\section{(2) Second Law Results}

Equation (4.4) indicates a plot of the logarithm of the equilibrium constant against the reciprocal of the absolute temperature yields a curve whose slope at each point is related to the standard enthalpy change of the reaction and whose intercept is related to the standard entropy change of the reaction. Frequently such a plot yields a straight line within the uncertainty of the measurements. In such a case the slope and intercept yield the standard enthalpy and entropy changes for the reaction at the mean temperature of the measurements. If enthalpy and entropy increments are available for products and reactants between the mean temper- 
ature and reference temperature, usually $0^{\circ} \mathrm{K}$ or $298.15^{\circ} \mathrm{K}$, the standard enthalpy and entropy changes may be calculated at the reference temperature.

Second law results obtained in RS-MS-TiO-Y are summarized in Table 5.12, page 119. The first column indicates the chemical reaction. The second column gives the number of data points. The third column contains the temperature range of the measurements. The fourth and fifth columns give the standard enthaply and entropy changes of the reactions at the mean temperature of the measurements. The last two columns give the standard enthalpy and entropy changes at $298.15^{\circ} \mathrm{K}$.

The equilibrium constants used in the second law calculations for reactions (1) and (2) in Table 5.12 were taken equal to the vapor pressures of $\mathrm{TiO}(\mathrm{g})$ and $\mathrm{Ti}(\mathrm{g})$ respective1y. The pressures are given in equations (5.20) and (5.21). Setting the equilibrium constants equal to the respective vapor pressures assumes the vapors behave ideally and also the activities of $\mathrm{TiO}$ and $\mathrm{Ti}$ in the solid solution are unity. The value of the activity of TiO and Ti in the solid solution depends in part on the standard state chosen for each substance and the composition of the solution. For a given composition, the stoichiometric composition, in.this case, the activity of $\mathrm{TiO}$ and $\mathrm{Ti}$ can be made unity by appropriate choice of standard states for each substance. The problem of choice of standard states is treated more fully in the 
Table 5.12

Second Law Thermodynamics for Vaporization of $\mathrm{TiO}_{1} .00$

Experiment RS-MS-TiO-Y (Chart 1976-009)

\begin{tabular}{ccccccc}
\hline Reaction (a) & $\begin{array}{c}\text { No. of } \\
\text { Points }\end{array}$ & $\begin{array}{c}\text { Temp } \\
\text { Range }\left({ }^{\circ} \mathrm{K}\right)\end{array}$ & $\begin{array}{l}\Delta \mathrm{H}_{\mathrm{T}}^{\circ} \\
(\mathrm{kcal})\end{array}$ & $\begin{array}{l}\Delta \mathrm{S}_{\mathrm{T}}^{\circ} \\
(\mathrm{eu})\end{array}$ & $\begin{array}{l}\Delta \mathrm{H}_{298}^{\circ}(\mathrm{b}) \\
(\mathrm{kcal})\end{array}$ & $\begin{array}{l}\Delta \mathrm{S}_{298}^{\circ}(\mathrm{b}) \\
(\mathrm{eu})\end{array}$ \\
\hline 1 & 10 & $1694-1919$ & $130.2 \pm 3.0$ & $37.0 \pm 2.0$ & $138.2 \pm 3.0$ & $45.0 \pm 2.0$ \\
2 & 10 & $1696-1919$ & $116.3 \pm 3.2$ & $31.8 \pm 1.8$ & & \\
\hline
\end{tabular}

(a) Vaporization Reactions

(1) $\mathrm{TiO}\left(\mathrm{TiO}_{1.00}\right.$ solid soln. $)=\operatorname{TiO}(\mathrm{g}, 1 \mathrm{~atm})$

(2) $\mathrm{Ti}\left(\mathrm{TiO}_{1.00} \mathrm{solid} \operatorname{soln}.\right)=\mathrm{Ti}(\mathrm{g}, 1 \mathrm{~atm})$

(b) Enthalpy and entropy increments from JANAF Tables, December 31, 1973. 
discussion section of this thesis.

The second law results for reaction (1) at $298.15^{\circ} \mathrm{K}$ in Table 5.12 were obtained from enthalpy and entropy increments from the JANAF tables (13). More recent laser photoluminescence of $\mathrm{TiO}$ in Ne at $4^{\circ} \mathrm{K}$ has placed the $\mathrm{a}^{1} \Delta$ electronic state at $3500 \mathrm{~cm}^{-1}$ above the $\mathrm{X}^{3} \Delta$ ground state (16). The JANAF tables base their calculation on an assignment of $1000 \mathrm{~cm}^{-1}$ as the difference between the $a^{1} \Delta$ and $x^{3} \Delta$ states. If the electronic contribution to the enthalpy and entropy increments are based on the laser work, the second law heat at $298.15^{\circ} \mathrm{K}$ in Table 5.12 is raised by only $0.2 \mathrm{kcal}$ and the entropy at $298.15^{\circ} \mathrm{K}$ raised by only $0.3 e . u$.

(3) Third Law Results

A standard enthalpy change at $298.15^{\circ} \mathrm{K}$ may be calculated from each measurement of the equilibrium constant at each temperature using equation (4.5) and published free energy functions for products and reactants. The results for reaction (5.22) are summarized in Table 5.13, page 121. The data are presented in the order of increasing temperature. The first column gives the absolute temperature of the measurement obtained from Table 5.10. The order of the measurements is indicated by the second column. The third column contains the pressure in atmospheres of $\mathrm{TiO}(\mathrm{g})$ obtained from the measured intensities in Table 5.10 and equation (5.19). The fourth column gives the logarithm of the pressure listed in column three. The fifth and sixth columns contain pub- 
Table 5.13

Third Law Thermodynamics for TiO(TiO 1.00 solid soln $:$ ) = TiO(g, 1atm)

Experiment RS-MS-TiO-Y (Chart 1976-009)

\begin{tabular}{|c|c|c|c|c|c|c|c|c|}
\hline \multirow[t]{2}{*}{$\begin{array}{l}\text { Temp. } \\
\left({ }^{\circ} \mathrm{K}\right)\end{array}$} & \multirow[t]{2}{*}{$\begin{array}{c}\text { Order of } \\
\text { Measurement }\end{array}$} & \multirow[t]{2}{*}{$\begin{array}{l}\text { Pressure, } \\
\left(10^{-8} \text { atm }\right)\end{array}$} & \multirow[t]{2}{*}{$\mathrm{P}$} & \multirow[t]{2}{*}{$-\ln (P)$} & \multicolumn{2}{|c|}{$\begin{array}{l}\text { fef } 298 \text { (a) } \\
\left(\operatorname{cal} /{ }^{\circ} \mathrm{K}\right)\end{array}$} & \multirow{2}{*}{$\begin{array}{l}\Delta \mathrm{H}_{298}^{\circ} \\
(\mathrm{kcal})\end{array}$} & \\
\hline & & & & & Solid & Gas & & \\
\hline 1694 & 5 & 0.212 & & 19.97 & 20.106 & 63.539 & 140.79 & \\
\hline 1694 & 6 & 0.205 & & 20.00 & 20.106 & $63: 539$ & 140.90 & \\
\hline 1724 & 4 & 0.333 & & 19.52 & 20.307 & 63.666 & 141.62 & \\
\hline 1744 & 1 & 0.561 & & 19.00 & 20.440 & 63.750 & 141.37 & \\
\hline 1765 & 3 & 0.974 & & 18.45 & $20.581^{\circ}$ & 63.839 & 141.06 & \\
\hline 1795 & 2 & 2.12 & & 17.67 & 20.781 & 63.965 & 140.54 & \\
\hline 1805 & 7 & 1.90 & & 17.78 & 20.846 & 64.006 & 141.67 & . \\
\hline 1843 & 10 & $4: 52$ & & 16.91 & 21.093 & 64.160 & 141.30 & \\
\hline 1869 & 8 & 7.64 & & 16.39 & 21.261 & 64.265 & 141.24 & \\
\hline 1919 & 9 & 17.8 & & 15.54 & 21.582 & 64.464 & 141.54 & \\
\hline
\end{tabular}

Average $=141.20 \pm 0.12 \mathrm{kcal}$

(a) Free energy functions from JANAF tables, December 31, 1973. 
lished free energy functions at $298.15^{\circ} \mathrm{K}$ for $\mathrm{TiO}$ solid and gas respectively. The last column contains the calculated standard enthalpy change for reaction (5.22) at $298.15^{\circ} \mathrm{K}$.

From the standard enthalpy of formation of TiO(g) at $298.15^{\circ} \mathrm{K}$ of $13 \pm 2 \mathrm{kcal}$ (13) and the standard enthalpy change at $298.15^{\circ} \mathrm{K}$ of $141.20 \pm 0.12 \mathrm{kcal}$ given in Table 5.13 for reaction (5.22) a standard enthalpy of formation of $\mathrm{TiO}(\beta)$ is calculated to be $128.2 \pm 2.0 \mathrm{kcal}$. The reverse calculation for the standard enthalpy of formation of $\mathrm{TiO}(\mathrm{g})$ using the published standard enthalpy of formation of solid titanium monoxide and the standard enthalpy change for reaction (5.22) measured in this work was not done owing to uncertainties in the thermodynamics of the solid discussed in Chapter 2 of this thesis.

It was noted previously that from laser photoluminescence of $\mathrm{TiO}$ in $\mathrm{Ne}$ at $4^{\circ} \mathrm{K}$ the $\mathrm{a}^{1} \Delta$ electronic state was placed at $3500 \mathrm{~cm}^{-1}$ above the ground state, $\mathrm{X}^{3} \Delta$. The JANAF tables base their calculation on a $1000 \mathrm{~cm}^{-1}$ separation between these two states. If the electronic contribution to the free energy function of $\mathrm{TiO}(\mathrm{g})$ is corrected for the laser work, the results in Table 5.13 for the standard enthalpy change at $298^{\circ} \mathrm{K}$ are lowered by $0.40 \mathrm{kcal}$ and $0.48 \mathrm{kcal}$ at the lowest and highest temperatures respectively.

(4) Oxygen Potential

Although oxygen was not directly observed with the mass spectrometer, oxygen pressures can be calculated from 
the gaseous equilibrium (5.8), the measured pressures of $\mathrm{Ti}(\mathrm{g})$ and $\mathrm{TiO}(\mathrm{g})$ given by equations (5.20) and (5.21), and published thermodynamic data. The equilibrium constant for reaction ( 5.8$)$ is given in equation (5.24).

$$
\mathrm{K}=\left(\mathrm{P}_{\mathrm{Ti}} \mathrm{P}_{\mathrm{O}}\right) / \mathrm{P}_{\mathrm{TiO}}
$$

Taking the logarithm of equation (5.24) and rearrangement yields equation ( 5.25$)$.

$$
\ln \left(\mathrm{P}_{\mathrm{O}}\right)=\ln \left(\mathrm{P}_{\mathrm{TiO}}\right)-\ln \left(\mathrm{P}_{\mathrm{Ti}}\right)+\ln (\mathrm{K})
$$

The variation of the logarithm of the equilibrium constant of reaction (5.8) with temperature at a mean temperature of $1807^{\circ} \mathrm{K}$ is given in equation $(5.26)$.

$$
\ln (K)=\frac{-81372 \pm 1125}{\mathrm{~T}}+14: 48 \pm 0.03
$$

The slope and intercept of equation (5.26) were calculated from the standard enthalpy and entropy changes for reaction (5.8) at $1807^{\circ} \mathrm{K}$ using published thermodynamic data $(13,31)$. The JANAF data is summarized in Table 5.14, page 124. The first column identifies the species, the second gives the standard enthalpy of formation, and the last gives the standard entropy. Substitution of equations (5.20), (5.21), and (5.26) into equation (5.25) yields equation (5.27)

$$
\ln \left(\mathrm{P}_{\mathrm{O}}\right)=\frac{-88369 \pm 2454}{\mathrm{~T}}+17.11 \pm 1.35
$$

\section{(5) Partial Molal Quantities}

As discussed previously" titanium monoxide may exhibit a wide deviation from stoichiometry at high temperatures and hence is properly treated as a solid solution and by the 
Table 5.14

JANAF The rmochemical Data (a)

\begin{tabular}{|c|c|c|}
\hline Species & $\left.{ }_{(\mathrm{kcal})}^{\Delta \mathrm{H}_{1}^{\circ} 807}\right)^{\mathrm{f}}$ & $\mathrm{s}_{1807}^{\circ}$ \\
\hline $\mathrm{TiO}(\mathrm{g})$ & $8.229 \pm 2.0$ & $71.437 \pm 0.06$ \\
\hline $\mathrm{Ti}(\mathrm{g})$ & $108.990 \pm 1.0$ & 52.646 \\
\hline$O(g)$ & $60.926 \pm 0.03$ & 47.569 \\
\hline
\end{tabular}

(a) JANAF Tables

TiO--December 31,1973

O--June 30, 1962

Ti--June 30,1967

thermodynamics of solutions. Specifically, partial molal enthalpies and entropies for titanium and oxygen in the solid stoichiometric material may be derived from the results of experiments RS-MS-TiO-Y. The results are summarized in Tables 5.15 and 5.16 , pages 125 and 126, for titanium and oxygen respectively. The first column lists the reaction. The second column contains the absolute temperature of the reaction. For second law results from this work temperatures in the second column of Tables 5.15 and 5.16 represent the mean temperature of the measurements. The third and fourth columns give the enthalpy and entropy changes for the reactions. The fifth column gives the free energy change calcu- 
Table 5.15

Partial Molal Quantities

Experiment RS-MS-TiO-Y

\begin{tabular}{|c|c|c|c|c|c|}
\hline Reaction & $\begin{array}{l}\text { Temp } \\
\left({ }^{\circ} \mathrm{K}\right)\end{array}$ & $\begin{array}{l}\Delta \dot{H} \\
(\mathrm{kcal})\end{array}$ & $\begin{array}{l}\Delta \mathrm{S} \\
(\mathrm{eu})\end{array}$ & $\begin{array}{l}\Delta \mathrm{F} \\
(\mathrm{kcal})\end{array}$ & Reference \\
\hline 1 & 1808 & $-116.3 \pm 3.2$ & $-31.8 \pm 1.8$ & $-58.8 \pm 4.6$ & This work, equation (5.20) \\
\hline 2 & 1808 & $109.0 \pm 1.0$ & 31.821 & $51.5 \pm 1.0$ & JANAF \\
\hline 3 & 1808 & $-7.3 \pm 3.4$ & $0.021 \pm 1.8$ & $-7.3 \pm 4.7$ & $\begin{array}{l}\text { Reactions } 1 \text { and } 2 \text { this } \\
\text { table. }\end{array}$ \\
\hline
\end{tabular}

(1) $\mathrm{Ti}(\mathrm{g}, 1 \mathrm{~atm})=\mathrm{Ti}\left(\mathrm{TiO}_{1} .00\right.$ solid soln. $)$

(2) $\mathrm{Ti}(\beta)=\mathrm{Ti}(\mathrm{g}, 1 \mathrm{~atm})$

(3) $\mathrm{Ti}(\beta)=\mathrm{Ti}\left(\mathrm{TiO}_{1} .00^{\text {solid }}\right.$ soln. $)$ 
Table 5.16

Partial Molal Quantities

Experiment RS-MS-TiO-Y

\begin{tabular}{|c|c|c|c|c|c|}
\hline Reaction & $\begin{array}{l}\text { Temp } \\
\left({ }^{\circ} \mathrm{K}\right)\end{array}$ & $\begin{array}{l}\Delta \mathrm{H} \\
(\mathrm{kcal})\end{array}$ & $\begin{array}{l}\Delta \mathrm{S} \\
(\mathrm{eu})\end{array}$ & $\begin{array}{l}\Delta F \\
(\mathrm{kcal})\end{array}$ & Reference \\
\hline 1 & 1807 & $-175.6 \pm 4.9$ & $-34.0 \pm 2.7$ & $-114.2 \pm 6.9$ & This work, equation (5.27) \\
\hline 2 & 1807 & $121.8 \pm 0.03$ & 31.839 & $64.3 \pm 0.03$ & JANAF \\
\hline 3 & 1807 & $-229.4 \pm 9.8$ & $-36.2 \pm 5.4$ & $-164.0 \pm 13.8$ & $\begin{array}{l}\text { Reactions } 1 \text { and } 2 \text { this } \\
\text { table. }\end{array}$ \\
\hline
\end{tabular}

(1) $O(\mathrm{~g}, 1 \mathrm{~atm})=O\left(\mathrm{TiO}_{1} .00^{\text {solid }}\right.$ soln. $)$

(2) $\mathrm{O}_{2}(\mathrm{~g}, 1 \mathrm{~atm})=20(\mathrm{~g}, 1 \mathrm{~atm})$

(3) $\mathrm{O}_{2}(\mathrm{~g}, 1 \mathrm{~atm})=\mathrm{O}_{2}\left(\mathrm{TiO}_{1.00}\right.$ solid soln.) 
lated from the third and fourth columns. The last column gives the source of the thermodynamic data.

The enthalpy and entropy changes for reaction (1) in Table 5.15 were obtained from equation (5.20) using the second law method. The results are repeated from Table 5.12 except that in Table 5.15 the reaction is written as the reverse reaction given in Table 5.12. The results for the third reaction in Table 5.15 give the difference in the partial molal enthalpy and entropy of titanium in a stoichiometric titanium monoxide solid solution and the corresponding molal enthalpy and entropy of pure, beta phase, titanium metal.

The enthalpy and entropy changes for reaction (1) in Table 5.16 were obtained from the slope and intercept of equation (5.27). The reciprocal of the pressure of oxygen given by equation (5.27) was taken equal to the equilibrium constant for reaction (1). Taking the equilibrium constant equal to the reciprocal pressure assumes oxygen gas behaves ideally and also the standard state of oxygen in a titanium monoxide solid solution is taken as oxygen in a solution of stoichiometric composition. As usual the effect of total external pressure on condensed phases was ignored. The standard state for oxygen gas was the conventional one, i.e., the hypothetical ideal gas state at 1 atm. The results for reaction (3) in Table 5.16 were obtained from reactions (1) and (2) in the same table. The results for the third reac- 
tion in Table 5.16 give the difference in the partial molal enthalpy and entropy of oxygen in a stoichiometric titanium monoxide solid solution and the corresponding molal enthalpy and entropy of ideal, diatomic oxygen gas at $1 \mathrm{~atm}$.

Partial molal enthalpies and entropies of titanium and oxygen are related to the integral enthalpy, $\Delta H$, and entropy, $\Delta S$, of formation of 1 mole of solid solution in equations $(5.28),(5.29)$, and (5.30).

$$
\begin{aligned}
& 2 / 3 \mathrm{Ti}(\mathrm{s})+1 / 3 \mathrm{O}_{2}(\mathrm{~g}, 1 \mathrm{~atm})=2 / 3 \mathrm{Ti}\left(\mathrm{O}_{2}\right)_{\frac{1}{2}} \\
& \begin{aligned}
\Delta \mathrm{H} & =\mathrm{X}_{\mathrm{Ti}} \Delta \overline{\mathrm{H}}_{\mathrm{Ti}}+\mathrm{X}_{\mathrm{O}_{2}} \Delta \overline{\mathrm{H}}_{\mathrm{O}_{2}} \\
& =2 / 3(-7.3 \pm 3.4)+1 / 3(-229.4 \pm 9.8) \\
& =-81.3 \pm 4.0 \mathrm{kcal} \\
\Delta \mathrm{S} & =\mathrm{X}_{\mathrm{Ti}} \Delta \overline{\mathrm{S}}_{\mathrm{Ti}}+\mathrm{X}_{\mathrm{O}_{2}} \Delta \overline{\mathrm{S}}_{\mathrm{O}_{2}} \\
& =2 / 3(0.021 \pm 1.8)+1 / 3(-36.2 \pm 5.4) \\
& =-12.0 \pm 2.2 \mathrm{e} . \mathrm{u} .
\end{aligned}
\end{aligned}
$$

The "barred" quantities in equations (5.29) and (5.30) were obtained from reaction (3) in Tables 5.15 and 5.16. The standard enthalpy and entropy of formation of 1 mole of titanium monoxide are obtained by multiplying the enthalpy and entropy of formation of 1 mole of solid solution by $3 / 2$. The results are $\Delta H_{1808, f}=-122.0 \pm 6.0 \mathrm{kcal}$ and $\Delta S_{1808, f}^{\circ}=-18.0^{ \pm}$ 3. 3e.u.

\section{(e) Sample Composition}

The thermodynamic properties reported for titanium monoxide from experiment RS-MS-TiO-Y were for "nearly" stoichiometric material. As indicated by reactions (5.22) and 
(5.23) titanium monoxide vaporizes incongruently and therefore any experiment involving the vaporization of a finite amount of material will result in a change in sample composition. The purpose of this discussion is to estimate the change in sample composition occurring in experiment RS-MSTiO-Y.

A temperature profile of experiment RS-MS-TiO-Y is given in Figure 5.12, page 130. The spike at an elapsed time of 20 minutes was caused by a failure in the electron bombardment control circuit. The width of the spike was estimated to be 35.5 seconds from the intensity of $\mathrm{Ti}^{+}(48)$ on the strip chart recorder. The height of the spike was taken to be $2023^{ \pm} 30^{\circ} \mathrm{K}$ from the melting point of titanium monoxide (13). The actual height of the spike was not measured but the melting point was chosen since there was evidence the sample may have partially but not completely melted.

From the temperature profile given in Figure 5.12, the initial mass and composition of the sample, the pressures of $\mathrm{Ti}(\mathrm{g})$ and $\mathrm{TiO}(\mathrm{g})$ given by equations (5.20) and (5.21), and the Knudsen equation (4.19), the final composition of the residue is calculated to be $\mathrm{TiO}_{1.001}$. The initial composition was taken as $\mathrm{TiO}_{0.997 \pm 0.004}$ from Wheatley's combustion (7) and the initial mass was measured to be $99.08 \mathrm{mg}$. The calculated weight loss of the cell is $388 \mu \mathrm{g}$.

\section{(f) Residue}

The residue had the typical golden-brown color char- 


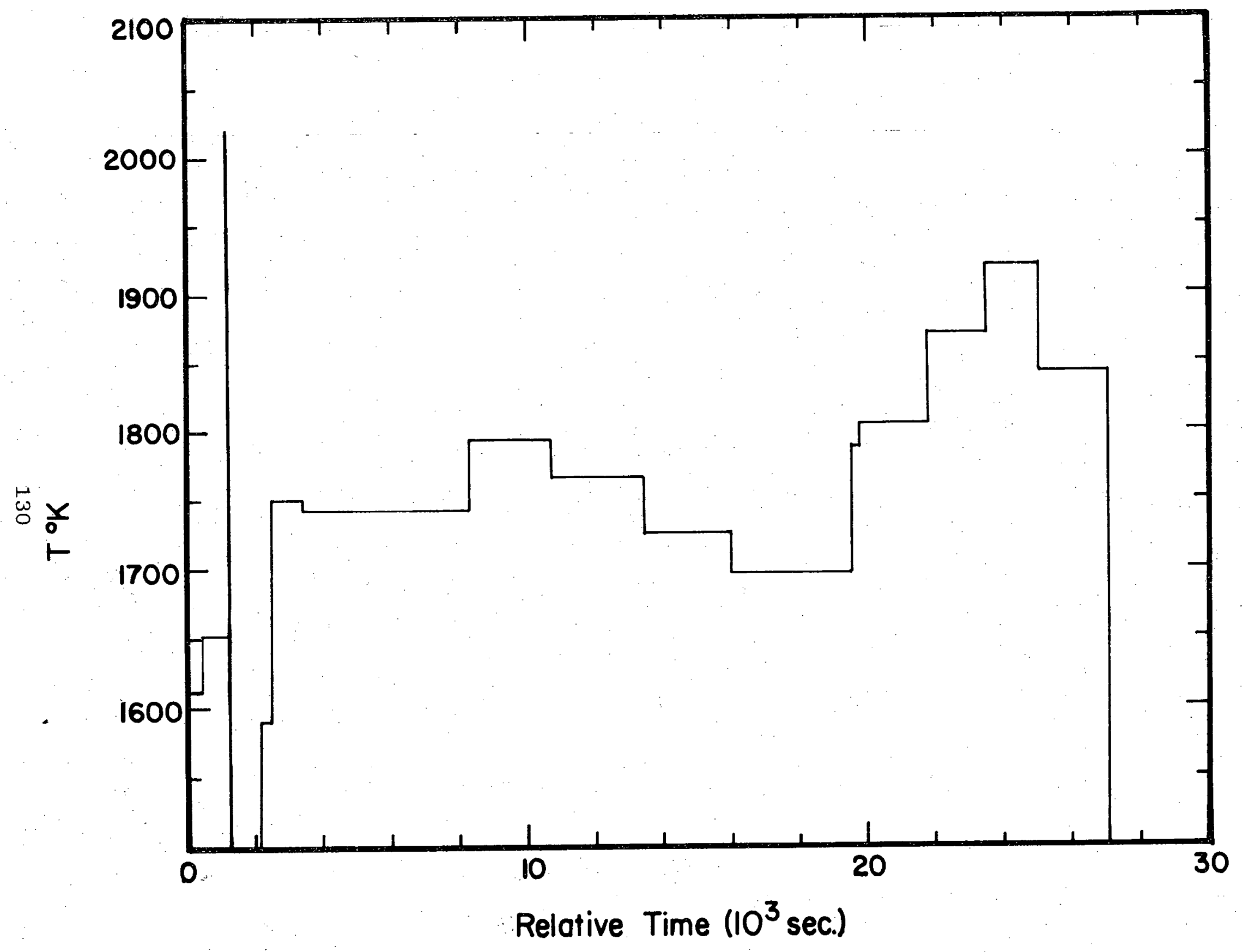

FIG. 5.12 TEMPERATURE PROFILE-Expt. RS-MS-TIO-Y 
acteristic of titanium monoxide. There was no visual evidence of condensation of material on the cell walls, lid, or orifice. It appeared the sample had partially melted around the edges. The measured weight loss of the cell was $640 \pm$ $100 \mu \mathrm{g}$. 
CHAPTER 6

DISCUSSION

The Knudsen effusion-collection experiments, RS-TiO1 and RS-TiO-2, and mass spectrometer experiments RS-MS-TiO$\mathrm{X}$ and RS-MS-TiO-Y, are discussed. The thermodynamic results obtained from the vaporization of titanium monoxide in this work are compared with published thermodynamic data and certain discrepancies are discussed. Finally, possible future studies extending this work are noted.

\subsection{Titanium Analysis}

The colorimetric analysis of titanium used in the Knudsen effusion-collection experiments worked quite satisfactorily. No problems were encountered with the operation of the Beckman DU Spectrophotometer.

As described in section 3.6.4 one motivation for experiment RS-TiO-1 was to check for interfering substances in the titanium analysis. Because this experiment was conducted with an empty crucible it provided no check for interfering substances which might arise from the sample itself. One such interfering substance is iron. In section 5.4 .2 $\mathrm{Fe}^{+}(56)$ was reported as a possible temperature dependent ion most probably originating as an impurity in the sample. From Figure 5.9 it was deduced that the iron was rapidly distilling out of the sample because its intensity decreased 
with time. If the iron was indeed originating from the TiO1 sample it should have been observed in both mass spectrometric experiments, RS-MS-TiO-X and RS-MS-TiO-Y. A check of the mass spectrometer charts from experiment RS-MS-TiO-X did reveal the signal at mass 56 increased relative to the neighboring peaks at 55 and 57 as the temperature was increased from room temperature to $1806^{\circ} \mathrm{K}$. During the course of RS-MSTiO-X the signal at mass 56 continually decreased relative to the neighboring background peaks. Both of these observations are consistent with iron rapidly distilling from the sample. It was observed that the temperature dependent species at mass 56 was resolved from the hydrocarbon background in $\mathrm{RS}-\mathrm{MS}-\mathrm{TiO}-\mathrm{Y}$ but not resolved in $\mathrm{RS}-\mathrm{MS}-\mathrm{TiO}-\mathrm{X}$. No explanation for this anamolous behavior is known because the resolution of the mass spectrometer was not changed between the two experiments.

If iron distilled out of the sample as indicated in the mass spectrometer experiments it would presumably be collected on the quartz cap surrounding the crucible in the Knudsen effusion-collection experiment, RS-TiO-2. Because of its yellow color in solution the iron could interfere with the colorimetric analysis of titanium. It is of importance to estimate the extent of the interference.

Two pieces of information are needed to decide on the extent of the interference of iron. First, the amount of iron deposited on the cap must be estimated. As a worst 
possible case it will be assumed that all the iron in the sample was vaporized and deposited on the cap. The amount of iron in the sample is estimated from wheatley's thesis to be less than $0.01 \%$ by weight ( 7 ). This estimate is based on a spectrochemical analysis on a portion of the titanium monoxide sample submitted to the University of California Radiation Laboratory. Based on this analysis the maximum amount of iron in the $10.24 \mathrm{mg}$ sample used in RS-TiO-2 was $102 \mu \mathrm{g}$.

The second piece of information needed is the effect of this amount of iron on the analysis. The effect of foreign substances on the titanium analysis has been reported by Sandell (39). From his results an $\mathrm{Fe}^{+3}$ concentration of $1000 \mu \mathrm{g} / \mathrm{ml}$ is equivalent to an apparent titanium concentration of $3.2 \mu \mathrm{g} / \mathrm{ml}$. If $102 \mu \mathrm{g}$ of iron was collected on the cap, the concentration of iron in the colorimetric analysis would be $4.08 \mu \mathrm{g} / \mathrm{ml}$. On the basis of Sandell's result this would correspond to an apparent titanium concentration of $0.013 \mu \mathrm{g} / \mathrm{ml}$ or an apparent amount of titanium of only 0.326 ug. This amount is insignificant compared to the total amount of titanium measured. Even ten times this amount is less than $1 \%$ of the total titanium measured. 6.2 X-ray Results on TiO-1 and Residues

The X-ray diffraction results obtained in this work and also by Gilles, et. al.,. (50) indicate the titanium mon- 
oxide sample, laboratory designation TiO-1, obtained from the U.S. Bureau of Mines consists of a two-phase mixture. The results indicate the mixture is about one-third high temperature TiO and two-thirds low temperature TiO. Heat capacity measurements (21) and heat of combustion measurements (20) made on these samples must be regarded as characteristic of this mixture. The somewhat low enthalpy of transition of only $0.82 \mathrm{kcal}$ found at $1264^{\circ} \mathrm{K}$ by Naylor (22), probably arises because the sample was a mixture. The suggestion of Kleppa (30) that the heat of combustion measurements of the Bureau of Mines (20) were made on material consisting largely of high temperature TiO now seems, unlikely.

The X-ray diffraction results for the residues from experiments RS-TiO-2, RS-MS-TiO-X, and RS-MS-TiO-Y indicate a partial reversion to the low temperature form of Tio on cooling after the sample had been hot. Only a small amount of the low temperature form was present in the residues from the first two experiments but roughly one-third of the residue from RS-MS-TiO-Y consisted of the low temperature phase. Possibly the conversion was more nearly complete in RS-MSTiO-Y because of slower cooling due to the larger mass of sample; possibly because the sample was more nearly stoichiometric. Ten times as much sample was used in RS-MS-TiO-Y as in experiments RS-TiO-2 and RS-MS-TiO-X. Presumably the high temperature form can be isolated by quenching (54). 


\subsection{Knudsen Vapor Pressure Measurements}

\subsubsection{Performance of Equipment}

Two problems were encountered with the induction generator during experiments RS-TiO-1 and RS-TiO-2. The first problem was poor temperature stability and was present in both experiments. Because RS-TiO-1 was a blank run, temperature stability for this experiment was not critical. The instability arose from two sources. These were spikes in the line voltage supplying the induction heater caused by a large elevator motor located in the building and a poor contact on one of three vacuum tube rectifiers in the induction generator. These problems prevented the feedback control circuit on the induction heater from being used to maximum efficiency as described in section 3.6.2. The temperature of the crucible in RS-TiO-2 was maintained constant within about $10^{\circ} \mathrm{K}$ at $1806^{\circ} \mathrm{K}$. As described in section 4.3 the average temperature is an appropriate temperature to report for RS-TiO-2 and the temperature instability in this case is not deemed important.

The second problem encountered in RS-TiO-2 was the failure of a cooling blower for the induction generator. Heating was interrupted twice during RS-TiO-2, once for repair of the cooling fan and again for an unsuccessful attempt to repair the rectifier contact.

\section{3 .2 RS-TiO-1}

Experiment RS-TiO-1 consisted of heating empty cru- 
cible \#4 in the Knudsen effusion-collection apparatus. Following the heating the quartz cap which surrounded the cell was run through the titanium analysis. The experiment served as a check for possible interfering substances in the titanium analysis. The experiment was deemed necessary because Wahlbeck experienced some minor difficulties with the same colorimetric analysis for titanium from contamination of vacuum grease used on the glass joints of the vacuum system (55). Apparently the grease caused a yellow color to develop at the dissolution stage prior to adding the peroxide. Wahlbeck solved the problem by reducing the amount of grease. The experiment also served as a check on possible contamination arising from the crucible.

As described in section 5.3.1 the apparent amount of titanium of $4.5 \pm 1.5 \mu \mathrm{g}$ found in $\mathrm{RS}-\mathrm{TiO}-1$ is less than $1 \%$ of the titanium found in RS-TiO-2. This amount is considered negligible.

It was noted in section 5.3.1 that a blank solution in both cells gave an apparent amount of titanium of $3.0 \pm 1.5$ $\mu \mathrm{g}$. The reason for this is not clear but possibly one of the cells was dirty. Figure 5.1 indicates the calibration curve passes through the origin within the uncertainty of the least squares results, i.e., the cells were matched at the time the calibration curve was prepared.

\section{3 .3 RS-TiO-2}

Experiment RS-TiO-2 involved the vaporization of a 
nearly stoichiometric sample of titanium monoxide from a tungsten cell at constant temperature. The vapor was condensed on a quartz cap surrounding the cell and sublimate analyzed for titanium.

(a) Comparison with Wheatley.

Experiment RS-TiO-2 was similar in many respects to vaporization experiments performed by wheatley in his study of the dissociation energy of $\mathrm{TiO}(\mathrm{g})$ (7). Wheatley's titanium monoxide samples were taken from a larger sample of material prepared at the U.S. Bureau of Mines. A portion of one of the same samples, TiO-1, used by Wheatley was used in the present work. Wheatley vaporized the titanium monoxide from a Mo crucible and collected the vapor on either Pt or quartz targets. The targets were analyzed for titanium colorimetrically and weight-loss measurements were also made on the crucible. Wheatley incorrectly concluded that TiO(s) vaporized congruently to give TiO(g). He calculated pressures of $\mathrm{TiO}(\mathrm{g})$ for his weight-loss and target collection results on the assumption TiO(g) was the only vapor species. Wheatley's results are compared with the present work in Figure 6.1, page 139. Consider first the collector data. Wheatley calculated pressures of TiO(g) at temperatures ranging from $1845^{\circ} \mathrm{K}$ to $2016^{\circ} \mathrm{K}$ based on the colorimetric analysis of titanium collected on Pt and quartz targets. A line has been drawn through Wheatley's collector data in Figure 6.1 using the method of least squares. In section 


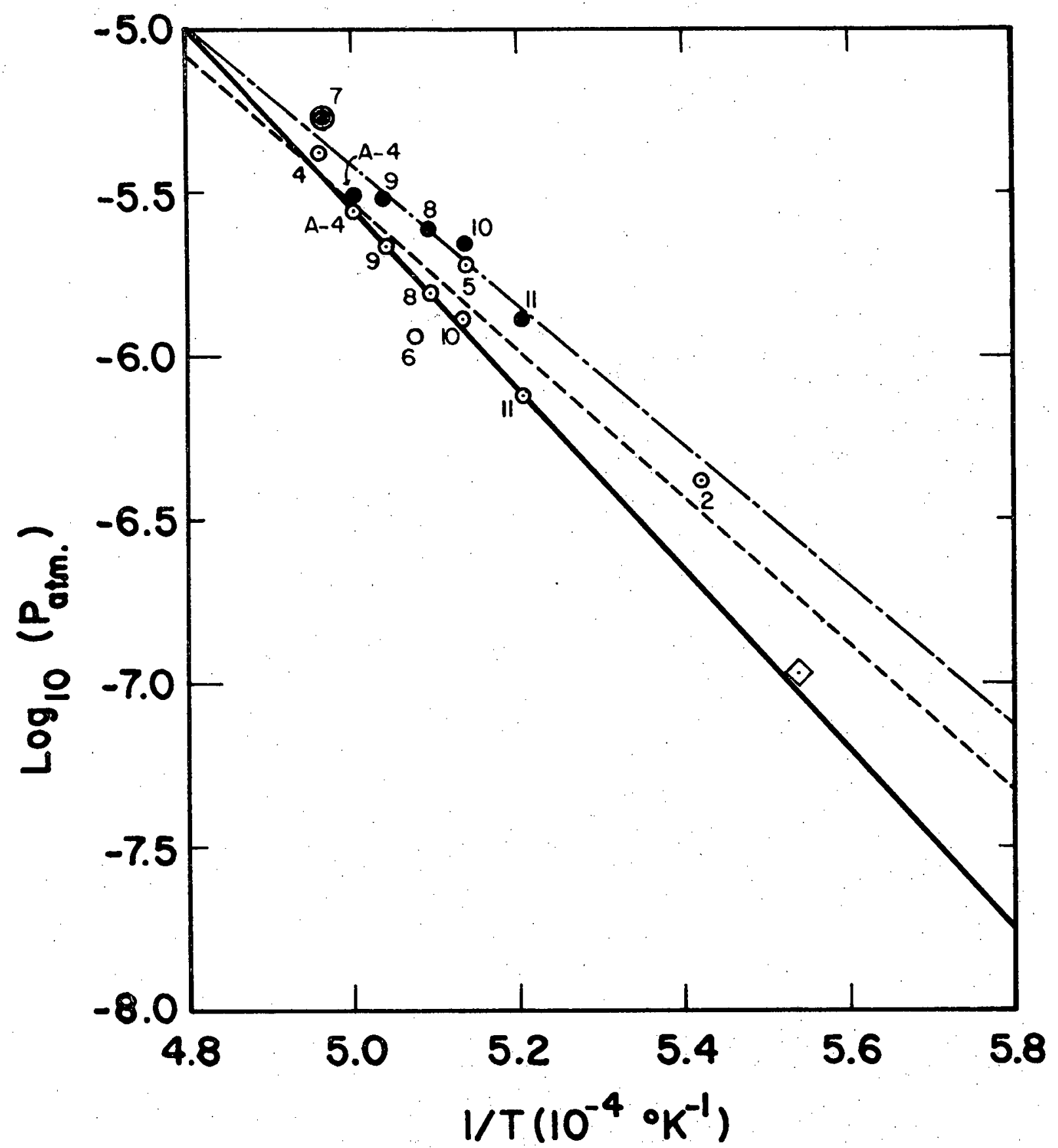

Fig. 6.1

PLOT OF LOG $\left(P_{\text {aim }}\right)$ VERSUS $\mathrm{VT}$. Wheatley weight-loss $\odot$, Wheatley collector $\bullet$,This work $\diamond$. Least squares lines: Wheatley weight-loss-----, Wheatley collector _- Wheatley best points _- 
5.3.2 of this thesis a pressure, $\mathrm{P}_{\mathrm{E}}$, was calculated from the amount of titanium collected in a vaporization of titanium monoxide at $1806^{\circ} \mathrm{K}$. The amount of titanium was measured colorimetrically and the pressure calculated on the assumption the vapor was entirely $\mathrm{TiO}(\mathrm{g})$ just as was done in Wheatley's work. Reference to the least squares line through Wheatley's collector data shows a pressure higher than indicated by this work by a factor of about 2.4. The uncertainty in the logarithm of the pressure calculated from the least squares line is \pm 0.156 at $1806^{\circ} \mathrm{K}$. The higher pressure indicated by the least squares line is not surprising because, as Wheatley points out, his collector data are probably high for two reasons. First, except for runs labeled 11 and $\mathrm{A}-4$, the colorimetric results are high by an indeterminate amount because of an improperly prepared blank solution in the colorimetric analysis. Second, collector results are high because some of the effusate from the Knudsen cell that condensed on radiation shielding revaporized on to the collector target. Wheatley estimated that $11 \%$ to $16 \%$ of the total titanium collected during a vapor pressure run could be accounted for by material revaporized from the shields. This estimate was made by heating an empty cell and subsequently analyzing the target for titanium. Wheatley notes that this method will give only a lower limit to the actual error from revaporization because in a vapor pressure run material is being deposited on the shields con- 
tinuously, thus replacing some of the material that vaporizes. Run A-4, done with the shields removed, also confirms the revaporization hypothesis. Wheatley also points out that the condensation coefficient of the vapor on hot molybdenmum shields may be far from unity. This possibility means an estimate of the revaporization using an empty cell will give a low result.

The easiest method of comparing the present work with Wheatley's weight-loss data is to first calculate an expected weight-loss for RS-TiO-2. In section 5.4.1 the mass of titanium and titanium monoxide vaporized during RSTiO-2 were calculated to be $\left(4.28^{ \pm 0.60)} \times 10^{-4} \mathrm{~g}\right.$ and $\left(1.42^{ \pm}\right.$ $0.80) \times 10^{-4} \mathrm{~g}$ respectively. The large uncertainty in these numbers arose mainly from the large uncertainty assigned to the ionization cross section for $\mathrm{Ti}(\mathrm{g})$ and $\mathrm{TiO}(\mathrm{g})$. On the basis of these numbers a weight-loss of $(5.70 \pm 1.00) \times 10^{-4} \mathrm{~g}$ would be expected for RS-TiO-2. Using this calculated weightloss, a pressure of $\mathrm{TiO}(\mathrm{g})$ at $1806^{\circ} \mathrm{K}$ may be calculated from the Knudsen effusion equation and the assumption that the weight-loss is entirely from the vaporization of $\mathrm{TiO}(\mathrm{g})$ just as was done by Wheatley. The calculated pressure of TiO(g) is $(8.74 \pm 1.53) \times 10^{-8}$ atm and the common logarithm of this number is $-7.06 \pm 0.08$. This last result is lower than that predicted at $1806^{\circ} \mathrm{K}$ from the least squares line drawn through Wheatley's weight-loss data. Wheatley states that weightloss data obtained early in the work were considered unreli- 
able relative to later results for a number of reasons. Specifically, runs 2,4 , and 7 were believed to yield high weight-losses because samples had not been degassed at high temperature prior to use. Run 6 was thought to be low because the sample had nearly been exhausted. Wheatley selected the weight-loss data from runs $8,9,10,11$, and $A-4$ as the best data from which he determined a heat of sublimation of TiO(s). The least squares line through these "best runs" in Figure 6.1 is seen to be in excellent agreement with the value $-7.06 \pm 0.08$ for the logarithm of the pressure calculated as described above from this work.

By way of summary, comparison of this work with Wheatley's "best runs" indicates excellent consistency between his work and this work. Wheatley's conclusion that his collector data indicate too large an amount of titanium because of revaporization from the shields and an improperly prepared blank solution in the colorimetric analysis seems to be consistent with this work.

Experiment RS-TiO-2 is considered more reliable than Wheatley's vaporization experiments for several reasons. The blank solution was properly prepared in the titanium analysis in RS-TiO-2. No shields were used around the crucible in RS-TiO-2 thus eliminating the problem of revaporization. In experiment RS-TiO-2 the total vapor effusing from the crucible was collected on a water cooled quartz cap. This procedure has two distinct advantages over the target 
method used by Wheatley. First, the necessity of calculating the fraction of the total vapor collected on the target from the geometry of the apparatus is avoided. Second, the total collection technique is more sensitive than the target method. This last feature is especially important for incongruently vaporizing samples where the amount of material vaporized should be kept to a minimum if significant change in sample composition is to be avoided.

\section{(b) Total Titanium}

It is of interest to compare the amount of titanium found in RS-TiO-2 with the amount expected from published thermodynamic data. The titanium is transported in the vapor as $\mathrm{TiO}(\mathrm{g})$ and $\mathrm{Ti}(\mathrm{g})$. The pressure of $\mathrm{TiO}(\mathrm{g})$ may be calculated from the standard free energies of formation of gas and stoichiometric solid monoxide. At $1806^{\circ} \mathrm{K}$ the JANAF tables give these as $\Delta \mathrm{F}_{1806, f}^{\circ}[\mathrm{TiO}(\mathrm{g})]=-26.016 \pm 2.0 \mathrm{kcal}$ and $\Delta \mathrm{F}_{1806, f}^{\circ}[\mathrm{TiO}(\beta)]=-89.775^{ \pm 3} .1 \mathrm{kcal}$ (13). The calculated pressure of TiO(g) is $1.92 \times 10^{-8}$ atm. The calculated pressure is estimated to be uncertain by a factor of 2.8 based on the uncertainties in the tabulated thermodynamic data.

The pressure of $\mathrm{Ti}(\mathrm{g})$, the second important titanium bearing vapor species in equilibrium with stoichiometric titanium monoxide, may be calculated from the equilibrium (6.1).

$$
\mathrm{TiO}(\mathrm{B})=\mathrm{Ti}(\mathrm{g})+1 / 20_{2}(\mathrm{~g})
$$

The equilibrium constant at $1806^{\circ} \mathrm{K}$ is calculated from the standard free energy of formation of $\mathrm{TiO}(\beta)$ given previously 
and the standard free energy of formation of titanium gas, $\Delta \mathrm{F}_{1806, \mathrm{f}}[\mathrm{Ti}(\mathrm{g})]=51.520 \pm 1.0 \mathrm{kcal}$ (31). The standard free energy of formation of oxygen is zero. The pressure of oxygen in equilibrium with stoichiometric titanium monoxide at $1806^{\circ} \mathrm{K}$ is interpolated graphically from the emf work of Suzuki and Sambongi (25). The result is $\mathrm{P}_{\mathrm{O}_{2}}=6 \times 10^{-19} \mathrm{~atm}$. The uncertainty in this result is difficult to estimate from the emf work. Suzuki and Sambongi give their emf and thermodynamic data in graphical form only with no explanation of how the lines in their figures were drawn among the data points. Also inconsistencies exist among their figures and equations as noted by Cater $(27,56)$. From the above results the titanium pressure in equilibrium with stoichiometric titanium monoxide is calculated to be $1.02 \times 10^{-8}$ atm at $1806^{\circ} \mathrm{K}$.

The mass of total titanium expected in RS-TiO-2 based on the pressures of $\mathrm{TiO}(\mathrm{g})$ and $\mathrm{Ti}(\mathrm{g})$ given in the preceding paragraphs is calculated from the Knudsen equation (4.19) and experimental parameters given in section 5.3.2 to be $151 \mu \mathrm{g}$. This predicted result is in poor agreement with the $534.5 \pm 2.0 \mu \mathrm{g}$ of titanium measured in RS-TiO-2. Although the uncertainty in the predicted amount of titanium is unknown due to the unknown uncertainty in the oxygen potential noted above, any reasonable estimate of the uncertainty based on random errors is much less than the discrepancy between the measured and predicted amounts of titanium. Even 
if the oxygen pressure given by the emf work was lowered by a factor of 10 the predicted amount of titanium would be only $277 \mu \mathrm{g}$, still far short of the measured amount. It might also be noted that the measured mass loss of the crucible in RS-TiO-2 of $490 \pm 70 \mu \mathrm{g}$ is inconsistent with the predicted amount of titanium of $151 \mu \mathrm{g}$ regardless of the proportion of $\mathrm{Ti}(\mathrm{g})$ and $\mathrm{TiO}(\mathrm{g})$ in the vapor.

The explanation of this discrepancy between the predicted and measured amount of titanium found in RS-TiO-2 must lie within the published thermodynamics of solid or gaseous titanium monoxide, the published thermodynamics of titanium gas, the oxygen potential of Suzuki and Sambongi, experiment RS-TiO-2, or some combination of these. These possibilities will be discussed more completely later in this section of this thesis.

\subsection{Mass Spectrometer Measurements}

\subsubsection{Performance of Equipment}

The mass spectrometer and data acquisition system performed well except for one problem. This problem was the occasional lack of control of the electron bombardment heating of the. Knudsen cell. As described in the experimental section of this thesis the control problem resulted in the sample being at an undetermined high temperature for a few seconds in RS-MS-TiO-X and for 35.5 seconds in RS-MS-TiO-Y. The melting temperature, $2023 \pm 30^{\circ} \mathrm{K}$ (13), of titanium monoxide is taken as an upper limit of the temperature ex- 
cursion in experiment RS-MS-TiO-X because visual inspection of the residue indicated no sign of melting. Visual inspection of the residue from RS-MS-TiO-Y indicated the sample may have partially melted; hence the melting temperature of titanium monoxide is considered a reasonable estimate of the maximum temperature reached in the temperature excursion encountered in this experiment.

The problem of these temperature excursions is more serious for an incongruently vaporizing material such as titanium monoxide than for a congruently vaporizing one. The vapor pressure increases roughly in an exponential manner with temperature. During a temperature excursion a relatively large amount of sample may be vaporized and for an incongruently vaporizing sample a large composition change may result. It is estmated that of the $388 \mu \mathrm{g}$ of material calculated to have vaporized in RS-MS-TiO-Y about $4 \%$ was lost during the 35.5 second temperature excursion. The measured weight-loss of the cell of $640 \pm 100 \mu \mathrm{g}$ is higher than the calculated value but large uncertainties exist in both numbers. The calculated weight-loss depends on a knowledge of the temperature and vapor pressures during the temperature excursion. Both of these quantities were only roughly estimated. As noted above the temperature was estimated from the melting point and the pressures were estimated from an extrapolation of the least squares results in equations (5.20) and (5.21) to the melting point. Weighing of the ti- 
tanium monoxide, sample TiO-1, was difficult because the sample was an extremely fine, hygroscopic powder. In any case, the measured weight-loss represents only. $0.6 \%$ of the initial sample mass and the final composition of the residue could not be too much different than $\mathrm{TiO}_{1.001}$ as calculated in section 5.4 .2 .

The temperature excursion encountered in RS-MS-TiO$X$ is potentially more serious than for RS-MS-TiO-Y with regard to changing sample composition because the amount of sample used in RS-MS-TiO-X was about ten times less than used in RS-MS-TiO-Y. However, the length of time of the temperature excursion was less than 5 seconds in experiment RS-MS-TiO-X compared to 35.5 seconds in RS-MS-TiO-Y. Also the maximum temperature reached was probably less in RS-MSTiO-X because there was no indication of melting as there was in RS-MS-TiO-Y. Based on these facts the amount of material vaporized during the temperature excursion in RS-MSTiO-X is believed to be less than $3 \mu \mathrm{g}$, a negligible amount.

One anomaly exists in the measured weight-loss of $2.3 \pm 0.1 \mathrm{mg}$ in experiment $\mathrm{RS}-\mathrm{MS}-\mathrm{TiO}-\mathrm{X}$. The reason for this apparent large weight-loss is unclear. It seems unlikely this much material could have been vaporized during the temperature excursion. The large weight-loss is inconsistent with the calculated weight-loss based on the volitility of TiO(s) and is inconsistent with the measured weight-loss found in experiments RS-TiO-2 and RS-MS-TiO-Y: Most likely 
the problem arises from a weighing error.

6.4 .2 RS-MS-TiO-X

(a) Intensity Ratio, $\mathrm{I}_{\mathrm{TiO}}^{+} / \mathrm{I}_{\mathrm{T} i}^{+}$

In a constant temperature experiment such as RS-MSTiO-X the intensity ratio, I $\left.\right|_{i O} / \mathrm{I}_{\mathrm{T}}^{+}$, is proportional to the atomic oxygen potential in the system. Intensity ratios measured at several electron energies for experiment RS-MSTiO-X were presented in Figure 5.2. As noted previously, the increase in the ratio with time is entirely consistent with the incongruent nature of the vaporization. As vaporization proceeds the sample becomes more oxygen rich and the oxygen potential increases as indicated by the intensity ratio.

The results of Figure 5.2 indicate the oxygen potential increased by a factor of 1.4 during the first 12 hours of RS-MS-TiO-X. It was estimated in section 5.4.1 that the sample composition changed from $\mathrm{TiO}_{0.997 \pm 0.004}$ to $\mathrm{TiO}_{1.06} \pm$ 0.02 during the first 12 hours of RS-MS-TiO-X.

The dependence of the ion ratio on electron energy cannot be explained by the fragmentation of $\mathrm{TiO}\left(\mathrm{g}^{\prime}\right)$ to form $\mathrm{Ti}^{+}$. If fragmentation becomes more important at higher electron energies the ratio should decrease, not increase, with increasing electron energy. The dependence of the ion ratio on electron energy is thought to be due to the relative shapes of the ionization efficiency curves rather than fragmentation phenomena. 
It is of interest to compare the value of the intensity ratio, $\mathrm{I}_{\mathrm{T} i \mathrm{O}}^{+} / \mathrm{I}_{\mathrm{T} i}^{+}$, measured in RS-MS-TiO-X with the value predicted from the published thermodynamic data. The pressure ratio, $\mathrm{P}_{\mathrm{TiO}} / \mathrm{P}_{\mathrm{Ti}}$, may be calculated from the equilibrium (6.2) and the oxygen potential.

$$
\mathrm{TiO}(\mathrm{g})=\mathrm{Ti}(\mathrm{g})+1 / 2 \mathrm{O}_{2}(\mathrm{~g})
$$

The equilibrium constant may be calculated from published. standard free energies of formation of $\mathrm{TiO}(\mathrm{g})$ and $\mathrm{Ti}(\mathrm{g})$. These are taken as $-26.016 \pm 2.0 \mathrm{kcal}$ and $51.520 \pm 1.0 \mathrm{kcal} \mathrm{re}-$ spectively at $1806^{\circ} \mathrm{K}(13,31)$. The oxygen potential is obtained from the emf work of Suzuki and Sambongi (25). The result obtained by graphical interpolation to a temperature of $1806^{\circ} \mathrm{K}$ is $\mathrm{P}_{2}=6 \times 10^{-19} \mathrm{~atm}$. From the above published results a pressure ratio is calculated to be $\mathrm{P}_{\mathrm{TiO}} / \mathrm{P}_{\mathrm{Ti}}=1.87$ at $1806^{\circ} \mathrm{K}$ over stoichiometric titanium monoxide. From equation (5.6) and ionization cross sections for $\mathrm{TiO}(\mathrm{g})$ and $\mathrm{Ti}(\mathrm{g})$ of 9.94 and 8.67 given previously an intensity ratio may be calculated. The result is $\mathrm{I}_{\mathrm{TiO}}^{+} / \mathrm{I}_{\mathrm{Ti}}^{+}=2.15$. The uncertainty in this number is not known for two reasons. First, the uncertainty in the ionization cross sections is unknown. In section 5.4.1 the uncertainty in the cross sections was given as $50 \%$ but this assignment was entirely arbitrary. Second, the uncertainty in the oxygen potential is difficult to estimate as previously noted.

The ion intensity ratio, $\mathrm{I}_{\mathrm{TiO}}^{+} / \mathrm{I}_{\mathrm{Ti}}^{+}$, obtained from Table 5.7 based on the least squares line calculated for all 
points regardless of the electron energy of the measurement at an elapsed time of 360 minutes is $0.329 \pm 0.011$. The agreement of the observed and predicted intensity ratio is poor. Even the highest ratio measured near the end of RS-MS-TiO-X is smaller than the predicted ratio by nearly a factor of five. If the cross section ratio, $\sigma_{\mathrm{T} i O} / \sigma_{\mathrm{T} i}$, was reduced by a factor of 6.5 the measured intensity ratio could be brought into line with the predicted ratio. Similarly if the oxygen pressure were lowered by a factor of 42.6 the predicted and measured ratio would agree. Agreement could be obtained if the difference in standard free energy of $\mathrm{Ti}(\mathrm{g})$ and $\mathrm{TiO}(\mathrm{g})$ were made smaller by $6.73 \mathrm{kcal}$. A further discussion of these possiblities will follow later in this chapter.

In an early mass spectrometric study of the vaporization of TiO(s) Berkowitz, Chupka, and Inghram observed approximately equal ion intensities for $\mathrm{Ti}^{+}$and $\mathrm{TiO}^{+}$with no detectable Tiof (5). Their sample consisted of equimolar. quantities of $\mathrm{Ti}$ and $\mathrm{TiO}_{2}$. Silver was included to calibrate the mass spectrometer. The crucible was molybdenum. Their ion ratio (approximately unity) was lower than the predicted ratio of 2.15 but higher than the ratio of 0.329 found in this work.

(b) Thermodynamics

(1) Vapor Pressures

As indicated by reactions $(5.22)$ and (5.23) two va- 
por species, $\mathrm{Ti}(\mathrm{g})$ and $\mathrm{TiO}(\mathrm{g})$, are important in the vaporization of stoichiometric titanium monoxide. A determination of the vapor pressures of these two species requires that two independent measurements be made. In this work the two measurements consisted of the colorimetric analysis of the total titanium vaporized in experiment RS-TiO-2 and a mass spectrometric measurement of the vapor composition in RS-MSTiO-X. As noted previously, the experimental conditions in RS-TiO-2 and RS-MS-TiO-X were chosen to match as closely as possible with regard to sample, sample mass, crucible, orifice, temperature, and time of vaporization. This matching was deemed important because of the incongruent vaporization of titanium monoxide. By having matching conditions in both experiments the same change in sample composition should occur in both.

Figure 6.2 , page 152 , is presented to summarize vapor pressure information in the titanium-oxygen system calculated from available thermodynamic data and also from this work for stoichiometric titanium monoxide. The figure is drawn for a temperature of $1806^{\circ} \mathrm{K}$ the same temperature as experiments RS-TiO-2 and RS-MS-TiO-X. The common logarithm of the pressure of $\mathrm{Ti}(\mathrm{g}), \mathrm{TiO}(\mathrm{g}), \mathrm{TiO}_{2}(\mathrm{~g}), \mathrm{O}(\mathrm{g})$, and $\mathrm{O}_{2}(\mathrm{~g})$ is plotted as a function of composition. The curves were calculated from published thermodynamic data. The arrow on the "Ti(g) curve" indicates the pressure of titanium calculated from RS-TiO-2 and RS-MS-TiO-X. No arrow is shown on 


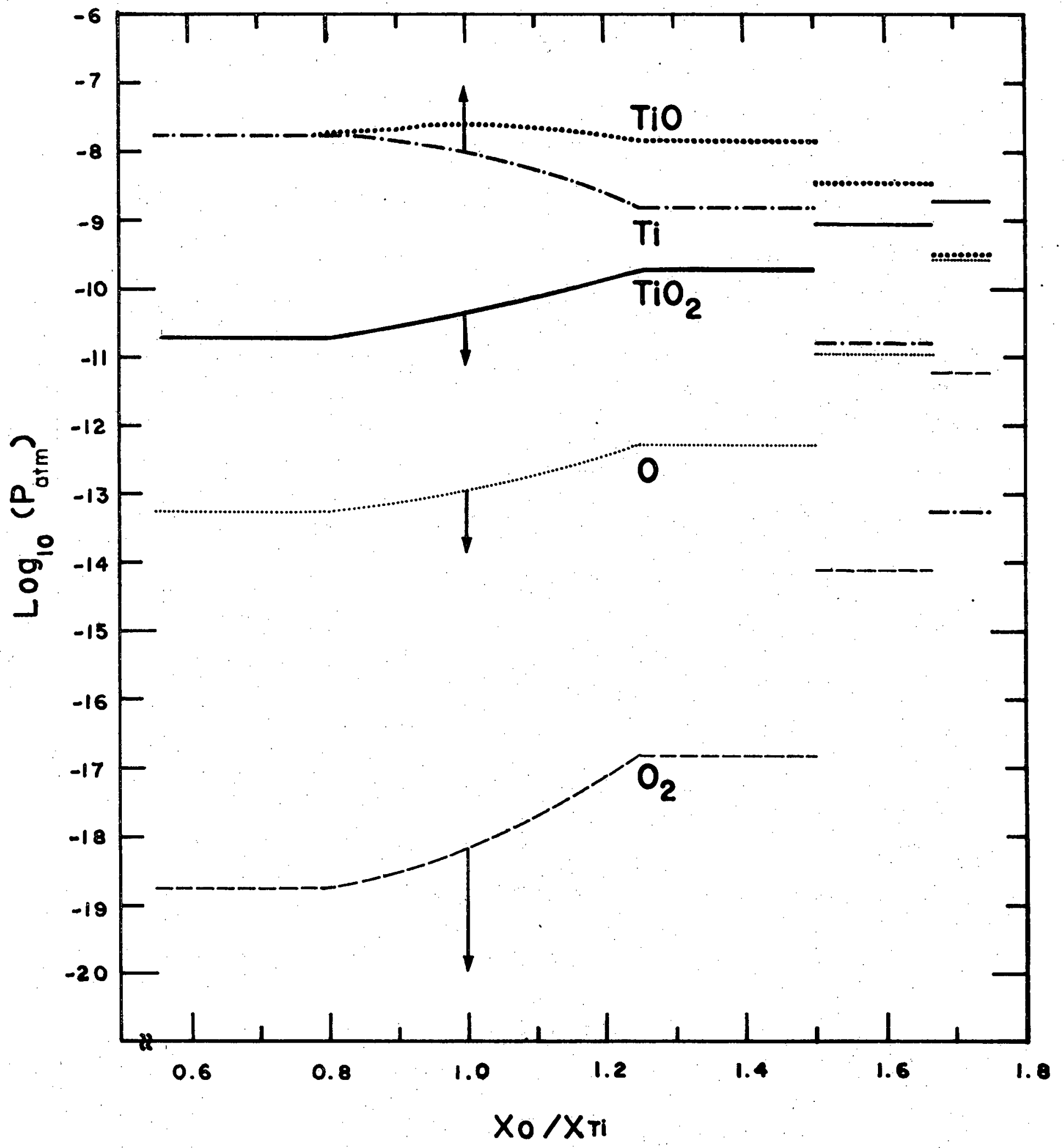

FIG. 6.2

Plot of $\log _{10}\left(P_{\text {atm. }}\right.$ ) versus composition, $X_{0} / X_{T i}$, at $1806^{\circ} \mathrm{K}$. Curves from published data. Arrows indicate results from this work. 
the "TiO(g) curve" because the results based on this work and from published work are indistinguishable in the figure. The arrows on the remaining curves indicate pressures calculated from this work and auxiliary thermodynamic data.

A detailed description of the construction of Figure 6.2 follows. The oxygen potential in the composition range $0.5 \leq 0 / T i \leq 1.5$ was obtained from the emf work of Suzuki and Sambongi by graphical interpolation of their Figure 14 to a temperature of $1806^{\circ} \mathrm{K}$ (25). The phase diagram of Wahlbeck and Gilles indicates the oxygen potential should be invariant over the range $0.5 \leq 0 / \mathrm{T} i \leq 0.8$ because this corresponds to the two phase field $\mathrm{Ti}_{2} \mathrm{O}-\mathrm{TiO}(\beta)$ (1). This same phase diagram indicates a very narrow composition range for the $\mathrm{Ti}_{2} \mathrm{O}_{3}$ phase in contrast with the much wider range of $1.425 \leq \mathrm{O} /$ Ti<1.585 proposed by Suzuki and Sambongi. Cater finds the upper phase boundary of $\mathrm{Ti}_{2} \mathrm{O}_{3}$ is not appreciably different from the stoichiometric composition in his emf study of the $\mathrm{Ti}_{2} \mathrm{O}_{3}-\mathrm{Ti}_{3} \mathrm{O}_{5}$ equilibrium (27). On the basis of the phase diagram of Wahlbeck and Gilles and the arguments given by Cater, $\mathrm{Ti}_{2} \mathrm{O}_{3}$ is shown as a line phase in Figure 6.2. Also, $\mathrm{Ti}_{3} \mathrm{O}_{5}$ is shown as a line phase. Oxygen potentials for compositions where $0 / T i \geq 1.5$ were obtained from the published thermodynamics for the "compounds". (13).

The titanium potential was obtained from the oxygen potential by means of a Gibbs-Duhem integration, equation $(6.3)$. 


$$
\int \mathrm{d} \ln \mathrm{P}_{\mathrm{Ti}}=-\int\left(\mathrm{X}_{\mathrm{O}} / \mathrm{X}_{\mathrm{Ti}}\right) \mathrm{dln} \mathrm{P}_{\mathrm{O}}
$$

In equation (6.3) ${\underline{\mathrm{P}_{\mathrm{T} i}}}_{\text {and }} \mathrm{P}_{\mathrm{O}}$ are the pressures of titanium and oxygen and $\mathrm{X}_{\mathrm{Ti}}$ and $\mathrm{X}_{\mathrm{O}}$ are the mole fractions of titanium and oxygen respectively in the solid solution. A knowledge of the variation of the oxygen potential with composition is sufficient to allow the calculation of the relative variation of the titanium potential over the same composition range from equation (6.3). To obtain the absolute variation of the titanium potential from equation (6.3) the pressure of titanium must be known at one point within the composition range for which the oxygen potential is known. In section 6.3 .3 the titanium pressure at $1806^{\circ} \mathrm{K}$ for the stoichiometric composition was calculated to be $1.02 \times 10^{-8} \mathrm{~atm}$.

The result was based on the work of Suzuki and Sambongi and the standard free energies of formation of $\mathrm{Ti}(\mathrm{g})$ and $\mathrm{TiO}(\beta)$ given in the JANAF tables. Pressures at compositions other than the stoichiometric one were obtained from the above result and equation (6.3). Starting the Gibbs-Duhem integration at the stoichiometric composition rather than at pure metal has the advantage of avoiding the singular behavior of the logarithm of the oxygen pressure at pure metal. This singular behavior makes graphical integration difficult.

The pressures of $\mathrm{TiO}(\mathrm{g})$ and $\mathrm{TiO}_{2}(\mathrm{~g})$ were calculated using equilibria (5.8) and (6.4) and the pressures of titanium and oxygen calculated as described above.

$$
\mathrm{TiO}_{2}(\mathrm{~g})=\mathrm{TiO}(\mathrm{g})+\mathrm{O}(\mathrm{g})
$$


The equilibrium constant for reaction (6.4) was calculated from the JANAF tables. The standard free energies of formation of $\mathrm{TiO}(\mathrm{g})$ and $\mathrm{O}(\mathrm{g})$ were given in section 5.4.1. The standard free energy of formation of $\mathrm{TiO}_{2}(\mathrm{~g})$ is $\Delta \mathrm{F}_{1806, f}=$ $-79.071 \pm 3.5 \mathrm{kcal}(13)$.

The maximum in the $\mathrm{TiO}(\mathrm{g})$ pressure at the stoichiometric composition is understandable from equation (6.5) which was derived from equation (5.24) and the Gibbs-Duhem equation.

$$
\mathrm{d} \log \mathrm{P}_{\mathrm{TiO}} / \mathrm{dx}=(1-\mathrm{x}) \mathrm{d} \log \mathrm{P}_{\mathrm{O}} / \mathrm{dx}
$$

In equation (6.5) $\mathrm{x}$ is the composition variable giving the ratio of the number of moles of oxygen to titanium. At the stoichiometric composition $x=1.00$ and the right side of equation ( 6.5$)$ is zero. The derivative on the right side of equation (6.5) is positive near the stoichiometric composition because the log function is strictly increasing in this composition range. For compositions more oxygen rich than stoichiometric titanium monoxide $(1-x)<0$ and for more metal rich compositions $(1-x)>0$. Thus there is a local maximum in $\log _{\mathrm{TiO}}$ and also $\mathrm{P}_{\mathrm{TiO}}$ at the stoichiometric composition. The pressures of $\mathrm{Ti}(\mathrm{g})$ and $\mathrm{TiO}(\mathrm{g})$ derived from experiments RS-TiO-2 and RS-MS-TiO-X are independent of auxiliary thermodynamic data. The major source of uncertainty in these pressures arises from the uncertainty in the ionization cross sections for $\mathrm{Ti}(\mathrm{g})$ and $\mathrm{TiO}(\mathrm{g})$. The pressure of TiO(g) of $2.18 \times 10^{-8}$ atm obtained in this work at $1806^{\circ} \mathrm{K}$ 
for the stoichiometric composition is for practical purposes indistinguishable in Figure 6.2 from the value of $1.92 \times 10^{-8}$ atm calculated from standard free energies of formation of gaseous and solid titanium monoxide obtained from the JANAF tables.

The titanium pressure of $7.58 \times 10^{-8}$ atm obtained from experiments RS-TiO-2 and RS-MS-TiO-X is higher by a factor of 7.4 than the pressure calculated from published thermodynamic data. These data include the standard free energies of formation of TiO(s) and Ti(g) from the JANAF tables and the oxygen potential of Suzuki and Sambongi. The higher pressure for titanium calculated from this work is no surprise considering the amount of titanium found in collection experiment RS-TiO-2 was larger than expected on the basis of the published thermodynamic data and the ion ratio, $\mathrm{I}_{\mathrm{TiO}}^{+} / \mathrm{I}_{\mathrm{Ti}}^{+}$, measured in $\mathrm{RS}-\mathrm{MS}-$ TiO-X was smaller than expected on the basis of published data. The higher pressure necessarily follows from these two observations.

Oxygen pressures cannot be calculated from the results of experiments RS-TiO-2 and RS-MS-TiO-X without auxiliary thermodynamic data. The pressures $\mathrm{P}_{\mathrm{O}}=1.52 \times 10^{-14} \mathrm{~atm}$ and $\mathrm{P}_{\mathrm{O}_{2}}=1.41$ $x 10^{-20}$ atm calculated in section 5.4 .1 are significantly lower than pressures obtained from the work of Suzuki and Sambongi as indicated on Figure 6.2. A more complete discussion of the discrepancies between this and published work will come later.

(2) Standard Free Energy

The primary result of RS-TiO-2 and RS-MS-TiO-X is 
the standard free energy change of reaction (5.2) at $1806^{\circ} \mathrm{K}$. The result is $\Delta \mathrm{F}_{1806}=63.3 \pm 2.0 \mathrm{kcal}$ and is calculated directly from measurements made in this work without recourse to auxiliary thermodynamic data. This result may be combined with published information in two different ways. The result may be combined with the standard free energy of formation of $\mathrm{TiO}(\mathrm{g})$ at $1806^{\circ} \mathrm{K}$ to calculate a free energy of formation of solid TiO( $\beta)$ of $-89.3 \pm 2.8 \mathrm{kcal}$ as was done in section 5.4.1. The reverse calculation starting with the free energy of formation of the solid to calculate the corresponding quantity for the gas could also be done. At the time this work was undertaken uncertainties existed for both the thermodynamics of gaseous and solid titanium monoxide. Recent studies of the dissociation energy of TiO(g) by a beamgas chemiluminescence technique (57) yielded a value discordant with several other experimental studies $(3,10,12$ and 14). However, additional investigation by Gole (15 and 57) now indicate his original sample was impure and a new measurement of the dissociation energy by this novel technique has yielded a lower bound consistent with other published values. The thermodynamics for TiO(g) now appear to be in splendid agreement and the dissociation energy of $158.5 \pm 2.0$ kcal given by the JANAF tables is believed to be the best value based on many experimental measurement.s.

$$
\text { Consider now the result } \Delta \mathrm{F}_{1806, f}^{\circ}[\mathrm{TiO}(\beta)]=-89.3 \pm 2.8
$$
kcal calculated from this work and the thermodynamic data 
given for TiO(g) in the JANAF tables. Reference to Figure 2.2 shows this result to be in excellent agreement with the standard free energy of formation of TiO( $\beta$ ) based in part on the combustion calorimetry of Kleppa (30). This agreement lends support to the hypothesis that the U.S. Bureau of Mines calorimetry yielded a result that was not negative enough for the enthalpy of formation of titanium monoxide as suggested by Kleppa and the compilers of the 1975 JANAF supplement.

It should be noted however that if the curve for $\mathrm{O}_{2}(\mathrm{~g})$ in Figure 6.2 is uniformly shifted as indicated by the arrow, the free energy of formation of TiO(B) calculated from a Gibbs-Duhem integration of the oxygen potential over the composition range $1.00 \leq 0 / \mathrm{T} i \leq 1.5$ is about $-85 \mathrm{kcal}$. The result also depends on the standard free energy of $\mathrm{Ti}_{2} \mathrm{O}_{3}$ of $\Delta \mathrm{F}_{1806, f}\left[\mathrm{Ti}_{2} \mathrm{O}_{3}\right]=-247.913 \pm 2.0 \mathrm{kcal}$ (13). The fact that this result is $4.3 \mathrm{kcal}$ higher than the value $-89.3 \mathrm{kcal}$ calculated above does not necessarily imply the oxygen potential indicated by the arrow in Figure 6.2 is incorrect. It is possible to retain the value indicated by the arrow at the stoichiometric composition while raising the curve between TiO and $\mathrm{Ti}_{2} \mathrm{O}_{3}$ in such a way to obtain a free energy of formation of $\mathrm{TiO}(\beta)$ consistent with the -89.3 kcal value. Clearly additional measurements are needed at compositions between TiO and $\mathrm{Ti}_{2} \mathrm{O}_{3}$

(3) Activity of TiO

In the calculation of the standard free energy change 158 
of reaction $(5.2)$ in section 5.4 .1 the standard state for solid titanium monoxide was taken as stoichiometric material. It was assumed that the small change in solid composition due to the incongruent vaporization of titanium monoxide would cause negligible deviation from unit activity. It is now appropriate to examine the validity of this assumption.

From equation (6.5) it was noted the TiO(g) pressure exhibits a local maximum at the stoichiometric composition. Thus the TiO(g) pressure would be expected to change more slowly near the maximum than far removed from it and, in fact, the instantaneous rate of change is zero at $\mathrm{O} / \mathrm{Ti}=1.00$. Since the pressure of $\mathrm{TiO}(\mathrm{g})$ is proportional to the activity of TiO, the above arguments apply equally well to the activity. Finally the measurements of the $\mathrm{TiO}^{+}(64)$ intensity made during RS-MS-TiO-X and listed in Table 5.2 indicate the activity of TiO was essentially constant throughout the vaporization.

\section{(c) Ionization Efficiency Curves}

Appearance potentials of $7.1 \mathrm{eV}$ and $8.1 \mathrm{eV}$ were reported in section 5.4 .1 for $\mathrm{Ti}(\mathrm{g})$ and $\mathrm{TiO}(\mathrm{g})$ respectively. These results were obtained by extrapolation of the linear portion of the ionization efficiency curves to zero ion current using the method of least squares. The electron energy scale was adjusted to the ionization potential of mercury. The appearance potential of $\mathrm{Ti}(\mathrm{g})$ compares favorably with 
the spectroscopic ionization potential of $6.82 \mathrm{eV}$. Recently Rauh and Ackermann obtained appearance potentials of $6.8 \mathrm{eV}$ and $6.4 \mathrm{eV}$ for $\mathrm{Ti}(\mathrm{g})$ and $\mathrm{TiO}(\mathrm{g})$ respectively using the linear extrapolation technique (58). In addition to adjusting their energy scale to the ionization potential of mercury they checked the linearity and accuracy of the scale in a series of measurements of the appearance potentials of barium, calcium, and magnesium. The ionization potential for these elements are well known from spectroscopy.

The investigation of possible fragmentation of $\mathrm{TiO}(\mathrm{g})$ to give $\mathrm{Ti}^{+}$in the electron impact process was the primary reason for making ionization efficiency measurements in this work. As noted previously there are no breaks in the ionization efficiency curves which might indicate fragmentation. The appearance potential of $\mathrm{Ti}^{+}$indicates at least part of the titanium ion signal originates from titanium gas. Indeed $\mathrm{Ti}(\mathrm{g})$ must be an important vapor species for this metal rich sample relative to the congruently vaporizing composition. Normally fragmentation of TiO(g) would not be expected to occur below energies equal to the sum of the appearance potential of $\mathrm{Ti}(\mathrm{g})$. of $7.1 \mathrm{eV}$ and the dissociation energy of $\mathrm{TiO}(\mathrm{g})$ of $6.87 \mathrm{eV}$. Intensity ratios in Figure 5.2 at $10.5 \mathrm{eV}$ and $12.5 \mathrm{eV}$ were measured at energies below the sum of the appearance potential of $\mathrm{Ti}(\mathrm{g})$ and dissociation energy of $\mathrm{TiO}(\mathrm{g})$. Ion intensity ratios measured at $14.5 \mathrm{eV}$ and $22.5 \mathrm{eV}$ are higher than those measured at $10.5 \mathrm{eV}$ and $12.5 \mathrm{eV}$. This result is in- 
consistent with the formation of $\mathrm{Ti}^{+}$from the fragmentation of $\mathrm{TiO}(\mathrm{g})$. Finally, the ions $\mathrm{Ti}^{+}(48)$ and $\mathrm{TiO}^{+}(64)$ have different temperature coefficients indicating $\mathrm{Ti}^{+}(48)$ is not a fragment ion.

It should be noted that other electron impact phenomena are possible. The ion pair production in equation (6.6) and the dissociative electron attachment in equation (6.7) are two examples.

$$
\begin{aligned}
& \mathrm{TiO}(\mathrm{g})+\mathrm{e}^{-}=\mathrm{Ti}^{+}+\mathrm{O}^{-}+\mathrm{e}^{-} \\
& \mathrm{TiO}(\mathrm{g})+\mathrm{e}^{-}=\mathrm{Ti}+\mathrm{O}^{-}
\end{aligned}
$$

Although no search was made for negative ions in this work, processes (6.6) and (6.7) are probably of negligible importance. Kiser notes that typically negative ion currents from electron impact are smaller by a factor of $10^{3}$ than positive ion currents (59).

(d) Summary and Conclusions

At this point it is appropriate to summarize in one place the thermodynamic implications of experiments RS-TiO-2 and RS-MS-TiO-X. It will be recalled that the total amount of titanium collected in vaporization experiment RS-TiO-2 was higher by a factor of 3.5 than the amount expected on the basis of published thermodynamic data. However, the amount of titanium collected in RS-TiO-2 was shown to be in good agreement with similar vaporization experiments by Wheatley. A second discrepancy exists between the ion ratio, $\mathrm{I}_{\mathrm{TiO}}^{+} / \mathrm{I}_{\mathrm{T} i}^{+}$, observed in $\mathrm{RS}-\mathrm{MS}-\mathrm{TiO}-\mathrm{X}$ at $1806^{\circ} \mathrm{K}$ for stoichiomet- 
ric titanium monoxide and the ratio predicted from published data. These two discrepancies lead directly to the discrepancies in the pressures in Figure 6.2.

The titanium analysis in RS-TiO-2 and ion intensity measurements in RS-MS-TiO-X represent independent measurements. The fact that both disagree with predicted values indicates the problem lies in the published thermodynamic data. Otherwise, two separate errors must be found, one in RS-TiO-2 and one in RS-MS-TiO-X.

Consider now the total mass of titanium expected in experiment RS-TiO-2 calculated from published thermodynamic data. The standard free energies of formation of $\mathrm{Ti}(\mathrm{g})$, TiO(g) and TiO( $\beta$ ) are involved. All values were taken from the JANAF tables. An error in the free energy of the first two quantities seems unlikely. A recent investigation of the heat of sublimation of $\mathrm{Ti}(\beta)$ (60) by Wahlbeck yielded a result in good agreement with the JANAF compilation. Similarly the dissociation energy of TiO(g) has been measured in several laboratories by a variety of techniques with excellent agreement.

The standard free energy of formation of $\mathrm{TiO}(\beta)$ is much less certain than the free energies of $\mathrm{T} i(\mathrm{~g})$ and $\mathrm{TiO}(\mathrm{g})$. This is evident from Figure 2.2. If the solid is made less stable by about $4.5 \mathrm{kcal}$ the expected amount of titanium in RS-TiO-2 is $532 \mu \mathrm{g}$, essentially the same as the measured amount. Increasing the standard free energy of formation of 
TiO( $B$ ) given by JANAF by $4.5 \mathrm{kcal}$ results in a value of $-85.275 \mathrm{kcal}$ in near agreement with the U.S. Bureau of Mines result in Figure 2.2 at $1806^{\circ} \mathrm{K}$. If instead of making TiO( $\beta$ ) less stable by $4.5 \mathrm{kcal}$, the oxygen potential of Suzuki and Sambongi is lowered by a factor of about 44 good agreement results between the predicted and observed amounts of titanium in RS-TiO-2. A decision concerning which of these two possibilities is most likely will be postponed until a consideration of RS-MS-TiO-X.

It should be noted if the orifice area, Clausing factor, or vaporization time were incorrect by a factor of 3.5 the predicted amount of titanium would be incorrect by a factor of 3.5. It seems unlikely that any combination of errors in the measurement of these quantities could be this large.

The measured ion intensity ratio, $\mathrm{I}_{\mathrm{TiO}}^{+} / \mathrm{I}_{\mathrm{Ti}}^{+}$, in experiment RS-MS-TiO-X was found to be lower than the ratio calculated from published information by a factor of 6.5 . The largest uncertainty in predicting the mass spectrometric intensity ratio from published thermodynamic data arises from the uncertainty in the ratio of ionization cross sections of $\mathrm{TiO}(\mathrm{g})$ and $\mathrm{Ti}(\mathrm{g})$. If the cross section ratio, $\sigma_{\mathrm{TiO}} /$ $\sigma_{\mathrm{Ti}}$, was lowered by a factor of 6.5 , good agreement results between the predicted and measured ratio. Although this seems to be an unreasonably large adjustment in the cross section ratio the possibility cannot be ruled out. However, 
even if the cross section ratio used in calculating the intensity ratio was high by a factor of 6.5 another error must be discovered if the measured and predicted mass of titanium in RS-TiO-2 are to agree. Finally, if the pressure ratio, $\mathrm{P}_{\mathrm{TiO}} / \mathrm{P}_{\mathrm{Ti}}$, calculated from published thermodynamic data is taken as an approximation to the measured intensity ratio, the calculated result is still higher than the measured ratio by a factor of 5.7 .

If the cross section ratio is assumed to be correct then an error or errors must be found in the oxygen potential of Suzuki and Sambongi or in the free energies of formation of $\mathrm{Ti}(\mathrm{g})$ and $\mathrm{TiO}(\mathrm{g})$ from the JANAF tables. Note the free energy of formation of solid $\mathrm{TiO}(\beta)$ is not involved in this case.

Agreement could be obtained between predicted and observed ion ratios if the free energy of formation of $\mathrm{Ti}(\mathrm{g})$ was lower by $6.7 \mathrm{kcal}$, the free energy of formation of TiO(g) higher by $6.7 \mathrm{kcal}$, or both free energies adjusted such that their difference is lower by $6.7 \mathrm{kcal}$. As noted above such an adjustment is unlikely in view of all the careful measurements made to establish these quantities.

Finally, agreement is obtained if the oxygen pressure, $\mathrm{P}_{2}$, is lowered by a factor of 42.6 , approximately the same factor required to obtain agreement in the measured and predicted amount of titanium found in RS-TiO-2. Because $\Delta \mathrm{F}_{\mathrm{f}}^{\circ}[\mathrm{TiO}(\beta)]$ is not involved in the intensity ratio calcula- 
tion an error in this quantity alone cannot account for both discrepancies.

In conclusion, if only one error is to account for both discrepancies then on $1 y$ one reasonable choice is available. The oxygen potential of Suzuki and Sambongi for stoichiometric titanium monoxide at $1806^{\circ} \mathrm{K}$ must be lower as indicated in Figure 6.2. Although the oxygen potentials of Suzuki and Sambongi are in good agreement with Cater in the two phase field, $\mathrm{Ti}_{2} \mathrm{O}_{3}-\mathrm{Ti}_{3} \mathrm{O}_{5}$, (27) and with oxide pairs in the range $1.67 \leq \mathrm{O} / \mathrm{Ti} \leq 2.0$ determined by Meritt, et. $\underline{\text { al }} .$, (26), it is not inconceivable Suzuki and Sambongi's result for stoichiometric titanium monoxide may be in error. As Cater points out Suzuki and Sambongi present arguments justifying the extension of the emf method down to compositions of $\mathrm{O} / \mathrm{Ti}$ $=1.1$ but they themselves express concern about the interpretation of their data for $0 / T i \leq 1.1$ (56). Cater notes that oxygen potentials below $0 / \mathrm{T} i \leq 1.5$ are generally thought too low to maintain essentially total ionic conductivity in the YDT electrolyte.

The free energy, $\Delta \mathrm{F}_{1806}^{\circ}=63.3 \pm 2.0 \mathrm{kcal}$, for reaction (5.2) is in excellent agreement with the thermodynamics of $\mathrm{TiO}(\mathrm{g})$ and $\mathrm{TiO}(\beta)$ reported in the JANAF tables. The compilers of the 1975 JANAF supplement base their tabulation for TiO( $\beta$ ) largely on the combustion calorimetry of Kleppa (30), heat capacity data of Shomate (21), and enthalpy data of Naylor (22). The JANAF compilers arbitrarily take 
$\Delta \mathrm{H}_{1265}^{\circ}=1.0 \mathrm{kcal}$ for the alpha to beta transition. An apparent enthalpy difference of $0.82 \mathrm{kcal}$ between alpha and beta TiO was obtained by Naylor from drop calorimetry.

The value $\Delta \mathrm{F}_{1806, f}^{\circ}[\mathrm{TiO}(\beta)]=-89.3 \pm 2.8 \mathrm{kcal} \mathrm{calcu}-$ lated from this work and standard free energy of TiO(g) from JANAF indicate the U.S. Bureau of Mines calorimetry for TiO yielded a too positive result. The source of the problem with the Bureau of Mines calorimetry is not known. Kleppa's hypothesis that the difference arose from use of samples consisting of mostly beta phase seems unlikely in view of recent $X-r a y$ analysis of the original Bureau of Mines samples (50). The X-ray results do confirm the samples contain as much as one-third high temperature, beta phase, but this amount is too small to account for the some 5 kcal difference in the combustion work of Kleppa and the Bureau of Mines.

6.4 .3 RS-MS-TiO-Y

(a) Thermodynamics

(1) Standard States

In the treatment of the second law results in section 5.4.2 the standard state for solid titanium monoxide was taken as stoichiometric material. Normally the standard state would include a specification of a total external pressure on the solid of $1 \mathrm{~atm}$. As is often the case for condensed phases deviation from standard conditions due to external pressures not equal to 1 atm are ignored. With the 
above choice of standard state for TiO in a titanium monoxide solid solution the activity of TiO in the solid is unity for reaction (5.22). The equilibrium constant for reaction (5.22) is given simply by the pressure of $\mathrm{TiO}(\mathrm{g})$ so long as the solid does not deviate from the stoichiometric composition.

While the standard state for solid titanium monoxide chosen above would probably be considered a conventional choice, the standard state chosen for $\mathrm{Ti}$ in the solid solution in section 5.4 .2 probably would not. It is therefore instructive to consider an alternate treatment of the temperature dependence of the $\mathrm{Ti}^{+}$intensity data.

The partial molal free energy of titanium in a titanium monoxide solid solution is given by equation (6.8).

$$
\overline{\mathrm{F}}_{\mathrm{T} \mathrm{i}}=\mathrm{RT}_{\ln \mathrm{f}_{\mathrm{T} i}}+\mathrm{B}(\mathrm{T})=\overline{\mathrm{H}}_{\mathrm{Ti}}-\mathrm{T} \overline{\mathrm{S}}_{\mathrm{T} \mathrm{i}}
$$

In the above equation $\mathrm{f}_{\mathrm{Ti}}$ is the fugacity of titanium, $\overline{\mathrm{H}}_{\mathrm{Ti}}$ is the partial molal enthalpy and $\underline{\underline{S}}_{\text {Ti }}$ is the partial molal entropy of titanium. The quantity $B(T)$ is the partial molal free energy of titanium at unit fugacity. Its numerical value, just as all absolute free energies, is unknown. The conventional choice of standard state for titanium gas is the hypothetical ideal gas state at unit fugacity. Thus $\underline{B(T)}$ may be identified with the molal free energy, $\mathrm{F}_{\mathrm{T} i, g}^{o}$, of $\mathrm{Ti}(\mathrm{g})$ in its conventional standard state. This result is expressed in equation (6.9) where $\mathrm{H}_{\mathrm{T} i, \mathrm{~g}}^{\circ}$ and $\mathrm{S}_{\mathrm{T} i, \mathrm{~g}}^{\circ}$ are the standard molal enthalpy and entropy of $\mathrm{Ti}(\mathrm{g})$. 


$$
\mathrm{B}(\mathrm{T})=\mathrm{F}_{\mathrm{T}}^{\circ} \mathrm{i}, \mathrm{g}=\mathrm{H}_{\mathrm{T} i, \mathrm{~g}}^{\mathrm{o}}-\mathrm{TS}_{\mathrm{T}}^{\circ} \mathrm{i}, \mathrm{g}
$$

If the condensed titanium monoxide phase is in equilibrium with the vapor phase the fugacity of titanium in the solid must equal the fugacity of titanium in the vapor. For the low pressures encountered in this work the vapor may be treated ideally. The fugacity of titanium is thus given by its vapor pressure and equation (6.8) becomes

$$
\ln \mathrm{P}_{\mathrm{Ti}}=\overline{\mathrm{H}}_{\mathrm{Ti}} / \mathrm{RT}-\overline{\mathrm{S}}_{\mathrm{Ti}} / \mathrm{R}-\mathrm{B}(\mathrm{T}) / \mathrm{RT}
$$

Substitution of equation (6.9) into (6.10) yields equation (6.11).

$$
\ln \mathrm{P}_{\mathrm{T} i}=\left(\overline{\mathrm{H}}_{\mathrm{T} i}-\mathrm{H}_{\mathrm{T} i, \mathrm{~g}}^{\circ}\right) / \mathrm{RT}-\left(\overline{\mathrm{S}}_{\mathrm{T} i}-\mathrm{S}_{\mathrm{T} i, \mathrm{~g}}^{\circ}\right) / \mathrm{R}
$$

A plot of the logarithm of the titanium pressure against the reciprocal absolute temperature yields a straight line. The enthalpy and entropy change for reaction (6.12) may be deduced from the slope and intercept of such a plot. $\mathrm{Ti}($ ideal gas, $1 \mathrm{~atm})=\mathrm{Ti}\left(\mathrm{TiO}_{1.00}\right.$ solid soln.) (6.12) But this reaction is just the reverse of reaction (2) in Table 5.12. The treatment given here is entirely equivalent to that given in section 5.4.2.

\section{(2) Second Law Results}

It is of interest to compare the second law heats for reaction (1) in Table 5.12 with published values. The second law heat at $1806^{\circ} \mathrm{K}$ obtained in this work is independent of auxiliary thermodynamic data and independent of the mass spectrometer calibration based on experiments RS-TiO-2 and RS-MS-TiO-X. The value given in Table 5.12 of $+130.2 \pm 3.0$ 
kcal compares favorably with that obtained from the 1975 JANAF supplement of $+133.7 \pm 3.6 \mathrm{kcal}$. Recall the JANAF value for the solid is based on Kleppa's combustion calorimetry. A result of $+128.4 \pm 2.2 \mathrm{kcal}$ obtained from an earlier JANAF compilation for the solid based on the combustion calorimetry of Humphrey at the U.S. Bureau of Mines also compares favorably with this work. The large uncertainties associated with these results preclude a choice of one result in favor of another.

The second law result in Table 5.12 for reaction (1) at $298^{\circ} \mathrm{K}$ of $+138.2 \pm 3.0 \mathrm{kcal}$ compares very well with the result obtained by Berkowitz, et. al., of $+139 \pm 5$ kcal (5).

\section{(3) Third Law Results}

An examination of the third law results in Table 5.13 shows no significant trend in the third law standard enthalpy of reaction with temperature. Agreement between the third law standard enthalpy of $+141.2^{ \pm 0.12} \mathrm{kcal}$ and the second law result at $298^{\circ} \mathrm{K}$ from Table 5.12 of $+138.2 \pm 3.0 \mathrm{kcal}$ is excellent.

The standard enthalpy of reaction calculated from the 1975 JANAF supplement at $298^{\circ} \mathrm{K}$ is $+141.7 \pm 3.6 \mathrm{kcal}$. This result which depends on the standard heat of formation of TiO( $\beta$ ) obtained by Kleppa is in excellent agreement with this work. The value of $+136.9 \pm 2.2$ obtained from an earlier JANAF compilation based on Humphrey's combustion calorimetry at the U.S. Bureau of Mines is in less satisfactory agree- 
ment with this work.

(4) Partial Molal Quantities

Partial molal heats and entropies obtained in this work were summarized in Tables 5.15 and 5.16. It is interesting to compare similarities between these results and those obtained by Darken and Gurry in a comprehensive study of the iron-oxygen system (61). They give partial molal heats of solution of oxygen and metallic iron in wustite solid solutions of various compositions ranging from $1.055 \leq 0 /$ Fe $\leq 1.16$. Both the titanium-oxygen and iron-oxygen systems show highly exothermic partial molal heats of solution of oxygen. Both systems also show much smaller exothermic partial molal heats of solution of the metals. In fact, the partial molal heat of solution of iron becomes endothermic for the more oxygen rich compositions.

The small entropy change reported for reaction (3) in Table 5.15 is thought to be a reasonable result for a reaction involving 1 mole each of solid reactant and product. It should be noted that integral thermodynamic properties calculated from partial molal results in this work are not new, independent results. The derivation of integral quantities from partial molal quantities was presented merely to show the relationships among the two different types of properties.

\subsection{Future Work}

The most obvious extension of this work is to other 
compositions in the titanium monoxide solid solution range. Studies similar to this one performed at other compositions would help to establish the activities of the various species throughout the homogeneity range of TiO. Future studies should pay particular attention to characterization of samples with regard to composition, phase(s), and vacancy concentration.

As has been noted several times throughout this thesis, the largest source of uncertainty in the thermodynamic results arises from uncertainties associated with the ionization cross sections of $\mathrm{Ti}(\mathrm{g})$ and $\mathrm{TiO}(\mathrm{g})$. Generally ionization cross sections are difficult to establish experimentally. An alternate method of determining the vapor composition in equilibrium with titanium monoxide would be desirable. The simplest imaginable scheme would be to weigh the sublimate, combust it to $\mathrm{TiO}_{2}(\mathrm{~s})$, and re-weigh it. These two independent measurements would allow the two pressures, $\underline{\mathrm{P}_{\mathrm{Ti}}}$ and $\mathrm{P}_{\mathrm{TiO}}$, to be calculated. The problem with this scheme is to obtain enough sublimate for accurate measurements without incurring a large sample composition change due to the incongruent vaporization. Perhaps other chemical or spectroscopic techniques could be developed for the analysis of the sublimate.

The low temperature heat capacity of TiO should be measured down to liquid helium temperatures. Previous measurements were made only to $52.6^{\circ} \mathrm{K}$ (21). High temperature 
enthalpy contents should be re-investigated for both $\operatorname{TiO}(\alpha)$ and $\operatorname{TiO}(\beta)$.

The thermodynamics and kinetics of the $\alpha=\beta$ transition should be studied. It now seems certain that the rather low enthalpy of transition found by Naylor resulted in part from a sample that was a mixture of the high and low temperature form of TiO ( 22 and 50 ). The JANAF tables maintain that the $\alpha \rightarrow \beta$ transition is rapid while the reverse transformation is sluggish. In the present work some reversion to the low temperature form was always noted on cooling of samples (samples were not quenched). It would be interesting to study this transition with a high temperature diffractometer using the methods employed by Gilles, et. al. (50). 


\section{REFERENCES}

(1) P. G. Wahlbeck and P. W. Gilles, "Reinvestigation of the Phase Diagram for the System Titanium-Oxygen", J. Amer. Ceram. Soc., 49 (4), 180-183 (1966).

(2) P. W. Gilles, K. D. Carlson, H. F. Franzen, and P. G. Wahlbeck, "High-Temperature Vaporization and Thermodynamics of the Titanium Oxides.. I. Vaporization Characteristics of the Crystalline Phases", J. Chem. Phys., 46(7), 24612465 ( 1967 ).

(3) P. J. Hampson and P. W. Gilles, "High-Temperature Vaporization and Thermodynamics of the Titanium oxides. VII. Mass Spectrometry and Dissociation Energies of TiO(g) and $\mathrm{TiO}_{2}(\mathrm{~g})^{\prime \prime}, \underline{J}$. Chem. Phys., 55(8); 3712-3729 (1971).

(4) P. W. Gilles, B. R. Conard, R. I. Sheldon, and J. E. Bennett, "High-Temperature Vaporization and Mass Spectrometric Measurement of the Extent of Non-Stoichiometry in Oxide Phases", Thermodynamics of Nuclear Materials (International Atomic Energy Agency, Vienna) 499-504 (1975).

(5) J. Berkowitz, W. A. Chupka, and M. G. Inghram, "Thermodynamics of the $\mathrm{Ti}-\mathrm{Ti}_{2} \mathrm{O}_{3}$ System and the Dissociation Energy of $\mathrm{TiO}$ and $\mathrm{TiO}_{2}$ ", J. Phys. Chem., 61, 1569-1572 (1957).

(6) P. W. Gilles, The Chemistry of Extended Defects in NonMetallic Solids, edited by L. Eyring and M. O'Keeffe (NorthHolland, London. 1970) pp. 75-90.

(7) Q. L. Wheatley, "A Thermodynamic Determination of the Dissociation Energy of the Gaseous TiO Molecule", Ph.D.

Thesis, University of Kansas, Lawrence, Kansas, 1954.

(8) W. O. Groves, M. Hoch, and H. L. Johnston, "Vapor-Solid Equilibria in the Titanium-Oxygen System", J. Phys. Chem., 59, 127-131 (1955).

(9) P. G. Wahlbeck and P. W. Gilles, "Dissociation Energy of $\mathrm{TiO}(\mathrm{g})$ and the High-Temperature Vaporization and Thermodynamics of the Titanium Oxides. II. Trititanium Pentoxide", J. Chem. Phys., 46 (7), 2465-2473. (1967).

(10) J. Drowart, P. Coppens, and S. Smoes, "Dissociation Energy of the Molecule TiO(g) and the Thermodynamics of the System Titanium-Oxygen", J. Chem. Phys., 50, 1046-1048 (1969). 
(11) P. W. Gilles, P. J. Hampson, and P. G. Wahlbeck, "Dissociation Energy of $\mathrm{TiO}(\mathrm{g})$ and the High-Temperature Vaporization and Thermodynamics of the Titanium-Oxides. V.", J. Chem. Phys., 50(2), 1048-1049 (1969).

(12) H. Y. Wu and P. G. Wahlbeck, "Vapor Pressures of TiO(g) in Equilibrium with $\mathrm{Ti}_{2} \mathrm{O}_{3}(\mathrm{~s})$ and $\mathrm{Ti}_{3} \mathrm{O}_{5}(\mathrm{~s}, \beta)$; Dissociation Energy of TiO(g)", J. Chem. Phys., 吕(9), 4534-4540 (1972).

(13) JANAF Thermochemical Tables, 1975 Supplement. J.. Phys. and Chem. Ref. Data, 4, 1 (1975).

(14). M. B. Liu and P. G. Wahlbeck, "A Knudsen-Mass-Spectrometric Study of the Dissociation Energy of TiO(g)", J. Chem. Phys., 63(4), 1694-1696 (1975).

(15) L. H. Dubois and J. L. Gole, "Determination of Do(TiO) and $\Delta \mathrm{H}_{\text {vaporization }} \mathrm{Ti}$ ) from Beam-Gas Chemiluminescence", to

be published.

(16) J. M. Brom, Jr. and H. P. Broida, "Laser Photoluminescence of TiO in Ne at $4^{\circ} \mathrm{K}^{\prime \prime}$, J. Chem. Phys., 63(9), 3718-3726 (1975).

(17) J. G. Phillips, "Note on the Identification of the Ground State of the TiO Molecule", Astrophys. J., 115, 567568 (1952).

(18) P. W. Gilles, "Discrepancies in the Thermodynamics of the Titanium-Oxygen System", J. Chem. Phys., 46 (12), 49874988 ( 1967 ).

(19) O. Kubaschewski and W. A. Dench, "The Free-Energy Diagram of the System Titanium-Oxygen", J. Inst. Metals, 82 , 87-91 (1953).

(20) G. L. Humphrey, "The Heats of Formation of TiO, $\mathrm{Ti}_{2} \mathrm{O}_{3}$, $\mathrm{Ti}_{3} \mathrm{O}_{5}$, and $\mathrm{TiO}_{2}$ from Combustion Calorimetry", J. Amer. Chem. Soc., 1587-1590 (1951).

(21) C. H. Shomate, "Specific Heats at Low Temperatures of $\mathrm{TiO}, \mathrm{Ti}_{2} \mathrm{O}_{3}, \mathrm{Ti}_{3} \mathrm{O}_{5}$, and $\mathrm{TiN}^{\prime \prime}$, J. Amer. Chem. Soc., 68, 310312 (1946).

(22) B. F. Naylor, "High-Temperature Heat Contents of TiO, $\mathrm{Ti}_{2} \mathrm{O}_{3}, \mathrm{Ti}_{3} \mathrm{O}_{5}$, and $\mathrm{TiO}_{2}$ ", J. Ámer. Chem. Soc., 68 1077-1080 (1946).

(23) O. Kubaschewski, "Thermochemistry of Metal-Refractory Interactions", Rev. Hautes Tempér. et Réfract. , 3(3), 229234 (1966). 
(24) K. L. Komarek and M. Silver, "Thermodynamic Properties of Zirconium-Oxygen, Titanium-Oxygen, and Hafnium-Oxygen Alloys", Thermodynamics of Nuclear Materials (International Atomic Energy Agency, Vienna, 1962) pp. 749-774.

(25) K. Suzuki and K. Sambongi, "High Temperature Thermodynamic Properties in Ti-O System"., Tetsu to Hagane, 58(12), 1579-1593 (1972).

(26) R. R. Merritt, B. G. Hyde, L. A. Bursill, and D. K. Philp, "The Thermodynamics of the Titanium + Oxygen System: An Isothermal Gravimetric Study of the Composition Range $\mathrm{Ti}_{3} \mathrm{O}_{5}$ to $\mathrm{TiO}_{2}$ at $1304^{\circ} \mathrm{K}$, Phil. Trans. Roy. Soc. London, A247 $(1245), 627-661 .(1973)$.

(27) R. G. Sommer and E. D. Cater, "A Solid-State Galvanic Cell Study of the $\mathrm{Ti}_{2} \mathrm{O}_{3}$, $\mathrm{Ti}_{3} \mathrm{O}_{5}$ Equilibrium", J. Electrochem. Soc., 122(10), 1391-1396 (1975).

(28) A. D. Mah, K. K. Kelley, N. L. Gellert, E. G. King, and C. J. O'Brien, "Thermodynamic Properties of Titanium-Oxygen Solutions and Compounds", U. S. Bureau of Mines, R.I. 5316 (1957).

(29) S. M. Ariya, M. P. Morozova, and E. Vol'f, "The Chemistry of Compounds of a Variable Composition VI. The Titanium Oxygen System", Russ. J. Inorg: Chem. (English Trans.) $\underline{2}(1), 16-30(1957)$.

(30) T. V. Charlu, O. J. Kleppa, and T. B. Reed, "High Temperature Combustion Calorimetry III. Enthalpies of Formation of Titanium Oxides", J. Chem. Thermodynamics, 6 , 10651074 (1974).

(31) JANAF Thermochemical Tables, Dow Chemical Co., NSRDSNBS-37, U. S. Government Printing Office (1971).

(32) A. N. Syverud, private communication, April 5, 1974.

(33) E. G. King, private communication, May 21, 1968.

(34) K. K. Kelley, private communication, May 5, 1953.

(35) W. C. DeMarcus, "The Problem of Knudsen Flow", Technical Report K-1302, Oak Ridge Gaseous Diffusion Plant, Oak Ridge, Tennessee (1957).

(36) S. Dushman, Scientific Foundations of Vacuum Technique, 2nd edition, $J: M$. Lafferty, editor (John Wiley and Sons, New York, 1962). 
(37) F. D. Rossini, "Report on the International Practical Temperature Scale of 1968", J. Chem. Thermodynamics, 2 , 447459 (1970).

(38) H. F. Franzen and P. W. Gilles, "High-Temperature Vaporization and Thermodynamic Properties of Titanium Monosulfide", J. Chem. Phys., 42(3), 1033-1038 (1965).

(39) E. B. Sandell, Colorimetric Determination of Traces of Metals, 3rd edition (Interscience Publishers, Inc., New York, 1959).

(40) M. G. Inghram and R. J. Hayden, Handbook on Mass Spectrometry, Nuclear Science Series, Report No. 14, National Academy of Sciences, National Research Council, Washington, D. C. (1956).

(41) W. A. Chupka and M. G. Inghram, "Direct Determination of the Heat of Sublimation of Carbon with a Mass Spectrometer", J. Phys. Chem. , 59(2), 100-104 (1955).

(42) M. J. Marple, "Hardware for the Chemical Physics Trilevel Computer Network", Doctor of Engineering Thesis, University of Kansas, Lawrence, Kansas, 1974.

(43) Program Documentation, High-Temperature Chemistry Laboratory, University of Kansas, Lawrence, Kansas.

(44) J. G. Edwards, "The Flow of Rarefied Gases Through Conical Orifices", Ph.D. Thesis, Oklahoma State University, Stillwater, Oklahoma, 1964.

(45) O. Kubaschewski, E. L. Evans, and C. B. Alcock, Metallurgical Thermochemistry, 4th edition (Pergamon Press, London, 1967).

(46) L. S. Darken and R. W. Gurry, Physical Chemistry of Metals (McGraw-Hill Book Co., Inc., New York, 1953).

(47) D. R. Gaskel1, Introduction to Metallurgical Thermodynamics (McGraw-Hill Book Co., Inc., New York, 1973).

(48) S. Andersson, B. Collén, G. Kruse, U. Kuylenstierna, A. Magnéli, H. Pestmalis, and S. Asbrink, "Identification of Titanium Oxides by X-Ray Powder Patterns", Acta Chemica Scandinavica, $11,1653-1657$ (1957).

(49) D. Watanabe, J.R. Castles, A. Jostons, and A. S. Malin, "The Ordered Structure of TiO", Acta Cryst., 23, 307313 (1967). 
(50) P. W. Gilles, G. H. Rinehart, and R. I. Sheldon, "High Temperature Vaporization and Thermodynamics of the Titanium Oxides. X. Kelley's TiO Sample", accepted for publication by J. Chem. Phys.

(51) J. B. Mann, "Ionization Cross Sections of the Elements", Recent Developments in Mass Spectroscopy, Proceedings of the Internation Conference on Mass Spectroscopy, edited by $\mathrm{K}$. Ogata and T. Hagakawa, University of Tokyo Press (1970).

(52) G. N. Lewis and M. Randall, rev. by K. S. Pitzer and L. Brewer, Thermodynamics (McGraw-Hill Book Co., Inc., New York, 1961).

(53) C. E. Moore, Natl. Stand. Ref. Data Ser. NSRDS-NBS-34, Sept., 1970 .

(54) A. D. Pearson, "Studies on the Lower Oxides of Titanium", J. Phys. Chem. Solids, $\underline{5}, 316-377$ (1958).

(55) P. G. Wahlbeck, private communication, January, 1976.

(56) E. D. Cater, private communication, November, 1975.

(57) J. L. Gole, private communication, June, 1976.

(58) E. G. Rauh and R. J. Ackermann, "First Ionization Potentials of Some Refractory Oxide Vapors", J. Chem. Phys., $\underline{60}(4), 1396-1400$ (1974).

(59) R. W. Kiser, Introduction to Mass Spectrometry and Its Applications, (Prentice-Hall, Inc., Englewood Cliffs; New Jersey, 1965).

(60) H. Y. Wu and P. G. Wahlbeck, "Vapor Pressures and the Standard Enthalpy Change for Sublimation of Ti(s, B), High Temperature Science, $\underline{3}, 469-477$ (1971).

(61) L. S. Darken and R. W. Gurry, "The System Iron-Oxygen. I. The Wüstite Field and Related Equilibria", J. Am. Chem. Soc. , 67, 1398-1412 (1945). 


\section{APPENDIX I \\ Pulse Counting Parameters}

109A Ortec Preamplifier

Gain

x 10

451 Ortec Spectroscopy Amplifier

Front Panel Controls

Fine Gain

x 1

Course Gain

Input Polarity

Unipolar Output

Polarity

Rear Panel Controls

Delay

Baseline Restore

Internal Controls (Peak Shaping)
S1-1st Diff.
2 useconds
S2-1st Integ.
$1 \mu$ second
s3-1st Integ.
1 usecond
S4-Active Integ.
$0.5 \mu$ second
S5-2nd Diff.
$0.5 \mu$ second
S6-Output Range
$3.0 \mathrm{~V}$

5201L HP Scaler-Timer

PHA Mode

$\mathrm{E}_{\max }$

$\mathrm{E}_{\min }$ 
$E_{\max }$

Gate Time

Sample Mode
$5.00 \mathrm{~V}$

1.00 second

Auto 
APPENDIX II

Computer Program Description 
T. TLEPTIFICHTIDPA

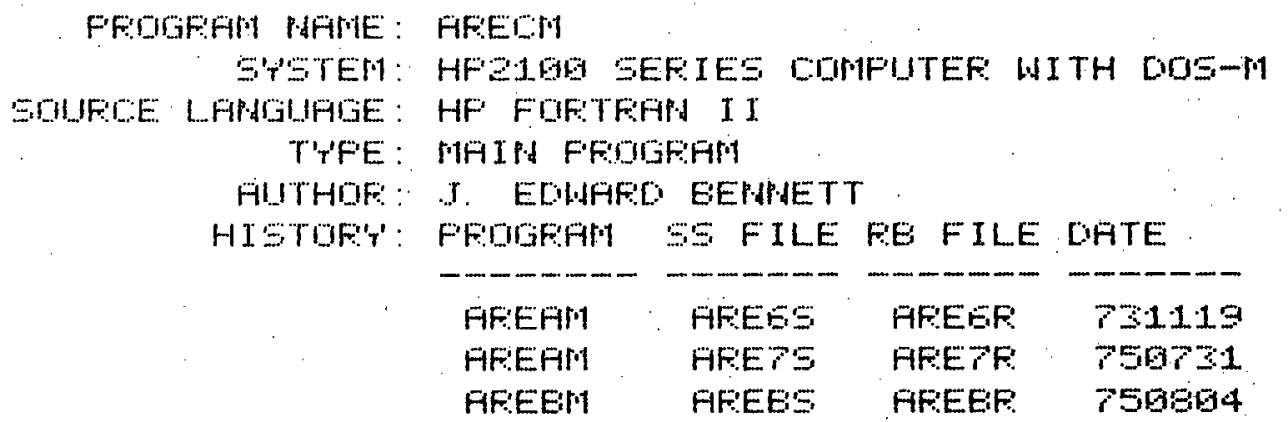

II. PUFFOEE APA EFFAETLTTIES

THE FUFFISE DF HFELM IS TO EALEILATE MFSS SFEDTRDMETEF

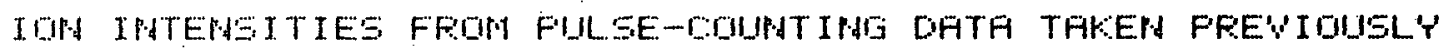

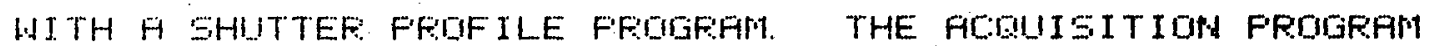
STOFES WHTH FOF EFICH SHITTER FOSITIOH. THE DATUM STDRED FDF

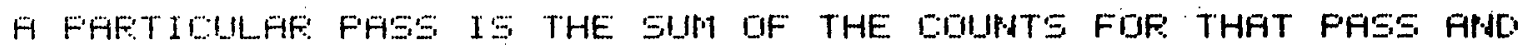

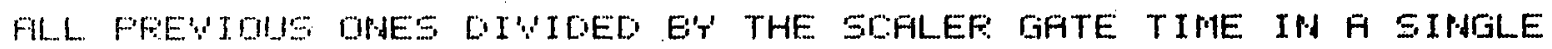

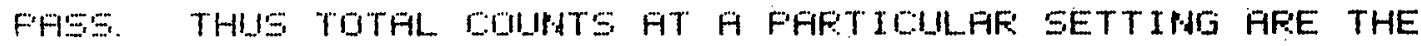

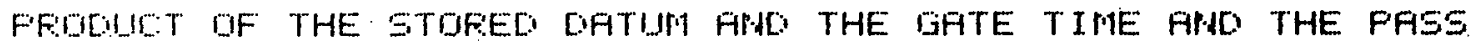

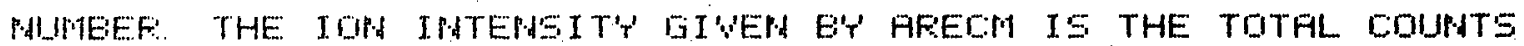

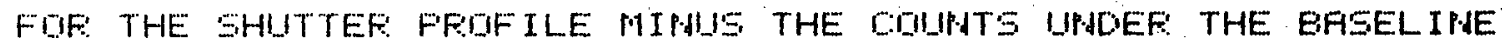
DUE TO EFIFGFOUND SFEEIES. THE TOTAL EOUHTS FFE GETAIHED

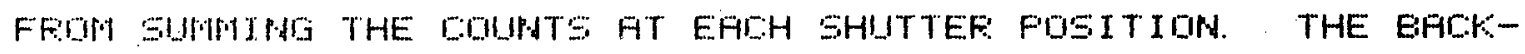

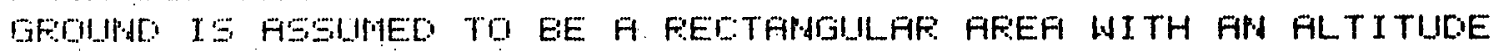

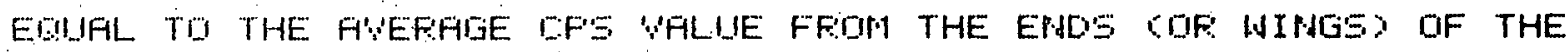
GHITTEF FFIFILE, APD A WIOTH EDIFL TO THE ELAFEED COUPTIMG TIME WOF THE SHUTTEF FROILE. THE TFEFATOF SPECIFIES THE PUMEER DF SHITEF FUSITIOHS FFOM. THE WIMISE DF THE SHUTTER FROFILE TO EE USEO IP GOHFUTING THE EFSELIHE FLTITLICE DF THE EFCKGiFindild:

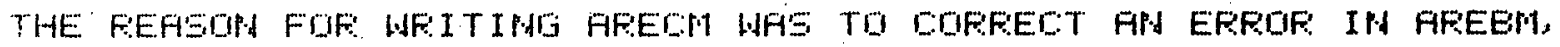

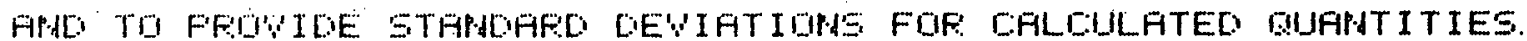

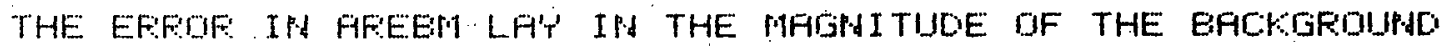

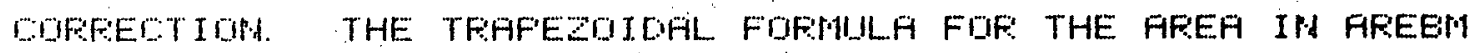

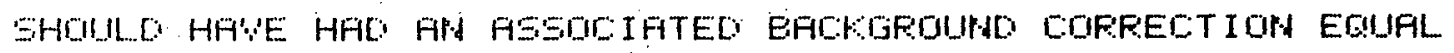

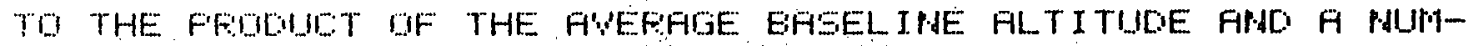

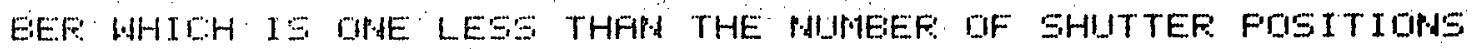

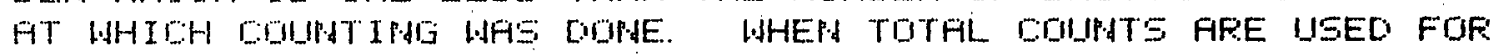

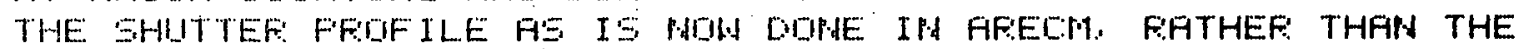

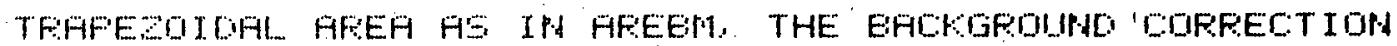

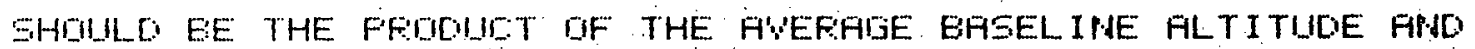

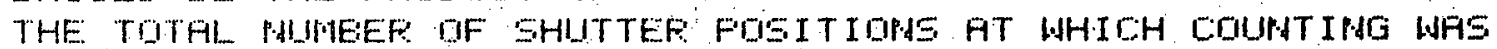
[MIPAE. 
1 FTPA, L.

2 FFOIFEFH CF'T'EN

182

:

WEFSIOP: $E$

[AFTE: 740E24-1

WOFK FILE: CF'T'1S

55

E

\section{ILENT IF ICAT I OH}

THE UPI'UEFSIT'Y OF RANGAS

LFWREWCE, KAPSAE EE045

HIGH TEMFERATURE CHEMISTR''T LFEORATOR'T'

$912-864-3829$

\section{DOMPITER FROIIFAM OESCRIFTIOH}

PFOCIFAM PAMME: CF'Y'EM

SYSTEM: HFZ19G SEFIES COMFUTEF: FHD DOS-M

SOURCE LFWGUAIGE: HF FORTRAR II

T'TFE : MAIN FFOGFAM

AUTHOR: ERUCE R. COHARE

EDITOF: J. EDWFARD EEWHETT

HIETOF'T' PAPINE SS FILE

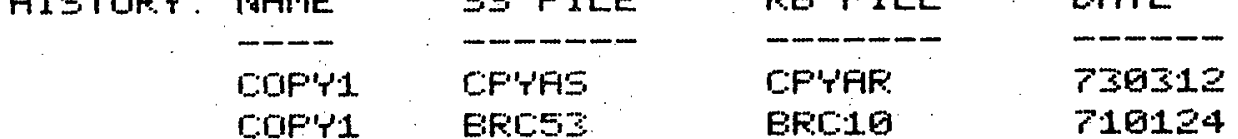

II. FURFOSE AND CAFREILITIES

CF'TEM IS A DOS FOFTFAM LEER MAIN FROIGRAM IT IS USED TO COF'T' $P$ SECTIFS OF A TEMFORFE'T', LAFGE DATA FILE INTO A CATTA FILE OF EXFCTL'T' $N$ SECTORE. THE PRDGRAM READS THE PUMEER OF SECTOFS FILLED IN THE LFRTE TEMPORFE'T FILE FROM THE FIFST WORD OF THE SECOHD SECTOF OF THE LFFGE FILE. IT THEW COFIES EACH DF THE FIFST M SECTORS OF THE LARGE FILE IPTTO THE COFEE EFONDING SECTOR OF. THE EXACT-SIZED FILE PEEY IOUSL'Y CREATED. 
$\cdots$

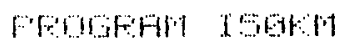

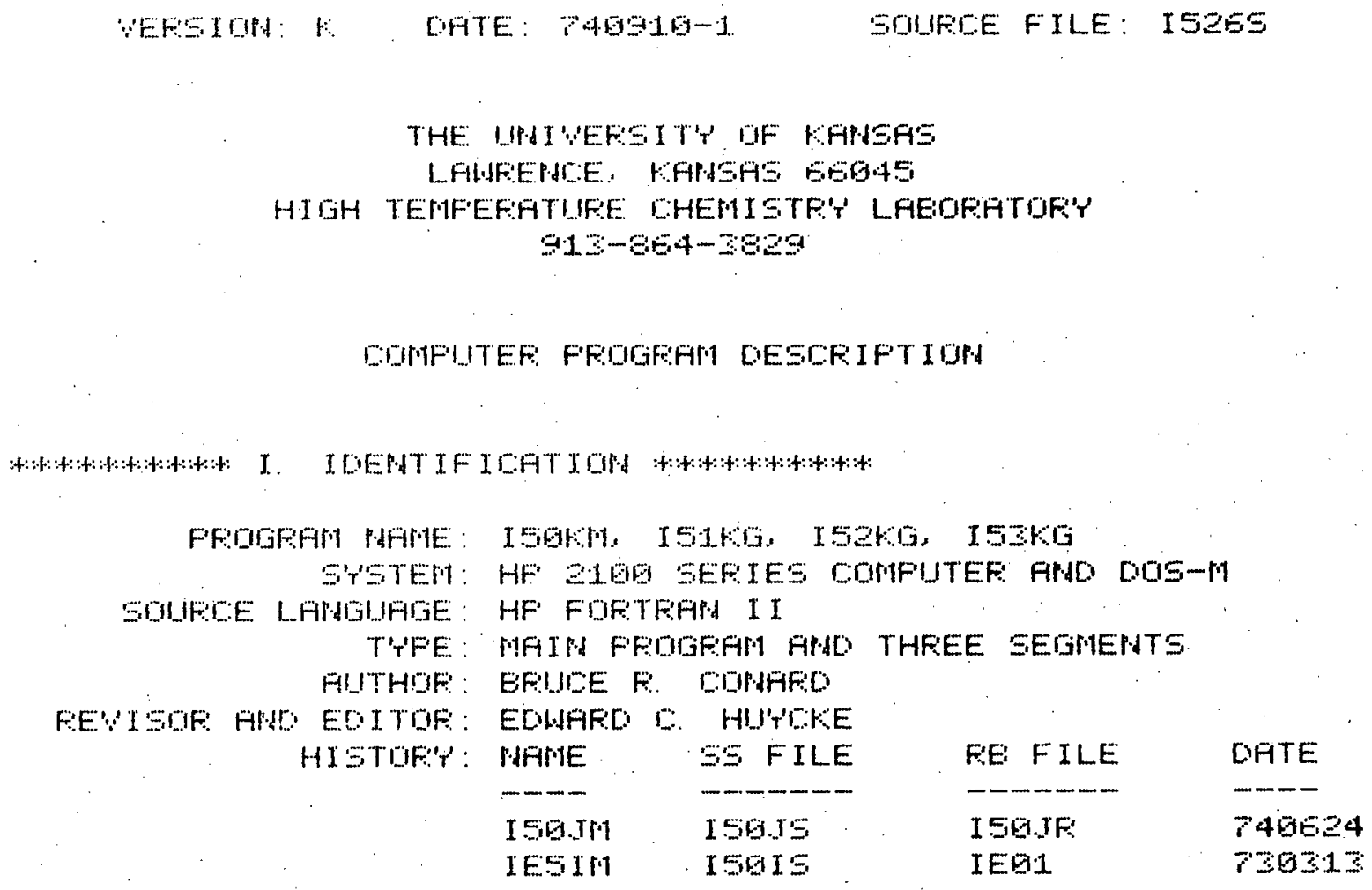

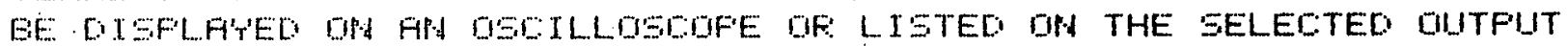

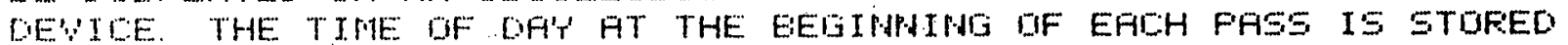
OW THE WISE MULTFLE FHSEES OPU THE SRME SFESIES. WITH SIGHFL

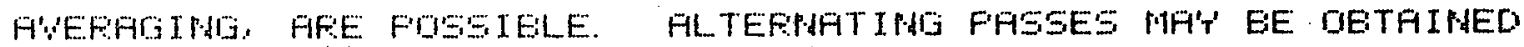
WITH THE GHITTEF SLIT FIFET OFEP THEP CLOSED FOF THE PULLICE MHES OFETFOMETEF . FE.TETIOH OF A FASS. FDLLOWED E'T FE-

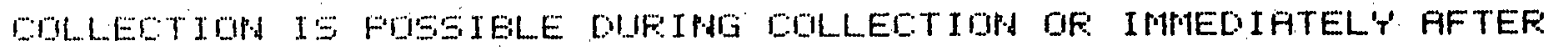
FILI.E.E.TIIIH.

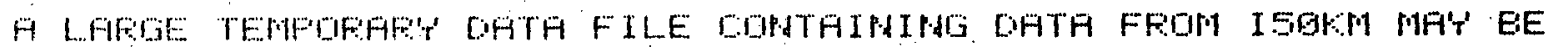

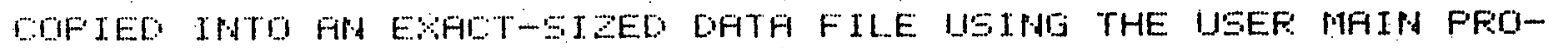

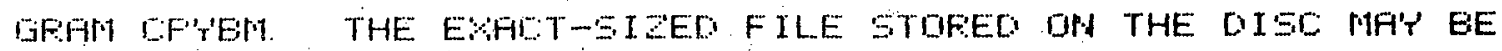

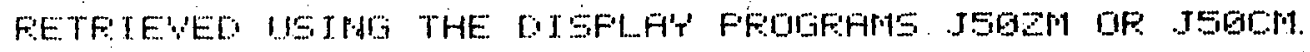

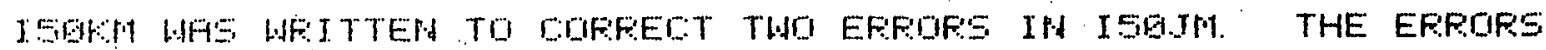

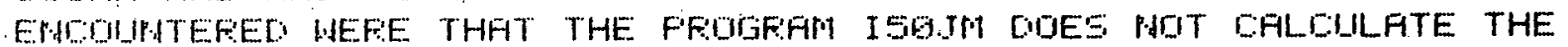

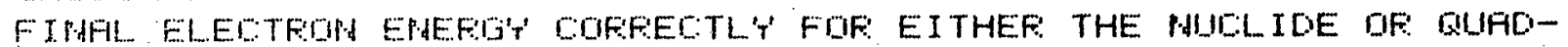

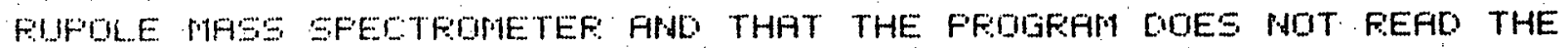
INTEPSIT'T AT THE. FIPAL ELECTFICA EPEFI'T' SETTIPU. 
1 FTPA L. T

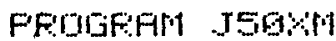

D

$$
\text { WEREIDR: } \because \text { DFTE : 75ESG }
$$

184

THE UPIWEFEIT' UF KFHEFS

LFHFENCE, KAPUSE BEG45

HIGH TEMFEFATIJFE CHEMISTR:'T' LAEORATQR'T'

$913-864-3829$

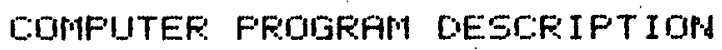

\section{IDEHT IF I CFT I QPA}

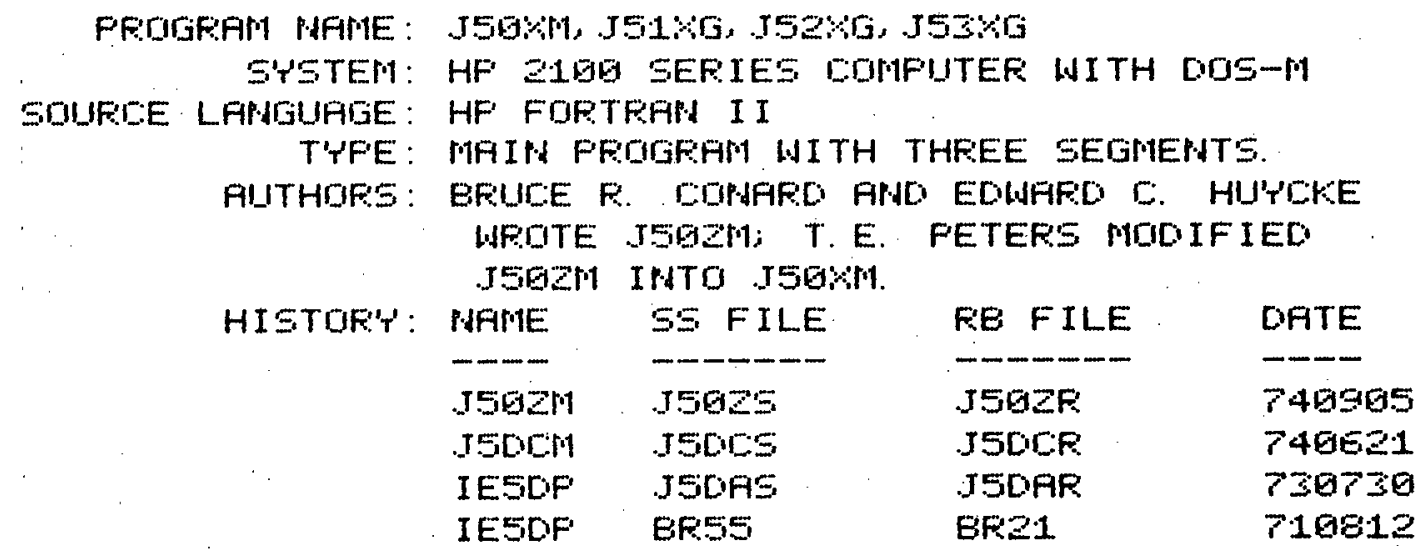

II. PUFPDEE FIPI EFF'FEILITIES

TSEXM IS A DOS FOFTFEM USER MAIP PFCIGFAM WITH THFEE

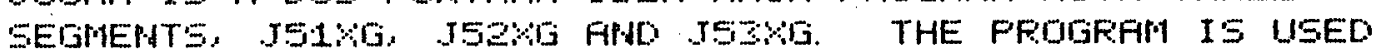
TO FETFIE'V. TO OISFLF'T DPA SCOAF, TU CFEATE F FLIT FILE FHD TO LIST THE AVEFAGE INTENSIT' DF FLL PASSES UF TD FHD IPULLUINIS THE SPEIIFIED FHSE FRCH F OATA FILE COHTHIMING

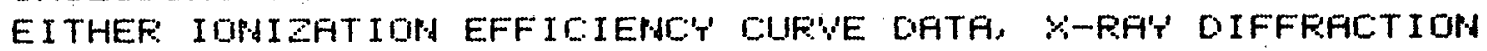
EUF:WE DATH. IPTEPSITIES TAFEA AT FFBITRAR'T ELECTRDN EPAEFIIES, DF SHITTEP PFOFILE DATA. THE OATA FILE MIIST HFWE EEEP COLLECTED UPADEF FI'T DF THE

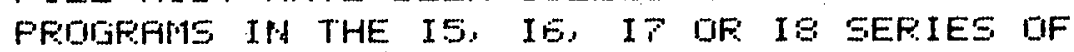

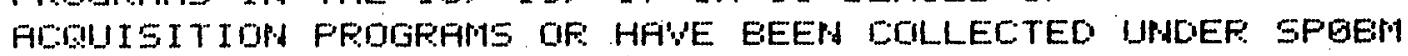
COF HFWE EEEW COLLECTED E'T THE FFEDECESSOFS DF FP'T OF THESE FRIIIFIFIS?

THE FHSS NUMEER FFOM A GIVEN DATA FILE DN THE DISC IS INFUT E'T THE DFEFATIF. THIS FASS MUMEEF IS USED E'T THE FRDGEFM TO GI'WE THE FWEFAIE IPTEPSIT'T' OF RLL FASEES UP TO FPAO IPCLUOING THE SFECIFIEC FASS. FELEYAPT IPAFOFMATIOA FEIOUT THE COLLECTIDN IS LISTED DN THE SELECTED DUTFUT DEVICE. NEW SCOFE-SCALING FARAMETEFS AFE EPTERED VIA THE OPERATOR-S 
$57 \quad$

$50 \mathrm{C}$

53

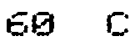

E1 C

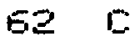

53 C

54 C

$65 \mathrm{C}$

EE C

6r C

68 :

Eg

$7 \mathrm{C}$

$71 \mathrm{C}$

$72 \quad 5$

$73 \quad 0$

$74 \mathrm{C}$

75 :

$7 E$ C

$77 \quad 5$

78

$79 \quad \mathrm{C}$

Eg $\mathrm{C}$

B1 C

825

$83 \quad C$

84

85 C

EE $C$

Br $C$

ge $\mathrm{C}$

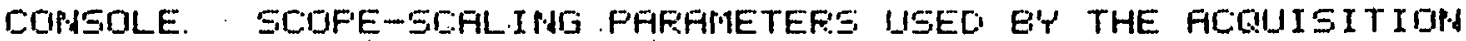

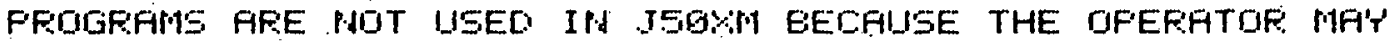
WAMT TO ADIJUST THE LIMITS AND THEFEE'Y THE SCALING OF THE DISFLF'T' SCOFE DISFLF'' OF THE OATA MA'T' EE SELECTED FS' EITHER CFS WS. $\because$ OR AS LWCOFS; ' $\because$ THE DATA MA'T FLSO EE LISTED OR STORED IN A FLOT FILE FWAILFELE FOF: LFTEF: PLDTTIPG ON A VEFEATEC FRIATEF PLOTTEF: IF FLOTTIMI IS FEDUESTED, ISGKM REQUUSTS VFRIOUS FLOT PRFRMETEPS, WHICH FLLOW FIJTOMATIC SCFL IMG, LFEELED FXES. SUPEFIMFOSITIOH DF DUR'VES. FEFFESEPTATIOP OF FOINTS E'T' SFECIAL CHAFACTEPS. FNO SELECTION DF FLOT

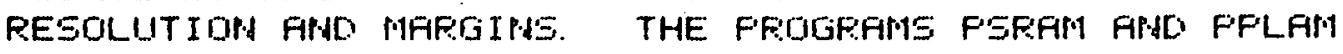
CANA EE USEO TO EOFT FPIO THEN FLOT THE PLOT FILE CREATED E'T JSG\%

ISGMM WAS WRITTEN TO EXTEND THE FETPIEWAL CHFHEILITIES DF

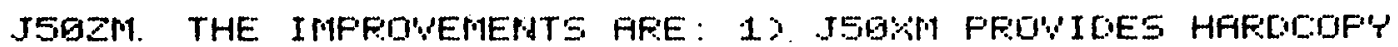
FLOTS WITH SCALED FHO LFEELED AXES; 2 ) J5OKM PFOWIDES THE AEILIT' TO DISFLF'T' $X$-FF'T DIFFFERTION DATA COLLECTED WITH THE PPOGRAM SPBEM: ZXFATHEF THFM SIMFL'? FLOTTING MOTOR FOEITIOW, JSGM FLOTS FLOHG THE X-FXIS EITHEF THE ELECTFON WOLTFGE OF: THE FPAGLE, DEFENDIMIG

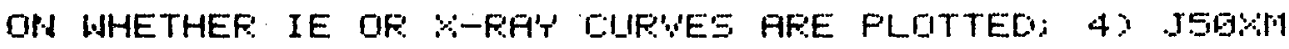
CAM SUFERIMPOSE THE HAFOCOF"'T FLOTS OF SEVERAL DATA FILES DNTO DNE FLOT. OIFFEFENT CHARFCTEFE CAN EE SELECTED TO REFFESENT THE FOIPTS OF THE DIFFEREPT DATA FILES.

J50MM CFM NOT SLIPERIMFOSE CLRUES DN THE SCOFE. FOF THE OISFLA'T OF FEOM OHE TO FIVE CUFUES ON $F$ SINGLE SCOFE DISFLF'T', SEE ISIGLM. 
1. FTPA. L

2 FFIIIFFIM FFLAH

2

THE IPATYEFSIT'T' DF RAPASE

LFHAEPHEE, KAPSAE EEG4S

HIGH TEMFEFATURE CHEMI STF''T' LABOFATOE''

$913-364-3 e 29$

COMPUTEF FFOIEAM DESCFIFT TOPA

\section{IDERTIFICAT ION}

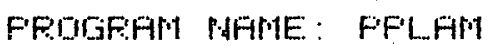

S'STEM: HF 219Q EEFIES COMFUTEF WITH DOS-M

GOUICE LFPIGUACE: HF FOFTRAPA II

T'T'FE: MAIPA FFOGIFAM

FISTHDE: T. E. FETERS

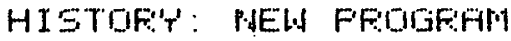

II. FUFFOSE AHO CAFFEILITIES

FFLAM PLOTS SOFTED FLOT FILES OPd THE VEFSATEC FEIMTEF: FLOTTEF: IN FOOM 39 MALOTT HALL. THE IPATEF-COMFUTER COMTIUPACATIOHE LIPSK IS USED EETHEEH THE HF21GGA COMPUTER IP FOOM 31 MFLOTT HFLL FWO THE MODOOMF I I COMFUTEF IN FOOM 39 MALOTT HALL. FFLFM FLOTS FILES

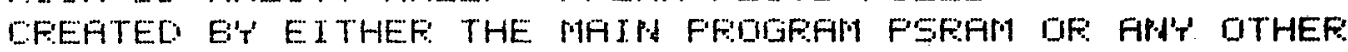
MFIP FFOISEFM WHICH USES THE SUEFOUT INE FLSA TO EFEATE THE SOFTED PLOT FILE. THIS PLOTTIMG FORMS THE THIFO STAIEE OF THE THFEE STAIGES, CFEATION, SORTIMG, FHO FLOT W WICH ARE NECESEFF'' TO MAKE A HFFCDOF"T' FLOT OH THE WEREATEC. 
FTP L

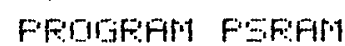

YEFEIDH: A

DATE : PBOS2-1

FILE: FSP4S

THE UPI'UEFEIT'T' OF FAPSEAS

LFIWEEPICE, KAPASHS EE945

HIGH TEMFEFATUFE LHEMISTE'T' LFEORATOF''

$$
313-804-2329
$$

GOMFUTEF FFOLFAM DESCFIFTIOPA

\title{
I. IDENT IF ICFT IOHA
}

\author{
FFCIIEAM PAME: PSFEMM \\ STSTEM: HF 21 GQ EEFIES COMFUTEF WITH DOS-M \\ SOUPCE LAPUGUAGE: HF FOFTFAM II \\ T'T'FE: MAIPA FFIULEFI \\ HUTHOF: : T.E. FETEFE \\ HISTOF'' : PEW FFIIGFIM
}

\section{PUFFOEE FPA CFFFEILITIES}

FEFAM SOFTS A DISL FLOT FILE AHO CREATES A SORTED DISC FLOT FILE. FEFAM WAS DESIGPEO TO EE RUP AFTEF THE FFOIFAM ISG\% HAO CFEATEO AN UPSOORTED DISC FLOT FILE. PATUIFILL'T', PSRAM CFIA EE LSED TO SOFT FPI'T FLOT FILE WHICH HAS THE FROFER FORMAT.

THE EOFT IS FIP AECEPAIPII SORT EASED OP. THE FIRST WOFD OF EFICH TWO-WOFD ELEMEPT: SEE FLSA FWD SRSA FOF THE PETHOOS DF SOETTMSI. 
1 FTP L

$2 \quad$ FFOIFFFI SFGEN

35

4 :

50

6 C

7

8

9

105

11

$1 \geq$

13

14

15

16

17

18

19

20

21

22

23

24

25

$2 E$

27

25

29

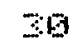

21

34

35

30

37

3

5

49

41

42

43

44

45

40

47

$4:$

49

515

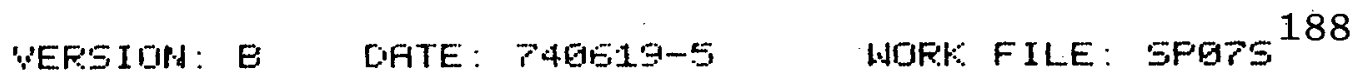

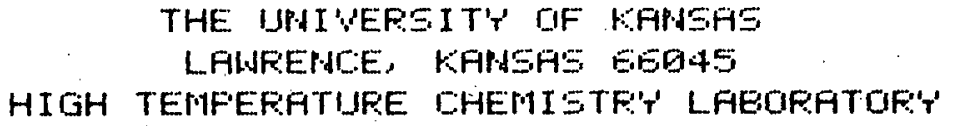

$913-864-3029$

COMFUTEF: PFOKRAM DESCFIPTION

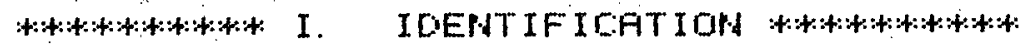

PFOM.JFM PAME: SFGEM, SF'1EG. SFZGI

S'T'STEM: HF 2100 SERIES COMFUTER WITH DOS-M

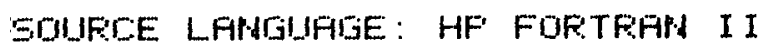

T'TPE: MAIN APAO THO SEGMEPTS

FUTHOF: EFIUCE P. CORAFED

EDITOF: I. EDLAFE EEPANAT

HISTORY: PAME SS FILE FE FILE DATE

\begin{tabular}{|c|c|c|c|}
\hline- & & & \\
\hline & SFBHS & SFEFR & 735 \\
\hline$\Xi F$ & EFEE & EF:SB & 719BGS \\
\hline SHFFCI & ERCES & ERC: 38 & 719427 \\
\hline
\end{tabular}

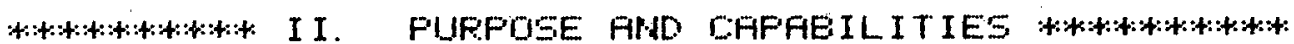

SFGEM IS A DOS FORTEFH USER MAIM FROGFAM, WITH THO SEGMENTS.

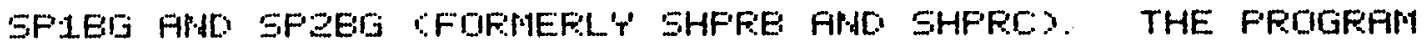

IS USED TO ALOUIRE A SHUTTER FROFILE USING THE NULLIDE

MASS SFEOTFOMETEF. THE SHUTTEF SLIT IS MONED B'T' STEFFER MOTOR

PUMEER 3 THE ION INTENSIT'T' IS DETAIMED E'T COUNT ING FULSES WITH

THE SCALEF. THE COUNT RATES FOF UAFIDUS SHUTTER SLIT FOSITIONS

FFE STOFEO DP THE DISC, EFN EE DISFLF'TED ON THE DSCILLOSCOFE,

DF LISTEO OP THE DUTPUT DEVICE. THE TIME OF OA'T AT THE BEGIN-

WIMI OF EACH PASS, DETAIHED FFOM THE OIGITAL CLOUKO IS FLSO

STOFED ON THE DISC. MULTIFLE FFSSES ON THE SATE SFECIES. WITH

SICHALL FWEFAIIMG. ARE FOSSIBLE. FEJECTION OF F FFSS IS FOSSIBLE DUFIPAIS COLLECTIOPA OF THE FHSS.

FHA EFFLIEF FROIGFAM, SPFEM GFORMEFL'T' SHPROY, DOES NOT OETAIN THE TIME DF DF'T'. 
APPENDIX III

HIGH TEMPERATURE VAPORIZATION AND THERMODYNAMICS

OF THE TITANIUM OXIDES. X. KELLEY'S TIO SAMPLE 
HIGH TEMPERATURE VAPORIZATION AND THERMODYNAMICS

OF THE TITANIUM OXIDES. $\mathrm{X}$. KELLEY'S TIO SAMPLE

Paul W. Gilles, Gary H. Rinehart and Robert I. Sheldon

Department of Chemistry

University of Kansas, Lawrence, Kansas 66045

In a series of forward-looking studies in the mid 1940's Kelley and co-workers ${ }^{1-3}$ of the U. S. Bureau of Mines measured the thermodynamic properties of some of the titanium oxides. Their measurements have long been used as the base for the thermodynamics of the titanium oxides. This system is a complex one. As the JANAF Tables ${ }^{4}$ have recently pointed out in the summary of the thermodynamic properties of the titanium oxides, one of the uncertainties has been the nature of the titanium monoxide sample that was used by Kelley and coworkers. Current interest is evidenced by recent work on the heat of formation at high temperature by Charlu, Kleppa, and Reed, 5 and on the dissociation energy of gaseous $\mathrm{TiO}^{6,7}$. We show herein that the Bureau of Mines' sample of Tio is a mixture of two phases, a fact Kelley subsequently knew. 8

Titanium monoxide exhibits two crystalline phases, a high temperature, sodium chloride-type phase with a wide range of solid solubility, and a low-temperature, nearly stoichiometric monoclinic phase whose structure was finally established by Watanabe, Castles, Jostsons, and Malin ${ }^{9}$, much later than Kelley's work. The two phases are similar, differing in that the vacancies are ordered in the monoclinic phase, but are random in the cubic phase. The strongest $\mathrm{x}$-ray reflections in the monoclinic pattern are related 190 
to the cubic reflections.

We received three lots of the Bureau of Mines' sample of Ti0 during the period $1949-1953^{8}$. Two of the lots were combined in our laboratory. Apparently other portions of these samples no longer exist ${ }^{10}$. The method of preparation and composition of the sample has been reported by the original investigators. X-ray diffraction patterns were taken of the samples soon after receipt in our laboratory, then again some ten years later by the Debye-Scherrer technique. We have recently taken Guinier x-ray diffraction patterns and Norelco diffractometric patterns. Copper radiation was used. All the patterns are of poor quality. No perceptible timedependence of the diffraction records was found.

The diffractometer and a minicomputer-based data acquisition and equipment control system were used to scan repetitively the angular region containing the cubic (111) and (200) reflections, and to provide ensemble averaging. On the basis that the diffraction record contained intensity from both cubic and monoclinic forms, the computer was used to synthesize Gaussian-shaped lines which were fitted to the data. The published structure factors were used to obtain the relative intensities of the monoclinic reflections, and the published lattice parameters gave the angular separations. The output was the relative intensities of the contributing reflections. The proportions of the two phases in the sample were obtained by simple arithmetic $^{11}$. In addition, an earlier analog diffractometric pattern of a sample that had been annealed at $900^{\circ}$ for one week was examined.

Results. The sample annealed at $900^{\circ}$ gave a very good monoclinic pattern with a small contribution from the cubic phase. The peak intensities of monoclinic (031) and (2îli) reflections corresponding to cubic (111) and 
and $(1 \overline{1} I)$ were estimated to be of equal intensity within 3 percent, as predicted by the structure analysis. The peak intensities of the monoclinic (220) and the overlapping monoclinic $(2 \overline{4} 0)$ and $(002)$ lines were estimated to be within 7 percent of the ratio $1 / 2$, again as predicted.

For the original samples the diffractometer pattern reveals an incompletely resolved doublet in both angular regions, with the lower angle member of each broader than the higher. Resolution of the doublets in the region $36-38.5^{\circ}$ in $2 \Theta$ into the three monoclinic $(1 \overline{3} 1),(031),(2 \overline{1} 1)$ reflections and the cubic (111) reflection and in the region $42.25-44.75^{\circ}$ into the monoclinic $(220),(2 \overline{4} 0),(002)$ and cubic (200) reflections yielded the results.

The sample denoted as Tio-1, resulting from the combination of two lots, was found to be 25 and 34 percent cubic from the doublets at $37^{\circ}$ and $43^{\circ}$. The sample Ti0-3R showed 23 and 31 percent cubic. The uncertainties in these results are probably about 20 percent.

The samples are somewhat different in composition even though all three lots were presumably from the same stock. The average of the four measurements is $28.25 \pm 2.56$ percent cubic. We round off and report that Kelley's samples were $30 \pm 5$ percent cubic and $70 \pm 5$ percent monoclinic.

Discussion. Both the low and high temperature heat capacity measurements must be regarded as characteristic of this mixture. The rather low enthalpy of transition found at about $1264^{\circ} \mathrm{K}$ arises, in part at least, because the sample was not entirely monoclinic. The heat of combustion measurements were made on a sample that had been further annealed at $325^{\circ}$. At such a low temperature conversion is very likely slow; our conclusion is that these measurements were also made with the same mixture.

A reassessment by us of the thermodynamics of this complicated system 192 
at the present time does not appear warranted because data on the different phases of the monoxide are not available.

The authors are pleased to acknowledge the support of the U.S.E.R.D.A. under contract ER(11-1)-1140, to thank Dr. K. K. Kelley of the U. S. Bureau of Mines who kindly sent the samples, associates Dr. Q. D. Wheatley and Dr. P. G. Wahlbeck, who took many of the early x-ray diffraction patterns and who provided stimulating discussion, and $\mathrm{Mr}$. Stephen A. Heideman who carried out the final resolutions. 


\section{REFERENCES}

1. C. H. Shomate, J. Amer. Chem. Soc., 68, 310(1946).

2. B. F. Naylor, J. Amer. Chem. Soc., 6\&, $1077(1946)$.

3. G. L. Humphrey, J. Amer. Chem. Soc., ZR, 1587 (1951).

4. JANAF Tables 1975 Supplement. J. Phys. and Chem. Ref. Data, 4, 1(1975).

5. T. V. Charlu, O. J. Kleppa, and T. B. Reed, J. Chem. Thermodynomics, $6,1065(1974)$.

6. M. B. Liu and P. G. Wahlbeck, J. Chem. Phys., 63, 1694(1975).

7. J. L. Gole, private communication, June, 1976.

8. K. K. Kelley, private communications, Aug. 23, 1949 and May 5, 1953.

9. D. Watanabe, J. R. Castles, A. Jostsons, and A. S. Malin, Acta. Cryst., $23,307(1967)$

10. E. G. King, private communication, May 21, 1968.

11. M. J. Buerger, Crystal Structure Analysis, equation (80), p. 46, John Wiley \& Sons, New York (1960). 